Universidade de São Paulo

Faculdade de Saúde Pública

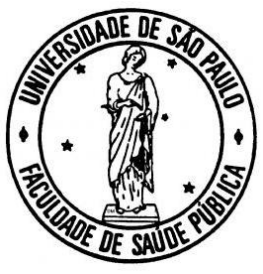

Relações entre atividade física, corpo e imagem corporal entre universitários da Argentina, Brasil, Estados Unidos da América e França

Aline Cavalcante de Souza

São Paulo

2017 


\title{
Relações entre atividade física, corpo e imagem corporal entre universitários da Argentina, Brasil, Estados Unidos da América e França
}

\author{
Aline Cavalcante de Souza
}

Dissertação de mestrado apresentada ao Programa de PósGraduação em Nutrição em Saúde Pública da Faculdade de Saúde Pública da Universidade de São Paulo para obtenção do título de Mestre em Ciências

Orientadora: Prof ${ }^{\underline{a}}$ Dra. Marle S. Alvarenga

São Paulo 
Autorizo a reprodução e divulgação total ou parcial deste trabalho, por qualquer meio convencional ou eletrônico, para fins de estudo e pesquisa, desde que citada a fonte.

\section{Catalogação da Publicação}

Biblioteca/CIR: Centro de Informação e Referência em Saúde Pública

Faculdade de Saúde Pública da Universidade de São Paulo

Dados fornecidos pelo(a) autor(a)

Cavalcante de Souza, Aline

Relaçסies entre atividade física, corpo e imagem

corporal entre universitários da Argentina, Brasil, Bstados Unidos da América e França / Aline Cavalcante de Souza; orientadora Marle dos Santos Alvarenga. -- Såo Paulo, 2017.

202 p.

Dissertaçåo (Mestrado) -- Faculdade de Saúde Pública da Universidade de Săo Paulo, 2017.

1. Atividade física. 2. Imagem corporal. 3. Corpo humano. 4. Bducaçåo superior. 5. Comparaçăo transcultural. I. Alvarenga, Marle dos Santos, orient. II. Título. 


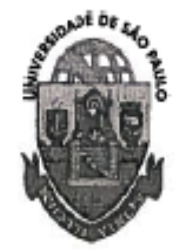

Fanus

\section{Universidade de Săo Paulo}

\section{ATA DE DEFESA}

Aluno: $6138-6843377-1 /$ Página 1 de 1

Ata de defesa pública de Dissertaçăo do(a) Senhor(a) Aline Cavalcante de Souza no Programa: Nutrição em Saúde Pública, do(a) Faculdade de Saúde Pública da Universidade de São Paulo.

Aos 03 dias do mês de julho de 2017, no(a) Sala 12 do CEAP realizou-se a Defesa da Dissertação do(a) Senhor(a) Aline Cavalcante de Souza, apresentada para a obtenção do título de Mestra intitulada:

"Relaçőes entre atividade f́sica, corpo e imagem corporal entre universitários da Argentina, Brasil, Estados Unidos da América e França"

Após declarada aberta a sessão, o(a) Sr(a) Presiderte passa a palavra ao candidato para exposição e a seguir aos examinadores para as devidas arguiçöes que se desenvolvem nos termos regimentais. Em seguida, a Comissão Julgadora proclama o resultado:

$\begin{array}{llll}\text { Nome dos Participantes da Banca } & \text { Função } & \text { Sigla da CPG } & \text { Resultado } \\ \text { Marle dos Santos Alvarenga } & \text { Presidente } & \text { Especialista-FSP } & \text { Não Votante } \\ \text { Alex Antonio Florindo } & \text { Titular } & \text { EACH - USP } & \text { Aproufaja } \\ \text { Yara Maria de Carvalho } & \text { Titular } & \text { EEFE - USP } & \text { UPovinds } \\ \text { Pedro Henrique Berbert de Carvalho } & \text { Titular } & \text { UFJ - Externo }\end{array}$

Resultado Final:

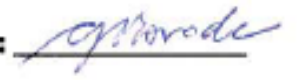

Parecer da Comissão Julgadora *

Eu, Jonathan Jorge Zeferino de Almeida Ton thm. $\% 2, \mathrm{~d} / \mathrm{thm}$ id , lavrei a presente ata, que assino juntamente com os(as) Senhores(as). São Paulo, aos 03 dias do mês de julho de 2017.

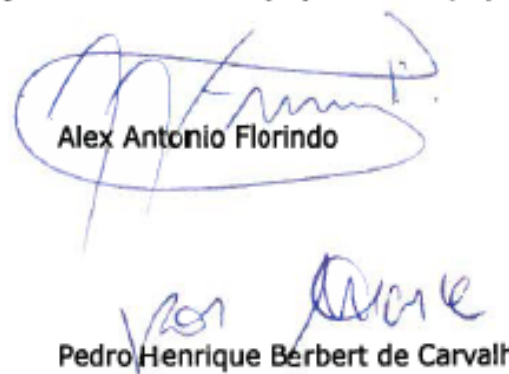

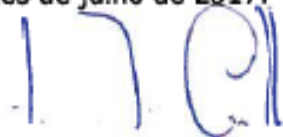

Yara Maria de Carvạlho

- Obs: Se o candidato for reprovado por algum dos membros, o preenchimento do parecer é obrigatório. 
Dedico este trabalho à minha mãe (Irailde Cavalcante), que com todo amor fez de seu corpo a minha primeira morada, a quem tenho eterna gratidão por todas as experiências que já passamos juntas. Linda, esta vitória é sua também! 


\section{AGRADECIMENTOS}

A Deus, que em Seu infinito amor, graça e fidelidade, é digno de toda a honra, glória e louvor, e mais uma vez, realizou um grande sonho, de uma forma extraordinariamente melhor do que eu poderia imaginar.

À minha mãe (Irailde), minha melhor amiga e companheira de todas as horas, por todo o amor, carinho, paciência, cuidado, confiança, esforços, dedicação, risadas e claro, comidas gostosas! Obrigada por ser esta mãe tão maravilhosa, é um privilégio enorme ser sua filha! Meu amor por ti é incondicional e infinito!

Ao meu padrasto (Anterio), que é um grande pai para mim, um exemplo de sabedoria, paciência e bom humor. Agradeço a Deus por tê-lo em nossas vidas.

À minha orientadora (Marle Alvarenga), por quem tenho uma admiração imensa. Muito obrigada por todos os ensinamentos - que certamente vão além da área acadêmica -, amizade, confiança, pela oportunidade de ser sua orientanda desde os tempos de iniciação científica e por abrir os meus olhos para uma Nutrição que me inspira a buscar cada vez mais conhecimento.

Ao meu pai (José, in memoriam), que embora não esteja fisicamente presente neste momento, jamais deixou de torcer por mim.

Às minhas queridíssimas amigas Debora, Deborah e Lunara, por todos os momentos incríveis dessa amizade tão linda e por provarem que a verdadeira amizade é o amor que nunca acaba. Nosso quarteto é fantástico!

Ao Leo Calderoni, pelo carinho, cuidado, alegrias e compreensão.

Ao estimado Paul Rozin, por sua excelência acadêmica e por permitir que eu fizesse parte de um projeto que me proporcionou enorme aprendizado. 
Às minhas housemates (Giuliana e Lívia) pelo companheirismo, amizade, risadas e compreensão deste meu jeito casualmente peculiar. Agradeço também à Patrícia, que já fez parte do nosso doce lar.

Aos amados Gilberto e à Priscila, pelo incentivo, apoio e orações constantes.

À minha madrinha (Elaine), uma inspiração de força, amor, dedicação e esperança.

À grande guerreira Beatriz Melo (in memoriam), que mesmo em tão tenra idade foi um dos mais belos exemplos de disposição, força, gratidão pela vida.

À queridíssima Larissa ("Rosângela"), que com seu doce sorriso, me proporcionou diversas crises de riso, mesmo nas horas mais difíceis.

Às minhas ex-chefes (Daniela Tomei e Verônica Maschi), por todo o aprendizado, confiança e apoio. Obrigada por permitirem a realização de meu mestrado e por tomarem a melhor decisão, num momento tão complexo para mim.

À minha psicóloga (Bárbara Capecce), por todas as terças-feiras de profundo autoconhecimento, por me mostrar que a vida pode ser muito mais leve e prazerosa.

À Marcela ("Ami"), amiga sempre disposta a me ouvir e partilhar alegrias, conselhos e palhaçadas.

À tão amável Betzabeth Slater, minha primeira orientadora de iniciação científica, por possibilitar meus primeiros passos como pesquisadora, quando eu ainda estava no início da graduação. À Silvia Voci, por toda a ajuda, amizade e ensinamentos.

Aos professores membros de minha banca julgadora (Alex A. Florindo, Pedro H. B. Carvalho e Yara M. Carvalho), que, gentilmente, partilharam de sua experiência a fim de tornar meu trabalho melhor. 
Às nutricionistas do AMBULIM (Programa de Transtornos Alimentares do Instituto de Psiquiatria do HC-FMUSP), pela grandiosa contribuição em minha formação como profissional, em especial, à Fernanda Pisciolaro, Alessandra Fabbri, Viviane Polacow e lamara Seara.

Às queridas Priscila Koritar e Jéssica Moraes pela amizade e divisão de experiências.

Ao Eduardo Magalhães, pelo apoio na desconstrução de alguns medos e conceitos prévios que, por diversas vezes, trouxeram prejuízos à minha vida.

Aos profissionais dos ambulatórios de Cirurgia e Traumatologia Buco-Maxilo-Facial, Estomatologia e Farmacodermia do HC-FMUSP, por me acolherem em momentos em que meu físico padeceu.

A todos os universitários argentinos, brasileiros, estadunidenses e franceses, que participaram deste estudo.

A todos vocês familiares, amigos, professores, colegas, conhecidos que acreditaram, oraram e torceram muito por mim! Muito obrigada! 
O corpo é a melhor ferramenta para aferir a vida social de um povo. Ao corpo cabe algo muito além de ocupar um espaço no tempo. Cabe a ele uma linguagem que se institui antes daquilo que denominamos "falar", que exprime, evoca e suscita uma gama de marcas e falas implícitas.

(Lévi Strauss) 


\section{RESUMO}

Cavalcante de Souza A. Relações entre atividade física, corpo e imagem corporal entre universitários da Argentina, Brasil, Estados Unidos da América e França. [Dissertação de mestrado apresentada ao Programa de Pós-Graduação de Nutrição em Saúde Pública]. São Paulo: Faculdade de Saúde Pública da Universidade de São Paulo; 2017.

Introdução: Ao corpo são atribuídos diversos significados e a imagem corporal é influenciada por múltiplos fatores. Jovens universitários constituem um grupo vulnerável aos ideais de aparência corporal, e podem buscá-los por meio de exercícios físicos, dietas, restrições alimentares e cirurgias plásticas, com consequências adversas. Objetivo: Avaliar a relação entre atividade física, relação com corpo e imagem corporal entre universitários, e verificar como estes construtos se relacionam e se diferenciam entre quatro países em ambos os sexos. Método: A amostra incluiu 1.695 universitários de ambos os sexos, com idade entre 18 e 30 anos, da Argentina $(n=304)$, Brasil $(n=583)$, França $(n=441)$ e EUA $(n=367)$, que responderam a um questionário online com questões sociodemográficas, estado nutricional, atividade física, imagem corporal, cirurgia plástica e atitudes alimentares. $\mathrm{Na}$ avaliação do efeito do país, do sexo, razão para se exercitar e estado nutricional sobre as demais variáveis, utilizaram-se modelos lineares generalizados; enquanto a avaliação da associação de variáveis categóricas nominais foi feita por meio de teste de Qui-quadrado $\left(X^{2}\right)$ de Pearson. Resultados: A "saúde" foi apontada como principal razão para exercício entre argentinos $(\varphi=40,2 \% ; \hat{\delta}=52 \%)$, brasileiros $(\varphi=36,4 \%$; $\hat{\delta}=29,1 \%$ ) e estadunidenses $(q=52,1 \% ; \hat{\delta}=48,8 \%$ ) de ambos os sexos; entre os franceses, a "saúde" foi mais frequente para as mulheres (43,4\%), e a "diversão" para os homens $(38,3 \%)$. Independente do país, ser do sexo feminino determinou piores atitudes alimentares, como dietas $(p<0,001)$, vômitos $(p<0,001)$, e maior insatisfação corporal $(p<0,001)$ - mais de $80 \%$ das mulheres e dos homens apresentaram insatisfação corporal: desejando formas corporais menores ( $q=88,5 \%$; $\left.\delta^{\lambda}=52,9 \%\right)$ ou maiores $(\phi=11,5 \% ; \hat{\delta}=47,1 \%)$. Ser mulher também determinou maior escore para restrições alimentares (pior na Argentina, $p<0,001$ ) e para preocupação com excesso de peso (pior no Brasil, $p<0,05$ ); enquanto ser do sexo masculino determinou desejar peso e imagem corporal maiores. O país foi determinante para a frequência semanal de atividade física, preocupação com a rotina de exercícios (maiores nos EUA, 
$p<0,001)$, restrições e compulsões alimentares [maiores escores na Argentina $(p<0,001)$ e na França $(p<0,001)$, respectivamente]. No Brasil, houve maior possibilidade de aderir a uma cirurgia plástica $(p<0,001)$ e maior média de anos de vida que abria mão por um corpo ideal $(p<0,05)$. Discussão: Embora a "saúde" tenha sido a resposta mais frequente para a razão para se exercitar, verificaram-se atitudes disfuncionais para com a alimentação, o corpo e exercício. As atitudes alimentares foram piores entre as mulheres, enquanto a relação com o corpo/aparência e atividade física parece ser mais influenciada pelos países. Conclusão: Houve bastante semelhança quanto às atitudes alimentares disfuncionais e insatisfação corporal para os jovens dos quatro países - a maior diferença foi o sexo. Já os significados e importância dados à atividade física e aparência corporal apresentaram mais diferenças culturais, sendo os estadunidenses os que mais valorizam a rotina de exercícios, e os brasileiros os que mais consideram realizar cirurgias plásticas. Ressalta-se a importância de um olhar mais amplo por parte dos nutricionistas e profissionais de saúde quanto à alimentação, atividade física e ao corpo - bem como considerar possíveis diferenças entre homens e mulheres, e entre culturas.

Descritores: Atividade física. Imagem corporal. Corpo humano. Educação superior. Comparação transcultural. 


\section{ABSTRACT}

Cavalcante de Souza A. Relation among physical activity, body and body image of college students from Argentina, Brazil, United States and France. [Dissertação de mestrado apresentada ao Programa de Pós-Graduação de Nutrição em Saúde Pública]. São Paulo: Faculdade de Saúde Pública da Universidade de São Paulo; 2017.

Introduction: Different meanings are attributed to the body and body image is influenced by multiple factors. Young college students represent a vulnerable group to body appearance ideals, and this group tries to achieve these ideals through physical exercises, diets, food restrictions and plastic surgeries with adverse consequences. Objective: To evaluate the relationship between physical activity, body and body image of college students, and how they relate and differentiate themselves between four countries in both genders. Method: The sample included 1,695 college students, aged between 18 and 30 years, from both genders in Argentina ( $n=304)$, Brazil $(n=$ 583), France $(n=441)$ and USA ( $n=367)$, that answered to an online questionnaire composed by sociodemographic questions, nutritional status, physical activity data, body image, plastic surgery and eating attitudes. To evaluate the effect of country, gender, reason to exercise and nutritional status over other variables, generalized linear models were used, and the evaluation of categorical nominal variables associations were done by Pearson Chi-square Test $\left(X^{2}\right)$. Results: "Health" was mentioned as the main reason to exercise among Argentinean ( $Q=40,2 \% ; \quad \delta=52 \%)$, Brazilians ( $Q=36,4 \% ; \delta=29,1 \%$ ) and Americans ( $q=52,1 \% ; \delta=48,8 \%)$ in both genders; among French, "health" was more frequent for women $(43,4 \%)$, and, the reason "fun" for men $(38,3 \%)$. Despite of the country, the female group showed worst eating attitudes as dieting $(p<0,001)$, vomiting $(p<0,001)$, and a higher body dissatisfaction $(p<0,001)$ - more than $80 \%$ of woman and men were dissatisfied with their bodies: desired a smaller body size $(q=88,5 \% ; \hat{\delta}=52,9 \%)$ or larger $(q=11,5 \%$; $\delta=47,1 \%$ ). Being a woman also determined greater score to food restriction (worst in Argentina, $p<0,001$ ) and to concerns about overweight (worst in Brazil, $p<0,05$ ); whereas being a male determined the desire to have a greater weight and larger body image. The country was determinant for the physical activity weekly frequency, concerns about exercise's routine (greater in USA, $p<0,001$ ), food restriction and binge [greatest scores in Argentina $(p<0,001)$ and France $(p<0,001)$, respectively]. In Brazil, 
there was the higher adherence possibility to plastic surgery $(p<0,001)$ and the highest number of years of life that they are willing to give up for an ideal body $(p<0,05)$. Discussion: Although "health" was the most frequent reason to exercise, there were also verified dysfunctional attitudes towards food, body and exercises. Eating attitudes were worse in women, whereas the relationship with body/appearance and physical activity seems more influenced by countries. Conclusion: There was considerable similarity regarding dysfunctional eating attitudes and body dissatisfaction among the students of the four countries - the greatest was gender. The meaning and importance of physical activity and body appearance presented more cultural differences, the Americans were the ones who most valued the exercise routine, and Brazilians were the ones who most consider going under plastic surgeries. The importance of a deeper understanding must to be considered by nutritionists and health professionals regarding eating, physical activity and body - as well as to consider the possible differences between men and women and cultures.

Keywords: Physical activity. Body image. Human body. Higher education. Crosscultural comparison. 


\section{Lista de Figuras}

Figura 1. Esquema para avaliação da satisfação corporal.

Figura 2. Frequência (\%) da principal forma de exercício entre os universitários ( $n=1.695)$ - de ambos os sexos - da Argentina, Brasil, EUA e França. 66

Figura 3. Frequência (\%) da principal forma de exercício entre o sexo feminino, segundo o país $(n=1.126)$. .68

Figura 4. Frequência (\%) da principal forma de exercício entre o sexo masculino, segundo o país $(\mathrm{n}=569)$. 69

Figura 5. Frequência (\%) das principais razões para se exercitar entre o sexo feminino e o masculino, segundo o país ( $n=1695)$.

Figura 6. Tamanhos de efeito $\left(\mathrm{r}^{2}\right)$ do sexo, país e da interação país e sexo sobre as variáveis (quando $r^{2}$ foi superior a 0,01 ). .78

Figura 7. Escala de Silhuetas de Stunkard (STUNKARD et al., 1983). .80

Figura 8. Correlações entre insatisfação corporal e demais variáveis. .91

Figura 9. Análise de correspondência do estado nutricional, país e a principal razão para se exercitar entre as universitárias $(n=1.126)$. 109 


\section{Lista de Quadros}

Quadro 1. Classificação das variáveis do estudo. .55

Quadro 2. Classificação do Índice de Massa Corporal segundo a Organização Mundial de Saúde .56

Quadro 3. Classificação dos universitários de ambos os sexos em função da diferença entre a imagem atual e a imagem desejada $(n=1691)$.

Quadro 4. Universitários que desejavam ter formas corporais menores, de acordo com a diferença entre imagem atual e imagem desejada $(n=1.085)$.

Quadro 5. Efeito da principal do país, do sexo e da interação destas variáveis sobre a insatisfação corporal.

Quadro 6. Efeito da principal razão para se exercitar, do sexo e da interação destas variáveis sobre a insatisfação corporal.

Quadro 7. Efeito do estado nutricional, do sexo e da interação destas variáveis sobre a insatisfação corporal. .90

Quadro 8. Hierarquia da principal razão para se exercitar, segundo o país. .97

Quadro 9. Efeito da principal razão para se exercitar, do país e da interação destas variáveis sobre as restrições alimentares.

Quadro 10. Efeito da principal razão para se exercitar, do país e da interação destas variáveis sobre a preocupação com a comida e sua influência na aparência. 100 Quadro 11. Efeito da principal razão para se exercitar sobre a prática de dietas. ..101 Quadro 12. Efeito da principal razão para se exercitar sobre a preocupação sobre ter excesso de peso. 102

Quadro 13. Efeito da principal razão para se exercitar e do país sobre as compulsões alimentares. 103

Quadro 14. Frequência de dietas e restrições alimentares de acordo com a frequência de compulsões alimentares 104

Quadro 15. Efeito da principal razão para se exercitar sobre os vômitos intencionais após as refeições, com o objetivo de perder de peso. 105

Quadro 16. Associações entre o estado nutricional e o país, e entre o estado nutricional e a principal razão para se exercitar. 107 Quadro 17. Efeito da principal razão para se exercitar, do país e da interação destas variáveis sobre a preocupação com a rotina de exercícios. 
Quadro 18. Efeito da principal razão para o exercício sobre a culpa por não se exercitar

Quadro 19. Efeito do país, da principal razão para se exercitar e da interação destas variáveis sobre a possibilidade de realizar uma cirurgia plástica.

Quadro 20. Hierarquia da principal razão para se exercitar, segundo o país. 122

Quadro 21. Frequências dos três principais tipos de exercícios de acordo com o país.

Quadro 22. Associações entre a principal forma de exercício e a principal razão para se exercitar entre os universitários do Brasil, EUA e França

Quadro 23. Efeito da principal forma de exercício e da interação desta variável com o país sobre a preocupação com a rotina de exercícios. 126 Quadro 24. Efeito da principal razão para se exercitar sobre a preocupação com a rotina de exercícios.

Quadro 25. Efeito do país, da principal razão para se exercitar e da interação destas variáveis sobre a preocupação com a comida e aparência.

Quadro 26. Associações que ocorreram entre os países e o estado nutricional.....130 Quadro 27. Efeitos do país, da principal razão para se exercitar e da interação destas variáveis sobre o Índice de Massa Corporal. 132

Quadro 28. Associação entre a principal razão para se exercitar e o estado nutricional, entre os universitários estadunidenses. 133

Quadro 29. Número de academias, faturamento anual e posição no ranking das academias da Argentina, Brasil, França e EUA no ano de 2016. 


\section{Lista de Tabelas}

Tabela 1. Procedimentos (cirúrgicos e estéticos) realizados nos EUA, Brasil e França no ano de 2015.

Tabela 2. Distribuição dos universitários $(n=1.695)$ segundo o país, sexo, peso atual, Índice de Massa Corporal (IMC), idade, peso considerado ideal e dias de atividade física (AF) na semana.

Tabela 3. Distribuição dos universitários $(n=1.695)$ quanto aos valores escolhidos na Escala de Silhuetas de Stunkard (imagem atual e desejada), e escores de variáveis relacionadas às atitudes alimentares, cirurgias plásticas, imagem corporal e atividade física. .73

Tabela 4. Poder observado (em \%) do país e do sexo sobre as variáveis. .79

Tabela 5. Distribuição dos universitários $(n=1.691)$ segundo os valores médios de insatisfação corporal, de acordo com o país e o sexo

Tabela 6. Estado nutricional das mulheres e homens satisfeitos com sua imagem corporal ( $n=276)$, de acordo com o país.

Tabela 7. Estado nutricional das mulheres e homens que desejavam formas corporais maiores ( $n=330)$, de acordo com o país.

Tabela 8. Estado nutricional das mulheres e homens que desejavam formas corporais menores $(n=1.085)$, de acordo com o país.

Tabela 9. Distribuição dos universitários $(n=1.684)$ segundo a classificação do estado nutricional (WHO, 2010), de acordo com o país e o sexo. 89

Tabela 10. Peso corporal atual e IMC das universitárias ( $n=1117)$ 106 Tabela 11. Distribuição das universitárias $(n=1117)^{*}$ dos quatro países quanto ao estado nutricional. 106

Tabela 12. Estado nutricional das universitárias que responderam "perda de peso" como principal razão para exercício $(n=212)$, de acordo com o país. 108

Tabela 13. Estado nutricional das universitárias que responderam "absolutamente verdadeiro" para preocupação e culpa relacionadas ao exercício. 112

Tabela 14. Estado nutricional das mulheres que já realizaram cirurgia plástica estética ( $n=26$ ), de acordo com o país.

Tabela 15. Universitárias que nunca considerariam realizar uma cirurgia plástica estética $(n=442)$, segundo o país. 
Tabela 16. Peso corporal atual e IMC dos universitários argentinos, brasileiros,

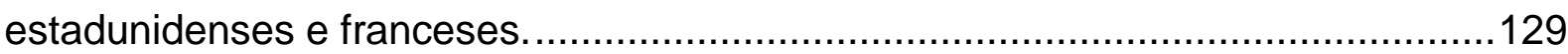

Tabela 17. Distribuição dos universitários $(n=567)$ dos quatro países quanto ao estado nutricional. 130

Tabela 18. Estado nutricional dos homens que responderam a opção "muito verdadeira" ou "absolutamente verdadeira" para a preocupação com a rotina de exercício, sobre a comida e a aparência, e ambas as preocupações. 131 


\section{Lista de Abreviaturas}

AF: Atividade Física

ANACOR: Análise de Correspondência (Múltipla)

ASAPS: American Society for Aesthetic Plastic Surgery

BSQ: Body Shape Questionnaire

DCNT: Doenças Crônicas Não Transmissíveis

DP: Desvio Padrão

EACH/USP: Escola de Artes, Ciências e Humanidades da Universidade de São Paulo

EUA: Estados Unidos da América

FISU: International University Sports Federation

FSP/USP: Faculdade de Saúde Pública da Universidade de São Paulo

GLM: Modelos Lineares Generalizados

HC-FMUSP: Hospital das Clínicas da Faculdade de Medicina da Universidade de São

Paulo

IC: Imagem Corporal

IHRSA: International Health, Racquet \& Sportsclub Association

IMC: Índice de Massa Corporal

IRDS: Institut Régional de Développement du Sport

ISAPS: International Society of Aesthetic Plastic Surgery

MASS: Muscle Appearance Satisfaction Scale

MBDS: Male Body Dissatisfaction Scale

OMS: Organização Mundial da Saúde

SBCP: Sociedade Brasileira de Cirurgia Plástica

SPSS: Statistical Package for Social Sciences

TA: Transtorno Alimentar

TCLE: Termo de Consentimento Livre e Esclarecido

TDC: Transtorno Dismórfico Corporal

UBA: Universidad de Buenos Aires

UPenn: University of Pennsylvania

USP: Universidade de São Paulo

WHO: World Health Organization 


\section{Lista de Símbolos}

$\mathrm{q}$ : Sexo feminino

ㅈ: Sexo masculino

\%: Porcentagem/ frequência relativa

kg: Quilogramas

$\mathrm{m}^{2}:$ Metros quadrados

$\mathrm{N}, \mathrm{n}$ ou $n$ : Número

p: Probabilidade (significância de um teste)

$\rho:$ Coeficiente de correlação de Spearman

$r^{2}$ : Coeficiente de correlação de Pearson

$X^{2}$ : Teste de Qui-quadrado de Pearson 


\section{SUMÁRIO}

1. INTRODUÇÃO

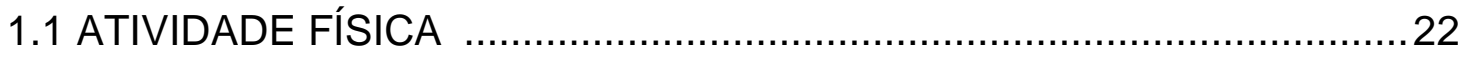

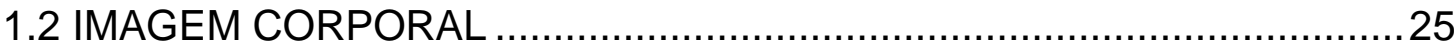

1.2.1 Imagem corporal: dimensões e distúrbios .................................27

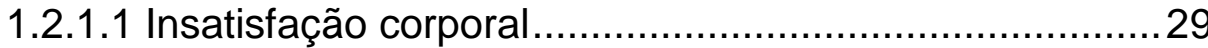

1.2.2 Ainda há uma esperança! Imagem corporal positiva.....................31

1.3 O CORPO, A BELEZA E SEUS DIFERENTES SIGNIFICADOS .............32

1.3.1 A era da exposição: o corpo do século XXI...............................35

1.4 CORTA, ESTICA, MODELA E TRANSFORMA: CIRURGIAS PLÁSTICAS, PROCEDIMENTOS ESTÉTICOS E AS QUESTÕES DE GÊNERO ..............38

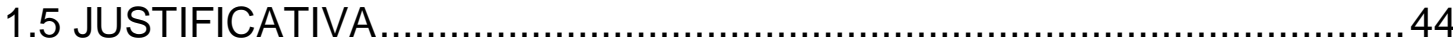

1.5.1 Argentina, Brasil, Estados Unidos da América e França: equivalências e distinções

2. OBJETIVOS

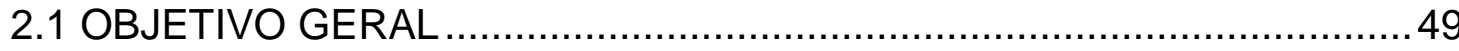

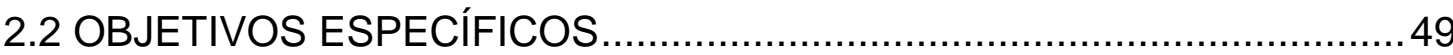

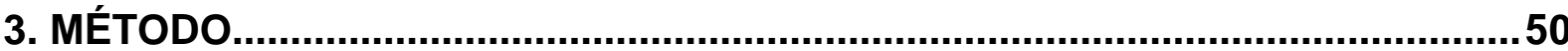

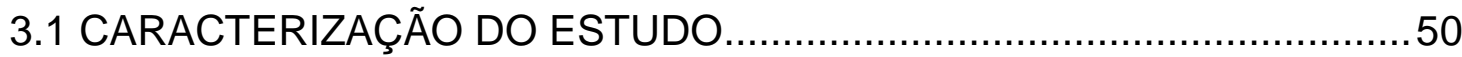

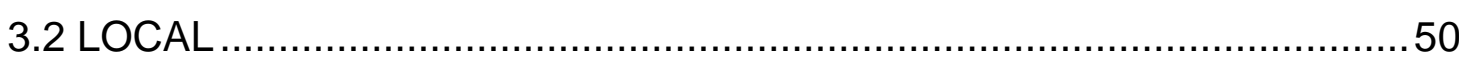

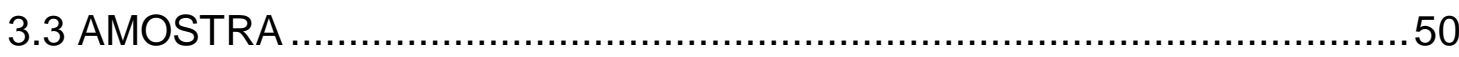

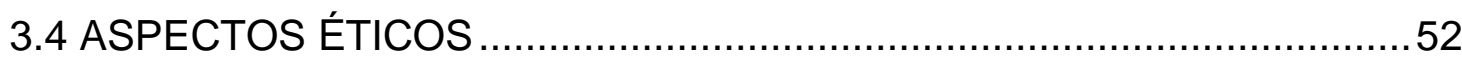

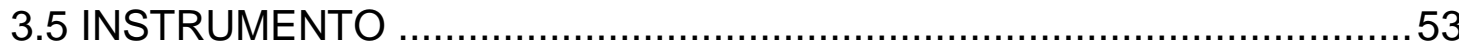

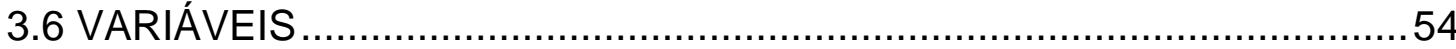

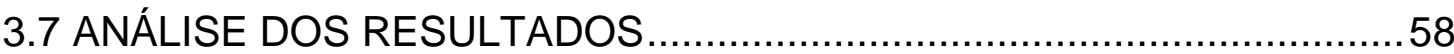

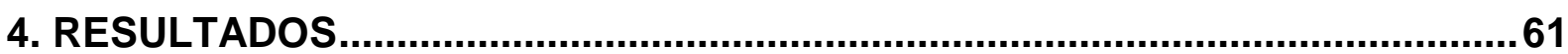

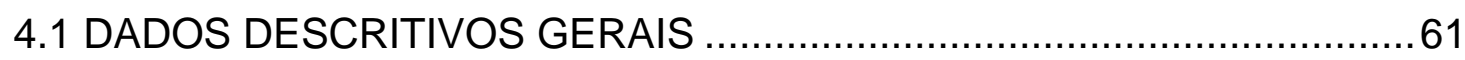

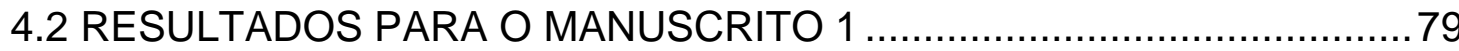

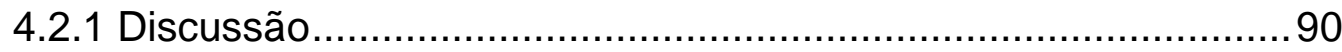


4.3 RESULTADOS PARA O MANUSCRITO 2 .96

4.3.1 Discussão

4.4 RESULTADOS PARA O MANUSCRITO 3

4.4.1 Discussão.

5. DISCUSSÃO GERAL DO ESTUDO

6. CONCLUSÃO 150

6.1 CONSIDERAÇÕES FINAIS: A CONSTRUÇÃO DE SABERES POR MEIO DE VIVÊNCIAS ESPECIALMENTE SINGULARES 152

7. REFERÊNCIAS BIBLIOGRÁFICAS 155

8. ANEXOS 187

ANEXO 1. Artigo publicado no Jornal Brasileiro de Psiquiatria 187

ANEXO 2. Documento emitido pelo Institutional Review Board, nos Estados Unidos da América: Isenção da necessidade de aprovação pelo Comitê de Ética e Pesquisa 188

ANEXO 3. Ofício de aprovação do projeto de pesquisa principal 189

ANEXO 4. Aprovação do presente estudo pelo Comitê de Ética e Pesquisa da Faculdade de Saúde Pública da Universidade de São Paulo 190

ANEXO 5. Página inicial de consentimento em participar da pesquisa 192

ANEXO 6. Questionário da pesquisa. 193

ANEXO 7. Escala de Silhuetas de Stunkard. 198

ANEXO 8. Atestado de participação no curso de verão "Corpo, arte e clínica", oferecido pela FSP/USP 199 ANEXO 9. Capítulo de e-book desenvolvido durante a disciplina "Estudos Interdisciplinares em Sociologia do Esporte e do Lazer" 200 ANEXO 10. Currículo Lattes: Aline Cavalcante de Souza 201 ANEXO 11. Currículo Lattes: Marle dos Santos Alvarenga 202 


\section{INTRODUÇÃO}

No mundo contemporâneo, o conceito que se tem sobre a aparência induz à ideia de que um corpo cuidadosamente trabalhado e definido é também um sinal de beleza interior, realização, disciplina, saúde física e mental. Neste contexto, a prática de atividade física constitui um caminho possível para a aquisição deste corpo "modelo de sucesso", na expectativa de uma eventual satisfação, bem-estar e prazer, tendo, desta forma, relação direta com os elementos do corpo e imagem corporal.

Em um panorama mais generalista, caberia ao profissional de Educação Física o campo de pesquisa relacionado à atividade física, todavia, considerando que esta temática é multidisciplinar e diretamente associada às questões alimentares (inclusive no que diz respeito às recomendações de hábitos para um estilo de vida saudável), sua compreensão no âmbito da Nutrição e demais Ciências da Saúde é de grande importância à Saúde Pública.

O corpo representa a identidade do indivíduo, um símbolo de distinção entre os outros, e a imagem por ele exposta apresenta-se como uma suposta via para o sucesso ou o fracasso, logo, na cultura ocidental, enaltecem-se os esforços despendidos para o alcance do sucesso (como, por exemplo, o excesso de exercícios físicos, uma enorme variedade de dietas e modismos alimentares, intervenções cirúrgicas).

O presente estudo está organizado da seguinte forma: na introdução há a fundamentação teórica referente aos temas analisados, que subsidia a pergunta de partida da pesquisa e justifica o estudo. A fundamentação teórica é construída predominantemente com base na literatura contemporânea e constitui-se de quatro temáticas: 1) "Atividade Física", na qual são descritos conceitos pertinentes, benefícios associados à prática, recomendações, além dos riscos associados à inatividade física e ao comportamento sedentário; 2 ) "Imagem Corporal", na qual são descritos aspectos históricos acerca da compreensão deste construto, bem como suas dimensões e atributos; 3 ) em "O corpo, a beleza e seus diferentes significados" discorre-se sobre alguns importantes acontecimentos que repercutiram nas concepções de corpo e beleza no decorrer da história, com o posterior olhar sobre o corpo no século XXI; 4) em "Corta, estica, modela e transforma: cirurgias plásticas, procedimentos estéticos e as questões de gênero" expõem-se breve histórico, estatísticas mundiais e uma reflexão acerca das transformações corporais, contemplando também as diferenças relacionadas aos aspectos corporais entre as 
mulheres e os homens. Na sequência, é apresentada a justificativa do estudo, na qual são destacadas particularidades da Argentina, Brasil, Estados Unidos da América (EUA) e França, relacionadas aos construtos aqui avaliados, e por fim, são indicadas as hipóteses testadas.

Posteriormente, têm-se o objetivo geral e os específicos, e o método. Os resultados estão divididos em: descritivos gerais e, em seguida, os resultados com três temáticas mais específicas - cada temática corresponde a uma "pergunta de partida" (objetivo), para a qual os resultados encontrados serão discutidos em seguida.

Em seguida, há a discussão geral do estudo e a conclusão. Por fim, nas considerações finais são expostas experiências acerca da trajetória acadêmica, seguidas das referências bibliográficas e dos anexos. 


\subsection{ATIVIDADE FÍSICA}

A atividade física (AF), entendida como uma característica inerente ao ser humano, com dimensão biológica e cultural, representa um tema interdisciplinar, e é definida como "qualquer movimento corporal, produzido pela musculatura esquelética, que resulta em gasto energético acima dos níveis de repouso", tendo como exemplos as atividades laborais, atividades da vida diária (vestir-se, comer, banhar-se), deslocamentos, e as atividades de lazer, incluindo exercícios físicos, esportes, dança etc (NAHAS, 2010; WHO, 2010; FERRARI, 2012). Embora relacionados, os conceitos de atividade física e de exercício físico não são sinônimos, umas vez que o exercício físico é uma forma de atividade física planejada, estruturada, repetitiva e proposta com o objetivo de melhora ou manutenção da aptidão física, de habilidades motoras ou a reabilitação orgânico-funcional (NAHAS, 2010; WHO, 2010).

A aptidão física, por sua vez, pode ser conceituada como a capacidade de realizar atividades físicas, distinguindo-se duas formas de abordagem: aptidão física relacionada ao desempenho motor e a aptidão física relacionada à saúde, que, em níveis adequados, possibilita mais energia para o trabalho e o lazer, proporcionando, paralelamente, menor risco de desenvolver doenças ou condições crônicodegenerativas associadas a baixos níveis de AF habitual (NAHAS, 2010).

A prática regular da atividade física é concebida como um componente fundamental ao desenvolvimento de aspectos positivos relacionados à saúde (FONTES e VIANNA, 2009; WHO, 2010). Seus benefícios são amplamente discutidos pela literatura: quando praticada com regularidade, a AF está intimamente relacionada à melhora das capacidades cardiovascular e respiratória, prevenção de doenças crônicas não transmissíveis (DCNT) - como diabetes tipo II, câncer de mama e cólon, artrite, doenças cardiovasculares e pulmonares - ao menor risco de fraturas e perda de massa óssea, ao aumento de massa muscular. Há também relação com benefícios à saúde mental, tais como: melhoria do bem-estar geral, autoestima, stress e humor (FLORINDO et al., 2001; BIZE et al., 2007; NUÑES, 2007; WHO, 2010; FORTES et al., 2011; GUALANO e TINUCCI, 2011; MIRANDA et al., 2013; FLORINDO et al., 2015; MORTON et al., 2015; PLOTNIKOFF et al., 2015). Além disto, o dispêndio energético proveniente da prática regular de AF é uma importante forma de manutenção do balanço energético e manejo do peso corporal (WHO, 2010).

De acordo com a Organização Mundial da Saúde - OMS (WHO, 2010), para a população adulta (entre 18 e 64 anos), a prática de AF inclui atividades de lazer, 
transporte (caminhar, andar de bicicleta), ocupacional (trabalho), atividades domésticas, exercícios planejados ou esportes. Com o objetivo de melhorar a capacidade cardiorespiratória e muscular, saúde óssea, redução do risco de DCNT e depressão, a OMS recomenda a esta população: 1) prática de, no mínimo, 150 minutos de AF aeróbica de intensidade moderada semanalmente, ou, no mínimo, 75 minutos de intensidade vigorosa; 2) a AF aeróbia deve ser realizada em sessões de, pelo menos, dez minutos de duração; 3) para benefícios de saúde adicionais, podese aumentar a AF aeróbica de intensidade moderada para 300 minutos por semana, ou, 150 minutos de intensidade vigorosa, ou ainda, uma combinação equivalente de intensidade moderada e vigorosa; 4) atividades de fortalecimento muscular devem ser feitas envolvendo grandes grupos musculares em dois ou mais dias por semana.

Com o advento das revoluções industriais e tecnológicas, algumas tendências mundiais têm repercutido na saúde dos indivíduos, em especial a maior expectativa de vida, processos de urbanização e industrialização mal planejados, e a globalização, o que pode ter contribuído para a redução dos níveis de atividade física (LEGNANI, 2009; WHO, 2010; MENEGUCI et al., 2015). Segundo NAHAS (2010), considera-se sedentário um indivíduo que tenha um estilo de vida com um mínimo de atividade física, equivalente a um gasto energético (trabalho + lazer + atividades domésticas + locomoção) inferior a $500 \mathrm{kcal}$ por semana, e o sedentarismo, portanto, é o estilo de vida que não inclui atividades físicas regulares, onde predomina o trabalho sentado $e$ o lazer passivo. Cabe mencionar também o conceito de comportamento sedentário, que tem sido definido na literatura como a exposição a atividades com baixo dispêndio energético, com $\leq 1,5$ equivalentes metabólicos (METs), como as atividades realizadas na posição deitada ou sentada, que não aumentam o dispêndio energético acima dos níveis de repouso - por exemplo, ver televisão, usar computador, assistir às aulas, trabalhar ou estudar numa mesa (GUERRA et al., 2014; MENEGUCl et al., 2015).

O sedentarismo e o comportamento sedentário estão positivamente associados ao maior risco de doença arterial coronariana, infarto agudo do miocárdio, câncer de cólon e de mama, diabetes tipo II, hipertensão, osteoporose, mortalidade, obesidade, dislipidemia, depressão, demência, ansiedade e alterações do humor (WHO, 2010; GUALANO e TINUCCI, 2011; MENEGUCl et al., 2015; SALERNO et al., 2015; SOUSA et al., 2016).

Tal fenômeno tem se constituído em um importante campo de investigação, com destaque para a população de adolescentes e jovens universitários. O ingresso 
na universidade é um evento marcado por intensas mudanças de hábitos, maior autonomia, maior gasto de horas com obrigações acadêmicas, o que leva à possibilidade de adoção de comportamentos sedentários (SANTOS, 2012; MENEGUCI et al., 2015; PLOTNIKOFF et al., 2015; SOUSA et al., 2016). Considerando-se que os hábitos adquiridos neste período poderão ser mantidos na vida adulta, a AF é uma temática de fundamental interesse entre os universitários, além disto, destaca-se a influência que estes indivíduos terão na sociedade como profissionais formadores de opinião (IRWIN, 2004; SILVA e NUNES, 2014; FLORINDO et al., 2015).

$A$ atividade física é intimamente relacionada às atitudes em relação ao corpo. O construto atitude é definido por OPPENHEIM (apud ALVARENGA e PHILIPPI, 2011) como "uma organização duradoura de crenças e cognições em geral, dotada de uma carga afetiva pró ou contra um objeto definido, que predispõe a uma ação coerente com as cognições e afetos relativos a este objeto". Este construto possui três componentes: o afetivo, que se refere a sentimentos, humor e emoções (favoráveis ou desfavoráveis) causados por um objeto específico; o cognitivo, que se refere a crenças e conhecimento sobre o objeto (influenciado por fatores diversos); e o componente volitivo, de vontade, se refere à intenção comportamental em relação ao objeto, ou seja, predisposição para agir de forma coerente com as cognições e afetos (EAGLY e CHAIKEN, 1993; FISHBEIN e AJZEN, 1995; ALVARENGA e PHILIPPI, 2011; ALVARENGA e KORITAR, 2015). As atitudes somente podem ser estudadas indiretamente, pois não são sempre verbalizáveis, nem sequer conscientes (POULIN e PROENÇA, 2003).

Neste contexto, cabe também a diferenciação dos conceitos de práticas objetivadas e das práticas declaradas, visto que o desejo de aceitação social pode motivar alguns indivíduos a fornecer respostas que acreditam ser as mais desejadas ou aceitas pela sociedade, independente do fato de serem verdadeiras (SCAGLIUSI et al., 2004). Segundo POULIN e PROENÇA (2003), as práticas objetivadas são os comportamentos reais, não observados diretamente, mas objetivados de maneira indireta, por meio dos traços que deixam, enquanto as práticas declaradas correspondem àquilo que os sujeitos pretendem fazer ou já fizeram, quando respondem de maneira espontânea a um questionamento.

São diversos os métodos disponíveis quando se trata da avaliação da prática de atividade física, como por exemplo, marcadores fisiológicos, calorimetria direta e 
indireta, acelerômetros, autorrelatos/ métodos qualitativos, e também os questionários, com destaque ao Questionário Internacional de Atividade Física - IPAQ (GUERRA et al., 2014; OLIVEIRA et al., 2014). Contudo, embora tenha sido questionada a frequência semanal de AF e o principal tipo de exercício, a intenção predominante deste estudo foi avaliar as atitudes para com a atividade física, e não apenas os níveis de atividade física, intensidade e aptidão física.

A atividade física se relaciona à imagem corporal (IC), uma vez que pode ser um dos meios de se alcançar o corpo desejado e culturalmente valorizado; e cuja prática recebe influência das dimensões da IC (NOVAES, 2006; FERRARI, 2012; SANTOS, 2012; MIRANDA et al., 2013; WEBB et al., 2015; JAIN e TIWARI, 2016). De acordo com TAVARES (2003) a AF deve proporcionar ao indivíduo vivências que o possibilitem tornar-se consciente de seus próprios sentimentos e reações fisiológicas em relação ao corpo e à atividade, respeitando seus limites e suas possibilidades.

\subsection{A IMAGEM CORPORAL}

De acordo com CASH e PRUZINSKY (2002), o campo de pesquisa da imagem corporal pode ser caracterizado em quatro fases: na primeira fase (entre o final do século XIX e início do século $X X$ ) houve o esforço clínico em compreender as formas de neuropatologias das experiências corporais; o foco da segunda fase (até a metade do século XX) foram experiências corporais nas distorções perceptivas, induzidas por lesões cerebrais; a terceira fase (iniciada na segunda metade do século $X X$ ) caracterizou-se pelos estudos sob a perspectiva psicanalítica e psicodinâmica; e na quarta fase (a partir da década de 1990 até os dias atuais) foi proposta uma teoria sistêmica e integrativa, relacionando informações de várias áreas da psicologia experimental, considerando a experiência corporal como multidimensional (FERREIRA et al., 2014).

No cenário científico do início do século $X X$, o cérebro ocupava um lugar de destaque. Os estudos sobre sua estrutura, sua forma de organizar e conduzir informações, sensações, memórias, aprendizados e pensamentos eram os grandes temas, foi neste contexto que as primeiras pesquisas e conceitos sobre IC se organizaram (CAMPANA e TAVARES, 2009). Os primeiros estudos documentados na temática de imagem corporal foram conduzidos com o objetivo de descobrir quais estruturas do cérebro eram centrais para manter um padrão normal de reconhecimento do corpo, bem como o que uma determinada lesão acarretava na 
percepção do sujeito sobre seu próprio corpo ou sobre o espaço que o circundava (CAMPANA e TAVARES, 2009).

O neurologista francês Pierre Bonnier, em 1905, introduziu o conceito de "esquema corporal", como "uma representação espacial consciente do corpo, que determina a orientação do corpo e de suas partes, incluindo o volume, a localização exata das informações sensoriais, o que baseia a noção de ter um corpo". Em 1911, os neurologistas Head e Holmes, da escola britânica, desenvolveram a teoria de que cada um de nós tem um "padrão postural", ou seja, uma figura inconsciente de si formada pela postura do corpo (CAMPANA e TAVARES, 2009).

O pesquisador alemão Paul Schilder introduziu a visão sistêmica sobre IC, a partir dos anos 1930. Nos anos subsequentes, sua pesquisa propôs a consideração sobre a importância que a cultura, as atitudes e os sentimentos têm em cada comportamento humano. Schilder também chamou a atenção para a beleza, a aparência, a atratividade; especulou sobre as diferenças de percepção entre a superfície e as partes internas do corpo e observou as fantasias sobre invasão corporal (CAMPANA e TAVARES, 2009; SILVA et al., 2012b).

A imagem corporal foi definida por Paul Schilder como "a figura de nossos corpos que formamos em nossa mente", caracterizada por aspectos fisiológicos relacionados à organização cerebral do esquema corporal, sociológicos - que dizem respeito à influência do meio na imagem corporal, e libidinais - relacionados às pulsões, emoções e fantasias (CAMPANA e TAVARES, 2009; AMARAL, 2011). Na mesma época Seymour Fisher buscou em suas investigações valorizar as relações entre a IC e a personalidade (CAMPANA e TAVARES, 2009; FERREIRA et al., 2014).

No Brasil, as pesquisas relacionadas à IC iniciaram-se no âmbito da avaliação dos transtornos alimentares (TA), e o principal interesse era compreender fenômenos como a vivência conturbada com próprio corpo e a imagem, assim, a maior parte das investigações desenvolvidas até a década de 1990 avaliou a IC entre populações clínicas, por meio de instrumentos diversos. Inicialmente, CORDÁS e CASTILHO (1994) traduziram o Body Shape Questionnaire (BSQ - Questionário de Imagem Corporal) para o português, que teve versão adaptada e validada no Brasil apenas mais de uma década depois (CONTI et al., 2009; DiPIETRO e SILVEIRA, 2009).

Outra importante contribuição na área da IC foi a definição proposta por SLADE (1994), segundo a qual a IC pode ser compreendida como "a imagem que o indivíduo tem do tamanho, da forma e do contorno de seu próprio corpo, bem como dos 
sentimentos em relação a essas características e às partes que o constituem" (CAMPANA e TAVARES, 2009; SATO et al., 2011). Nesta perspectiva, a IC é compreendida como um "fenômeno multidimensional", reflexo dos desejos, emoções e da interação social, formada pela dimensão perceptiva e a atitudinal (SLADE, 1994; CASH e PRUZINSKY, 2002; AMARAL, 2011).

A dimensão perceptiva define a exatidão no julgamento do tamanho, da forma e do peso corporais; e o atitudinal envolve três principais componentes: 1) afetivo experiência de sentir emoções relacionadas ao corpo, que resultam na avaliação e interpretação individual de eventos, objetos ou situações; 2) cognitivo - os pensamentos que revelam um elevado senso crítico mental a respeito do próprio corpo; 3) comportamental - as ações sobre ou relacionadas ao próprio corpo, caracterizadas por comportamentos autodefensivos, motivados para prevenir algum desconforto relacionado ao próprio corpo ou para evitar uma dor emocional (CAMPANA e TAVARES, 2009; SATO et al., 2011).

\subsubsection{Imagem corporal: dimensões e distúrbios}

A imagem corporal é, portanto, um construto multidimensional, subjetivo e dinâmico (AVALOS et al., 2005; FORTES et al., 2014), em constante processo de construção, destruição e reconstrução a partir das experiências do sujeito consigo e com o mundo (CAMPANA e TAVARES, 2009; AMARAL, 2011). A formação da imagem corporal é influenciada por aspectos intrínsecos ao indivíduo, como sexo e idade, e extrínsecos, como os valores inseridos em determinada cultura, os meios de comunicação e mídia, a percepção de familiares e amigos, além de fatores cognitivos e afetivos relacionados às experiências corporais (MARTINS et al., 2012; CLAUMANN et al., 2014).

No que diz respeito aos valores culturais, nota-se ao longo da História que eles desempenham um importante papel como reguladores do comportamento humano. Assim, pode-se dizer que há uma tendência de o indivíduo moldar as suas atitudes e ações em função do que é aceitável no seu meio social, buscando se enquadrar nos requisitos exigidos pela sua cultura (FERRARI, 2012).

A mídia de massa tem um papel crucial na formação e reflexão da opinião pública, ela pode influenciar valores, normas e padrões estéticos incorporados pela sociedade moderna (THOMPSON et al., 1999; ALVARENGA et al., 2010a). Considerada a principal responsável pela propagação dos ideais de forma física - 
sobre os quais se discorrerá no tópico a seguir - que passam a ser desejados e cultivados, a mídia interfere na IC de forma passiva, por meio da sensibilização (que representa o conhecimento dos padrões existentes); e/ou ativa, com a incorporação profunda ou aceitação do valor, a ponto de o "ideal" afetar as atitudes ou os comportamentos pessoais de um sujeito, ou seja, é capaz de incitar a internalização do conceito de IC ideal (AMARAL, 2011; FORBES et al., 2012; LAUS, 2012; ANDREW et al., 2015; CARVALHO, 2016; CARVALHO et al., 2017).

Similarmente, o interesse e atenção das pessoas ao redor influenciam na IC, assim, as experiências e sensações obtidas nas relações sociais são parte integrante do processo e da construção da IC (SILVA et al., 2012b). O ser no mundo ao construirse também exerce influência sobre aqueles que o circundam, segundo Paul Schilder (apud SILVA et al., 2012b), "as experiências visuais que levam à construção da imagem corporal pessoal levam, ao mesmo tempo, à construção da imagem corporal dos outros".

Considerando a multiplicidade de construtos que influenciam a IC, os distúrbios de IC são alterações graves e persistentes na dimensão perceptiva ou atitudinal, de maneira independente ou simultânea, e causam sofrimento, prejuízos sociais, físicos e emocionais (SATO et al., 2011).

Quando a dimensão perceptiva é afetada, há uma alteração na forma como o indivíduo percebe seu corpo, ou seja, ele é incapaz de estimar acuradamente o tamanho do seu corpo e mostra uma discrepância entre as proporções percebidas e as proporções reais do próprio corpo (PAULA, 2010). Tal distúrbio pode ser, portanto, nomeado como distorção da imagem corporal, e pode afetar o corpo como um todo ou apenas partes específicas (SATO et al., 2011).

Diferente dos distúrbios perceptivos, os distúrbios atitudinais, são definidos como alterações graves e persistentes nos sentimentos e/ou pensamentos sobre o corpo e/ou nas ações voltadas para o corpo. Um dos distúrbios atitudinais mais comuns é a insatisfação corporal - que comporta duas facetas: 1) a avaliativa, caracterizada pela diferença entre o corpo atual e o considerado ideal pelo indivíduo; e 2) a afetiva, o quanto o indivíduo sofre em função dessa diferença. Outros exemplos de distúrbios atitudinais, são depreciação corporal, evitação corporal, preocupação extrema com o corpo, medo mórbido de engordar, valorização extrema do corpo, checagem repetitiva do corpo, investimento extremo no corpo (SATO et al., 2011). 
A imagem corporal é um fator bastante afetado nos transtornos alimentares, e faz parte dos critérios diagnósticos de diversos quadros (APA, 2013). Distúrbios relacionados à avaliação do corpo nos TA incluem: pensamentos dicotômicos (o indivíduo pensa em extremos com relação à sua aparência ou é muito crítico em relação a ela); comparação injusta (o indivíduo compara sua aparência com padrões extremos); atenção seletiva (o indivíduo focaliza um aspecto específico da aparência); erro cognitivo (o indivíduo acredita que os outros pensam como ele em relação à sua aparência) - (SAIKALI et al., 2004; DAMASCENO et al., 2011; TIMERMAN et al., 2015; CARVALHO et al., 2017).

Tendo em vista a amplitude das consequências dos distúrbios de imagem corporal à saúde física e mental, esta questão tem sido avaliada não apenas no âmbito dos transtornos alimentares (CORDÁS e CASTILHO, 1994; STICE e SHAW, 2002; TIMERMAN et al., 2010; SATO et al., 2011; TIMERMAN et al., 2015), mas também em populações específicas, como os adolescentes (FERRIANI et al., 2005; FORTES et al., 2013; FORTES et al., 2015; MEIRELES et al., 2015), os atletas (OLIVEIRA et al., 2003; SCHTSCHERBYNA et al., 2009; GONÇALVES et al., 2012b; REEL et al., 2013; KONG e HARRIS, 2015), e os universitários - sobre os quais se discorrerá a seguir.

\subsubsection{Insatisfação corporal}

A imagem corporal é um construto que abrange diversos elementos, desta forma, são inúmeros os fatores que podem contribuir para a insatisfação corporal, como prática de dietas, exposição ao conteúdo de mídias e redes sociais, ser do sexo feminino, prática de atividades físicas nas quais a aparência/peso corporal é primordial (por exemplo, ballet, ginástica olímpica, hipismo, lutas), além do padrão ocidental de beleza (ROBINSON e FERRARO, 2004; BOSI et al., 2006; MAHMUD e CRITTENDEN, 2007; HERNÁNDEZ et al., 2012; MAYO e GEORGE, 2014; COHEN e BLASZCZYNSKI, 2015; FARDOULY e VARTANIAN, 2015; SWAMI et al., 2015).

A insatisfação corporal está associada à consequências nocivas, como baixa autoestima, depressão, ansiedade, diminuição da qualidade de vida, ideação suicida, desenvolvimento e manutenção de transtornos alimentares, bem como a comportamentos e atitudes alimentares disfuncionais - muitas vezes com o objetivo de controlar o peso, como por exemplo: uso de laxantes, substâncias anorexígenas, esteroides anabolizantes, adesão a cirurgias plásticas estéticas (RODRíGUEZ-CANO 
et al., 2006; POMPILI et al., 2007; BOSI et al., 2009; ALVARENGA et al., 2010b; RECH et al., 2010; SIDES-MOORE e TOCHKOV, 2011; MIRANDA et al., 2012; SILVA et al., 2012a; AS-SA'EDI et al., 2013; RUNFOLA et al., 2014). Indivíduos insatisfeitos com sua IC podem, ainda, adotar rituais de pesagens, medidas e comparações de seu corpo com o de outros indivíduos, como parâmetro de avaliação no julgamento de seu sucesso ou sua "falha" no controle do peso (CARVALHO et al., 2013b; CARVALHO, 2016; CARVALHO et al., 2017).

No período universitário, a instabilidade psicossocial e as intensas alterações biológicas decorrentes da transição da adolescência à juventude associadas às mudanças na rotina referentes ao ingresso na universidade (FONTES e VIANNA, 2009; DAMASCENO et al., 2011; FERRARI et al., 2012; PRADO, 2012; SOUSA et al., 2016) - como novas relações sociais e obrigações acadêmicas, maior independência, distanciamento do convívio familiar, adoção de novos comportamentos (IRWIN, 2004; NICHOLS et al., 2009; SANTOS, 2012; CARVALHO et al., 2013b; PLOTNIKOFF et al., 2015) - torna os estudantes vulneráveis às pressões exercidas pela sociedade quanto aos aspectos corporais (MIRANDA et al., 2012).

Neste contexto, foi realizada uma revisão integrativa da literatura nacional e internacional sobre a insatisfação corporal entre estudantes universitários. Tal busca gerou um artigo já publicado sobre a temática (SOUZA e ALVARENGA, 2016 - Anexo 1), que selecionou 40 estudos nacionais e 36 internacionais. Encontrou-se que a amplitude da insatisfação de imagem corporal em ambos os sexos foi de $8,3 \%$ a $87 \%$ nos estudos nacionais, e de 5,2\% a 85,5\% nos internacionais, avaliados, principalmente, por escalas de silhuetas e/ou questionários (como o Body Shape Questionnaire, o Eating Disorder Inventory, e o Body-Self Relations Questionnaire Appearance Scales). Fatores como exposição à mídia e redes sociais, prática de dietas, período menstrual e baixa autoestima foram relacionados à insatisfação corporal.

Nos estudos nacionais que apresentaram a frequência de insatisfação corporal em relação ao sexo, encontrou-se de $17,4 \%$ a $82,5 \%$ para as mulheres, e de 2,25\% a $73,41 \%$ para homens, e quando houve a descrição do curso no qual os universitários eram matriculados, os avaliados com maior frequência foram os de Educação Física e de Nutrição. No cenário internacional quando se fez a distinção da frequência de insatisfação corporal em relação ao sexo, a variação foi de $40,4 \%$ a $87 \%$ para 
mulheres, e de $32,8 \%$ a $70 \%$ para homens, e o curso mais frequentemente avaliado foi o de Psicologia, seguido pelo de Medicina.

1.2.2 Ainda há esperança! Imagem corporal positiva

A imagem corporal tem sido predominantemente estudada no contexto negativo e patológico, ao passo que, menor destaque é dado a uma visão mais positiva (AVALOS et al., 2005, TYLKA E WOOD-BARCALOW, 2015; CARVALHO, 2016).

Segundo AVALOS et al. (2005) a imagem corporal positiva é caracterizada por: (1) opiniões favoráveis sobre o corpo independentemente da aparência física, (2) aceitação corporal apesar do peso, formas corporais e "imperfeições", (3) respeito ao corpo, atendendo às suas necessidades e tendo comportamentos saudáveis, e (4) proteção do conteúdo midiático acerca de imagens corporais irreais.

ANDREW et al. (2015) definem imagem corporal positiva como um construto fundamentado em respeito, amor, apreciação e aceitação da aparência e funcionalidade do corpo.

A imagem corporal positiva envolve mais do que a inexistência de afetos, cognições e percepções negativas sobre corpo. Da mesma forma que a felicidade é mais complexa do que a ausência de depressão, a imagem corporal positiva é mais complexa do que a mera ausência de insatisfação corporal (AVALOS et al., 2005, ANDREW et al., 2015; GILLEN, 2015; TYLKA E WOOD-BARCALOW, 2015).

A apreciação corporal ("body appreciation") é definida por AVALOS et al. (2005) como uma contemplação das capacidades, funcionalidade e saúde do corpo, ou seja, valorizar o corpo pelo que ele representa, por ser único, e não apenas apreciar a aparência e atendimento aos padrões de beleza.

A aceitação e amor ao corpo ("body acceptance and love"), segundo TYLKA E WOOD-BARCALOW (2015), são expressos pelo conforto e bem-estar com o corpo, mesmo quando não se está completamente satisfeito com ele. Estas autoras também elucidam o "adaptive appearance investment", que representa um autocuidado relacionado à aparência e higiene, a fim de aprimorar as características naturais de forma benéfica.

WEBB et al. (2015) definem "body functionality" como um reconhecimento e apreciação das diversas funções desempenhadas pelo corpo, não apenas no âmbito físico. O conceito de ampla concepção da beleza ("broad conceptualization of beauty") 
reforça a ideia de que beleza não é restrita à determinada aparência, mas sim algo flexível que abrange diferentes formas e estilos.

Desta forma, a imagem corporal positiva é holística, à medida que comporta simultaneamente as diversas esferas e vivências do autocuidado e valorização corporais. Ter uma imagem corporal positiva envolve a satisfação com o corpo e a aparência, menor angústia associada ao corpo, maior otimismo, autoestima e autocuidado (AVALOS et al., 2005; TYLKA E WOOD-BARCALOW, 2015; WEBB et al., 2015).

Estes diferentes conceitos ("body appreciation", "body acceptance and love", "adaptive appearance investment", "body functionality", "broad conceptualization of beauty") devem ser mais bem estudados e avaliados, especialmente no que diz respeito ao planejamento de estratégias de prevenção da IC negativa. Até onde se conhece, este tipo de trabalho e intervenção está bastante circunscrito à prevenção de TA (DUNKER et al., 2015)

A compreensão da temática de imagem corporal pode ser aprimorada ao se considerar também o universo do corpo os significados a ele atribuídos, sendo que este é um valor de identidade e distinção do indivíduo perante aos elementos externos.

\subsection{O CORPO, A BELEZA E SEUS DIFERENTES SIGNIFICADOS}

$O$ corpo é a forma elementar de comunicação do indivíduo com o universo. No decorrer da vida, de maneiras distintas, esta comunicação é influenciada por diversos elementos como sentimentos, emoções, crenças e religião, costumes, hábitos, história, aprendizado, cultura, desejos, expectativas, desafios, família, genética, alimentação, fisiologia, vivências, avaliação externa, condições socioeconômicas entre outros.

Como principal elo entre o sujeito e o mundo, é o corpo também que traduz o diálogo "natureza e cultura", tornando-se a arena onde acontecem os conflitos políticos, culturais, étnicos, históricos, religiosos e econômicos (FERREIRA, 2006). Assim, cada cultura modela e fabrica, à sua maneira, um corpo humano - seja por meio de razões sociais, seja por rituais ou apenas por razões estéticas (NOVAES, 2006) - e determina também aquilo que se considera ideal ao enfatizar determinados atributos em detrimento de outros, ao criar os seus próprios padrões de beleza, de sensualidade, de saúde, de postura, que dão referências aos indivíduos para se construírem (BARBOSA et al., 2011; SOARES, 2016). Estes padrões não são fixos, e 
seus elementos e significados passaram por mudanças no decorrer do tempo e da história (SAMPAIO e FERREIRA, 2009). As descobertas do corpo possuem uma história secular e vasta, pontuada pelos avanços e limites do conhecimento humano (SANT'ANNA, 2000).

Na Idade Média o corpo era entendido como fonte de pecado (BARBOSA et al., 2011), sendo então reprimido e censurado pelo dogmatismo religioso (CASSIMIRO et al., 2012). De um lado, o corpo era fruto da benção e da glorificação - principalmente religiosa, quando se trata do corpo de Cristo -, e de outro, era desprezado, condenado, humilhado, caracterizando certo conflito entre o material e o espiritual (BARBOSA et al., 2011), em uma sociedade que se preocupava mais com a salvação da alma do que com os cuidados que se deviam dar ao corpo (CASSIMIRO et al., 2012).

A sexualidade feminina, seus gestos, suas práticas, sua conduta na sociedade eram questões mediadas pela Igreja e aceitas pela sociedade - de forma conflituosa também, pois o corpo feminino estava associado ao "bem" (procriação, virgindade, castidade e cuidado com a família) e ao "mal" (sexualidade, prostituição, luxúria e perversão da alma). Neste contexto, valorizou-se também a renúncia à alimentação (jejuns) como uma forma de purificar a alma, abandonar o material e alcançar o espiritual, bem como se condenaram os excessos alimentares, ao considerar a gula como um pecado (WEINBERG e CORDÁS, 2006; ROIZ, 2010; BARBOSA et al., 2011; CASSIMIRO, 2012; CARVALHO et al., 2016).

Foi apenas a partir dos séculos XVII e XVIII que a preocupação com a saúde e o bem-estar emergiu, pois até então seria considerado uma blasfêmia qualquer tentativa de se prolongar a vida (NOVAES, 2006). No Renascimento, o progresso científico e técnico trouxe uma nova visão ao corpo, que, como objeto de estudos e experiências, era o corpo anatômico e biomecânico da Medicina (NOVAES, 2006; BARBOSA et al., 2011; SOARES, 2016).

Os avanços científicos dos séculos XVII e XVIII também fomentaram maior liberdade para as atividades comerciais da burguesia, o que favoreceu o surgimento de um novo modo de produção: o capitalismo (CASSIMIRO, 2012). Com a ascensão do sistema capitalista, o trabalho passou a ser realizado em série (lógica industrial) e o corpo percebido como "máquina manipulável" (BARBOSA et al., 2011), corpoprodutor, corpo-instrumento, corpo-alienado, disciplinado para render, que, paradoxalmente, via sua perfectibilidade ameaçada por enfermidades causadas pelas 
condições insalubres das fábricas (MALAGOLI, 2006). Neste período, as grandes metrópoles mundiais passaram por reformas urbanas guiadas principalmente pela Medicina, com a expansão das práticas de saneamento e higiene a fim de sanar as epidemias (COSTA e VENÂNCIO, 2004; BARBOSA et al., 2011), tratava-se do pensar na limpeza do corpo, das roupas, das habitações (SOARES, 2016).

Com a expansão dos processos de modernização que atingiram esferas como a arte, a ciência, os pensamentos e os valores (PEREIRA, 2010), o início do século $X X$ foi marcado por importantes acontecimentos que influenciaram os significados atribuídos ao corpo, dentre eles o advento do cinema como nova forma de entretenimento e grande divulgador de tendências, modismos e pensamentos - 0 modelo corporal de atores e atrizes (principalmente norte-americanos) passou a ser objeto de desejo da sociedade emergente (MALAGOLI, 2006).

No cenário político-econômico, as Guerras Mundiais evidenciavam que a força física do corpo e as habilidades de luta já não eram suficientes, e os corpos mutilados eram apenas números, sem história, rostos ou identidade (MALAGOLI, 2006; GOMES, 2013) - reforçando-se a ideia de que o poder humano estava na ciência, na física, nos cálculos, na precisão do movimento do controle de uma bomba.

No Brasil, o Regime Militar imprimiu nos corpos as dolorosas marcas de tortura a pesquisadores, intelectuais, artistas, líderes políticos e a todas as outras "vozes dissonantes". A prática da tortura foi utilizada como controle político, momento permeado pelo poder de um que subjugava e aquele que era subjugado, numa relação na qual a vítima se via despojada de sua autodeterminação em razão da dor e o torturador se reafirmava pela mesma razão (GOMES, 2014).

A conquista brasileira do tricampeonato em 1970 foi um estímulo à prática de atividade física e esporte como artifício de entretenimento entre os jovens, e com o objetivo de preparar novos talentos esportivos para competições internacionais (ANZAI, 2000; SANT'ANNA, 2000; COSTA e VENÂNCIO, 2004; ALMEIDA e GUTIERREZ, 2010; ALMEIDA et al., 2013; GALAK, 2015). Aumentavam-se assim os locais para cuidar do corpo, bem como a oferta de cosméticos e roupas que incentivavam uma homogeneização de corpos e padrão de beleza jovem (GOELLNER, 2003; MALAGOLI, 2006; GALAK, 2015; COSTA, 2016).

Entre os anos 1980 e 1990 os meios de comunicação reafirmaram seu caráter massificador e mudaram a relação do indivíduo com o tempo-espaço (PEREIRA, 2010), as distâncias entre as culturas foram encurtadas com o fenômeno da 
globalização. Novos comportamentos, gestos, hábitos e crenças foram apropriados e adaptados de diferentes sociedades ao redor do mundo; o cultural (e o estético) passou a ser consumido na moda, nos cuidados corporais, no lazer, na alimentação, nas compras e práticas cotidianas, ou seja, a economia tornou-se questão cultural e a cultura passou definitivamente a compor o mercado (TRINCA, 2008; ALMEIDA e GUTIERREZ, 2010).

Ao final do século $X X$ o corpo se consolidou como consumidor do capitalismo, sujeito à lógica do mercado e à sociedade de consumo, quando a ciência e o conhecimento colocaram em xeque algumas verdades absolutas instituídas pelo pensamento religioso (GOMES, 2013; COSTA, 2016).

\subsubsection{A era da exposição: o corpo do século XXI}

O corpo do início do século XXI é marcado pelos crescentes avanços da ciência e tecnologia, imediatismo, fluidez das relações e sujeição ao mercado do consumo (COSTA e VENÂNCIO, 2004; NUNES et al., 2007; COSTA, 2016), tratado como um corpo completamente manejável pela tecnociência, desenhado para superar todos os "defeitos" do corpo biológico (BARBOSA et al., 2011; LEITZKE et al., 2014). A atualidade prima por disseminar mensagens ambíguas sobre a saúde das pessoas e seus corpos, por um lado, existe uma ideia de que o corpo é frágil e vulnerável, porém, ao mesmo tempo, consome-se a otimização da vida, o aperfeiçoamento genético, a saúde perfeita (COSTA, 2016). Assim, o corpo é cultuado como um objeto de adoração e desejo com todos os holofotes voltados a ele (TRINCA, 2008), e simultaneamente tratado como objeto descartável, sem sentido e sem valor (TRINCA, 2008; SAMPAIO e FERREIRA, 2009; SOUZA et al., 2013).

O padrão de beleza vigente preconiza um corpo jovem, esbelto, símbolo de perfeição, livre de gorduras, modelo de saúde e disposição - magro e definido para as mulheres, forte e musculoso para os homens (NUNES et al., 2007; COSTA et al., 2010a; PEREIRA, 2010; EGLI et al., 2011; FERRARI, 2012; MARTINS et al., 2012; HURST et al., 2017). A imagem do corpo se tornou um componente imprescindível, de modo que o eu é o corpo, tendo a subjetividade reduzida ao corpo, à sua imagem, à sua performance, à sua saúde, à sua juventude e longevidade (TRINCA, 2008; GOMES, 2013).

O corpo, na atualidade, parece assim se apresentar como uma síntese de desejo, ciência e tecnologia, a serviço do chamado bem-estar (COSTA e VENÂNCIO, 
2004; DANTAS, 2011; GOMES, 2013), as relações que o mercado estabelece são múltiplas, criando sempre demandas corporais e novas exigências. A indústria do culto ao corpo apresenta-se como um possível instrumento de adequação a valores idealizados, ligados à estética, ao comportamento, aos estados de ânimo e, por fim, como meio eficiente de conduzir a tão sonhada felicidade, orientando o que se deve fazer para tornar o corpo um modelo que obedece ao que se espera no mundo social (SABINO, 2007; TRINCA, 2008; LEITZKE et al., 2014).

Se anteriormente o corpo foi dividido em duas partes (matéria física e a parte abstrata representada pela alma), atualmente ele é a própria fragmentação, decomposto em músculos, glúteos, coxas, seios, boca, olhos, cabelos, órgãos genitais etc. Cada um destes pedaços se torna um potencial alvo de consumo e de tratamento (BARBOSA et al., 2011), e o mercado lhes oferece inúmeros tipos de cosméticos, cirurgias plásticas, procedimentos estéticos, exercícios físicos, dietas e restrições alimentares, alimentos especiais (diet, light, gluten free), suplementos, medicamentos (emagrecedores, diuréticos, laxantes), hormônios anabolizantes (TRINCA, 2008; PEREIRA, 2010; LEITZKE et al., 2014).

Além desta fragmentação, há que se ressaltar a divisão do corpo no âmbito da ideologia do gênero: as partes superiores (braços, ombros, peitorais) representando os atributos da virilidade, enquanto as partes inferiores (quadris, nádegas, pernas) marcam os atributos da feminilidade (GOELLNER, 2003; MALYSSE, 2007). Assim, em geral, entre os homens, os esforços são voltados ao alcance de maior massa muscular (construto definido como drive for muscularity), já entre as mulheres, a finalidade é o controle/ perda de peso corporal a fim de ter um corpo magro e esbelto - drive for thinness (SABINO, 2007; GONÇALVES et al., 2008; MAYO e GEORGE, 2014; CARVALHO, 2016).

Como um rascunho que pode ser refeito ou aperfeiçoado de acordo com o desejo e o bolso do indivíduo (DANTAS, 2011), ao corpo é dado o significado de objeto de consumo cujas peças podem ser substituídas, redesenhadas, cortadas, modeladas e transformadas, conforme os anseios pessoais, de forma que seu valor é medido pelos atributos físicos que possui (ou conquista). Dissociado de si e dos outros, da natureza, da coletividade, o corpo torna-se uma esfera independente e voltada para si (NOVAES, 2006; VAZ, 2015), parte de um espetáculo, que precisa ver e ser visto (TRINCA, 2008; SAMPAIO e FERREIRA, 2009; VAZ, 2015). 
A busca por saúde e "boa forma" organiza a vida em torno do consumo, que, não é relacionado apenas com as necessidades básicas do sujeito, mas o consumo articulado ao desejo de ter, poder, adquirir, fazer (SOARES, 2000; ANDRADE, 2003; GOMES, 2013; COSTA, 2016). Esta busca desconhece limites e não importa a forma que o corpo tenha neste momento, sempre será possível melhorar. Há sempre uma dose irritante de "má forma" a ser aperfeiçoada, e cada alvo não passa apenas de mais um degrau em uma longa e sucessiva escada (DANTAS, 2011).

A indústria da beleza, implícita ou explicitamente induz à ideia de que para se ter sucesso, felicidade ou dinheiro, o único caminho é por meio da beleza estética, e, numa sociedade onde ser feliz muitas vezes está vinculado à aparência, ao status e ao sentir bem o tempo todo, o corpo torna-se objeto de constante investimento e preocupação (SAMPAIO e FERREIRA, 2009; DANTAS, 2011; LEITZKE et al., 2014; VAZ, 2015). O discurso da saúde se misturou ao discurso da aptidão e da estética e resultou num processo de constante insatisfação que converge para o que se acredita ser um "cuidado com o corpo" (NUNES, 2007; COSTA, 2016). Tal cuidado vem se tornando demasiado, quase uma obrigação diária, gerando por vezes sentimento de culpa, insuficiência, vergonha e fracasso naqueles que não podem alcançá-lo (NOVAES, 2006; DANTAS, 2011).

Neste cenário de "cuidados" com o corpo e saúde, tão enaltecidos como sinal de disciplina, não se pode desconsiderar a possibilidade de que desempenhem função predisponente e/ou mantenedora de doenças psiquiátricas, dentre elas o transtorno dismórfico corporal (TDC) e os transtornos alimentares (GONÇALVES et al., 2012a; APA, 2013; SCHAUMBERG e ANDERSON, 2016; CARVALHO et al., 2017). No TDC, as cirurgias plásticas podem ser uma estratégia de corrigir um defeito na aparência física - que não é observável ou parece apenas leve para os outros (APA, 2013; SCHIEBER et al., 2015).

Especificamente na dismorfia muscular (um tipo de TDC) os exercícios físicos anaeróbicos e de força podem ser praticados de forma excessiva para alcançar um corpo demasiadamente forte e musculoso, além do uso de suplementos para hipertrofia muscular, e eventual uso de anabolizantes (APA, 2013; SCHIEBER et al., 2015). O excesso de exercícios físicos pode ocorrer nos transtornos alimentares como método compensatório das calorias ingeridas; além de outras práticas compensatórias (SAIKALI et al., 2004; ALVARENGA et al., 2010b; APA, 2013; FORTES et al., 2015; TIMERMAN et al., 2015; SCHAUMBERG e ANDERSON, 2016). 
Além dos transtornos alimentares propriamente ditos, as práticas compensatórias inadequadas para alcance/manutenção de um corpo "ideal" podem estar presentes no cotidiano de indivíduos que não necessariamente preenchem os todos os critérios diagnósticos para TA - vale ressaltar que a adoção de práticas compensatórias é um fator de risco para os TA (ALVARENGA et al., 2013). No que diz respeito ao padrão de atividade física, alguns sinais de inadequação são: forçarse ao exercício mesmo quando não se sente bem, quase nunca se exercitar por prazer, ficar estressado e ansioso quando não se exercita, deixar de cumprir obrigações familiares para se exercitar, preferir fazer exercícios a estar com amigos, calcular quanto deve fazer de atividade física baseado em quanto come, não conseguir relaxar por que pensa que não está queimando calorias, preocupar-se em ganhar peso se pular um dia de atividade física (OGDEN et al., 1997; UUSITALO, 2001; TEIXEIRA et al., 2011; TEIXEIRA et al., 2015).

Diante de uma sociedade na qual a imagem tem predominância, a vida passou a ser permeada por uma era de plasticidade absoluta (TRINCA, 2008; LEITZKE et al., 2014) na qual o corpo é vitimizado por políticas de saberes/poderes que o identificam, classificam, estigmatizam, enfim, formam e deformam a imagem corporal. Pessoas são integralmente responsabilizadas pela conquista de um corpo perfeito, jovem e saudável, não importando suas preferências, biologia, valores e condições. Sob a moral da "boa forma", valoriza-se um corpo trabalhado, sem marcas indesejáveis, sem excessos, que mesmo sem roupas esteja decentemente vestido por sua perfeição e beleza (COSTA e VENÂNCIO, 2004; GOLDENBERG e RAMOS, 2007; MALYSSE, 2007; SAMPAIO e FERREIRA, 2009; GOMES, 2013), moldadas por meio de tecnologias corporais, dentre estas, as cirurgias plásticas e procedimentos estéticos (NOVAES, 2006).

\subsection{CORTA, ESTICA, MODELA E TRANSFORMA: CIRURGIAS PLÁSTICAS, PROCEDIMENTOS ESTÉTICOS E AS QUESTÕES DE GÊNERO}

Existem várias hipóteses sobre a origem da cirurgia plástica. Contudo, a mais aceita remota à Índia como o primeiro país no qual se tem notícia de ter sido feita a primeira cirurgia desse tipo (por volta do ano 1000 a.C.). De acordo com historiadores, na tradição hindu, as mulheres adúlteras tinham seus narizes amputados uma forma de castigo ao mau comportamento. As cirurgias plásticas realizadas na época 
tratavam então da reconstrução nasal dessas "desviantes", que possuíam no corpo a marca da regulação social (NOVAES, 2006, LEMMA, 2010).

A cirurgia plástica é um procedimento cirúrgico eletivo, por meio do qual se busca a manutenção, restauração e/ou melhora aparência física, modificando os traços originais da face ou as formas do corpo (SWAMI et al., 2009b; CAMPANA et al., 2012), que foi consolidada no século XVI, com o Renascimento. Entretanto, é somente no lluminismo do século XVIII, quando são resgatados os ideais estéticos renascentistas de simetria como medida para o belo, que a prática ressurge. Nesse mesmo século ocorreram mudanças significativas no processo de emergência e valorização das cirurgias plásticas, destacando-se duas delas: o surgimento paulatino de um processo de individualização (a autonomia assume valor central na vida do sujeito), e a passagem de uma lógica religiosa (na qual o corpo era visto como dádiva divina, e qualquer modificação no âmbito corporal era interpretada como um sacrilégio contra a vontade de Deus) para uma lógica do livre arbítrio (NOVAES, 2006).

Associado aos ideais raciais da medicina higienista do século XIX, o aperfeiçoamento das cirurgias plásticas ocorreu inicialmente com a função de corrigir traços físicos das raças consideradas "inferiores", compreendidos como deformidades inaceitáveis. Contudo, o boom da cirurgia plástica ocorreu após a segunda metade do século XX, como uma técnica fundamental no tratamento dos mutilados das Guerras. Historicamente, foi nesse momento que a cirurgia plástica ganhou status como especialidade médica, utilizada como instrumento de transformação estética (FERREIRA, 2006; NOVAES, 2006; HENDERSON-KIN e BROOKS, 2009; COELHO et al., 2017).

Diversos são os motivos associados aos procedimentos cirúrgicos e estéticos, dentre os quais se podem citar a "internalização" dos padrões de beleza, insatisfação com peso e imagem corporal, avanços da ciência e tecnologia, desejo constante de ter uma aparência melhor, experiências prévias bem-sucedidas (pessoais ou de pessoas próximas que também realizaram tais intervenções), necessidade de atender expectativas externas relacionadas à aparência física, medo de ser "trocado" pelo parceiro, perspectiva de sucesso na carreira profissional (SARWER et al., 2005a; SWAMI et al., 2008; HENDERSON-KIN e BROOKS, 2009; von SOEST et al., 2009; SWAMI et al., 2011; CAMPANA et al., 2012; SWAMI e MAMMADOVA, 2012; COELHO et al., 2015). De forma global, a motivação central para a adesão a estas técnicas é a busca por uma eventual satisfação corporal, que, de algum modo, poderia contribuir 
com a melhora a autoestima, estado emocional e saúde mental (SARWER et al., 2005a; von SOEST et al., 2009; ERICKSEN e BILLICK, 2012, COELHO et al., 2017).

Importante ressaltar também os efeitos da exposição ao conteúdo midiático acerca das intervenções cirúrgicas e estéticas, com destaque aos procedimentos realizados por pessoas famosas (SWAMI et al., 2009b; CAMPANA et al., 2012; COELHO et al., 2015), que ajuda a divulgar e banalizar estas práticas como alternativas facilmente incorporáveis à vida cotidiana e ao orçamento, rápidas, livres de riscos e complicações (SARWER et al., 2005a; FERREIRA, 2006; NOVAES, 2006; SWAMI e MAMMADOVA, 2012). Além da propaganda midiática, os programas de televisão específicos sobre pessoas que fizeram e/ou farão cirurgias plásticas e procedimentos estéticos contribuem para a divulgação (e consequente "internalização") destes como uma alternativa "fácil" para se alcançar a aparência ideal (SWAMI et al., 2008). O "vazio da existência", as questões emocionais e psíquicas são, muitas vezes, ignorados em nome da possibilidade de transformação imediata do corpo (FERREIRA, 2006; FERREIRA, 2010). Outro fator que também contribui à maior adesão às intervenções é a atual redução de custos e as facilidades de pagamento - como financiamentos e linhas de crédito -, tornando esta possibilidade mais acessível (FERREIRA, 2006; SWAMI e MAMMADOVA, 2012).

Estas intervenções compõem uma parcela fortemente lucrativa do mercado, por isso são estimulados pela mídia e endossados como a solução para todos os problemas e sofrimentos (RODRIGUES e CANIATO, 2009). Parece existir um sentimento generalizado de que a reflexão é inimiga da ação, tudo deve ser feito antes que se possa mudar de ideia (NOVAES, 2006), assim, importantes elementos emocionais e psicológicos podem não receber a devida atenção, como frustração e sofrimento por expectativas não atendidas, depressão, ansiedade, rejeição (pessoal e externa), risco de suicídio (LEMMA, 2010).

Há que se considerar que as cirurgias plásticas também podem servir de amparo a quem sofre com problemas orgânicos e dores que afetam tanto a vida social como a psíquica (RODRIGUES e CANIATO, 2009) como, por exemplo, as cirurgias plásticas reparadoras, indicadas aos pacientes submetidos a cirurgias oncológicas, nos casos de violência doméstica, vítimas de acidentes no trânsito ou problemas congênitos que evoluíram com perda ou prejuízo da forma ou da função de determinada região do corpo, queimaduras, além dos pacientes submetidos à cirurgia bariátrica - devido à flacidez e ao excesso de pele (SBCP, 2017). 
Mundialmente, há um expressivo número de indivíduos que se submetem às intervenções cirúrgicas e estéticas. De acordo com a International Society of Aesthetic Plastic Surgery (ISAPS, 2015), no ano de 2015 foram realizados mais do que 21 milhões de procedimentos (cerca de 9,641 milhões de cirurgias plásticas e 12,055 milhões de procedimentos estéticos), sendo que deste total o Brasil ocupou o segundo lugar (10,7\% do total mundial, aumento de 0,5\% em relação ao ano anterior), com 2.324.245 intervenções (1.224.300 cirurgias plásticas), ficando atrás apenas dos Estados Unidos da América (com um total de 4.042.610 de intervenções, o que equivale a $18,6 \%$ do total mundial). O terceiro lugar foi ocupado pela Coreia do Sul, seguida pela Índia, México, Alemanha, Colômbia, França e Itália.

As cirurgias plásticas mais frequentes no mundo em 2015 foram aumento de mamas, lipoaspiração, a blefaroplastia (cirurgia das pálpebras), abdominoplastia e rinoplastia. No Brasil, as cirurgias plásticas mais frequentes foram lipoaspiração, aumento de mamas, blefaroplastia, abdominoplastia e mastopexia (reposicionamento/elevação de mamas). Ressalta-se que em 2015 o Brasil foi o país onde mais se realizou blefaroplastia - 11,3\% do total mundial (ISAPS, 2015).

Quanto à faixa etária, de acordo com o ISAPS (2015) as três principais intervenções cirúrgicas entre jovens de 19-34 anos (abrangendo, portanto, a população alvo deste estudo) foram aumento de mamas, lipoaspiração e rinoplastia, sendo esta faixa a que mais realizou as referidas intervenções. Os adolescentes e jovens constituem um público no qual a aparência física exerce grande influência (direta ou indiretamente) nas relações sociais, aspectos como a vulnerabilidade às cobranças pessoais e externas de um ideal de beleza, aos apelos persuasivos da mídia e à perspectiva de transformação corporal imediata reforçam a tendência de comparação e insatisfação corporal (ZUCKERMAN e ABRAHAM, 2008; JORDAN e CORCORAN, 2013; SBCP, 2016), fato bastante preocupante, pois, além dos riscos anteriormente expostos, é importante lembrar que tais intervenções podem comprometer o desenvolvimento dos jovens, e os prejuízos à saúde podem assumir proporções ainda maiores (ZUCKERMAN e ABRAHAM, 2008; ASAPS, 2016; ASHIKALI et al., 2016).

Mais do que 18,5 milhões dos indivíduos que realizaram intervenções cirúrgicas e estéticas eram do sexo feminino $(85,6 \%$ do total), e as cirurgias plásticas com maior frequência foram aumento de mamas, lipoaspiração, blefaroplastia, abdominoplastia e rinoplastia. Quanto aos homens, foram mais do que 3,1 milhões (14,4\%) e as 
cirurgias mais frequentes foram a blefaroplastia, lipoaspiração, correção de ginecomastia, rinoplastia e transplante capilar (ISAPS, 2015).

Tabela 1. Procedimentos (cirúrgicos e estéticos) realizados nos EUA, Brasil e França no ano de 2015.

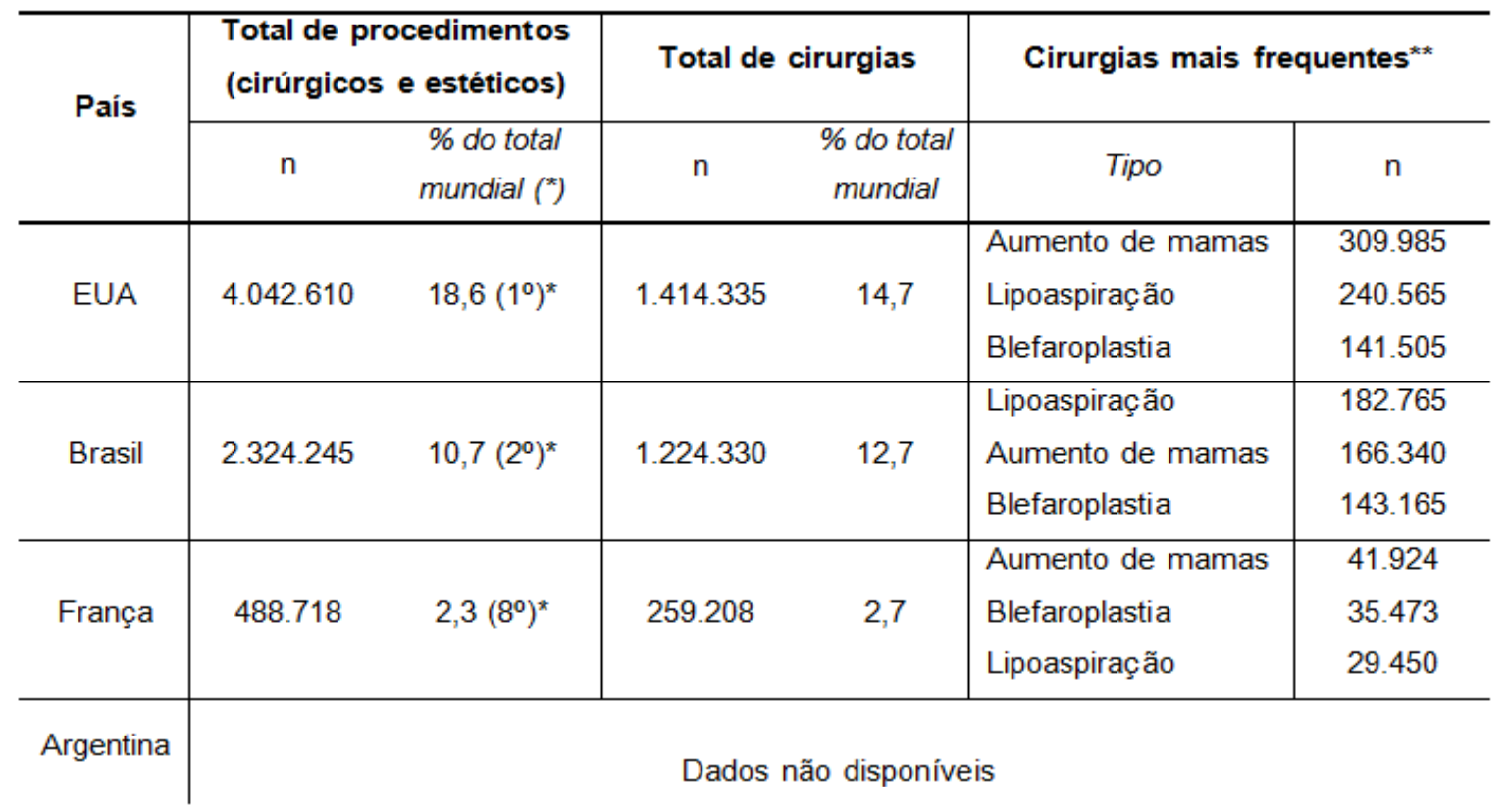

${ }^{*}$ Posição no ranking mundial. ${ }^{*}$ Considerando ambos os sexos.

Fonte: Adaptado de International Society of Aesthetic Plastic Surgery (ISAPS, 2015).

Os padrões de beleza impostos pela sociedade são muito mais rígidos às mulheres do que aos homens. No universo feminino não há justificativa possível para o não atendimento dos imperativos da beleza (VILHENA et al., 2005), enquanto a beleza masculina é associada ao status econômico e social, de forma a ressaltar qualitativos como imponência e potência; os "desvios" com relação ao padrão de beleza estão vinculados à falta de tempo em função do ritmo atribulado da vida profissional, e qualquer cuidado excessivo com a aparência pode ser interpretado como uma ameaça à masculinidade (NOVAES, 2006; DUTRA, 2007; SABINO, 2007).

A beleza feminina vem na forma de um trabalho árduo e constante sobre 0 corpo, e em traços como delicadeza, fragilidade, submissão e comportamento polido (GOELLNER, 2003; VILHENA et al., 2005; NOVAES, 2006). Os qualitativos estéticos têm função preponderante na felicidade amorosa, familiar e sexual: não basta ser uma boa mãe, uma esposa dedicada e uma profissional competente, é preciso ser linda, 
sensual, "sarada", jovem e magra para que cada um destes papéis seja valorizado socialmente (NOVAES, 2006, LEITZKE et al., 2014).

Se historicamente as mulheres se preocupavam com sua beleza, hoje elas são responsáveis por ela, ou seja, de dever social (conseguir ser melhor), a beleza tornouse um dever moral (NOVAES, 2006; LEITZKE et al., 2014). Uma nova moralidade, que, embora tenha conquistado a libertação física e sexual, prega a determinação do padrão estético convencionalmente chamado de "boa forma" (GOLDENBERG e RAMOS, 2007). Uma intensificação do dispositivo repressivo, do qual as mulheres, por meio de seus corpos, são objeto, gera um mal-estar constante (CASH e HENRY, 1995).

As práticas de embelezamento acabam se tornando obrigatórias, uma vez que é imposta a ideia de que a beleza da mulher deve ser apreciada nos mínimos detalhes, e um mero descuido já é suficiente para a "feiura" aparecer. Deixar-se feia é um sinal de "incapacidade" individual, cujas consequências levam à insatisfação corporal, prejuízos sociais, físicos e psicológicos (CASH e HENRY, 1995; GOELLNER, 2003; VILHENA et al., 2005; NOVAES, 2006; TANTLEFF-DUNN et al., 2011). A insatisfação generalizada com todos os aspectos que envolvem o corpo e a beleza tornou-se cada vez mais comum entre as mulheres, assim, há o descontentamento normativo: no qual estar insatisfeita é a regra e não a exceção (RODIN et al., 1985; LITTLETON, 2008; SWAMI et al., 2009a; ALVARENGA et al., 2010b).

Com o universo de possibilidades associadas às intervenções realizadas no corpo, este passa a ter um novo valor ao recusar a submissão ao destino, sendo possível modificar qualquer uma de suas partes, de forma que a moda hoje não se restringe à indumentária, ela se inscreve no próprio corpo (FERREIRA, 2006; MALYSSE, 2007). A anatomia não é mais um destino, mas um capital, um projeto em longo prazo (NOVAES, 2006), o corpo deixou de ser a expressão de um dado da natureza, para se sujeitar aos ditames das opções da sociedade de consumo (GOMES, 2013). O remodelamento do corpo ganha o sentido de uma busca pela autenticidade e autonomia, ambas paradoxais, ao passo que o ser autêntico é tentar se tornar igual ao padrão e cuja autonomia é usada para buscar um ideal que lhe é imposto (NOVAES, 2006; FERREIRA, 2010) - um corpo que, apesar de aparentemente mais livre para a exposição pública, é, na verdade, muito mais constrangido (GOLDENBERG e RAMOS, 2007) por nunca corresponder ao ideal de aparência. 


\subsection{JUSTIFICATIVA}

Sabe-se que a prática regular de atividade física pode trazer inúmeros benefícios à saúde física e mental (IRWIN, 2004; BIZE et al., 2007; NUÑES, 2007; WHO, 2010; FORTES et al., 2011; GUALANO e TINUCCI, 2011; MIRANDA et al., 2013, MORTON et al., 2015; PLOTNIKOFF et al., 2015). Entretanto, no contexto da busca ávida por corpos idealizados pelo padrão de beleza contemporâneo, nem sempre a atividade física é praticada com o objetivo de se alcançar os referidos benefícios e o estabelecimento uma imagem corporal bem estruturada.

Em nome da "boa forma", a prática de atividade física é, em muitos casos, trilhada por meio de uma árdua rotina de exercícios, grande dedicação de tempo e sacrifícios autoimpostos por meio dos quais se pretende superar os próprios limites (HANSEN e VAZ, 2004), o que pode precipitar ou agravar os distúrbios de imagem corporal e, consequentemente, trazer diversos prejuízos à qualidade de vida.

Quando se discute o corpo e a imagem corporal, não se pode dissociá-los da alimentação - e consequentemente da Nutrição. A relação com o corpo afeta o consumo e hábitos alimentares, a motivação para mudanças comportamentais, além de serem sintomas de alguns quadros que exigem tratamento nutricional (como no caso dos transtornos alimentares). Embora sejam construtos diretamente relacionados, na prática nutricional, comumente, a avaliação e classificação antropométrica dos indivíduos é preterida, em detrimento da reflexão acerca da magnitude de significados deste corpo. Em meio à falta de preparo específico sobre este tema durante a formação do nutricionista (cuja base é predominantemente fisiológica) aspectos relacionados à subjetividade do indivíduo têm menor espaço.

Vale salientar que a prescrição de exercício físico é competência do o profissional graduado em Educação Física, contudo, a promoção da atividade física é uma temática multidisciplinar. Considerando a comunicação direta da atividade física com o corpo, imagem corporal e alimentação, a avaliação conjunta destes construtos pode contribuir para uma perspectiva mais ampla e holística do assunto.

Os valores culturais podem influenciar o processo de construção e dimensão da atividade física, corpo, imagem corporal e atitudes alimentares, além disso, há que se considerar as diferenças associadas ao fato de ser mulher ou homem na concepção destes construtos, assim, a comparação destes entre estudantes universitários do Brasil em relação a outros países é de grande interesse, a fim de conhecer suas similaridades e diferenças. 
1.5.1 Argentina, Brasil, Estados Unidos da América e França: equivalências e distinções

Cada cultura enaltece determinados atributos da aparência física e detém, portanto, um ideal de corpo valorizado, assim não há um referencial integralmente universal de corpo "perfeito" - mesmo na vigência da globalização de ideias e conceitos (BARBOSA et al., 2011; CARVALHO, 2016).

Entretanto, o corpo ocidental encontra-se em constante transformação e a questão identitária parece estar muito mais ligada a imagens fluidas do que às tradições (GOLDENBERG e RAMOS, 2007; TYLKA E WOOD-BARCALOW, 2015). Neste contexto, alguns fatores justificam a escolha da Argentina, Brasil, Estados Unidos da América e França como "local" de estudo, dentre eles as questões relacionadas às atitudes alimentares. A princípio, merece destaque o estudo realizado por ROZIN et al. (1999), comparando as atitudes alimentares de belgas, japoneses, estadunidenses e franceses, no qual os autores verificaram que os estadunidenses faziam mais associações entre comida e saúde, diferentemente dos franceses, que associavam a comida mais ao prazer do que à saúde. Todavia, na literatura não há registros de comparação destes países no que diz respeito à imagem corporal e prática de atividade física, tampouco a comparação destes países com países em desenvolvimento (como o Brasil e a Argentina), assim, os resultados deste estudo podem trazer contribuições importantes - os próprios autores citam neste estudo clássico a necessidade de se avaliar países fora do eixo "desenvolvido".

As questões relacionadas à insatisfação corporal são mundialmente discutidas, mas com enfoque bastante localizado e em grupos específicos. Entre os estudantes universitários, o estudo de revisão integrativa realizado (Anexo 1) verificou grande amplitude e diversos fatores que influenciam a insatisfação corporal tanto para os brasileiros quanto para os estadunidenses, evidenciando que quando o assunto é corpo e imagem corporal, o descontentamento parece ser um fenômeno universal não foram localizadas referências sobre a insatisfação corporal em universitários argentinos e franceses nesta revisão. Entretanto, a literatura ainda é escassa no que diz respeito à comparação transcultural destas questões entre os universitários do Brasil, EUA e outros países (como Argentina e França); foi encontrada apenas uma referência que comparou a insatisfação corporal e as atitudes de risco para transtornos alimentares, entre universitários do Brasil, Argentina e EUA (FORBES et al., 2012). 
No âmbito dos aspectos relacionados à aparência corporal, os EUA e o Brasil são os países que se destacam, respectivamente, pelo número de academias de ginástica no mundo (são 36.180 academias nos EUA e 31.809 no Brasil). Em 2015, a Argentina ocupava o quarto lugar no ranking mundial, porém, de acordo com os últimos dados do International Health, Racquet \& Sportsclub Association (IHRSA), passou a ser o terceiro país em número de academias $(n=7.900)$. A França tem pouco mais do que $10 \%(n=3.800)$ do número de academias dos EUA e do Brasil (IHRSA, 2016).

Outro fator de interesse em relação aos países aqui avaliados é que os EUA e o Brasil são líderes mundiais em número de cirurgias plásticas. Juntos, nestes países foram realizadas quase $30 \%$ do total mundial de cirurgias plásticas em 2015 , enquanto a França ocupou o oitavo lugar no ranking mundial (2,7\%), com número total cerca de cinco vezes menor do que os EUA - não foram divulgados os dados referentes aos procedimentos cirúrgicos e estéticos realizados na Argentina (ISAPS, 2015).

Em relação aos valores culturais na Argentina, MEEHAN e KATZMAN (2001) discutem que este país tem uma fortíssima herança europeia (talvez a maior influência dentre os países da América do Sul), o que certamente influenciou o processo de formação de identidade do país, que associada à instabilidade econômica, faz da Argentina um país "oprimido", onde se tenta a todo custo alcançar o "padrão europeu" de beleza e onde a possibilidade de controlar o tamanho e a aparência do corpo detém não apenas uma sensação psíquica de vitória, mas também a oportunidade de maior sucesso econômico em um mercado que valoriza demasiadamente os ideais culturais de beleza e magreza.

Historicamente, a crise econômica sofrida pela Argentina em 2001 foi um dos piores momentos para o país, entretanto, a única indústria que teve crescimento no período foi a indústria da beleza (PELLICER, 2011). A moda deste país também reflete a pressão cultural pelo corpo escultural, uma vez que a foi necessária uma intervenção legal a fim de obrigar a indústria têxtil a produzir roupas em tamanhos maiores. De acordo com a Ley de Talles, a indústria deve produzir, obrigatoriamente, roupas nos tamanhos 38-48, e, opcionalmente, os tamanhos 50, 52 e 54 - entretanto, a aplicação desta normativa não é unânime em todo o país, mas em Buenos Aires e em províncias como Entre Ríos, Mendoza, Santa Cruz, Santa Fe, San Juan (MEEHAN E KATZMAN, 2001; BUENOS AIRES, 2005; BUENOS AIRES, 2010; BUENOS AIRES, 2012; FORBES et al., 2012; GIORIA et al., 2014). Esta Lei foi criada devido à pressão 
cultural a favor da magreza extrema, bem como uma medida de prevenção ao elevado número de indivíduos que sofrem de transtornos alimentares no país (PELLICER, 2011).

Quanto aos franceses, a literatura descreve especificidades na representação da comida e do corpo. Tradicionalmente, na França a refeição é também momento comunhão; comer significa sentar-se à mesa, aplicando certas regras que são implícitas (simplesmente ocorrem, não precisam ser ditas), como estar com outras pessoas, gastar um tempo mínimo, comer um número determinado de pratos entrada, prato principal, sobremesa (GOLDENBERG, 2011; ROZIN et al., 2011). No estudo de ROZIN et al. (2003) cuja temática central é o tamanho das porções de alimentos, os autores encontraram que diferentemente dos estadunidenses, os franceses consomem porções menores, dedicam mais tempo e atenção ao que estão comendo, e não têm o hábito de comer nos intervalos entre as refeições - diferenças que podem ser atribuídas ao ambiente que cada cultura estabelece na relação com a comida. Segundo Claude Fischler, a relação que os franceses têm com a comida, certamente influencia no menor número de indivíduos com excesso de peso, uma vez que o manejo da alimentação depende muito menos do controle de cada indivíduo, mas sim de toda uma vivência cultural GOLDENBERG (2011).

Mundialmente, a relação com a comida sofreu grandes transformações advindas dos ideais de beleza, do crescimento da produção industrial dos alimentos, da regulação científica e da cultura, neste sentido, a "mentalidade de dieta" (MENNUCCl et al., 2015) os modismos e mitos alimentares, o nutricionismo (SCRINIS, 2013), a ortorexia nervosa (obsessão pelo comer saudável) compõem um mal-estar que atravessa a experiência com a alimentação e com o corpo. A cultura centrada na valorização da imagem do corpo encontra na publicidade a disseminação da sua imagem, normalizando um determinado modelo de corpo, além de um conjunto de práticas necessárias à sua manutenção (BARBOSA et al., 2011). Nesse cenário, experiências negativas tornam-se comuns, como, por exemplo, a insatisfação corporal normativa (sobretudo entre as mulheres).

Considerando-se a coexistência do padrão de beleza ocidental com as particularidades de cada cultura e gênero quanto aos aspectos alimentares, corporais e em relação à atividade física, e que tal conhecimento auxiliar a compreensão de aspectos subjetivos relacionados a estes construtos, propõe-se a seguinte pergunta de partida: Quais as semelhanças e diferenças na relação entre a atividade física, 
corpo, imagem corporal e alimentação entre estudantes universitários do Brasil, Argentina, Estados Unidos e França?

\subsection{HIPÓTESES}

As hipóteses deste estudo são:

- Mulheres podem apresentar maior insatisfação corporal, fazer mais dietas e mais restrições alimentares do que os homens - independente do país;

- As razões para se exercitar e a frequência semanal de atividade física podem estar relacionadas à insatisfação corporal, preocupação e culpa com a rotina de exercícios, possibilidade de adesão a cirurgias plásticas, prática de dietas e restrição alimentar - e variam entre os sexos e países;

- Universitários estadunidenses e brasileiros podem apresentar maior possibilidade de adesão a cirurgias plásticas. 


\section{OBJETIVOS}

\subsection{OBJETIVO GERAL}

Avaliar a relação entre atividade física, relação com corpo e imagem corporal entre universitários da Argentina, Brasil, Estados Unidos da América e França.

\subsection{OBJETIVOS ESPECÍFICOS}

- Avaliar a influência do país e do sexo sobre variáveis relacionadas à atividade física, à alimentação e à imagem corporal;

- Verificar se a atividade física está relacionada à imagem corporal, estado nutricional, cirurgias plásticas e comportamentos compensatórios;

- Verificar se a possibilidade de aderir a cirurgias plásticas se relaciona à imagem corporal;

- Examinar a relação da atividade física, corpo, imagem corporal e atitudes alimentares de acordo com a principal razão para se exercitar. 


\section{MÉTODO}

\subsection{CARACTERIZAÇÃO DO ESTUDO}

Trata-se de um estudo do tipo observacional transversal, no qual a avaliação da exposição e efeito dos fenômenos é avaliada ao mesmo momento. Os desfechos são as semelhanças e diferenças nas frequências de fenômenos relacionados à atividade física, relação com corpo, imagem corporal e alimentação entre universitários de ambos os sexos em quatro países.

O presente estudo utiliza dados secundários, provenientes do banco da pesquisa transcultural "Atitudes para com o exercício, dieta e imagem corporal em quatro diferentes países", conduzido em parceria com a University of Pennsylvania (UPenn) - aprovado pelo CONEP FSP-USP 171/08 -, cujo objetivo geral foi investigar as atitudes para com o exercício, a alimentação e a imagem corporal de estudantes universitários argentinos, brasileiros, estadunidenses e franceses.

A coleta de dados da referida pesquisa se deu entre os anos de 2010 e 2012.

\subsection{LOCAL}

Os países participantes deste estudo são Brasil (São Paulo, SP), Argentina (Buenos Aires), França (Nantes) e Estados Unidos da América (Filadélfia, Pensilvânia). Um pesquisador ficou responsável pela divulgação da pesquisa, e discussão sobre esta em cada um dos países; a saber: Marle Alvarenga, na FSP/USP para Brasil; Guillermina Rutsztein, na Universidad de Buenos Aires (UBA) para Argentina; Mohamed Merdji, da Universidade de Nantes na França; e Paul Rozin, na Universidade da Pensilvânia, Estados Unidos da América.

\subsection{AMOSTRA}

A amostra foi composta por estudantes universitários provenientes do Brasil, Argentina, França e Estados Unidos da América ( $n=1$.695). A amostragem foi do tipo não-probabilística (de conveniência), na qual todos os universitários acessíveis que aceitaram o convite puderam responder ao questionário - portanto, não houve uma definição de $n$ mínimo antes da coleta de dados.

A fim de verificar a suficiência da amostra obtida na coleta de conveniência, utilizou-se o software GPower 3.1.7, adotando-se um nível de significância de $p<0,05$, tamanho de efeito (Cohen d) de 15\%, na opção "post hoc". Verificou-se que para a 
amostra avaliada $(n=1.695)$ o poder foi de $100 \%$. Considerando que o tamanho amostral mínimo é relativo a cada teste estatístico e que neste estudo foram realizados mais do que 30 testes, para esta simulação foi adotado o teste estatístico no qual foi necessário o maior $n$ de indivíduos na amostra. Embora a coleta já tivesse ocorrido, neste software também foi realizado o cálculo amostral na opção "a priori”, no qual foi possível verificar que o $n$ mínimo para as análises aqui desenvolvidas seria de 104 indivíduos. Portanto, a amostra obtida $(n=1.695)$ é bastante superior ao mínimo necessário.

Os universitários argentinos $(n=304)$ são alunos da Universidad de Buenos Aires. Fundada no ano 1821 na cidade de Buenos Aires, de acordo com o último senso da Universidade, há 262.932 alunos matriculados em 15 diferentes faculdades (UBA, 2011). Os alunos foram convidados a participar do estudo por meio de anúncios em aulas de psicologia e antropologia, e mediante a uma postagem na página do grupo de psicologia da Universidade (no Facebook), na qual foi solicitado aos alunos que compartilhassem o conteúdo da postagem.

A amostra de universitários brasileiros $(n=583)$ é proveniente da Universidade de São Paulo (USP). A USP é a maior universidade pública brasileira e uma das maiores instituições de ensino superior da América Latina, fundada no ano de 1934 e conta atualmente com 55.451 alunos de graduação matriculados em 300 diferentes cursos, distribuídos em oito campi (USP, 2015). Os alunos participantes do estudo foram convidados por meio de e-mails enviados aos centros acadêmicos dos cursos e redirecionados aos e-mails de turmas.

Os universitários franceses são alunos da Université de Nantes $(n=441)$, estes receberam o convite de participação no estudo por e-mail enviado aos alunos da Escola de Administração (Audencia Nantes School of Management). A Université de Nantes foi oficialmente fundada em 1961, e tem 45.200 alunos matriculados em suas 11 faculdades (Université de Nantes, 2017), e na Escola de Administração são 3031 os alunos matriculados (Audencia Nantes School of Management, 2017).

Por último, os universitários estadunidenses ( $n=367)$ são alunos da University of Pennsylvania e foram convidados para participar do estudo por meio de anúncios nos cursos de psicologia introdutória e social, e através de e-mail aos alunos de pósgraduação da Universidade. A UPenn foi fundada no ano de 1740, está localizada na cidade da Filadélfia (Pensilvânia) e conta com 24.960 alunos matriculados, sendo 
10.468 estudantes de graduação (distribuídos em 12 diferentes faculdades) e 10.890 estudantes de pós-graduação (UPenn, 2017).

A participação de todos os universitários (nos quatro países) foi voluntária, de acordo com as normas locais. Apenas no caso dos EUA, os alunos de graduação receberam um crédito no curso pela participação no estudo, e os alunos de pósgraduação concorreram em um sorteio para uma retribuição de US\$100,00. Nos EUA, amostra foi intencionalmente selecionada entre estudantes de graduação e pósgraduação, por dois motivos: 1) Neste país, muitos estudantes de graduação vivem nas dependências do campus, e buscou-se uma boa representatividade de universitários que vivem fora do campus, no caso, em outros países; 2) Universitários estadunidenses são um pouco mais jovens do que os de outros países.

Para inclusão, os universitários deveriam ter idade entre 18-30 anos; e como critério de exclusão considerou-se aqueles que nasceram (ou viveram a maior parte de sua vida após os dez anos de idade) fora do país de sua universidade - para consideração adequada do país como um fator do estudo.

Além destes critérios, a fim de se obter comparações transculturais mais representativas, foram eliminados os questionários dos participantes que deixaram mais do que $30 \%$ das respostas em branco (Argentina $=42$, Brasil $=95$, França $=67$ e EUA = 13). Foram excluídos também aqueles cuja idade estava fora do intervalo entre 18-30 anos, ou que não especificaram a idade (Argentina $=55$, Brasil $=50$, França = 6 e EUA = 43); aqueles que não especificaram seu sexo (Argentina = 19, Brasil = 1 e EUA = 9); bem como os universitários que nasceram fora do país $($ Argentina $=5$, Brasil = 2, França $=18$ e EUA = 64).

Até o momento, a literatura já conta com um artigo publicado que também avaliou esta amostra de universitários (RUBY et al., 2016), no qual os autores investigaram as atitudes em relação à carne nos quatro países, em ambos os sexos.

\subsection{ASPECTOS ÉTICOS}

Nos Estados Unidos, a University of Pennsylvania (responsável pelo projeto pesquisa principal - "Atitudes para com o exercício, dieta e imagem corporal em quatro diferentes países") recebeu da Institutional Review Board a isenção da necessidade de aprovação do Comitê de Ética e Pesquisa (Anexo 2), o que foi suficiente para o prosseguimento da pesquisa também na Universidad de Buenos Aires (Argentina) e na Université de Nantes (França). 
No Brasil, atendendo às recomendações da Resolução 196/96 do Conselho Nacional de Pesquisa (BRASIL, 1996), o projeto principal foi submetido à apreciação do Comitê de Ética e Pesquisa da Faculdade de Saúde Pública da Universidade de São Paulo em 2008, e foi aprovado (CONEP FSP-USP 171/08, Anexo 3).

$E m$ atendimento às orientações recebidas da Faculdade de Saúde Pública, este estudo foi novamente submetido à apreciação do Comitê de Ética e Pesquisa da Faculdade de Saúde Pública da Universidade de São Paulo, e aprovado - parecer 1.553.827/2016 (Anexo 4).

Os participantes consentiram em participar da pesquisa ao preencher 0 questionário online e, portanto, não houve um Termo de Consentimento Livre e Esclarecido (TCLE) impresso. Eles eram informados sobre a pesquisa da primeira página da mesma (antes das questões), e as informações sobre ética eram ali elencadas. A autorização era dada com seguimento das respostas ao clicar botão "aceito participar". Atendendo à legislação brasileira - Resolução 196/96 (BRASIL, 1996) - a versão do questionário em português contou com uma forma simplificada de TCLE (Anexo 5), por ser uma pesquisa online, no qual fica claro que se trata de uma pesquisa simples, cuja participação é absolutamente anônima, sem maior envolvimento do indivíduo que a responde, sendo possível desistir de participar a qualquer momento (da mesma forma, o consentimento foi dado ao clicar em "aceito participar").

\subsection{INSTRUMENTO}

A coleta de dados foi realizada por meio de um questionário online, utilizando o site seguro surveymonkey.com. Os dados ficaram hospedados em um servidor seguro, protegidos por senha e mantidos em um computador da Universidade da Pensilvânia, com acesso apenas ao pesquisador principal ou outros pesquisadores responsáveis pelo estudo em cada país.

Este questionário foi inicialmente desenvolvido em inglês, com base em pesquisas realizadas pelo pesquisador responsável na UPenn (ROZIN et al., 2003; ROZIN et al., 2006) e teve como "inspiração" especialmente o trabalho "Attitudes to food and the role of food in life in the U.S.A., Japan, Flemish Belgium and France: possible implications for the diet-health debate" (ROZIN et al., 1999) - neste estudo os autores já mencionavam a necessidade de maior entendimento das questões culturais envolvendo países do mundo em desenvolvimento. 
A versão piloto do questionário para esta pesquisa passou por pré-teste com universitários dos EUA, e em uma etapa posterior, o questionário foi traduzido e adaptado (quando necessário) por tradutores nativos e fluentes em português, espanhol da Argentina e francês. Dúvidas e discrepâncias foram discutidas durante todo processo pela equipe de pesquisadores, e uma versão final retrotraduzida do português para o inglês foi enviada à equipe da UPenn e aprovada para uso no Brasil. No entanto, este questionário não é uma escala validada. Várias questões são avaliadas por frequência, outras com escores do tipo Likert, mas não se objetivou uma análise de propriedades psicométricas, uma vez que nenhum tipo de "classificação" ou "diagnóstico" será feito - e sim, uma exploração de atitudes.

O tempo para preenchimento do questionário inteiro foi estimado em 30 minutos, neste constavam variáveis sociodemográficas, de estado nutricional, prática de atividade física, imagem corporal, atitudes alimentares (para com a comida em geral e para com a carne) e porções alimentares. No presente trabalho são exploradas as questões relativas à imagem corporal, atitudes alimentares (principalmente aquelas voltadas ao manejo do peso corporal) e atividade física; além das demográficas e de estado nutricional (Anexo 6). O tópico 3.6 apresenta a descrição detalhada de cada um destes conjuntos de variáveis.

\subsection{VARIÁVEIS}

O Quadro 1 apresenta as variáveis do estudo bem como sua classificação, que estão descritas detalhadamente a seguir. 
Quadro 1. Classificação das variáveis do estudo.

\begin{tabular}{|c|c|c|}
\hline Conjunto de variáveis & Variável & Categoria \\
\hline \multirow{9}{*}{ Sociodemográficas } & Idade (anos) & Quantitativa contínua \\
\hline & Sexo (feminino ou masculino) & Categórica nominal \\
\hline & Etnia & Categórica nominal \\
\hline & Ano do curso & Categórica nominal \\
\hline & Curso & Categórica nominal \\
\hline & Nacionalidade & Categórica nominal \\
\hline & País onde vive & Categórica nominal \\
\hline & Estado ou região & Categórica nominal \\
\hline & Classe socioeconômica & Categórica nominal \\
\hline \multirow{3}{*}{ Estado nutricional } & Peso referido $(\mathrm{kg})$ & Quantitativa contínua \\
\hline & Estatura referida (metros) & Quantitativa contínua \\
\hline & IMC $\left(\mathrm{kg} / \mathrm{m}^{2}\right)$ & Categórica ordinal \\
\hline \multirow{6}{*}{ Atividade física } & $\begin{array}{l}\text { Número de dias de atividade física na } \\
\text { semana }\end{array}$ & Quantitativa discreta \\
\hline & Principal forma de exercício & Categórica nominal \\
\hline & Principal razão para se exercitar & Categórica nominal \\
\hline & Faria exercícios apenas por diversão & Categórica nominal \\
\hline & $\begin{array}{lllll}\text { Preocupação } & \text { com } & \text { a } & \text { rotina } & \text { de } \\
\text { exercícios } & & & & \\
\end{array}$ & Categórica ordinal \\
\hline & Culpa por não se exercitar & Categórica ordinal \\
\hline \multirow{7}{*}{ Imagem corporal } & Peso considerado ideal (kg) & Quantitativa contínua \\
\hline & Preocupação com excesso de peso & Categórica ordinal \\
\hline & Figura que melhor a aparência atual & Categórica ordinal \\
\hline & Figura que gostaria de ser & Categórica ordinal \\
\hline & $\begin{array}{l}\text { Anos de vida que abriria mão para ter } \\
\text { e manter o corpo ideal pelos próximos } \\
20 \text { anos }\end{array}$ & Quantitativa contínua \\
\hline & Percepção da imagem corporal ${ }^{\star}$ & Categórica ordinal \\
\hline & Satisfação com a imagem corporal ${ }^{*}$ & Categórica ordinal \\
\hline Cirurgia plástica & $\begin{array}{l}\text { Em que extensão consideraria fazer } \\
\text { uma cirurgia plástica cosmética }\end{array}$ & Categórica ordinal \\
\hline \multirow{5}{*}{ Atitudes alimentares } & Prática de dietas & Categórica ordinal \\
\hline & Restrição alimentar & Categórica ordinal \\
\hline & $\begin{array}{l}\text { Preocupação sobre o que come e } \\
\text { como isso afeta a aparência }\end{array}$ & Categórica ordinal \\
\hline & $\begin{array}{l}\text { Frequência de vômitos com intuito de } \\
\text { perder peso }\end{array}$ & Categórica ordinal \\
\hline & Frequência de compulsão alimentar & Categórica ordinal \\
\hline
\end{tabular}

*A percepção e a satisfação corporal não são diretamente questionadas, mas avaliadas por meio da escala de silhuetas de Stunkard, descrita no tópico "Imagem corporal", a seguir. 
a) Sociodemográficas: foram coletadas com questões específicas dentro do instrumento geral. Os estudantes referiram: idade (anos), sexo' (feminino ou masculino), etnia (opções: indígena, asiático, negro, mulato, hispânico, branco/caucasiano), ano do curso (opções: $1^{\circ}, 2^{\circ}, 3^{\circ}, 4^{\circ}, 5^{\circ}, 6^{\circ}$ ou mais), curso de graduação, nacionalidade, país onde vive, estado ou região, condição socioeconômica (opções: baixa, média baixa, média, média alta, alta).

b) Estado nutricional: o peso (quilos) e estatura (metros) foram referidosii - e utilizados para cálculo do Índice de Massa Corporal (IMC): peso/altura ${ }^{2}\left(\mathrm{~kg} / \mathrm{m}^{2}\right)$. O estado nutricional foi classificado em baixo peso, eutrofia, sobrepeso e obesidade segundo a Organização Mundial de Saúde (WHO, 2006) conforme o Quadro 2.

Quadro 2. Classificação do Índice de Massa Corporal segundo a Organização Mundial de Saúde.

\begin{tabular}{|c|c|}
\hline IMC $\mathbf{( k g / \mathbf { m } ^ { 2 } )}$ & Classificação \\
\hline Abaixo 18,5 & Baixo peso \\
\hline $18,5-24,9$ & Eutrofia \\
\hline $25-29,9$ & Sobrepeso \\
\hline $30-34,9$ & Obesidade grau I \\
\hline $35-39,9$ & Obesidade grau II \\
\hline Acima de 40 & Obesidade grau III \\
\hline
\end{tabular}
Fonte: WHO, 2006.

c) Atividade física: as questões envolviam o número de dias de atividade física na semana (opções: de 0 - 7); principal forma de exercício (opções: caminhar, andar de bicicleta, correr, nadar, jogar em algum time de esporte, aparelhos de exercício aeróbico/cardiovascular, levantamento de pesos, dança/ginástica, yoga/pilates, nunca se exercita, outra); principal razão para se exercitar (opções: diversão, competição,

\footnotetext{
' Todas as menções feitas aos termos "feminino/mulher" e "masculino/homem" referem-se ao sexo do indivíduo (em termos genéticos e fisiológicos) e não à identidade sexual ou gênero.

ii $O$ autorrelato das variáveis peso e altura para cálculo de IMC é uma técnica válida para mulheres e homens adultos, como observado no seguinte estudo: Sousa TF, Barbosa AR. Validade das medidas referidas da massa corporal e estatura em universitários. ABCS Health Sci. 2016; 41(2):71-7.
} 
saúde, perda de peso, ficar em boa forma, nunca se exercita); questionamento se faria exercícios apenas por diversão (opções: sim ou não), preocupação com a rotina de exercícios (opções de resposta em escala Likert de 5 fatores: de "nem um pouco verdadeiro" a "absolutamente verdadeiro"); culpa por não se exercitar (opções de resposta em escala Likert de 5 fatores: de "nem um pouco verdadeiro" a "absolutamente verdadeiro").

d) Imagem corporal: questionamento do peso considerado ideal (em quilos); preocupação com excesso de peso (opções de resposta em escala Likert de 5 fatores de "nunca" a "quase sempre") e questionamento sobre quantos anos (do total da vida) o participante abriria mão para ter e manter o corpo ideal pelos próximos 20 anos.

A imagem corporal também foi avaliada por meio da Escala de Silhuetas de Stunkard (STUNKARD et al., 1983) - Anexo 7. A escala é composta por uma série de nove figuras de corpo humano específicas para o sexo masculino e para o feminino, as quais aumentam sequencialmente às formas corporais.

Os participantes foram convidados a selecionar duas figuras, aquela que acreditavam ser a mais representativa de seu corpo real e outra em que pensavam ser a representante de seu corpo ideal. A percepção corporal corresponde à imagem escolhida como corpo real; enquanto a insatisfação corporal corresponde à discrepância entre o número que representa o corpo atual e a que representa o corpo ideal (Figura 1), assim, quanto mais distante o corpo ideal estiver do real, mais insatisfeito o indivíduo se encontra com seu corpo e, quanto mais próximo, menor o nível de insatisfação. Se a figura relativa ao corpo real e ideal for a mesma, então, o indivíduo encontra-se satisfeito com sua dimensão e forma corporal (SCAGLIUSI et al., 2006).
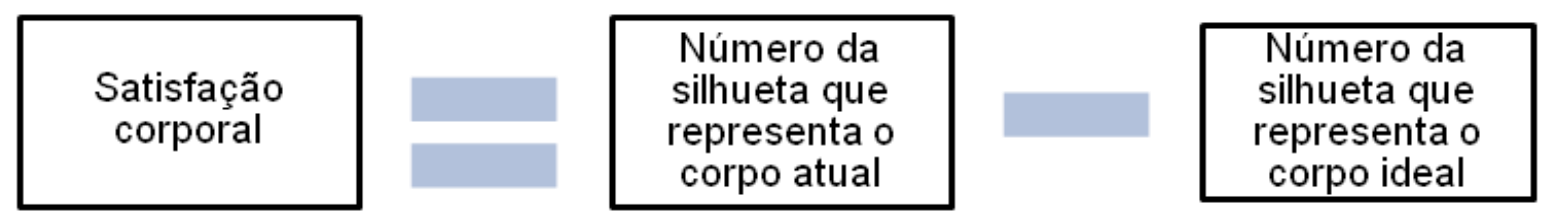

Figura 1. Esquema para avaliação da satisfação corporal. 
No presente estudo, estas figuras eram numeradas de 10 (mais magra) a 90 (mais gorda) e os universitários deveriam responder: qual a figura que melhor representa a aparência atual e a figura que gostariam de ser (sendo possível usar números intermediários nas respostas).

STUNKARD et al. (1983) encontraram boa validade geral da escala de silhuetas, e estudo posterior THOMPSON e ALTABE (1991) atestaram boa confiabilidade teste-reteste na seleção de figuras por mulheres $(r=0,71)$. A Escala de Silhuetas de Stunkard foi validada no Brasil por SCAGLIUSI et al. (2006) para a população feminina, e por CONTI et al. (2013) para a população masculina. Embora a Escala Silhuetas de Stunkard seja antiga, apresente algumas limitações, e de atualmente estar disponível a escala de silhuetas brasileiras (KAKESHITA, 2008), esta opção não seria válida para os outros países além do Brasil, portanto, o instrumento adotado foi o de Stunkard.

e) Cirurgia plástica: questionamento sobre a extensão em que considerariam fazer uma cirurgia plástica cosmética (opções em escala Likert de 4 fatores: "nunca consideraria", "talvez consideraria", "seriamente consideraria" e "eu já fiz uma cirurgia plástica").

f) Atitudes alimentares: dentre as questões deste tópico foram selecionadas para o presente estudo aquelas com possível relação com IC e atividade física questionamento sobre a prática de dietas (opções em escala Likert de 5 fatores de "nunca a "quase sempre"); restrição alimentar (opções em escala Likert de 5 fatores de "nunca a "quase sempre"); preocupação sobre o que come e como isso afeta a aparência (opções em escala Likert de 5 fatores de "nem um pouco verdadeiro" a "absolutamente verdadeiro"); frequência de vômitos com intuito de perder peso (opções em escala Likert de 5 fatores de "nunca" a "quase diariamente"); frequência de compulsão alimentar (opções em escala Likert de 5 fatores de "nunca" a "quase diariamente").

\subsection{ANÁLISES DOS DADOS}

As análises foram conduzidas por meio do software SPSS 21.0 (Statistical Package for Social Science Inc., Chicago, Illinois USA). O nível de significância adotado foi de $p<0,05$. A normalidade das variáveis foi avaliada por meio do teste de 
Kolmogorov-Smirnov, enquanto a homogeneidade foi avaliada por meio do teste de Levene.

Para avaliação do efeito das variáveis independentes como o sexo, o país, a razão para se exercitar e o estado nutricional sobre as variáveis dependentes relacionadas à atividade física (frequência semanal, preocupação e culpa), imagem corporal e atitudes alimentares disfuncionais foram utilizados modelos lineares generalizados (GLM) univariados - modelos nos quais é possível analisar o efeito de cada variável separadamente bem como da interação de mais de uma variável sobre o construto analisado (por exemplo, o efeito do país e do sexo sobre a prática de dietas). Em razão de o objetivo principal deste estudo ser avaliar a relação de diferentes construtos em universitários de ambos os sexos em quatro países, os GLM univariados são os modelos mais adequados, inclusive pelo motivo de o estudo não ter um desfecho em si.

Devido ao fato de a maior parte das variáveis ter distribuição não-normal e/ou não-homogênea, foi adotada a transformação de todas as variáveis (exceto na avaliação da insatisfação corporal), por meio de z-score. Assim, as diferenças entre as variáveis foram alteradas, sem, no entanto, alterar a força de relacionamento entre as variáveis - as diferenças relativas entre pessoas na amostra permaneceram as mesmas (FIELD, 2009).

Para a avaliação da insatisfação corporal (diferença entre a figura escolhida como atual e a desejada), que também tinha distribuição não-normal, foi realizado o teste não-paramétrico de Kruskal-Wallis, a fim de manter exatamente as diferenças entre as figuras (neste caso, o uso do z-score poderia minimizar esta diferença).

Nos GLMs, foi utilizado o teste post hoc Bonferroni a fim de examinar especificamente os níveis de diferenças entre os grupos. Para avaliação do tamanho de efeito (medida de magnitude padronizada do efeito observado), adotou-se o coeficiente de correlação de Pearson, de acordo com a classificação proposta por COHEN (1988), na qual o valor de $r^{2} \geq 0,01$ é classificado como "efeito pequeno", $r^{2} \geq$ 0,09 equivale a "efeito médio" e $r^{2} \geq 0,25$ a "efeito grande".

A presença de associações entre as variáveis categóricas, como o sexo, o país, a principal forma de exercício, a principal razão para se exercitar e estado nutricional foi avaliada por meio do teste de Qui-Quadrado de Pearson $\left(X^{2}\right)$, a fim de comparar as frequências observadas em certas categorias com as frequências esperadas ao acaso - a hipótese nula $\left(H_{0}\right)$ era de que as frequências observadas não diferiam das 
frequências esperadas (ausência de associação entre os grupos), e a hipótese alternativa $\left(H_{1}\right)$ era de que havia diferença entre as frequências observadas e as frequências esperadas (presença de associação entre os grupos). Quando as frequências esperadas foram menores ou iguais a cinco, foi usada a simulação de Monte Carlo, método que incorpora o comportamento probabilístico de amostragens aleatórias massivas para obter resultados numéricos - repetições sucessivas de simulações para calcular probabilidades (FIELD, 2009; GARCIA et al., 2010).

$\mathrm{Na}$ análise da variável que avaliou "quantos anos (do total da vida) o indivíduo abriria mão para ter e manter o corpo ideal pelos próximos 20 anos" foram detectados valores atípicos de resposta (outliers) - respostas discrepantes como, por exemplo, abrir mão de 95 anos de vida. A fim de evitar que tais valores gerassem uma resposta tendenciosa ao modelo estatístico, os outliers foram excluídos considerando-se os valores de $z$-score díspares, ou seja, as respostas cujo z-score foram $\leq-2,0$ ou $\geq 2,0$ (FIELD, 2009) não foram incluídas no modelo linear generalizado. Desta forma, foram excluídos os universitários que responderam abrir mão de mais do que 17 anos de vida ( $n=30 ;$; = 21 e $\delta^{\lambda}=9$ ) -12 da Argentina, 6 do Brasil, 1 dos EUA e 11 da França.

Especificamente no manuscrito 1, quando avaliada a correlação das variáveis com a insatisfação corporal, foi adotada a correlação de Spearman, devido à distribuição não-normal da variável (FIELD, 2009).

Por fim, exclusivamente no manuscrito 2 foi realizada uma análise de correspondência (ANACOR) entre o país, o estado nutricional e a principal razão para se exercitar - portanto, uma ANACOR múltipla, aplicada a três variáveis (SILVA, 2012). A ANACOR é uma técnica multivariada exploratória, complementar ao teste Qui-quadrado, que trata da distribuição de frequências resultantes de variáveis categóricas nominais ou ordinais, ao mostrar as suas associações em um espaço multidimensional - representação gráfica das relações existentes (HAIR et al., 2005; SILVA, 2012). 


\section{RESULTADOS}

O presente estudo contemplou um número considerável de variáveis sociodemográficas bem como daquelas relacionadas ao estado nutricional, atitudes alimentares, imagem corporal e cirurgia plástica; assim, inicialmente, serão apresentados os resultados descritivos gerais e, posteriormente, os resultados com três temáticas mais específicas. Nesta segunda sessão de resultados, cada temática corresponderá a uma "pergunta de partida" (objetivo), para a qual os resultados encontrados serão discutidos em seguida, no formato semelhante a um artigo científico - diferenciando-se pelo fato de que não haverá introdução e métodos específicos para cada temática.

Em atendimento ao disposto no Regulamento do Programa de Pós-Graduação em Nutrição em Saúde Pública da Faculdade de Saúde Pública, o Anexo 1 apresenta um artigo científico de revisão integrativa publicado no Jornal Brasileiro de Psiquiatria, cujo desenvolvimento ocorreu durante a primeira metade do Mestrado.

\subsection{DADOS DESCRITIVOS GERAIS}

Os dados referentes à distribuição dos universitários segundo o país, o sexo, o peso atual referido $(\mathrm{kg})$, o IMC $\left(\mathrm{kg} / \mathrm{m}^{2}\right)$, a idade (anos), o peso considerado ideal $(\mathrm{kg})$ e o número de dias de atividade física na semana são apresentados na Tabela 2 - a comparação dos valores médios entre os países e os sexos foi realizada por meio de GLM. 
Tabela 2. Distribuição dos universitários ( $n=1.695)$ segundo o país, sexo, peso atual, Índice de Massa Corporal (IMC), idade, peso considerado ideal e dias de atividade física (AF) na semana.

\begin{tabular}{|c|c|c|c|c|c|c|c|}
\hline País & Sexo & $\mathbf{N}$ & $\begin{array}{c}\text { Peso atual }(\mathbf{k g}) \\
\text { Média }(D P)\end{array}$ & $\begin{array}{c}\text { IMC }\left(\mathbf{k g} / \mathbf{m}^{2}\right) \\
\text { Média; mediana (DP) }\end{array}$ & $\begin{array}{c}\text { Idade (anos) } \\
\text { Média (DP) }\end{array}$ & $\begin{array}{c}\text { Peso considerado ideal }(\mathbf{k g}) \\
\text { Média }(D P)\end{array}$ & $\begin{array}{l}\text { Dias de AF } \\
\text { Média (DP) }\end{array}$ \\
\hline \multirow{2}{*}{ Argentina } & 우 & 254 & $58,2(9,57)$ & 21,$9 ; 21,7(3,35)$ & $23,5(2,86)^{9}$ & $54,4(5,69)$ & $2,47(1,48)^{\mathrm{h}}$ \\
\hline & 0 & 50 & $77,2(12,35)$ & 24,$5 ; 24,2(3,24)^{d}$ & $24,4(2,92)^{g}$ & $74,1(8,74)$ & $3,32(1,63)$ \\
\hline \multirow[t]{2}{*}{ Brasil } & 우 & 360 & $63,7(12,68)^{a}$ & 22,$5 ; 21,9(3,37)$ & $21,3(2,41)$ & $60,7(10,49)^{a}$ & $2,91(1,79)^{i}$ \\
\hline & $\hat{0}$ & 223 & $64,7(13,41)^{\mathrm{b}}$ & 22,$3 ; 21,3(3,48)$ & $21,2(2,55)$ & $62,4(11,23)^{\mathrm{b}}$ & $3,69(1,93)$ \\
\hline \multirow{2}{*}{$E \cup A^{*}$} & q & 238 & $59,5(9,90)$ & 22,$0 ; 21,5(3,29)$ & $21,8(3,27)$ & $55,3(6,30)$ & $4,20(2,01)^{a}$ \\
\hline & $\hat{0}$ & 129 & $73,9(10,32)$ & 23,$2 ; 23,0(2,74)^{\mathrm{e}}$ & $20,9(3,04)$ & $73,4(8,57)$ & $4,12(2,02)^{i}$ \\
\hline \multirow{2}{*}{ França } & q & 274 & $58,2(7,02)$ & 21,$0 ; 20,7(2,24)^{\dagger}$ & $21,5(1,41)$ & $54,5(5,20)$ & $1,96(1,49)^{\mathrm{j}}$ \\
\hline & $0^{\pi}$ & 167 & $72,2(8,75)^{\mathrm{c}}$ & 22,$4 ; 22,2(2,28)$ & $21,7(1,53)$ & $72,4(6,61)$ & $2,35(1,46)^{\mathrm{j}}$ \\
\hline
\end{tabular}

${ }^{*}$ EUA= Estados Unidos da América; $o$ : sexo feminino; ${ }^{\top}$ : sexo masculino.

$a=$ significativamente maior do que a Argentina $(p<0,001)$, França $(p<0,001)$ e EUA $(p<0,001)$; $b=$ significativamente menor do que a Argentina $(p<0,001)$, França $(p<0,001)$ e EUA $(p<0,001)$; $c=$ significativamente menor do que a Argentina $(p<0,05) ; d=$ significativamente maior do que o Brasil $(p<0,001)$ e França $(p<0,001)$; e = significativamente maior do que o Brasil $(p<0,05) ; f=$ significativamente menor do que a Argentina $(p<0,05)$, Brasil $(p<0,001)$ e EUA $(p<0,05)$; $g=$ significativamente maior do que o Brasil $(p<0,001)$, França $(p<0,001)$ e EUA $(p<0,001)$; $h=$ significativamente maior do que a França $(p<0,05) ; i=$ significativamente maior do que a Argentina $(p<0,05)$ e França $(p<0,001) ; j=$ significativamente menor do que a Argentina $(p<0,05)$, Brasil $(p<0,001)$ e EUA $(p<0,001)$. 
As mulheres representaram $66,4 \%(n=1.126)$ da amostra. Verificou-se efeito do país $(p<0,001)$, do sexo $(p<0,001)$ e da interação $(p<0,001)$ destas variáveis sobre o peso atual dos universitários, uma vez que as mulheres brasileiras apresentaram média de peso maior do que as demais, e o contrário foi observado no sexo masculino, tendo os homens do Brasil apresentado peso menor do que argentinos, estadunidenses e franceses (que, por sua vez, apresentaram peso menor do que argentinos).

Quanto ao IMC, as médias variaram entre $21,0 \mathrm{~kg} / \mathrm{m}^{2}$ a $24,5 \mathrm{~kg} / \mathrm{m}^{2}$ (mediana 20,7 a 24,2) - valores caracterizados pela OMS como eutrofia (WHO, 2010), mas não se o DP for levado em conta. Houve efeito do país $(p<0,001)$, do sexo $(p<0,001)$ e da interação destas variáveis $(p<0,001)$. As mulheres francesas apresentaram média de IMC menor do que as demais. No sexo masculino, a média de IMC foi maior entre os argentinos do que entre os franceses e brasileiros.

Em relação ao peso considerado ideal, também foi observado efeito da interação país e sexo $(p<0,001)$, bem como destas variáveis separadamente ( $p<0,001$; em ambas), tendo as mulheres brasileiras apresentado média superior às demais, e, novamente, os homens brasileiros apresentaram média menor do que os universitários dos demais países.

Observou-se efeito da interação país e sexo $(p<0,05)$, bem como apenas do país $(p<0,001)$ - mas não apenas do sexo - sobre a idade dos universitários; sendo que em ambos os sexos, os argentinos apresentaram médias de idade maiores do que nos demais países.

Quanto à etnia, verificou-se que entre os argentinos de ambos os sexos, a mais frequente foi branca $(q=65,4 \%$ e $\delta=64 \%)$, idem entre os brasileiros $(q=$ $78,6 \%$ e $\delta^{\lambda}=78,5 \%$ ), seguida da asiática (para $+=11,4 \%$ ) e da mulata (para $\hat{\delta}=$ $11,2 \%)$. Para os estadunidenses, a etnia branca foi a mais frequente $(q=69,7 \%$ e $\widehat{\delta}=76,7 \%$ ), também seguida da asiática ( $q=15,1 \%$ e $\hat{\delta}=11,6 \%$ ). Quanto aos universitários da França, a Lei 78-17 a respeito de proteção de dados (FRANÇA, 1978) proíbe que se questione a etnia dos franceses, portanto, esta informação não foi coletada.

Quanto ao curso de graduação, o mais frequente entre os argentinos foi o de Psicologia $\left(q=72,0 \%\right.$ e $\delta^{\lambda}=48,0 \%$ ) - com a presença de 25 diferentes cursos entre as mulheres e 11 entre os homens. Entre os brasileiros, para o sexo 
feminino foi o curso de Nutrição $(14,4 \%)$ - total de 28 cursos diferentes - e para o sexo masculino foi o de Física (22,9\%), dentre os 25 diferentes cursos mencionados. Para os franceses, o curso mais frequente para ambos os sexos foi o de Administração e Business ( $q=55,5 \% ; \hat{\delta}=36,5 \%$ ) - com 14 diferentes cursos entre as mulheres e 13 entre os homens. Entre os estadunidenses foi 0 curso de graduação em Economia (18\%) entre os homens - total de 28 cursos - e o de Psicologia (18,5\%) no sexo feminino - 31 diferentes cursos. No caso dos estadunidenses, este estudo incluiu também alunos de pós-graduação, devido ao fato de que muitos estudantes de graduação vivem nas dependências do campus (se diferenciando da amostra dos demais países) e também porque graduandos estadunidenses são um pouco mais jovens do que os demais, conforme descrito no item 3.3 do Método. Assim, para mulheres estadunidenses na pós-graduação o curso mais frequente também foi o de Psicologia (28\%) total de 28 cursos - enquanto que para os homens, o curso mais frequente foi 0 de Física (39,3\%, dos 11 diferentes cursos).

$\mathrm{O}$ ano de faculdade (tempo de curso) foi semelhante entre os sexos: $46,1 \%$ das mulheres argentinas e $46 \%$ dos homens estavam no quinto ano da faculdade quando responderam o questionário; $64,2 \%$ das mulheres e $69,5 \%$ dos homens brasileiros cursavam entre o primeiro e o terceiro ano; dentre os franceses, $81 \%$ das mulheres e $71,2 \%$ dos homens cursavam entre o terceiro e o quinto ano; e no caso dos estadunidenses, $58,9 \%$ das mulheres e $62,8 \%$ dos homens estavam no primeiro ou segundo ano de faculdade.

Em relação à classificação socioeconômica (auto-referida), a classe média foi a mais frequente entre os universitários da Argentina $\left(q=69,7 \%\right.$ e $\delta^{\lambda}=$ $70 \%$ ) e do Brasil ( $(=49,2 \%$ e $\hat{\delta}=56,1 \%$ ), enquanto a classe média alta foi mais frequente entre os universitários da França $(\varphi=48,5 \%$ e $\delta=47,9 \%)$ e dos EUA ( $Q=42,4 \%$ e ${ }^{\lambda}=42,6 \%$ ).

Para o número de dias de exercício físico na semana houve efeito do país $(p<0,001)$, do sexo $(p<0,001)$ e da interação $(p<0,05)$ destas variáveis, sendo que dentre as mulheres, as francesas apresentaram média menor do que as demais; as estadunidenses apresentaram média maior do que as mulheres dos demais países. Dentre os homens, os franceses também apresentaram a menor média, e os estadunidenses apresentaram média maior do que argentinos. 
Houve associação entre a principal forma de exercício e o país $(p<0,001)$, as diferenças significativas entre os países estão apontadas na Figura 2. 


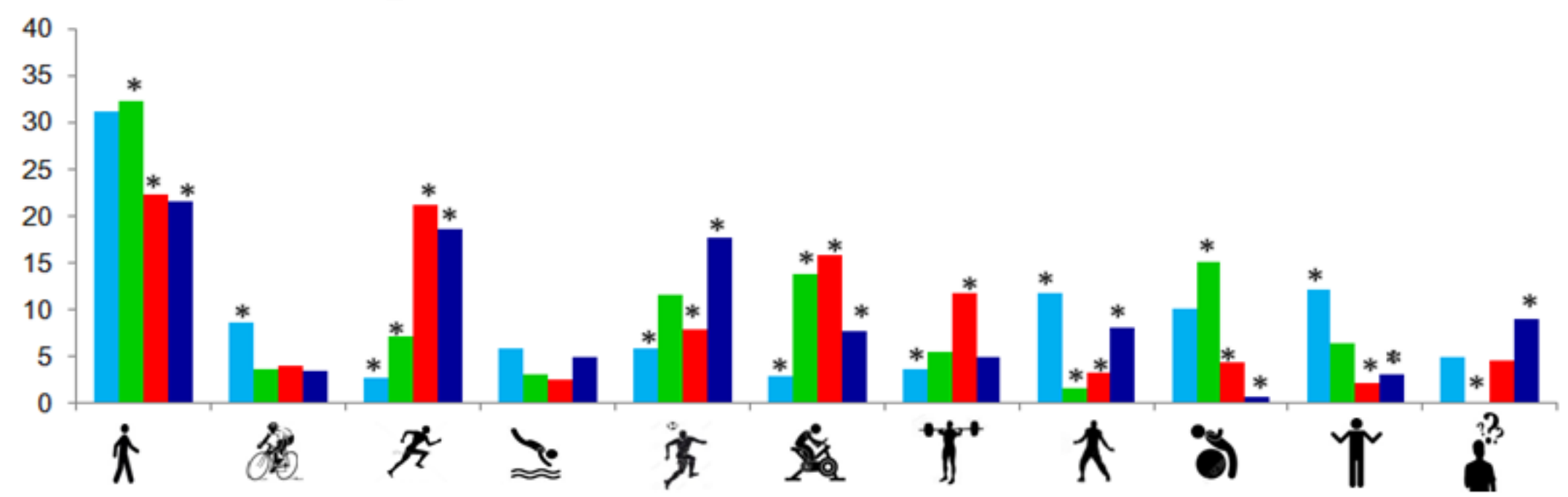

Figura 2. Frequência (\%) da principal forma de exercício entre os universitários $(n=1.695)$ - de ambos os sexos - da Argentina, Brasil, EUA e França.

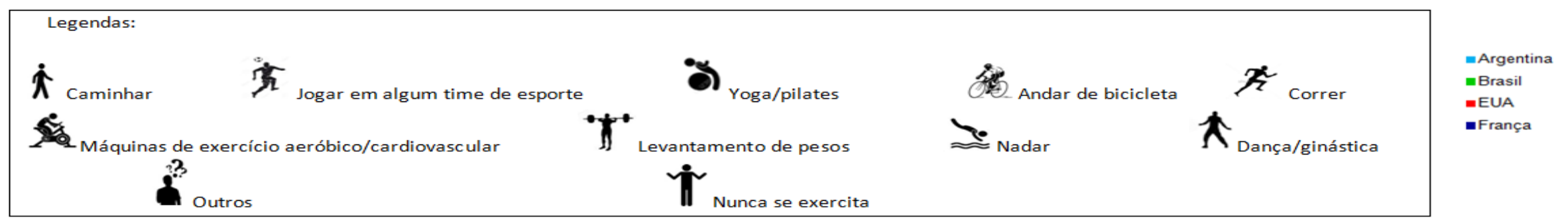

${ }^{*}$ Frequência maior ou menor do que a esperada ( $X^{2}$ com resíduo ajustado maior do que 2 ou menor do que -2 , respectivamente). 
Considerando-se ambos os sexos, para caminhar e yoga/pilates, a maior frequência de respostas foi entre os brasileiros; para andar de bicicleta, nadar, dança/ginástica e nunca se exercitar, a maior frequência foi para argentinos; a corrida, exercícios aeróbicos/cardiovasculares e levantamento de pesos foram mais frequentes para estadunidenses, enquanto jogar em time de esporte foi mais frequente para franceses.

A principal forma de exercício também foi associada ao sexo $(p<0,001)$ : entre as mulheres de todos os países, caminhar foi o exercício referido com maior frequência, bem como para os homens do Brasil e Argentina - os argentinos também apresentaram a mesma frequência para jogar em algum time de esporte. Dentre os homens dos EUA e França, o principal exercício foi levantamento de pesos e jogar em algum time de esporte, respectivamente dados apresentados nas Figuras 3 e 4. 


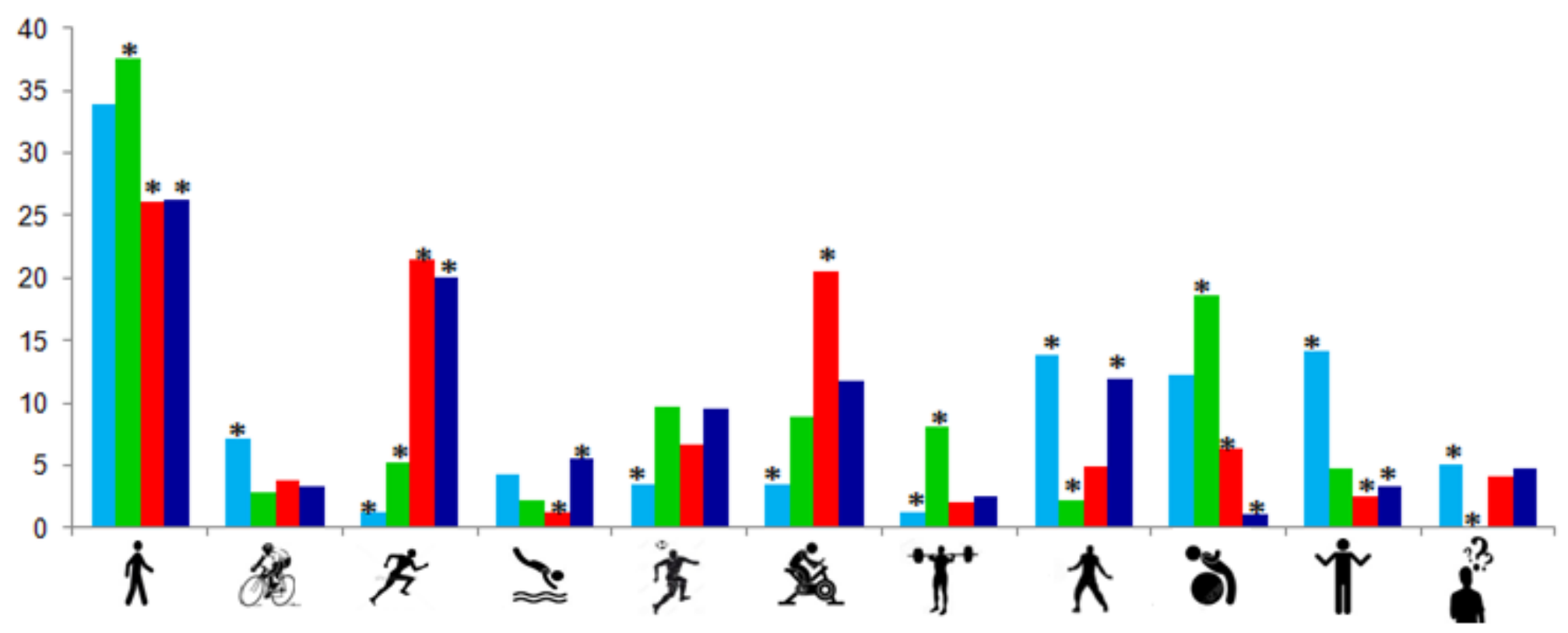

Figura 3. Frequência (\%) da principal forma de exercício entre o sexo feminino, segundo o país $(n=1.126)$.

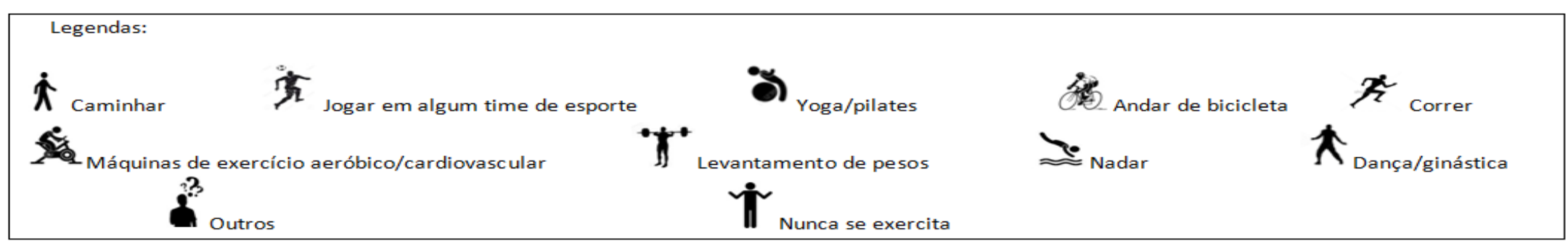

* Presença de associação: frequência maior ou menor do que a esperada ( $X^{2}$ com resíduo ajustado maior do que 2 ou menor do que -2, respectivamente). 


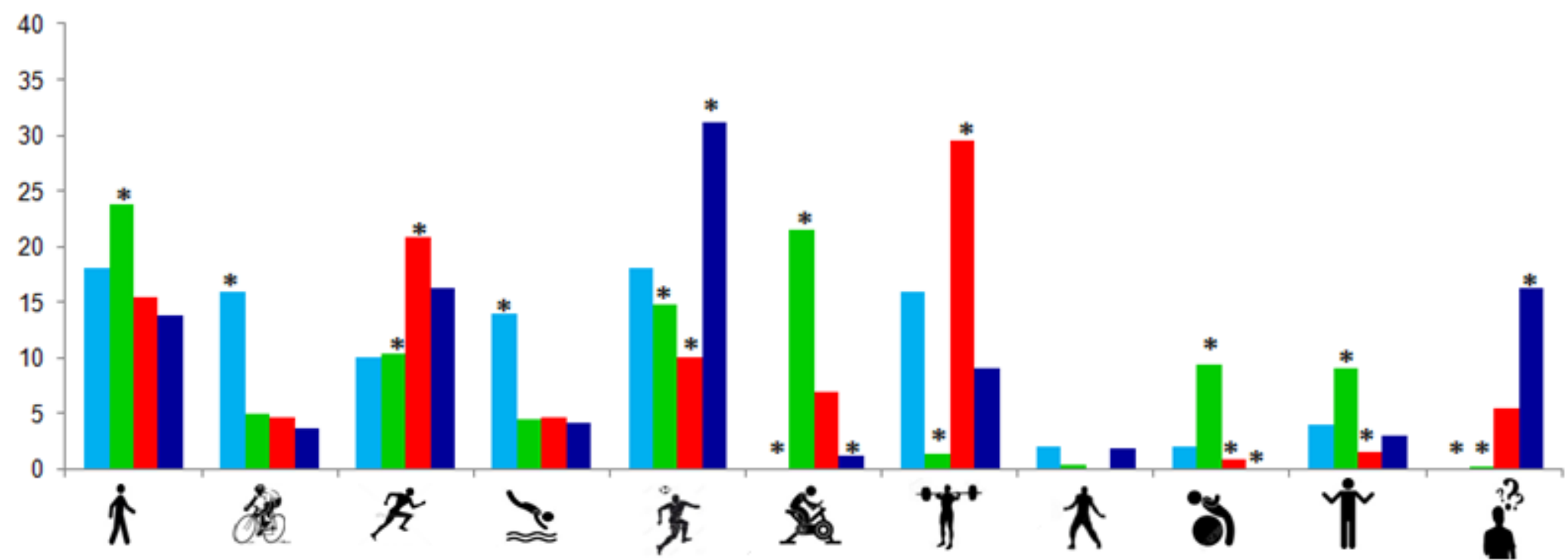

Figura 4. Frequência (\%) da principal forma de exercício entre o sexo masculino, segundo o país ( $n=569)$.

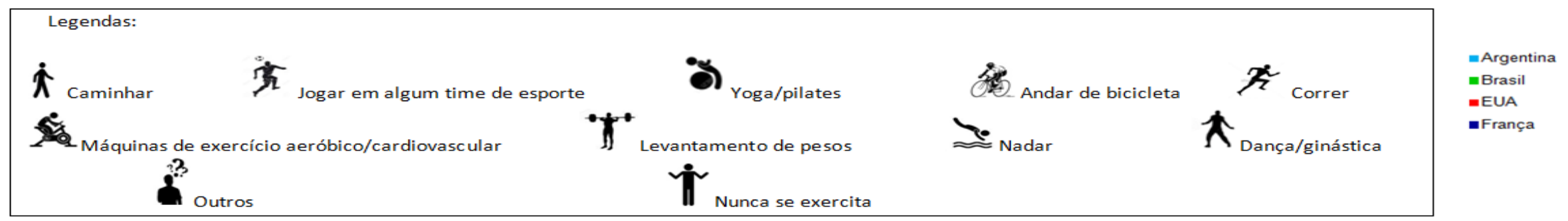

* Frequência maior ou menor do que a esperada ( $X^{2}$ com resíduo ajustado maior do que 2 ou menor do que -2, respectivamente). 
Observou-se associação entre a principal razão para se exercitar e o país $(p<0,001)$, bem como entre o sexo $(p<0,001)$. A "saúde" foi apontada com maior frequência em ambos os sexos para os argentinos ( $Q=40,2 \% ; \hat{\delta}=52 \%)$, brasileiros $(\uparrow=36,4 \% ; \hat{\jmath}=29,1 \%)$ e os estadunidenses ( $q=52,1 \%$; $\left.\oint^{\lambda}=48,8 \%\right)$, enquanto entre os franceses, a "saúde" foi a razão mais frequente apenas para as mulheres $(43,4 \%)$, entre os homens, a mais frequente foi a "diversão" - Figura 5. 


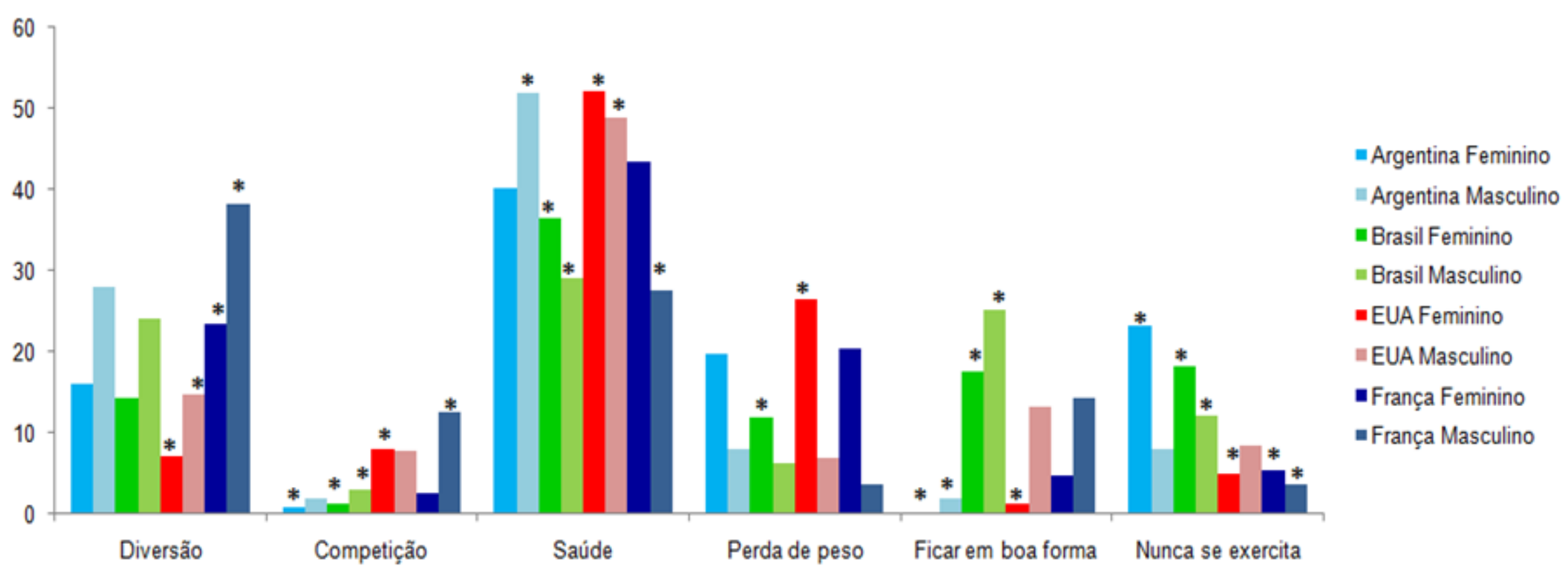

Figura 5. Frequência (\%) das principais razões para se exercitar entre o sexo feminino e o masculino, segundo o país ( $n=1695)$.

* Frequência maior ou menor do que a esperada ( $X^{2}$ com resíduo ajustado maior do que 2 ou menor do que -2, respectivamente). 
Quando se questionou se os universitários fariam exercícios "apenas por diversão", sem benefícios adicionais, houve associação entre esta resposta e 0 país $(p<0,001)$ : com frequência maior do que a esperada de respostas positivas para os universitários da Argentina e do Brasil e de respostas negativas nos EUA e França. Não houve associação entre esta resposta e o sexo.

Todas as variáveis classificadas nas categorias "atitudes alimentares" e "cirurgias plásticas" (Quadro 1 do item 3.6, no Método) foram avaliadas com respostas em escala do tipo Likert (cujas opções de resposta são descritas no item 3.6 do Método). Nestas categorias, quanto mais inadequadas as atitudes alimentares, maior a pontuação, e no caso das cirurgias plásticas, quanto maior a probabilidade de adesão, maior a pontuação. A preocupação com a rotina de exercícios e a culpa por não se exercitar, bem como a preocupação com excesso de peso também foram avaliadas com opções de resposta em escala do tipo Likert, na qual quanto maior a preocupação e a culpa, maior a pontuação.

Os escores das questões referentes às categorias "atitudes alimentares" e "cirurgias plásticas", bem como da preocupação com excesso de peso (categoria "imagem corporal"), da preocupação com a rotina de exercícios e a culpa por não se exercitar (categoria "atividade física") são apresentados na Tabela 3 - na qual são apresentadas também as médias dos valores escolhidos para a figura que melhor representa a aparência atual e a que gostariam de ter; e a média dos anos de vida que os universitários abririam mão para ter e manter o corpo ideal pelos próximos 20 anos. A comparação dos escores e médias foi realizada por meio de GLM. 
Tabela 3. Distribuição dos universitários ( $n=1.695)$ quanto aos valores escolhidos na Escala de Silhuetas de Stunkard (imagem atual e desejada), e escores de variáveis relacionadas às atitudes alimentares, cirurgias plásticas, imagem corporal e atividade física.

\begin{tabular}{|c|c|c|c|c|c|c|c|c|c|c|c|c|c|}
\hline & Sexo & Dieta & $\begin{array}{l}\text { Restrição } \\
\text { alimentar }\end{array}$ & $\begin{array}{c}\text { Preocupação } \\
\text { com excesso } \\
\text { de peso }\end{array}$ & $\begin{array}{c}\text { Preocupação } \\
\text { com } \\
\text { exercícios }\end{array}$ & $\begin{array}{l}\text { Culpa por } \\
\text { não se } \\
\text { exercitar }\end{array}$ & $\begin{array}{l}\text { Preocupação } \\
\text { com a comida } \\
\text { e aparência }\end{array}$ & $\begin{array}{l}\text { Imagem } \\
\text { atual }\end{array}$ & $\begin{array}{l}\text { Imagem } \\
\text { desejada }\end{array}$ & Vômitos & Compulsão & $\begin{array}{l}\text { Cirurgia } \\
\text { plástica }\end{array}$ & $\begin{array}{c}\text { Anos de } \\
\text { vida }\end{array}$ \\
\hline & & $\begin{array}{c}\text { Escore } \\
\text { médio (DP) }\end{array}$ & $\begin{array}{c}\text { Escore } \\
\text { médio }(D P)\end{array}$ & $\begin{array}{l}\text { Escore médio } \\
\text { (DP) }\end{array}$ & $\begin{array}{c}\text { Escore médio } \\
(D P)\end{array}$ & $\begin{array}{c}\text { Escore } \\
\text { médio (DP) }\end{array}$ & $\begin{array}{c}\text { Escore médio } \\
(D P)\end{array}$ & $\begin{array}{c}\text { Média** }^{* *} \\
(D P) \\
\end{array}$ & $\begin{array}{c}\text { Média }^{* *} \\
(D P) \\
\end{array}$ & $\begin{array}{c}\text { Escore } \\
\text { médio }(D P)\end{array}$ & $\begin{array}{c}\text { Escore médio } \\
(D P)\end{array}$ & $\begin{array}{c}\text { Escore médio } \\
(D P)\end{array}$ & Média* $^{*}(D P)$ \\
\hline \multirow{2}{*}{ Argentina } & q & $\begin{array}{r}2,28 \\
(1,21) \\
\end{array}$ & $\begin{array}{c}3,30 \\
(1,42)^{1} \\
\end{array}$ & $3,25(1,42)$ & $1,57(0,95)$ & $2,56(1,35)$ & $2,70(1,28)$ & $\begin{array}{c}40,01 \\
(12,89) \\
\end{array}$ & $\begin{array}{l}32,07^{\mathrm{t}} \\
(7,72)\end{array}$ & $1,16(0,53)$ & $2,02(1,07)$ & $1,80(0,74)$ & $1,84(3,37)$ \\
\hline & $\hat{\sigma}$ & $\begin{array}{r}1,86 \\
(1,01) \\
\end{array}$ & $\begin{array}{c}3,26 \\
(1,51)^{1} \\
\end{array}$ & $3,27(1,49)^{n}$ & $1,90(1,15)$ & $2,76(1,19)$ & $2,78(1,31)$ & $\begin{array}{c}46,18 \\
(13,00)^{n}\end{array}$ & $\begin{array}{l}40,54 \\
(9,61) \\
\end{array}$ & $1,06(0,24)$ & $1,74(0,83)$ & $1,46(0,68)$ & $2,50(4,07)$ \\
\hline \multirow{2}{*}{ Brasil } & 우 & $\begin{array}{r}2,08 \\
(1,17) \\
\end{array}$ & $\begin{array}{r}2,83 \\
(1,27) \\
\end{array}$ & $3,50(1,39)^{\circ}$ & $1,64(0,90)$ & $\begin{array}{c}2,99 \\
(1,33)^{r}\end{array}$ & $3,21(1,17)^{\mathrm{s}}$ & $\begin{array}{c}38,11 \\
(12,14) \\
\end{array}$ & $\begin{array}{l}31,65 \\
(7,69) \\
\end{array}$ & $1,17(0,51)$ & $2,29(1,05)^{v}$ & $2,19(0,77)^{x}$ & $2,44(3,45)^{z}$ \\
\hline & $\hat{\sigma}$ & $\begin{array}{c}1,69 \\
(1,01)\end{array}$ & $\begin{array}{c}2,21 \\
(1,26)\end{array}$ & $2,82(1,50)^{n}$ & $2,09(1,17)$ & $2,96(1,38)$ & $2,95(1,29)$ & $\begin{array}{c}41,79 \\
(14,21)\end{array}$ & $\begin{array}{l}41,48 \\
(8,57)\end{array}$ & $1,06(0,36)$ & $1,94(0,90)$ & $1,56(0,68)^{y}$ & $2,12(3,55)$ \\
\hline \multirow{2}{*}{$E^{*} A^{*}$} & 우 & $\begin{array}{c}2,28 \\
(1,17)\end{array}$ & $\begin{array}{c}2,49 \\
(1,07)^{\mathrm{m}}\end{array}$ & $3,06(1,39)$ & $2,87(1,22)^{\mathrm{p}}$ & $2,74(1,35)$ & $2,77(1,20)$ & $\begin{array}{c}37,79 \\
(11,56)\end{array}$ & $\begin{array}{l}29,80^{q} \\
(8,01)\end{array}$ & $1,25(0,62)$ & $2,22(0,99)$ & $1,53(0,74)$ & $1,73(2,81)$ \\
\hline & $\hat{\sigma}$ & $\begin{array}{c}1,94 \\
(1,04)^{\mathrm{k}}\end{array}$ & $\begin{array}{c}2,16 \\
(1,01)\end{array}$ & $2,41(1,25)$ & $2,41(1,14)^{q}$ & $3,02(1,46)$ & $2,64(1,08)$ & $\begin{array}{c}40,71 \\
(12,00)\end{array}$ & $\begin{array}{l}40,03 \\
(8,43)\end{array}$ & $1,02(0,12)$ & $1,96(0,99)$ & $1,19(0,50)$ & $2,21(2,85)$ \\
\hline \multirow{2}{*}{ França } & 우 & $\begin{array}{l}2,05 \\
(1,16)\end{array}$ & $\begin{array}{c}2,81 \\
(1,19)\end{array}$ & $3,30(1,31)$ & $1,91(1,14)^{\mathrm{q}}$ & $2,69(1,29)$ & $3,23(1,14)^{\mathrm{s}}$ & $\begin{array}{c}37,25 \\
(10,60)\end{array}$ & $\begin{array}{l}30,07 \\
(7,53)\end{array}$ & $1,17(0,55)$ & $2,56(0,98)^{u}$ & $1,51(0,57)$ & $1,71(3,17)$ \\
\hline & $\hat{0}$ & $\begin{array}{c}1,41 \\
(0,75)\end{array}$ & $\begin{array}{c}1,91 \\
(1,00)\end{array}$ & $2,35(1,30)$ & $2,32(1,21)$ & $2,77(1,31)$ & $2,71(1,18)$ & $\begin{array}{c}40,66 \\
(12,53)\end{array}$ & $\begin{array}{l}41,34 \\
(7,63)\end{array}$ & $1,02(0,19)$ & $2,56(0,92)^{w}$ & $1,40(0,56)$ & $2,00(3,67)$ \\
\hline
\end{tabular}


* EUA= Estados Unidos da América; ㅇ: sexo feminino; 8 : sexo masculino. ${ }^{* *}$ Avaliadas por meio da Escala de Silhuetas de Stunkard, com figuras numeradas de 10 (mais magra) a 90 (mais gorda): os universitários deveriam escolher qual a figura que melhor representa a aparência atual e a figura que gostariam de ser (sendo possível utilizar números intermediários nas respostas).

$\mathrm{k}=$ significativamente maior do que a França $(p<0,001)$; I = significativamente menor do que o Brasil $(p<0,001)$, França $(p<0,001)$ e EUA $(p<0,001)$; $m=$ significativamente menor do que o Brasil $(p<0,05)$ e França $(p<0,05)$; $\mathrm{n}=$ significativamente maior do que a França $(p<0,05)$ e EUA $(p<0,05)$; $0=$ significativamente maior do que a Argentina $(p<0,05)$ e EUA $(p<0,05)$; $p=$ significativamente maior do que a Argentina $(p<0,001)$, Brasil $(p<0,001)$ e França $(p<0,001)$; $q=$ significativamente menor do que a Argentina $(p<0,05)$ e Brasil $(p<0,05)$; $r=$ significativamente maior do que a Argentina $(p<0,05)$ e França $(p<0,05)$; $\mathrm{s}=$ significativamente maior do que a Argentina $(p<0,001)$ e EUA $(p<0,001)$; t = significativamente maior do que a França $(p<0,05)$; u = significativamente maior do que a Argentina $(p<0,001)$, Brasil $(p<0,05)$ e EUA $(p<0,05)$; v= significativamente maior do que a Argentina $(p<0,05)$; $w=$ significativamente maior do que a Argentina $(p<0,001)$, Brasil $(p<0,001)$ e EUA $(p<0,001) ; x=$ significativamente maior do que a França $(p<0,001)$ e EUA $(p<0,001) ; y=$ significativamente maior do que os EUA $(p<0,001)$; $z=$ significativamente maior do que a Argentina $(p<0,05)$, França $(p<0,001)$ e EUA $(p<0,001)$. 
A prática de dietas foi mais frequente entre as mulheres $(p<0,001)$ e também foi observado efeito do país para esta variável $(p<0,001)$, uma vez que os estadunidenses apresentaram escore médio superior aos franceses $(p<0,001)$, ou seja, aderiam às dietas mais frequentemente - este achado confirma parcialmente a primeira hipótese deste estudo, uma vez que, apesar de as mulheres aderirem mais do que os homens à prática de dietas, houve diferença entre os países. Os escores das mulheres brasileiras não foram diferentes das demais universitárias, o que também ocorreu para o sexo masculino. Não houve efeito da interação sexo e país sobre fazer dieta.

Quando se questionou a prática de restrições alimentares com o objetivo de não ganhar peso, a frequência foi maior no sexo feminino $(p<0,001)$ - da mesma forma, este resultado confirmou parcialmente a primeira hipótese do estudo. Além disso, houve efeito do país $(p<0,001)$ e da interação país e sexo $(p<0,001)$ : em ambos os sexos, a Argentina foi o país onde os universitários eram mais adeptos as restrições, com escores médios superiores aos demais. Para o sexo feminino, as estadunidenses apresentaram frequência menor do que as brasileiras e francesas (estas últimas não foram diferentes entre si).

A preocupação sobre ter excesso de peso foi significativamente superior entre as mulheres $(p<0,001)$. Houve efeito do país $(p<0,001)$, tendo as brasileiras apresentado escore maior do que as argentinas e as estadunidenses, e os homens argentinos e os brasileiros escores maiores do que os franceses e os estadunidenses - não houve diferença entre os homens brasileiros e argentinos.

Quanto à preocupação com a rotina de exercícios, verificou-se efeito do sexo $(p<0,05)$, do país $(p<0,001)$ e da interação destas variáveis $(p<0,001)$. Esta preocupação foi maior para os homens, e dentre os países, os estadunidenses eram mais preocupados do que os argentinos e brasileiros. Para o sexo feminino, as estadunidenses apresentaram escore maior do que as brasileiras, argentinas e francesas (tendo estas últimas um escore maior do que as brasileiras e argentinas).

A culpa por não se exercitar foi diferente apenas entre os países $(p<0,05$; sem efeito do sexo ou da interação destas variáveis): no Brasil, os escores foram maiores do que na Argentina $(p<0,05)$ e na França $(p<0,05)$. 
A preocupação sobre o que come e como isto afeta a aparência foi maior entre as mulheres $(p<0,05)$ - além disso, houve efeito do país $(p<0,001)$ e da interação país e sexo $(p<0,05)$. Entre as mulheres, o escore das francesas e das brasileiras foram maiores do que o das argentinas e o das estadunidenses - mas, não houve diferença entre brasileiras e francesas. Para o sexo masculino, não houve diferença entre os países.

Com relação à imagem corporal, o número da figura escolhida como a que melhor representa a aparência atual foi maior no sexo masculino $(p<0,001)$ e houve também efeito do país $(p<0,05)$ : entre os homens, os argentinos escolheram figuras menores do que os franceses e estadunidenses (não houve diferença nas médias dos brasileiros e demais países). Para as mulheres, não houve diferença entre os países avaliados.

Quanto à figura escolhida como a que melhor representa a aparência desejada, o sexo feminino apresentou média menor $(p<0,001)$ e houve efeito do país $(p<0,05)$ : as estadunidenses desejaram ser menores do que as brasileiras e as argentinas, que por sua vez, apresentaram média maior do que as francesas. Para o sexo masculino não houve diferença entre os países.

A frequência de vômitos intencionais depois de comer com o propósito de perder peso foi maior entre as mulheres $(p<0,001)$ e não houve efeito do país, tampouco da interação destas variáveis. A frequência de compulsões alimentares também foi maior para as mulheres $(p<0,001)$ - havendo efeito do país $(p<0,001)$ e da interação destas variáveis $(p<0,05)$ - dentre elas, as francesas apresentaram escore médio maior do que as demais (o escore médio das brasileiras foi maior do que o das argentinas); para o sexo masculino, a frequência de vômitos foi maior entre os franceses (não houve diferença entre os brasileiros e argentinos ou estadunidenses).

No Brasil, a possibilidade de realizar uma cirurgia plástica cosmética $(p<0,001)$ foi maior do que na França e EUA, confirmando parcialmente a terceira hipótese deste estudo, pois acreditava-se que a possibilidade seria maior no Brasil e nos EUA. Para esta variável, também foi verificado efeito do sexo $(p<0,001)$ e da interação país e sexo $(p<0,001)$. Para o sexo feminino o escore médio foi maior, e 
dentre elas, as brasileiras apresentaram escore maior do que as das francesas e as estadunidenses. Para o sexo masculino, houve diferença apenas entre o Brasil e os EUA, tendo os brasileiros apresentado escore maior.

Quando questionados sobre "quantos anos de vida abririam mão para ter e manter o corpo ideal pelos próximos 20 anos", a média dos brasileiros foi superior à dos franceses e estadunidenses $(p<0,001)$, mas não houve efeito do sexo e nem da interação país e sexo.

Todos os resultados descritos até aqui são provenientes das análises das variáveis quanto ao possível efeito ou associação do país, do sexo e da interação país e sexo, independentemente do tamanho do efeito. Entretanto, para um melhor entendimento da magnitude da diferença real (não a estatística) entre os resultados obtidos, bem como a validade interna do estudo, foi realizada uma análise do tamanho do efeito (coeficiente de determinação: $r^{2}$ ). Considerando-se o padrão de classificação proposto por COHEN (1988) - descrito no item 3.7 do Método - no qual o valor de $r^{2} \geq 0,01$ é classificado como "efeito pequeno", $r^{2} \geq 0,09$ equivale a "efeito médio" e $r^{2} \geq 0,25$ a "efeito grande", a Figura 6 apresenta os tamanhos de efeito do sexo, país e da interação país e sexo sobre as variáveis, bem como a classificação deste efeito. 


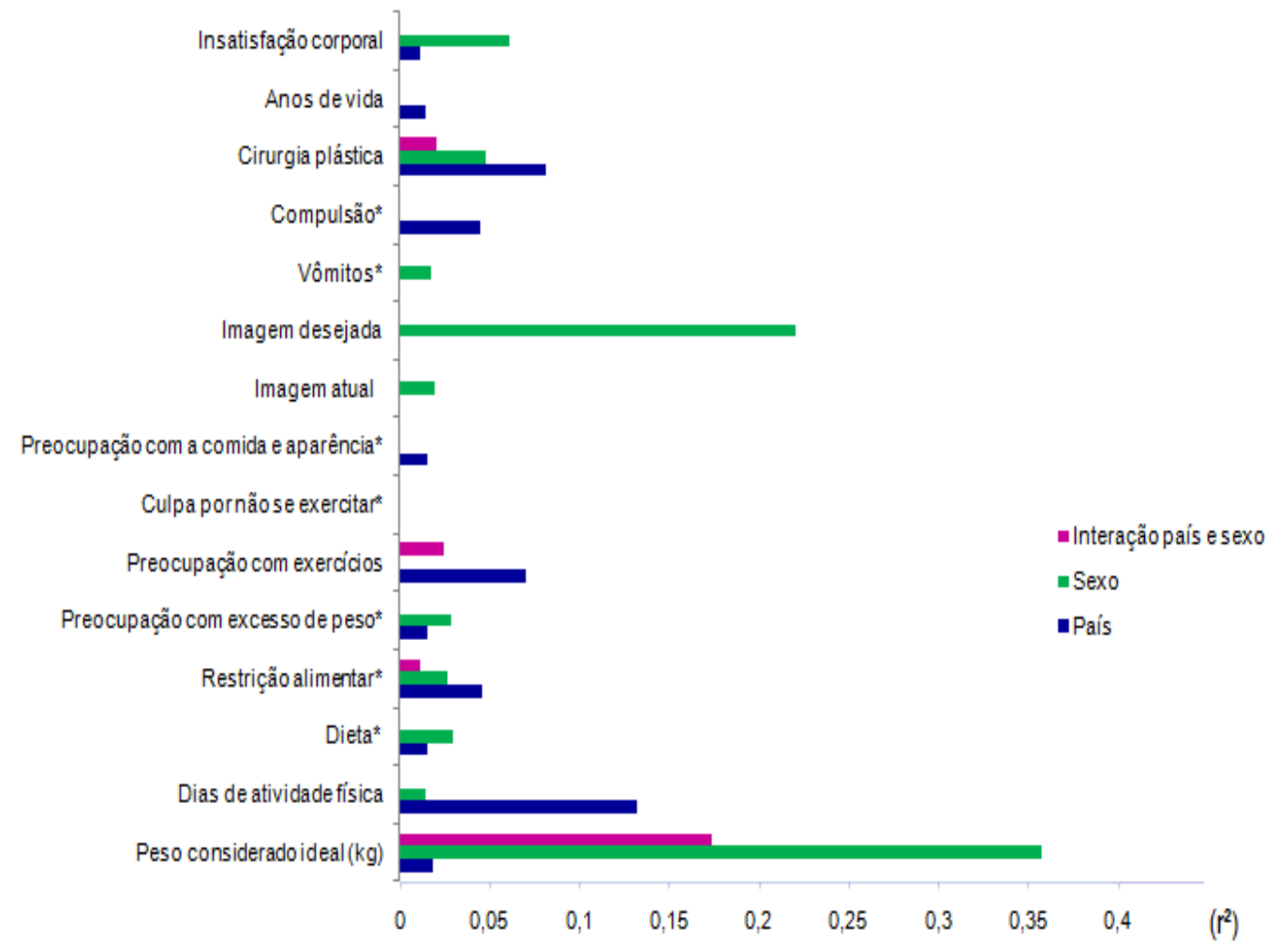

Figura 6. Tamanhos de efeito $\left(r^{2}\right)$ do sexo, país e da interação país e sexo sobre as variáveis (quando $r^{2}$ foi superior a 0,01 ).

Observa-se que o efeito do país foi maior para: dias de atividade física na semana ( $r^{2}=0,132$ - efeito médio), cirurgias plásticas $\left(r^{2}=0,081\right)$, preocupação com a rotina de exercícios $\left(r^{2}=0,07\right)$, restrição alimentar $\left(r^{2}=0,05\right)$, compulsões alimentares $\left(r^{2}=0,045\right)$, preocupação com a comida e a aparência $\left(r^{2}=0,015\right)$, anos de vida que abria mão por um corpo ideal $\left(r^{2}=0,014\right)$ - efeitos pequenos. $O$ efeito do sexo foi maior para o peso considerado ideal $\left(r^{2}=0,357\right.$ - efeito grande), imagem desejada $\left(r^{2}=0,22\right.$ - efeito médio), insatisfação corporal $\left(r^{2}=0,061\right)$, prática de dietas $\left(r^{2}=0,029\right)$, preocupação com excesso de peso $\left(r^{2}=0,028\right)$, imagem atual $\left(r^{2}=\right.$ 0,019), vômitos $\left(r^{2}=0,017\right)$ - efeitos pequenos.

Quanto ao poder observado - ou seja, a capacidade da amostra de detectar uma diferença que se espera existir na população, - a Tabela 4 apresenta os valores (\%) encontrados tanto do país, quanto do sexo e da interação país e sexo. 
Tabela 4. Poder observado (em \%) do país e do sexo sobre as variáveis.

\begin{tabular}{lccc}
\hline \multicolumn{1}{c}{ Variável } & País & Sexo & Interação país e sexo \\
\hline Peso considerado ideal $(\mathrm{kg})$ & 99,9 & 100 & 100 \\
\hline Dias de atividade física & 100 & 99,8 & 91,4 \\
\hline Dieta* & 99,4 & 100 & 39,5 \\
\hline Restrição alimentar & 100 & 100 & 96,4 \\
\hline $\begin{array}{l}\text { Preocupação com excesso de } \\
\text { peso* }\end{array}$ & 99,3 & 100 & 88,3 \\
\hline Preocupação com exercícios & 100 & 81,8 & 100 \\
\hline Culpa por não se exercitar* & 82,7 & 40,6 & 27,4 \\
\hline $\begin{array}{l}\text { Preocupação com a comida e } \\
\text { aparência* }\end{array}$ & 99,3 & 85,0 & 70,7 \\
\hline Imagem atual & 91,0 & 100 & 19,7 \\
\hline Imagem desejada & 74,4 & 100 & 37,2 \\
\hline Vômitos* & 12,5 & 100 & 39,5 \\
\hline Compulsão* & 100 & 97,5 & 64,5 \\
\hline Cirurgia plástica & 100 & 100 & 100 \\
\hline Anos de vida & 99,8 & 5,0 & 27,6 \\
\hline Insatisfação corporal & 96,2 & 100 & 77,2 \\
\hline${ }^{*}$ Escore médio de varíveis avaliadas por meio de Escala Likert. &
\end{tabular}

${ }^{\star}$ Escore médio de variáveis avaliadas por meio de Escala Likert.

Os tamanhos de efeito e de poder em uma população são relacionados ao tamanho da amostra, assim, quanto maior a amostra maior o poder observado (validade externa) e menor o tamanho de efeito, o que foi verificado no presente estudo.

\subsection{RESULTADOS PARA O MANUSCRITO 1}

Pergunta de partida: "De que modo se dá a relação entre insatisfação corporal, principal tipo, frequência e razão para exercício e estado nutricional entre os universitários de ambos os sexos?".

Conforme descrito no item 3.6 do Método, a satisfação corporal foi calculada a partir da diferença entre a figura escolhida como imagem atual e a figura escolhida 
como a imagem desejada (Escala de Silhuetas de Stunkard; Figura 7); assim, quanto maior o valor da diferença, maior a insatisfação corporal - quando os valores são positivos, a imagem desejada é menor do que a imagem atual, e o oposto ocorre quando os valores são negativos.

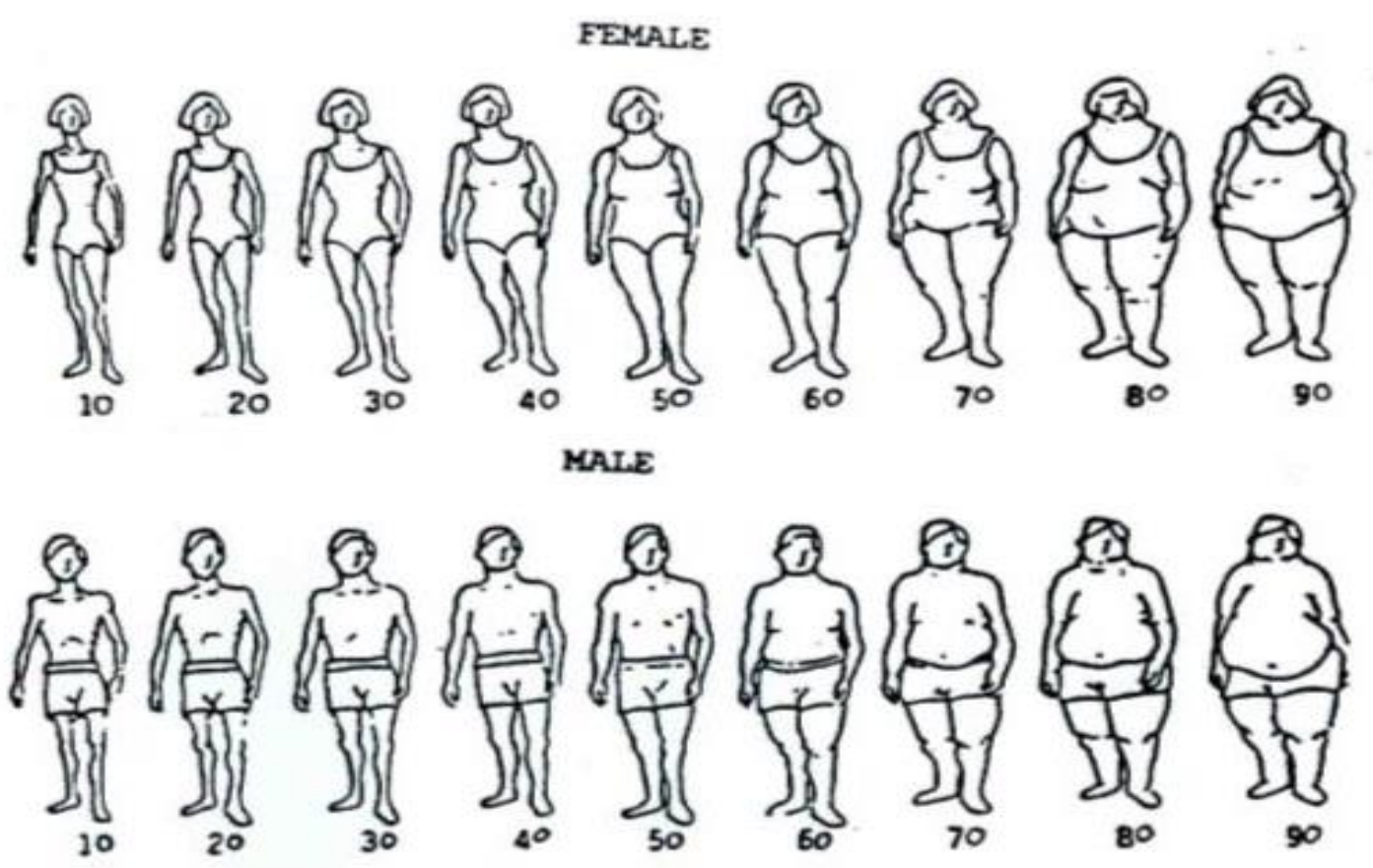

Figura 7. Escala de Silhuetas de Stunkard (STUNKARD et al., 1983).

Inicialmente, foi realizada a comparação das médias de insatisfação corporal em ambos os sexos nos quatro países (Tabela 5). 
Tabela 5. Distribuição dos universitários $\left(n=1.691^{*}\right)$ segundo os valores médios de insatisfação corporal, de acordo com o país e o sexo.

\begin{tabular}{|c|c|c|c|}
\hline País & Sexo & $\mathbf{N}$ & $\begin{array}{c}\text { Insatisfação corporal** } \\
\text { Média }(D P) \\
\end{array}$ \\
\hline \multirow{2}{*}{ Argentina } & 오 & 253 & $7,95(10,74)$ \\
\hline & $\hat{0}$ & 50 & $5,64(11,91)^{a}$ \\
\hline \multirow[t]{2}{*}{ Brasil } & 오 & 359 & $6,48(9,02)$ \\
\hline & $\hat{0}$ & 222 & $0,32(12,78)$ \\
\hline \multirow{2}{*}{ EUA } & 오 & 237 & $7,87(8,48)$ \\
\hline & $\hat{0}$ & 129 & $0,68(9,36)$ \\
\hline \multirow{2}{*}{ França } & q & 274 & $7,18(7,19)$ \\
\hline & $\hat{0}$ & 167 & $-0,68(10,24)$ \\
\hline
\end{tabular}

${ }^{*}$ Quatro universitários deixaram de responder a esta questão.

**Insatisfação corporal = número da silhueta que representa o corpo atual - número da silhueta que representa o corpo ideal. $\mathrm{a}=$ significativamente maior do que o Brasil $(p<0,05)$, os EUA $(p<0,05)$ e a França $(p<0,001)$.

Observa-se que, na comparação das médias de insatisfação corporal da amostra completa, as mulheres eram mais insatisfeitas (independente do país) resultado que corrobora com a primeira hipótese deste estudo. Entre os homens, os argentinos apresentaram maior insatisfação corporal.

Os universitários que escolheram a mesma figura para representar sua imagem atual e a imagem desejada foram classificados como satisfeitos com sua imagem corporal, assim, qualquer diferença entre estas imagens (seja positiva ou negativa) já caracterizou a insatisfação corporal. Portanto, entre os jovens insatisfeitos, foi necessário avaliar também se desejavam formas corporais maiores ou menores (Quadro 3). 
Quadro 3. Classificação dos universitários de ambos os sexos em função da diferença entre a imagem atual e a imagem desejada $(n=1691)^{*}$.

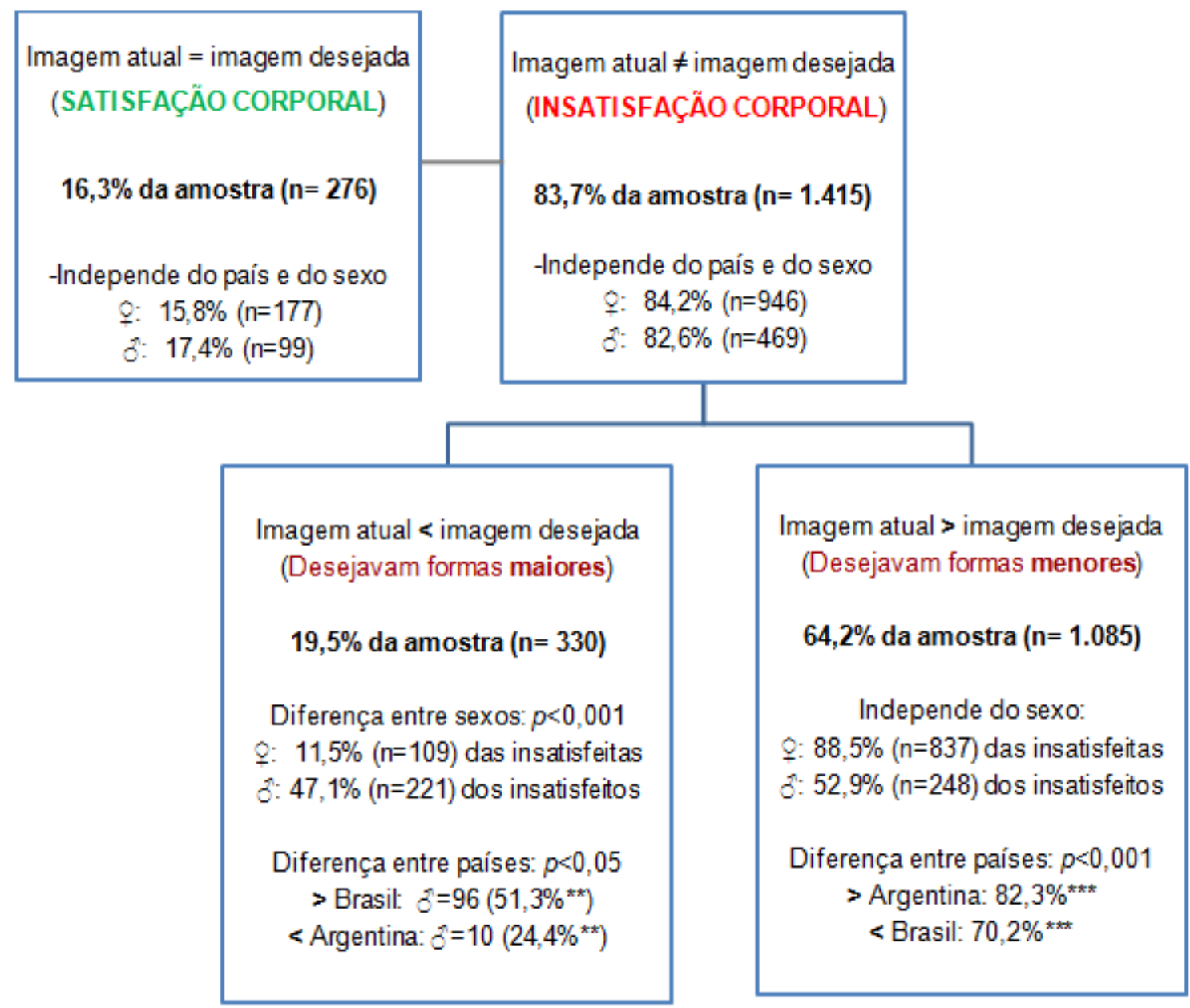

${ }^{*}$ Quatro universitários deixaram de responder a esta questão.

${ }^{\star *}$ Em relação aos homens insatisfeitos no país. ${ }^{* \star *}$ Considerando ambos os sexos.

Considerando-se a amostra geral, observou-se que apenas 16,3\% $(n=276)$ escolheram a mesma figura para imagem atual e imagem desejada (ou seja, estavam satisfeitos com sua imagem corporal). Entre as mulheres, a satisfação corporal correspondeu a $15,8 \%$ ( $n=177)$ e para os homens, correspondeu a $17,4 \%$ $(n=99)$ - sem diferença por país ou por sexo. O estado nutricional dos homens e mulheres satisfeitos com sua IC é apresentado na Tabela 6. 
Tabela 6. Estado nutricional das mulheres e homens satisfeitos com sua imagem corporal $(n=276)$, de acordo com o país.

\begin{tabular}{|c|c|c|c|c|c|c|c|c|}
\hline Estado nutricional & \multicolumn{2}{|c|}{ Argentina } & \multicolumn{2}{|c|}{ Brasil } & \multicolumn{2}{|c|}{ EUA } & \multicolumn{2}{|c|}{ França } \\
\hline & $q\left(\%^{*}\right)$ & $\hat{\delta}\left(\%^{*}\right)$ & $q\left(\%^{*}\right)$ & $\hat{\partial}\left(\%^{*}\right)$ & $q\left(\%^{*}\right)$ & $\hat{\partial}\left(\%^{*}\right)$ & $q\left(\%^{*}\right)$ & $\hat{\delta}\left(\%^{*}\right)$ \\
\hline Baixo peso & $08(17,4)$ & $07(77,8)$ & $06(10,2)$ & $03(8,6)$ & $07(20,0)$ & $01(3,8)$ & $16(43,2)$ & - \\
\hline Eutrofia & $38(82,6)$ & $02(22,2)$ & $39(66,1)$ & $26(74,3)$ & $27(77,1)$ & $21(80,8)$ & $21(56,7)$ & $26(90,0)$ \\
\hline Sobrepeso & - & - & $12(20,3)$ & $05(14,3)$ & - & $04(15,4)$ & - & $03(10,0)$ \\
\hline Obesidade grau I & - & - & $02(3,4)$ & $01(2,8)$ & $01(2,9)$ & - & - & - \\
\hline Obesidade grau II & - & - & - & - & - & - & - & - \\
\hline Obesidade grau III & - & - & - & - & - & - & - & - \\
\hline TOTAL & 46 & 09 & 59 & 35 & 35 & 26 & 37 & 29 \\
\hline
\end{tabular}

${ }^{\star}$ Em relação às mulheres e aos homens que desejavam formas corporais maiores no país.

Nos quatro países, para as mulheres satisfeitas com sua IC, as maiores frequências foram de eutróficas (maior frequência na Argentina e menor na França - país onde o número de mulheres com baixo peso foi semelhante ao de eutróficas); seguidas pelas jovens com baixo peso - exceto no Brasil, onde o segundo lugar foi representado pelas jovens com sobrepeso. Entre os homens, com exceção da Argentina, também houve mais eutróficos satisfeitos com a IC, seguidos por aqueles com baixo peso. Em ambos os sexos, nenhum obeso nos graus II e III estava satisfeito com a IC.

A frequência de jovens de ambos os sexos que escolheram diferentes figuras (maiores ou menores) representando a imagem atual e a desejada foi de $83,7 \%$ ( $n=1.415): 84,2 \%$ das mulheres $(n=946)$ e $82,6 \%$ dos homens $(n=469)$ - não houve diferença por país ou sexo.

Quando considerados apenas os casos em que a imagem desejada foi maior do que a atual (ou seja, apenas quem desejava ter formas corporais maiores) a frequência foi de $19,5 \%(n=330)$ da amostra total, maior entre os homens $(p<0,001)$ - $q=11,5 \%(n=109)$ e $\hat{\delta}=47,1 \%(n=221)$ - e também diferente entre os países $(p<0,05)$ : maior no Brasil, representando $51,3 \%(n=96)$ dos homens insatisfeitos 
deste país, e menor na Argentina (24,4\% dos homens insatisfeitos neste país; $\mathrm{n}=10$ ). A Tabela 7 apresenta o estado destes 330 universitários.

Tabela 7. Estado nutricional das mulheres e homens que desejavam formas corporais maiores $(n=330)$, de acordo com o país.

\begin{tabular}{|c|c|c|c|c|c|c|c|c|}
\hline \multirow[t]{2}{*}{ Estado nutricional } & \multicolumn{2}{|c|}{ Argentina } & \multicolumn{2}{|c|}{ Brasil } & \multicolumn{2}{|c|}{ EUA } & \multicolumn{2}{|c|}{ França } \\
\hline & $q\left(\%^{*}\right)$ & $\hat{\sigma}\left(\%^{*}\right)$ & $q\left(\%^{*}\right)$ & $\hat{\sigma}\left(\%^{*}\right)$ & $q\left(\%^{*}\right)$ & $\hat{\sigma}\left(\%^{*}\right)$ & $q\left(\%^{*}\right)$ & $\hat{\sigma}\left(\%^{*}\right)$ \\
\hline Baixo peso & $15(44,1)$ & - & $05(10,2)$ & $10(10,4)$ & $07(53,8)$ & $03(6,4)$ & $07(53,8)$ & $03(4,4)$ \\
\hline Eutrofia & $19(55,9)$ & $10(100)$ & $33(67,3)$ & $70(72,9)$ & $04(30,8)$ & $43(91,5)$ & $06(46,2)$ & $65(95,6)$ \\
\hline Sobrepeso & - & - & $10(20,5)$ & $14(14,6)$ & - & - & - & - \\
\hline Obesidade grau I & - & - & - & $02(2,1)$ & - & - & - & - \\
\hline Obesidade grau II & - & - & - & - & - & - & - & - \\
\hline Obesidade grau III & - & - & - & - & - & - & - & - \\
\hline Não respondeu** & - & - & $01(2,0)$ & - & $02(15,4)$ & $01(2,1)$ & - & - \\
\hline TOTAL & 34 & 10 & 49 & 96 & 13 & 47 & 13 & 68 \\
\hline
\end{tabular}

*Em relação às mulheres e aos homens que desejavam formas corporais maiores no país.

**Universitários que não responderam à variável peso atual e/ou altura.

Nos quatro países e em ambos os sexos, foi maior a frequência de universitários eutróficos que desejavam formas corporais maiores, exceto entre as mulheres estadunidenses e as francesas, para as quais o baixo peso foi pouco mais frequente do que a eutrofia. O Brasil foi o único país no qual os universitários com sobrepeso desejavam formas corporais maiores (assim como obesos grau I, no sexo masculino).

Os demais universitários insatisfeitos $(64,2 \% ; \mathrm{n}=1.085)$ desejavam ter formas corporais menores (escolheram uma figura desejada menor do que a atual): $88,5 \%$ das mulheres insatisfeitas ( $n=837$ ) e $52,9 \%$ dos homens insatisfeitos $(n=248)$. Não houve diferença por sexo, entretanto, houve diferença entre os países $(p<0,001)$ : maior na Argentina ( $82,3 \%$ dos insatisfeitos de ambos os sexos) e menor no Brasil (70,2\% dos insatisfeitos de ambos os sexos). O estado nutricional destes universitários é apresentado na Tabela 8. 
Tabela 8. Estado nutricional das mulheres e homens que desejavam formas corporais menores $(n=1.085)$, de acordo com o país.

\begin{tabular}{|c|c|c|c|c|c|c|c|c|}
\hline \multirow[t]{2}{*}{ Estado nutricional } & \multicolumn{2}{|c|}{ Argentina } & \multicolumn{2}{|c|}{ Brasil } & \multicolumn{2}{|c|}{ EUA } & \multicolumn{2}{|c|}{ França } \\
\hline & $q\left(\%^{*}\right)$ & $\hat{\sigma}(\% *)$ & $q(\% *)$ & $\hat{\sigma}\left(\% \%^{*}\right)$ & $q\left(\%^{*}\right)$ & $\hat{\sigma}\left(\%^{*}\right)$ & $q(\% *)$ & $\hat{o}\left(\%^{*}\right)$ \\
\hline Baixo peso & $03(1,7)$ & - & $26(10,4)$ & $07(7,7)$ & $08(4,2)$ & - & $09(4,1)$ & - \\
\hline Eutrofia & $139(80,3)$ & $16(51,6)$ & $175(69,7)$ & $60(65,9)$ & $149(78,9)$ & $28(50,0)$ & $197(87,9)$ & $54(77,2)$ \\
\hline Sobrepeso & $23(13,3)$ & $12(38,7)$ & $41(16,3)$ & $18(19,8)$ & $25(13,2)$ & $26(46,4)$ & $16(7,1)$ & $15(21,4)$ \\
\hline Obesidade grau I & $03(1,7)$ & $03(9,7)$ & $06(2,4)$ & $05(5,5)$ & $05(2,7)$ & $02(3,6)$ & - & $01(1,4)$ \\
\hline Obesidade grau II & $02(1,2)$ & $\cdot$ & $02(0,8)$ & - & - & - & - & - \\
\hline Obesidade grau III & $01(0,6)$ & - & - & - & $01(0,5)$ & - & - & - \\
\hline Năo respondeu ${ }^{* *}$ & $02(1,2)$ & $\cdot$ & $01(0,4)$ & $01(1,1)$ & $01(0,5)$ & . & $02(0,9)$ & - \\
\hline TOTAL & 173 & 31 & 251 & 91 & 189 & 56 & 224 & 70 \\
\hline
\end{tabular}

*Em relação às mulheres e aos homens que desejavam formas corporais maiores no país.

**Universitários que não responderam à variável peso atual e/ou altura.

Entre os universitários que desejavam ter formas corporais menores $(\mathrm{n}=$ 1.085), verificaram-se maiores frequências de sobrepeso e obesidade do que entre os satisfeitos com sua IC e os que queriam formas corporais maiores. Chama a atenção o fato de que, nos quatro países, até mesmo as mulheres com baixo peso desejaram ter corpo menor (mais magro); com exceção das argentinas, o número de mulheres com baixo peso que queriam formas menores foi, inclusive, maior do que o de obesas com o mesmo objetivo.

A fim de especificar a insatisfação corporal dos jovens que desejavam ter formas corporais menores e considerando que as figuras na Escala de Stunkard eram numeradas de 10 (mais magra) a 90 (mais gorda), analisaram-se também as frequências de insatisfeitos cuja diferença entre a figura atual e a desejada era $\geq 10$, $\geq 20$ e $\geq 30$ (Quadro 4). 
Quadro 4. Universitários que desejavam ter formas corporais menores, de acordo com a diferença entre imagem atual e imagem desejada $(n=1.085)^{*}$.

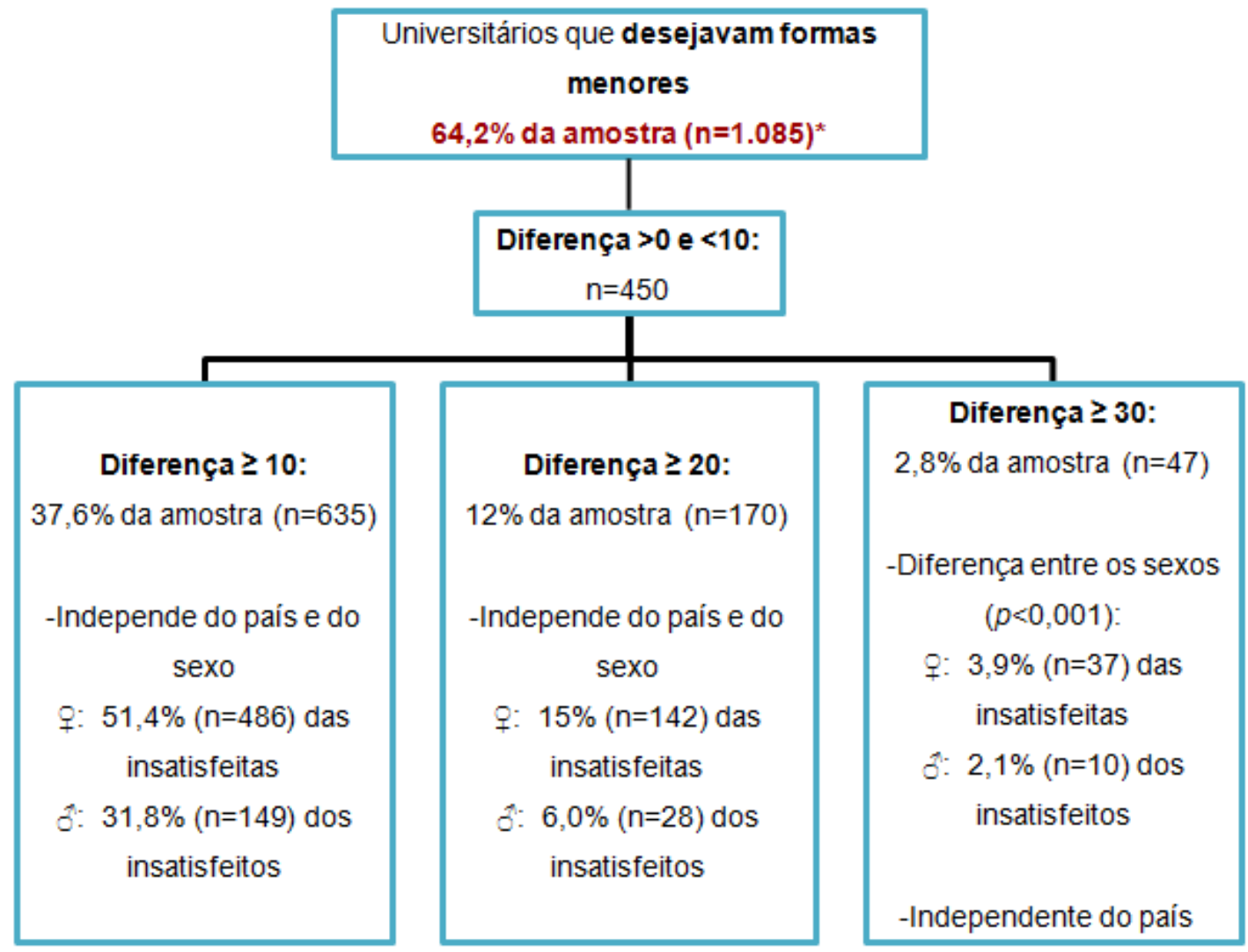

*Para $n=1.085$ jovens, a diferença entre "imagem atual - imagem desejada" foi maior do que 0 , entretanto, para $n=450$ a diferença foi inferior a uma figura $(<10)$ na Escala De Silhuetas de Stunkard.

Houve diferença entre os sexos apenas para aqueles cuja divergência entre as figuras atual e ideal foi $\geq 30: 3,9 \%(n=37)$ das mulheres insatisfeitas e $2,1 \%(n=10)$ dos homens insatisfeitos. Não houve diferença entre os países.

A fim de aprimorar o entendimento dos dados até aqui apresentados, avaliaram-se os efeitos do país, do sexo e da interação destas variáveis sobre a insatisfação corporal (Quadro 5). 
Quadro 5. Efeito da principal do país, do sexo e da interação destas variáveis sobre a insatisfação corporal.

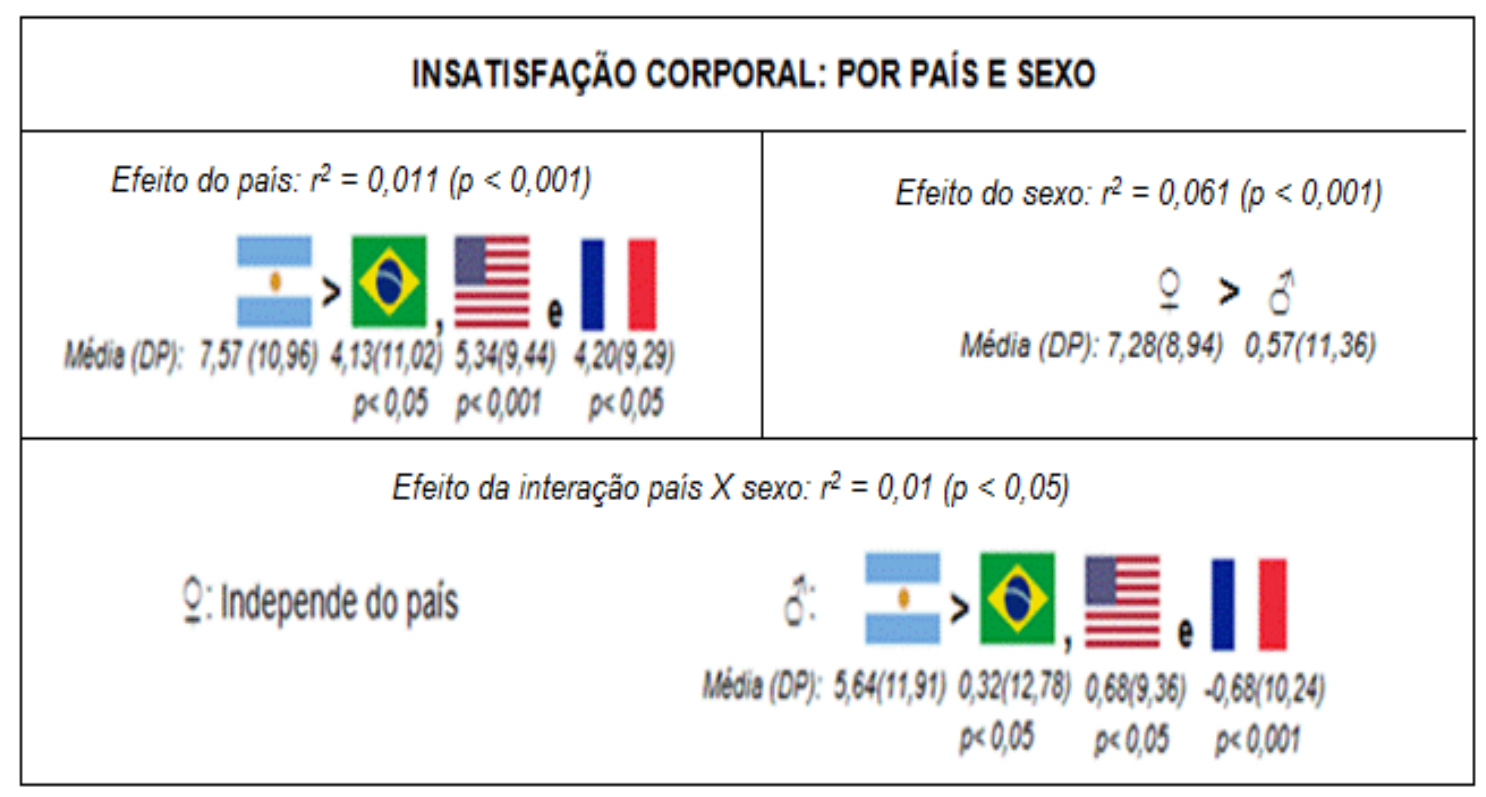

A insatisfação corporal foi diferente entre os países $\left(r^{2}=0,011\right)$, e na interação país e sexo $\left(r^{2}=0,01\right)$; contudo, o maior efeito foi do sexo separadamente $\left(r^{2}=0,061\right)$ - independente do país, as mulheres apresentaram maior insatisfação corporal. Dentre os homens, os argentinos apresentaram maior insatisfação do que os demais - não houve diferença entre as médias dos brasileiros, estadunidenses e franceses.

A insatisfação corporal foi analisada quanto à principal razão para exercício, de acordo com o sexo (Quadro 6). 
Quadro 6. Efeito da principal razão para se exercitar, do sexo e da interação destas variáveis sobre a insatisfação corporal.

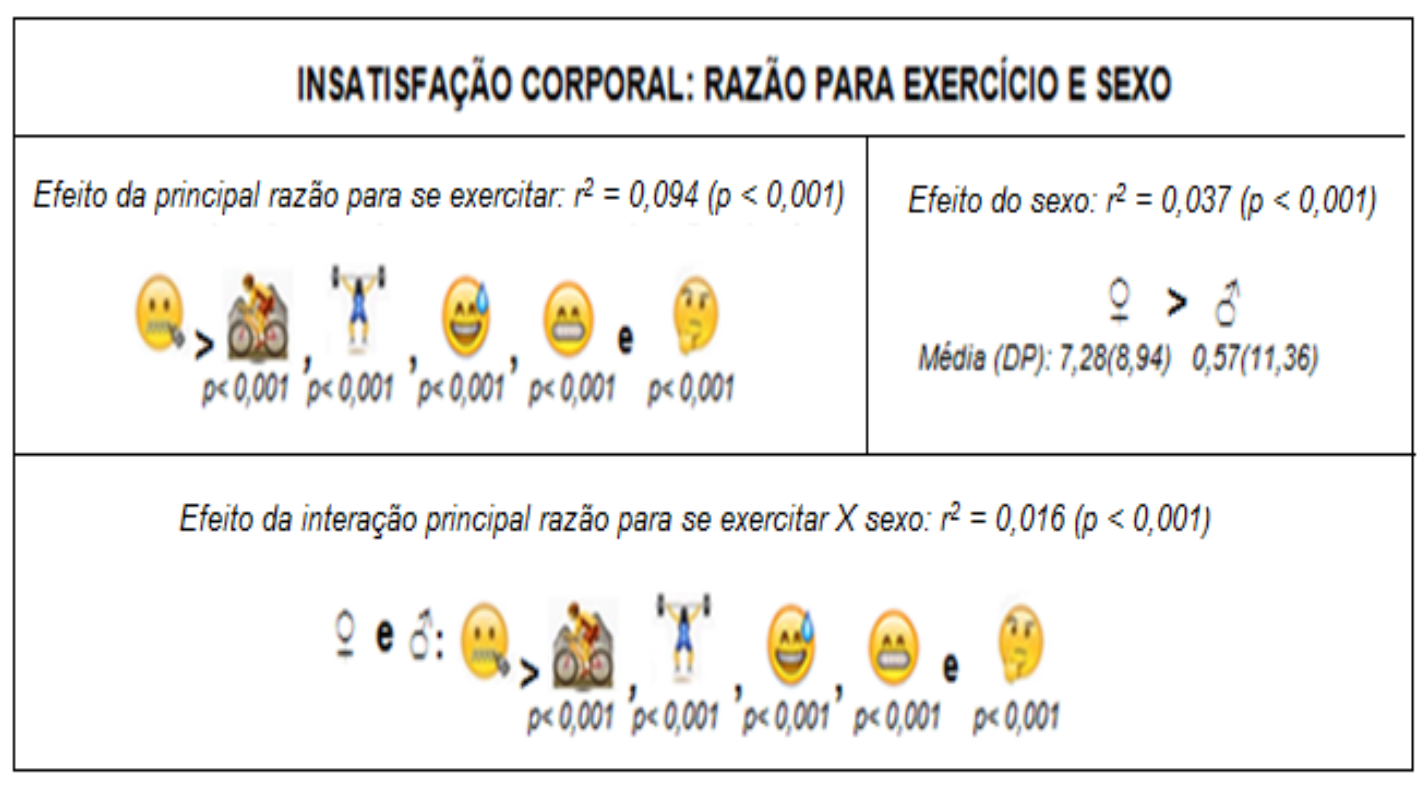

Legendas:

Principal razão para se exercitar:

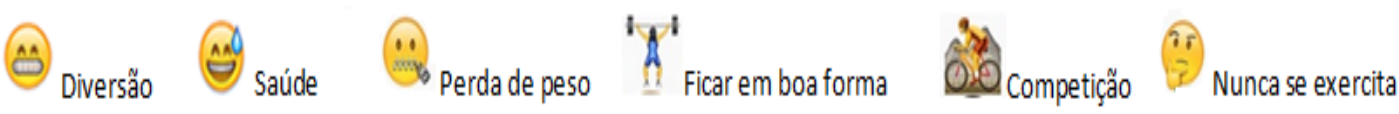

$r^{2}: 0,01=$ pequeno; $\geq 0,09=$ médio; $\geq 0,25=$ grande

Encontrou-se que o efeito, na insatisfação corporal, da razão para se exercitar $\left(r^{2}=0,094\right)$ foi maior do que o efeito do sexo $\left(r^{2}=0,037\right)$ e da interação destas variáveis $\left(r^{2}=0,016\right)$. Quando a principal razão para se exercitar foi "perda de peso", a insatisfação corporal foi maior do que por qualquer outra razão, em ambos os sexos, resultados que corroboram com a segunda hipótese do estudo.

Não houve efeito do principal tipo de exercício praticado sobre a insatisfação corporal.

A correlação entre a insatisfação corporal e a frequência semanal de atividade física foi nula $(\rho=-0,093)$, ou seja, não há relação entre estas variáveis (contrariando parte do que foi estabelecido na segunda hipótese do estudo). A correlação entre a insatisfação corporal e a preocupação excessiva com a rotina de 
exercício $(\rho=0,076)$ bem como insatisfação e culpa por não se exercitar $(\rho=0,120)$ foram também nulas.

Conforme apresentado no Quadro 6, a insatisfação corporal foi maior entre aqueles que se exercitam principalmente para "perder peso" - em ambos os sexos. A fim de explorar este resultado, a classificação do estado nutricional da amostra geral é apresentada na Tabela 9.

Tabela 9. Distribuição dos universitários $\left(n=1.684^{*}\right)$ segundo a classificação do estado nutricional (WHO, 2010), de acordo com o país e o sexo.

\begin{tabular}{l|cccc|cc|cc}
\hline \multirow{2}{*}{ Estado nutricional } & \multicolumn{2}{|c|}{ Argentina } & \multicolumn{2}{c|}{ Brasil } & \multicolumn{2}{c|}{ EUA } & \multicolumn{2}{c}{ França } \\
\cline { 2 - 10 } & $+\mathrm{N}(\%)$ & $\hat{0} \mathrm{~N}(\%)$ & $+\mathrm{N}(\%)$ & $\hat{0} \mathrm{~N}(\%)$ & $+\mathrm{N}(\%)$ & $\hat{0} \mathrm{~N}(\%)$ & $+\mathrm{N}(\%)$ & $\hat{\mathrm{N}}(\%)$ \\
\hline \multirow{2}{*}{ Baixo peso } & 26 & - & 37 & $20(9,0)$ & $22(9,4)$ & $04(3,1)$ & 32 & $03(1,8)$ \\
& $(10,4)$ & & $(10,3)$ & & & & $(11,8)$ & \\
\hline \multirow{2}{*}{ Eutrofia } & 197 & 33 & 248 & 157 & 180 & 92 & 224 & 145 \\
& $(78,1)$ & $(66)$ & $(69,3)$ & $(70,7)$ & $(76,9)$ & $(71,9)$ & $(82,4)$ & $(86,8)$ \\
\hline \multirow{2}{*}{ Sobrepeso } & 23 & 14 & 63 & 37 & 25 & 30 & 16 & 18 \\
& $(9,1)$ & $(28)$ & $(17,6)$ & $(16,7)$ & $(10,6)$ & $(23,4)$ & $(5,9)$ & $(10,8)$ \\
\hline Obesidade grau I & $03(1,2)$ & $03(6,0)$ & $08(2,2)$ & $08(3,6)$ & $07(3,0)$ & $02(1,6)$ & - & $01(0,6)$ \\
\hline Obesidade grau II & $02(0,8)$ & - & $02(0,6)$ & - & - & - & - & - \\
\hline Obesidade grau III & $01(0,4)$ & - & - & - & $01(0,4)$ & - & - & - \\
\hline TOTAL & 252 & 50 & 358 & 222 & 235 & 128 & 272 & 167 \\
\hline
\end{tabular}

*11 pessoas da amostra total (1695) não responderam à variável peso atual e/ou altura.

A maioria era eutrófica, como já destacado nos resultados gerais. Observase, em geral, maior frequência de baixo peso entre as mulheres, assim como de obesidade. Para as mulheres classificadas com sobrepeso, a frequência foi maior para as brasileiras, semelhante entre as argentinas e estadunidenses, e menor para as francesas.

Analisou-se o efeito do estado nutricional, da razão para exercício e da interação destas variáveis sobre a média de insatisfação corporal (Quadro 7) considerando-se todos os universitários que desejaram uma figura diferente da atual. 
Quadro 7. Efeito do estado nutricional, do sexo e da interação destas variáveis sobre a insatisfação corporal.

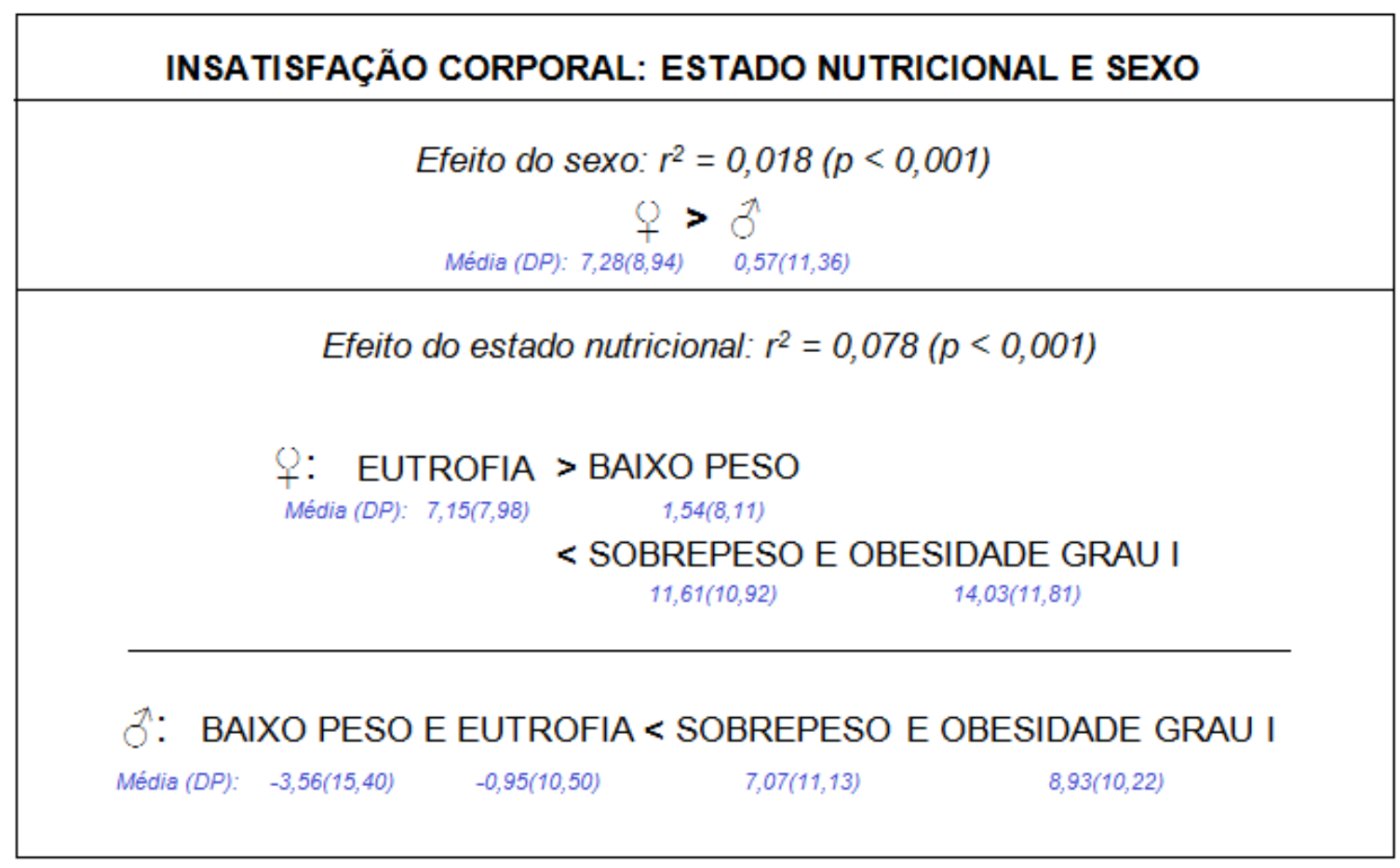

A insatisfação corporal também foi diferente de acordo com o estado nutricional $\left(r^{2}=0,078\right)$, com efeito maior do que o do sexo $\left(r^{2}=0,018\right)$. Entre as mulheres, a insatisfação das eutróficas foi maior do que daquelas com baixo peso e menor do que no sobrepeso e obesidade grau I; e entre os homens, aqueles com baixo peso e eutrofia apresentaram menor insatisfação do que os que tinham sobrepeso e obesidade grau I.

Comparando-se as médias de insatisfação corporal de acordo com ano de curso, nacionalidade, curso, condição socioeconômica e religião, não houve diferença entre os grupos avaliados.

Considerando o efeito do estado nutricional sobre a insatisfação corporal, avaliaram-se também as correlações desta variável com outras relacionadas ao corpo e ao contexto alimentar (Figura 8). 


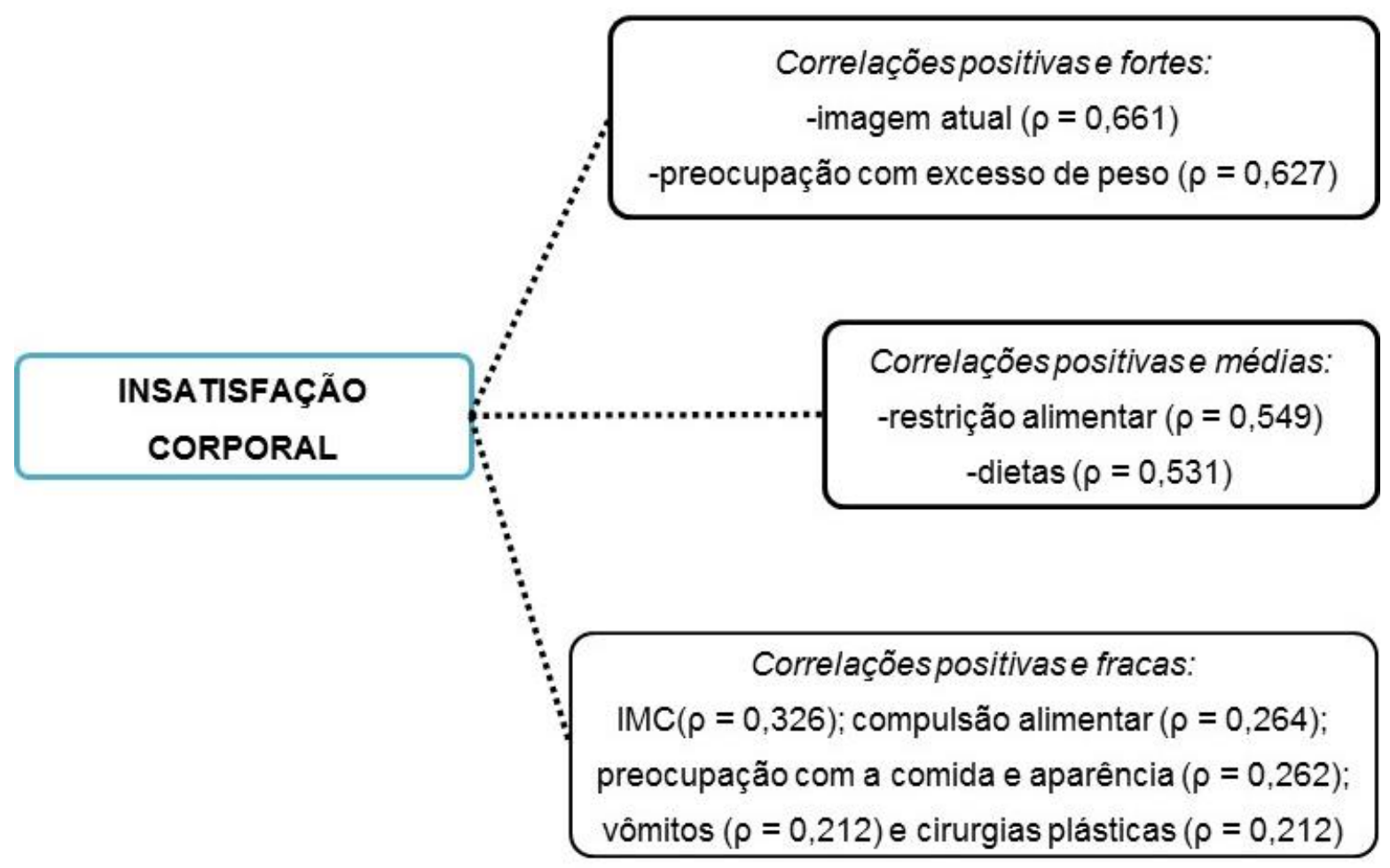

Figura 8. Correlações entre insatisfação corporal e demais variáveis.

Observa-se que tanto a imagem atual quanto a preocupação com excesso de peso tem forte correlação com a insatisfação corporal.

\subsubsection{Discussão}

As exigências da vida contemporânea têm gerado crescente insatisfação corporal (FERREIRA, 2010), e a preocupação com a aparência física e com a imagem corporal é uma realidade em diferentes países (CARVALHO, 2016). Esta insatisfação é observada em mulheres em homens, e pode ser influenciada por pela idade, mídia e redes sociais, IMC, prática de atividade física, padrão de beleza dentre outros (MAHMUD e CRITTENDEN, 2007; BOSI, 2009; NICHOLS et al., 2009; LEGNANI et al., 2012; BATISTA et al., 2015; SWAMI et al., 2015).

Em relação à amplitude da diferença entre imagem atual e a imagem desejada (que permite a classificação dos jovens em satisfeitos ou insatisfeitos), independente do país, as mulheres apresentaram maior insatisfação corporal do que os homens; entre os quais os argentinos eram os mais insatisfeitos. Dado o fato 
de que a insatisfação corporal é um fenômeno multidimensional, é importante destacar que entre todos os homens, os argentinos foram os que apresentaram maior média de idade e também os mais adeptos às restrições alimentares.

Além desta amplitude, analisou-se, entre os insatisfeitos, aqueles que desejavam formas maiores e os que desejam formas menores. Verificou-se que aproximadamente um sexto das mulheres e dos homens (apenas) estava satisfeito com sua IC, entretanto, não houve diferença por país ou por sexo.

Independente do país, a frequência de mulheres que desejaram formas corporais diferentes (maior ou menor) foi semelhante à dos homens. Especificamente, para os jovens que desejaram formas corporais maiores, a frequência foi maior $(p<0,05)$ para o sexo masculino, e no Brasil (mais da metade dos homens insatisfeitos no país) - enquanto apenas um décimo das mulheres queria ter formas maiores.

Para aqueles que queriam formas corporais menores, houve diferença entre os países $(p<0,001)$ : maior frequência na Argentina e menor no Brasil. Apesar de não ter ocorrido diferença estatística entre os sexos, enquanto cerca de $90 \%$ das mulheres insatisfeitas desejavam ter formas menores (mais magras), para os homens, a frequência foi de $52,9 \%$ - entre estes jovens, a diferença entre o corpo atual e o desejado foi de pelo menos uma figura da Escala de Stunkard $(\geq 10)$ para $51 \%$ das mulheres e $32 \%$ dos homens. Observaram-se também casos mais discrepantes, nos quais a imagem desejada foi de pelo menos três figuras na Escala de Stunkard $(\geq 30)$, com maior a frequência entre as mulheres $(p<0,001)$.

A frequência da insatisfação corporal foi compatível com a literatura. QUADROS et al. (2010), em estudo com $n=874$ universitários brasileiros, usando a Escala de Stunkard, verificaram que a insatisfação com a IC foi de $77,6 \%$ na amostra geral, sendo que $62,4 \%$ das mulheres desejavam ser menores e $43,3 \%$ dos homens desejavam ser maiores. Com o mesmo instrumento e também no Brasil ( $n=865$ ), MARTINS et al. (2012) encontraram que $62,4 \%$ das mulheres desejavam ser menores, enquanto $43,8 \%$ dos homens desejavam ser maiores.

A revisão integrativa realizada para este estudo (SOUZA e ALVARENGA, 2016) encontrou grande amplitude da insatisfação entre jovens universitários de em 
ambos os sexos: $8,3 \%$ a $87 \%$ nos estudos nacionais, e de $5,2 \%$ a $85,5 \%$ nos internacionais, parecendo indicar que o problema se apresenta de maneira semelhante mundialmente, e que as variações se devem principalmente ao sexo e método de análise do construto.

Os achados deste manuscrito atestam - assim como colocado na literatura - que as mulheres têm maior insatisfação corporal independente do país, o que lembra a "insatisfação normativa" das mulheres descrita por RODIN et al. (1985). $\mathrm{Na}$ visão da teoria feminista, a insatisfação corporal não é somente fruto de uma avaliação subjetiva negativa em relação ao próprio corpo, mas sim de um fenômeno social sistêmico, que entende o corpo feminino como um instrumento a ser usado e para dar prazer a outrem (GOELLNER, 2003; SIMÕES, 2004; FORBES et al., 2012; CARVALHO, 2016).

Segundo MALYSSE (2007), o corpo aparece como um campo de batalha, um terreno de conflitos e resistências, no qual as diferenças de raça, gênero e nacionalidade parecem desaparecer sob o peso das "escolhas" individuais feitas em relação ao corpo ideal. As mulheres são incessantemente bombardeadas e educadas para adequação aos padrões de beleza impostos, numa espécie de "ditadura" do que se deve fazer, vestir ou ser (LEITZKE et al., 2014), ao passo que para os homens, reconhecidos como naturalmente brutos, um investimento estético mais acentuado em geral é visto como "frescura", um traço de efeminação (SABINO, 2007).

Neste estudo, considerando-se todos os universitários que desejaram IC diferente da atual, em ambos os sexos, verificou-se que a insatisfação corporal daqueles com sobrepeso e obesidade grau I foi maior do que dos eutróficos - dado que também está em consonância com a literatura (ALMEIDA et al., 2002; HAUSENBLAS e FALLON, 2002; ALVARENGA et al., 2010b; RECH et al., 2010; HERNÁNDEZ et al., 2012; MARTINS et al., 2012).

Para quem desejou formas corporais maiores, o estado nutricional, em geral, foi de eutrofia ou baixo peso, com exceção dos brasileiros de ambos os sexos. Entre as mulheres brasileiras que desejavam ser maiores, a frequência de sobrepeso foi duas vezes maior do que a de baixo peso - o que de certa forma é compatível com 
o fato de que a maior frequência de sobrepeso entre as mulheres foi no Brasil, mas, ao mesmo tempo, é contrastante ao achado de que elas são também as mais preocupadas com excesso de peso. Quanto ao sexo masculino no Brasil, convêm lembrar que metade dos homens insatisfeitos com sua IC queria ter formas corporais maiores, e também que, em média, eles apresentaram peso corporal menor do que nos demais países, além de IMC médio menor do que argentinos e estadunidenses.

Por outro lado, entre os universitários que desejaram formas menores, o estado nutricional foi, principalmente, eutrofia ou sobrepeso - nos quatro países e em ambos os sexos.

Segundo JAIN e TIWARI (2016), nos últimos anos a concepção pessoal de imagem corporal é fortemente influenciada pelo desejo de perder peso, de ter beleza, saúde e bom desempenho físico. Tal afirmação fica evidenciada no achado deste estudo de que os universitários (de ambos os sexos) que fazem exercícios principalmente para "perder peso" apresentaram maior insatisfação corporal, e também pela forte correlação da imagem atual, ou seja, "como me vejo" com a insatisfação (e não "como sou" - o dado objetivo de IMC); bem como da correlação da preocupação com ganho de peso (novamente, não com dado objetivo de IMC) e a insatisfação.

Em virtude de a insatisfação corporal ser multidimensional, observaram-se diferentes efeitos das variáveis sobre o fenômeno - o efeito do sexo foi maior do que o efeito do país, entretanto, o estado nutricional teve efeito ainda maior que o sexo. Por fim, o maior efeito aqui encontrado foi o da razão para se exercitar, ou seja, em ordem decrescente de efeitos:

Razão para se exercitar > estado nutricional > sexo > país.

Até onde se conhece, não há registros na literatura de estudos que tenham avaliado a relação entre a insatisfação corporal e as razões pelas quais os indivíduos se exercitam, contemplando uma amostra tão ampla e proveniente de diferentes países - usualmente, os construtos são avaliados separadamente e/ou em amostra menos representativa, como o estudo de FERMINO et al. (2010) com brasileiros frequentadores de academia $(n=90)$, que encontrou maior insatisfação 
entre mulheres e indivíduos com maior IMC e maior percentual de gordura, que buscavam maior harmonia das formas corporais, por meio da $\mathrm{AF}$-, assim, há que se destacar a originalidade do presente estudo em avaliar construtos diversos em amostra grande e de diferentes países. Na cultura ocidental de insatisfação corporal normativa entre as mulheres, chama a atenção o fato de que outros fatores (além do sexo) tenham efeito ainda maior na insatisfação corporal, contudo, não é possível estabelecer relação causal - se a insatisfação corporal é anterior ao fazer exercícios desejando diminuir o peso corporal, ou se o indivíduo que faz exercícios com este objetivo acaba se tornando mais insatisfeito com o corpo por não alcançar o peso pretendido - em razão de este ser um estudo com delineamento transversal.

Em relação à insatisfação corporal em pessoas com excesso de peso (sobrepeso ou obesidade), há mais de 20 anos, CASH (1993) já pontuava que descontentamento relacionado ao peso é consequência de uma ênfase cultural na magreza e estigma social da obesidade. ALMEIDA et al. (2002) observaram sensação mais frequente de inferioridade, inadequação, descontentamento com relação ao próprio corpo, insegurança e depreciação diante do risco de julgamentos externos negativos em mulheres obesas, em comparação a mulheres eutróficas. Em uma sociedade que valoriza a magreza, a muscularidade e os baixos percentuais de gordura, a insatisfação corporal entre aqueles que não atingem tais padrões é crescente, sobretudo, quando estão acima do peso; assim, comportamentos como camuflar seus corpos com roupas largas, alterar movimentos ou postura, evitação corporal, aborrecimento e vergonha ao pensar sobre a aparência ou ao submeterem-se a situações sociais são também mais comuns quando se está acima do peso (SCHWARTZ e BROWNELL, 2004; SARWER et al., 2005b).

A insatisfação corporal está associada à diminuição da qualidade de vida, baixa autoestima, depressão, ansiedade, transtornos alimentares, risco de suicídio, dentre outros prejuízos à saúde física e mental (SARWER et al., 2005b; RODRÍGUEZ-CANO et al., 2006; POMPILI et al., 2007; SIDES-MOORE e TOCHKOV, 2011; MIRANDA et al., 2012; AS-SA'EDI et al., 2013; RUNFOLA et al., 2014), portanto, presumir que pessoas insatisfeitas com suas formas têm nisto uma 
"motivação" para se engajar nos exercícios e ter mais saúde pode ser um grande equívoco, um entendimento potencialmente prejudicial (SCHWARTZ e BROWNELL, 2004; ZACCAGNI et al., 2014; JUNG et al., 2017).

Por fim, pode-se concluir que, nesta amostra de universitários, a insatisfação corporal está relacionada, ao sexo feminino, ao estado nutricional - à eutrofia e baixo peso (quando se desejam formas corporais maiores) e à eutrofia ou sobrepeso (quando a intenção é ter formas menores) - e, principalmente, ao fato de se exercitar para "perder peso".

\subsection{RESULTADOS PARA O MANUSCRITO 2}

Pergunta de partida: "Como se dá a relação entre a razão para se exercitar, preocupação e culpa com a atividade física e atitudes alimentares inadequadas, estado nutricional e cirurgias plásticas entre as jovens universitárias?"

Esta parte do estudo busca elucidar a relação das questões alimentares, estéticas e referentes à atividade física entre as mulheres, que representaram $66,4 \%(n=1.126)$ da amostra.

Considerando-se amostra geral (homens e mulheres) o efeito do sexo foi superior ao do país para parte das variáveis. Especificamente em relação à insatisfação corporal (temática explorada no manuscrito 1), observou-se que 0 efeito da razão para se exercitar foi maior do que o efeito do sexo, que por sua vez, foi maior do que o efeito do país. Para as mulheres observou-se que o efeito da razão para se exercitar foi maior do que o do país em $78 \%$ das variáveis (prática de dieta, restrição alimentar, preocupação com a comida e aparência, vômitos, compulsões alimentares, cirurgias plásticas e preocupação com excesso de peso sete entre as nove variáveis ordinais).

Primeiramente, quando analisadas as razões para se exercitar, a "saúde" foi apontada como a principal, com frequência semelhante entre as argentinas e francesas, maior entre as estadunidenses, e menor entre as brasileiras (Quadro 8). 
Quadro 8. Hierarquia da principal razão para se exercitar, segundo o país.

\begin{tabular}{|c|c|c|c|c|}
\hline $\begin{array}{l}\text { Principal razão } \\
\text { para se exercitar }\end{array}$ & ARGENTINA & BRASIL & EUA & FRANÇA \\
\hline $1^{\mathrm{a}}$ & 스 $(40,2 \%)$ & $\begin{array}{l}\hat{\theta}(36,4 \%) \\
\text { Residuo ajustado: }-2,7\end{array}$ & $\begin{array}{l}\text { Residuo ajustado: } 3,5 \\
\text { (52,1\%) }\end{array}$ & $\begin{array}{l}\text { Residuo ajustado: } 4,2 \\
\text { (43,4\%) }\end{array}$ \\
\hline $2^{\mathrm{a}}$ & 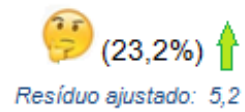 & Residuo ajustado: 3,3 & $\begin{array}{l}{ }_{0}(26,5 \%) \\
\text { Residuo ajustado: } 3,4\end{array}$ & (A) $(23,4 \%)$ \\
\hline $3^{\mathrm{a}}$ & $\overbrace{(19,7 \%)}$ & $\begin{array}{l}\text { 'A } \\
\text { Resíduo ajustado: } 9,4\end{array}$ & Residuo ajustado: 5,2 & $\ddot{8}_{(20,4 \%)}$ \\
\hline $4^{\mathrm{a}}$ & (4) $(16,1 \%)$ & (14,4\%) & Residuo ajustado: $-4,0$ & Residuo ajustado: $-4,5$ \\
\hline $5^{\mathrm{a}}$ & Residuo ajustado: $-2,3$ & Residuo ajustado: $-4,1$ & $\begin{array}{l}\text { Residuo ajustado: }-4,3 \\
(5,0 \%)\end{array}$ & 'A' \\
\hline $6^{a}$ & 'A ' & Residuo ajustado: $-2,1$ & Residuo ajustado: $-3,9$ & ใิ่อ $(2,6 \%)$ \\
\hline
\end{tabular}

Legendas:

Principal razão para se exercitar:

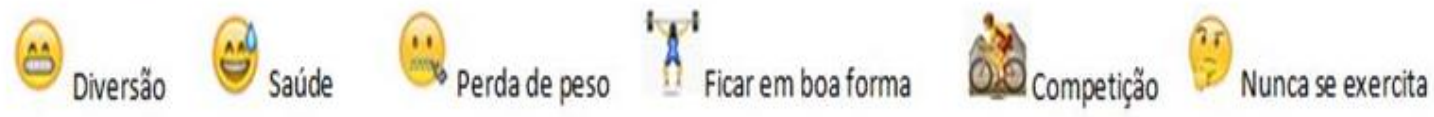

: Residuo ajustado $\leq-2$ (frequência menor do que a esperada). ॠ: Residuo ajustado $\geq 2$ (frequência maior do que a esperada).

Houve associação entre a razão para exercício e o país ( $p<0,001)$, sendo que entre as estadunidenses, o número de associações foi maior. Para as mulheres que afirmaram nunca se exercitar, verificaram-se semelhanças entre Argentina e Brasil (cuja frequência foi de aproximadamente $20 \%$ ) e entre EUA e França (nos quais a frequência foi cerca de $5 \%$ ).

Exercitar-se principalmente para a "perda de peso" foi uma razão mencionada por aproximadamente $20 \%$ das argentinas e das francesas (terceira razão mais frequente em ambos), por pouco mais de 25\% das estadunidenses (segunda principal razão) e por apenas $11,9 \%$ das brasileiras (penúltima razão mais 
frequente) - ou seja, mesmo onde a "perda de peso" foi a razão mais representativa (EUA), a frequência ainda foi inferior a $30 \%$.

Os resultados descritos a seguir, quanto às atitudes alimentares e prática de exercícios, evidenciam que o componente estético pode ter grande relevância no que se considera "saúde".

Buscando entender possíveis relações entre as razões para se exercitar e alguns comportamentos alimentares adotados na busca de um "corpo ideal", o escore de restrições alimentares (cuja resposta à adesão "quase sempre" correspondeu a $12,4 \%, n=140$, da amostra geral de mulheres) foi analisado com relação à razão para se exercitar (Quadro 9) - cabe ressaltar que o escore geral de restrições alimentares das argentinas foi maior do que o dos demais países $(p<0,001)$, e o das estadunidenses o menor $(p<0,05)$; além disso, na Argentina, a resposta "quase sempre" foi a opção com maior frequência $(29,5 \%)$.

Encontrou-se que as restrições foram mais frequentes entre aquelas que fazem exercícios principalmente para a "perda de peso" $\left(r^{2}=0,114\right)$ - houve maior efeito da razão para o exercício do que do país $\left(r^{2}=0,027\right)$ e da interação destas variáveis $\left(r^{2}=0,024\right)$. Os quatro países foram semelhantes quanto ao efeito da razão para o exercício sobre as restrições alimentares, embora as estadunidenses tenham apresentado menor escore em relação aos demais. 
Quadro 9. Efeito da principal razão para se exercitar, do país e da interação destas variáveis sobre as restrições alimentares.

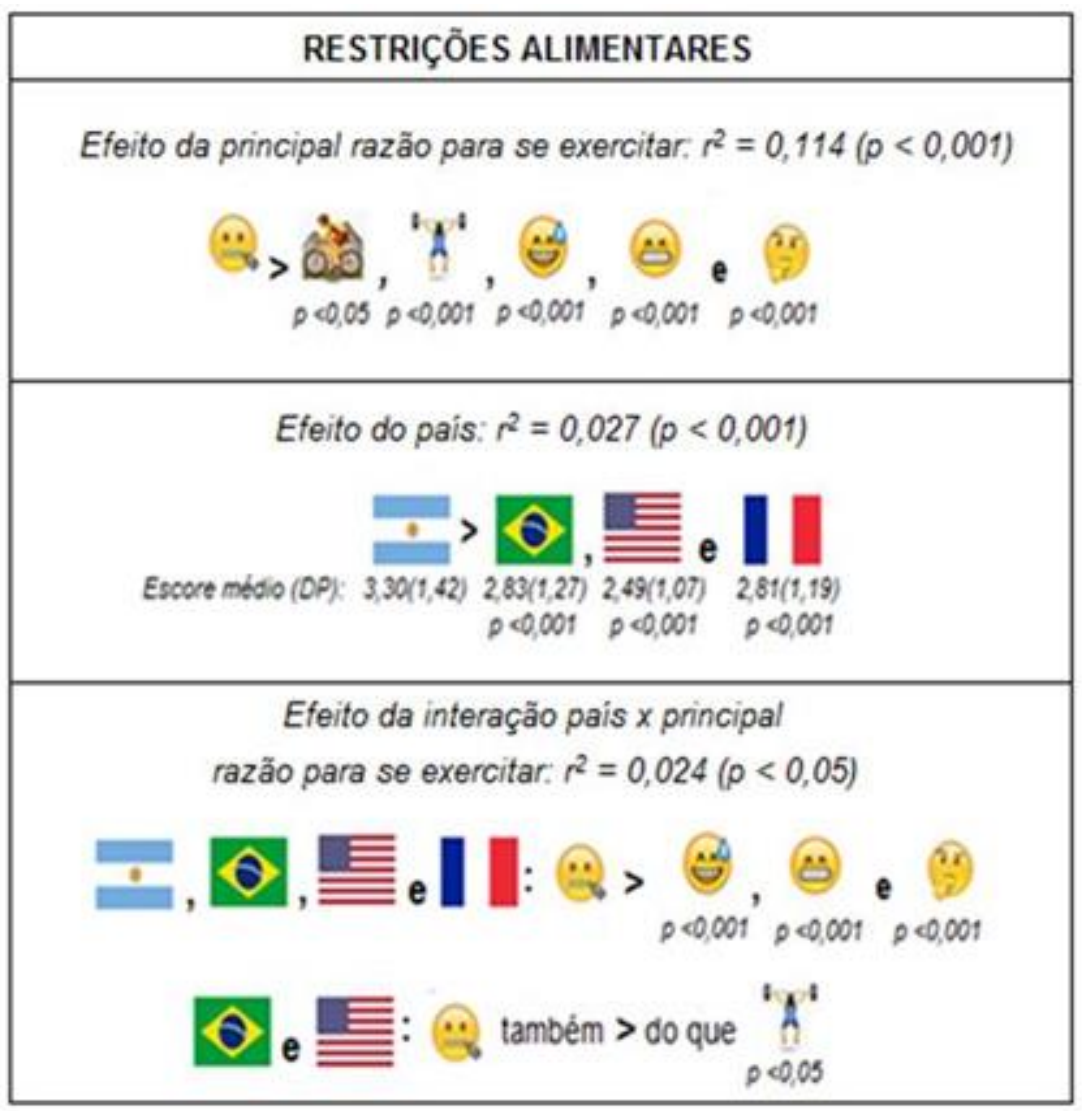

Legendas:

Principal razão para se exercitar:

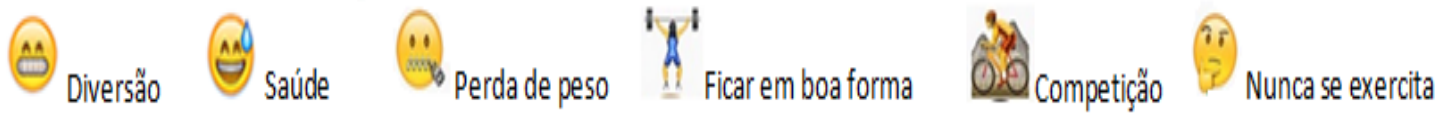
$r^{2}: 0,01=$ pequeno; $\geq 0,09=$ médio; $\geq 0,25=$ grande

Da mesma forma a resposta à "preocupação com a comida e como ela pode afetar a aparência" foi analisada com relação à razão para se exercitar (Quadro 10). 
Quadro 10. Efeito da principal razão para se exercitar, do país e da interação destas variáveis sobre a preocupação com a comida e sua influência na aparência.

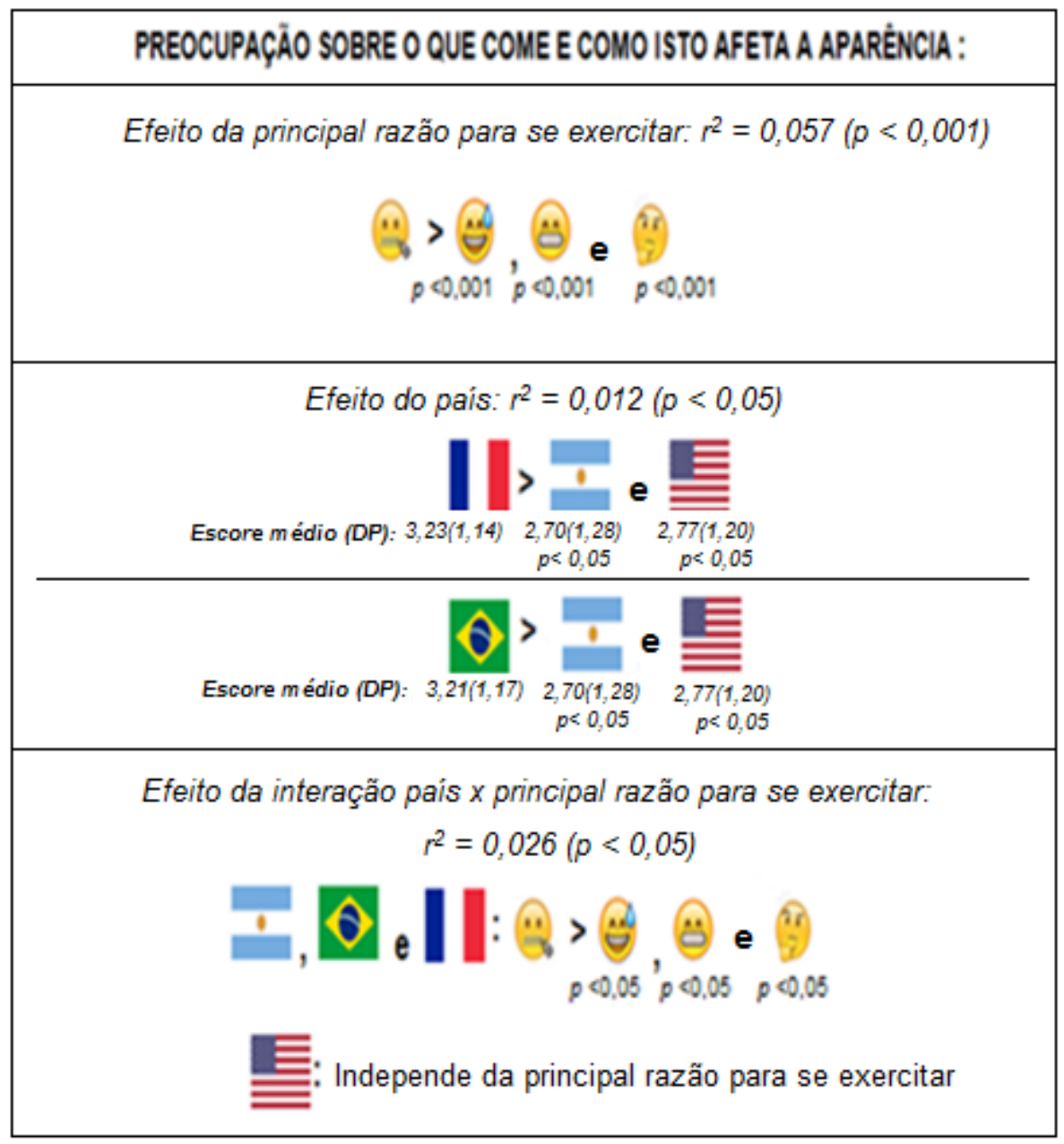

Legendas:

Principal razõo para se exercitar:

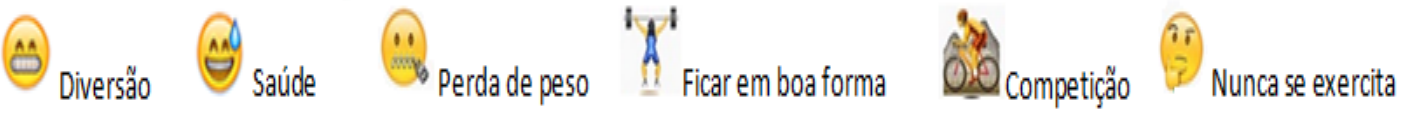

$r^{2}: 0,01=$ pequeno; $\geq 0,09=$ médio; $\geq 0,25=$ grande

As francesas e brasileiras apresentaram maiores escores para a preocupação com a comida e como ela afeta a aparência, sendo que para elas (e também para as argentinas), a preocupação foi maior quando se exercitam principalmente para "perder peso". Novamente, o efeito da razão para se exercitar 
$\left(r^{2}=0,057\right)$ foi maior do que o do país $\left(r^{2}=0,026\right)$ e o da interação destas variáveis $\left(r^{2}=0,012\right)$.

Na mesma linha de raciocínio, a prática de dietas (cuja resposta "quase sempre" foi de $4,4 \%$ das mulheres, $n=49$ ), foi analisada com relação à razão para se exercitar (Quadro 11).

Quadro 11. Efeito da principal razão para se exercitar sobre a prática de dietas.

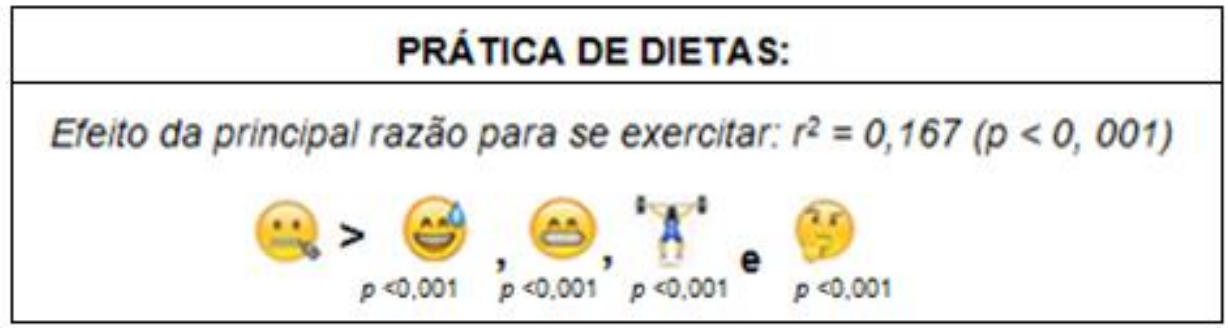

Legendas:

Principal razõo para se exercitar:

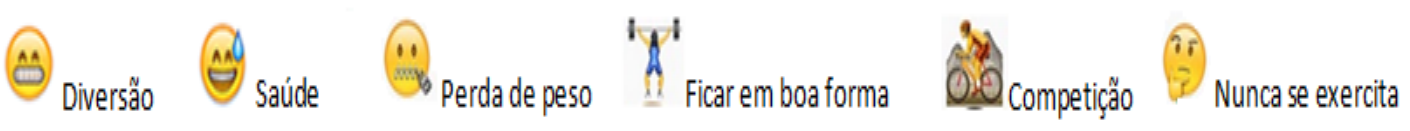

$$
r^{2}: 0,01=\text { pequeno; } \geq 0,09=\text { médio; } \geq 0,25=\text { grande }
$$

Independente do país, fazer dietas foi mais frequente entre as aquelas que se exercitam principalmente para "perder peso" do que as demais razões (exceto "competição").

Foi possível observar também efeito da razão para exercício e do país em relação à "preocupação sobre ter excesso de peso", sendo o efeito da razão maior que o do país (Quadro 12). 
Quadro 12. Efeito da principal razão para se exercitar sobre a preocupação sobre ter excesso de peso.

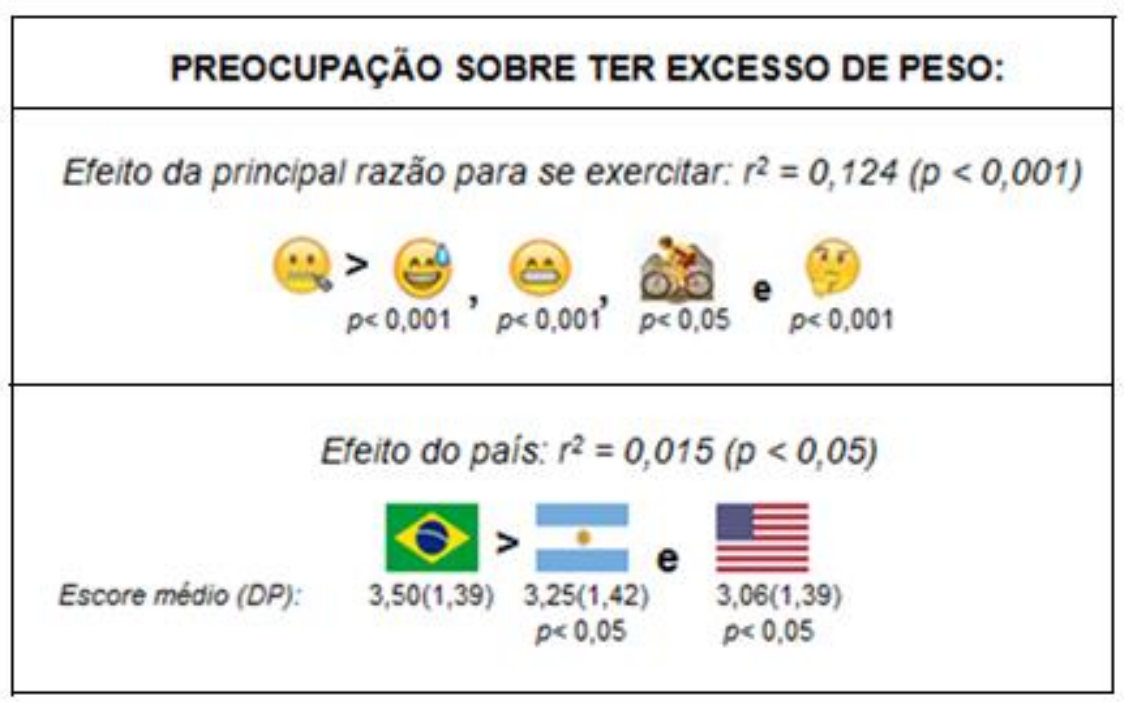

Legendas:

Principal raz̃õo para se exercitar:

(A) Diversão $\quad \forall$ Saúde
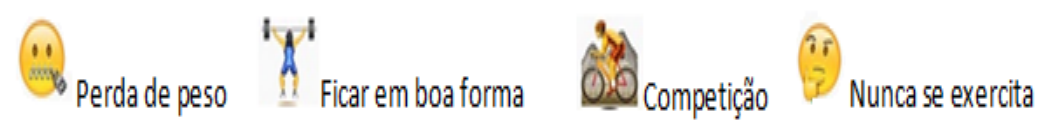

$r^{2}: 0,01=$ pequeno $; \geq 0,09=$ médio $; \geq 0,25=$ grande

A preocupação sobre ter excesso de peso foi maior para quem se exercita principalmente para "perder peso" do que por outras razões $\left(r^{2}=0,124\right.$; exceto para "ficar em boa forma"), além disso, o escore das brasileiras foi maior do que o das argentinas e das estadunidenses $\left(r^{2}=0,015\right)$. Não houve efeito da interação país e razão para exercício.

Analisou-se também presença de compulsões alimentares com relação à resposta para a razão para se exercitar e ao país, sendo maior efeito do país $\left(r^{2}=\right.$ 0,038) - Quadro 13. 
Quadro 13. Efeito da principal razão para se exercitar e do país sobre as compulsões alimentares.
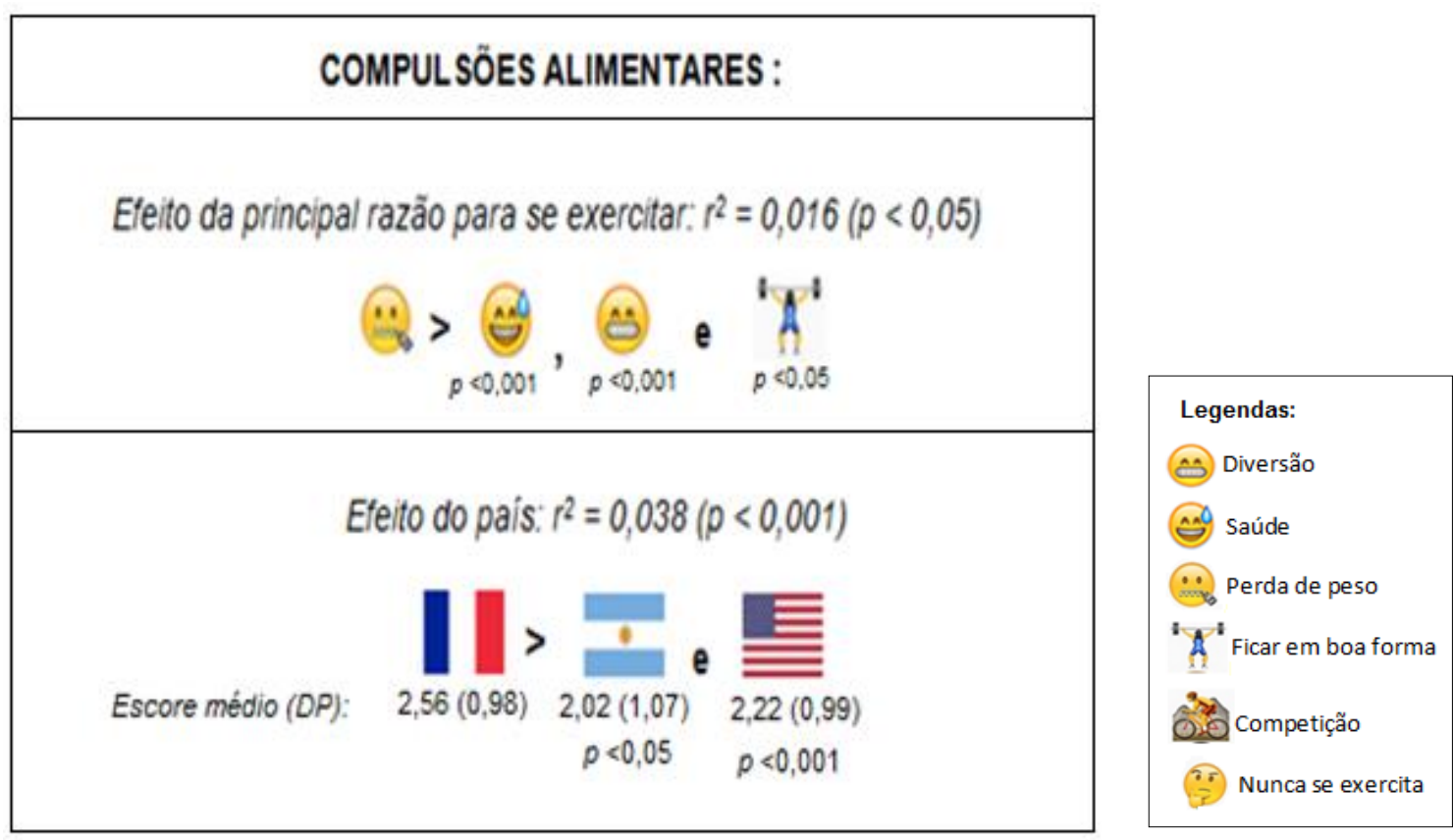

$r^{2}: 0,01=$ pequeno; $\geq 0,09=$ médio; $\geq 0,25=$ grande

O escore médio de compulsões alimentares foi maior entre as francesas do que entre argentinas e estadunidenses - para as brasileiras, não houve diferença em relação aos demais países. Não houve efeito da interação país e razão para se exercitar. Importante destacar que $11,3 \%$ da amostra $(n=127)$ responderam que as compulsões ocorrem "frequentemente", e 1,2\% (n=14) respondeu "quase diariamente".

De qualquer forma, as compulsões alimentares foram mais frequentes quando a principal razão para se exercitar foi "perda peso", do que quando os exercícios eram feitos por "diversão", "saúde" ou "ficar em boa forma" $\left(r^{2}=0,016\right)$. Dietas e restrição têm uma forte relação com as compulsões, pois, normalmente, a restrição leva aos excessos alimentares (ALVARENGA et al., 2015; MENNUCCI et al., 2015), desta forma, analisou-se a presença de dietas e restrições alimentares de acordo com a frequência de compulsões entre as universitárias - Quadro 14. 
Quadro 14. Frequência de dietas e restrições alimentares de acordo com a frequência de compulsões alimentares.

\begin{tabular}{|c|c|c|}
\hline Compulsão & Dieta/Restrição & N (\%) \\
\hline \multirow{3}{*}{ "Quase diariamente" } & "Quase sempre" & \\
\cline { 2 - 3 } & Dieta & $04(0,36)$ \\
\cline { 2 - 3 } & Restrição & $08(0,71)$ \\
\hline \multirow{3}{*}{ "Quase diariamente" } & "Quase sempre" ou "frequentemente" & \\
\cline { 2 - 3 } & Dieta & $05(0,45)$ \\
\cline { 2 - 3 } & Restrição & $11(0,98)$ \\
\hline \multirow{2}{*}{ "Quase diariamente" } & "Quase sempre" ou "frequentemente" & \\
\cline { 2 - 3 } & Dieta & $69(3,91)$ \\
\cline { 2 - 3 } & Restrição & $69,13)$ \\
\cline { 2 - 3 }
\end{tabular}

Nota: Para compulsão alimentar, a resposta "quase diariamente" representa a pior atitude (maior frequência de compulsões), seguida da resposta "frequentemente". Para a dieta e restrição alimentar, a pior atitude é a resposta "quase sempre", e em segundo lugar, "frequentemente".

Pode-se observar que as restrições e dietas ocorrem em conjunto com as compulsões. Destaca-se que $6,13 \%(n=69)$ responderam "frequentemente" ou "quase sempre/diariamente" para dietas e compulsões alimentares; e que 3,91\% $(n=44)$ responderam "frequentemente" ou "quase sempre/diariamente" para restrições e compulsões alimentares.

No mesmo raciocínio, a razão para se exercitar foi analisada com relação aos vômitos intencionais, houve efeito da principal razão para se exercitar (Quadro 15). 
Quadro 15. Efeito da principal razão para se exercitar sobre os vômitos intencionais após as refeições, com o objetivo de perder de peso.

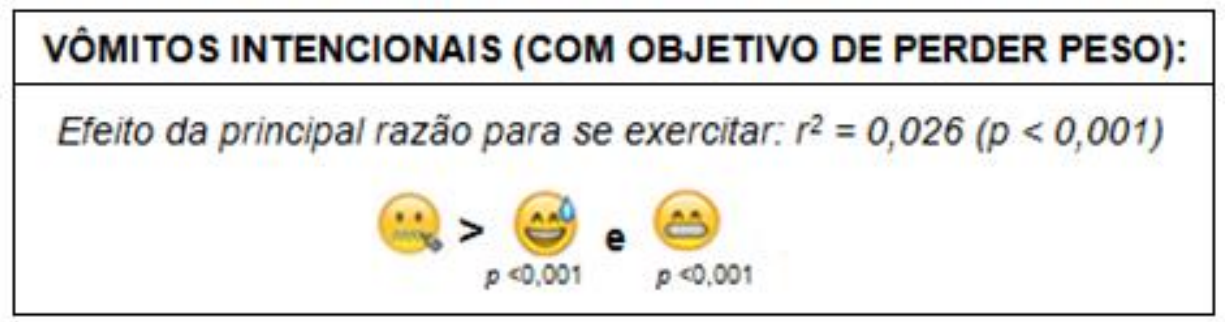

Legendas:

Principal raz̃õo para se exercitar:

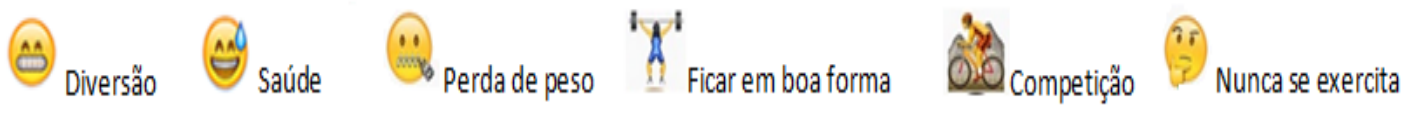

r2: 0,01 = pequeno; $\geq 0,09=$ médio; $\geq 0,25$ = grande

A prática de vômitos intencionais após as refeições com o propósito de perder peso foi diferente apenas de acordo com a principal razão para se exercitar $\left(r^{2}=\right.$ 0,026), sem efeito do país ou interação: para a razão "perda de peso", a frequência foi maior do que para "saúde" e "diversão" $-0,4 \%$ das mulheres $(n=4)$ responderam "quase diariamente" para a frequência de vômitos intencionais.

Portanto, os comportamentos alimentares inadequados como prática de dietas, vômitos intencionais (independentemente do país) e compulsões alimentares foram mais frequentes entre as mulheres que faziam exercícios com objetivo de perder peso - dados que corroboram a segunda hipótese deste estudo.

$O$ peso e estado nutricional destas mulheres pode ter algum efeito nestas práticas, assim devem ser considerados na análise. Pode-se observar na Tabela 10 o peso corporal e o IMC médio das universitárias de acordo com o país. 
Tabela 10. Peso corporal atual e IMC das universitárias $(n=1117)^{\star}$.

\begin{tabular}{|c|c|c|}
\hline País & $\begin{array}{l}\text { Peso }(\mathbf{k g}) \\
\text { Média }(D P)\end{array}$ & $\begin{array}{c}\text { IMC }\left(\mathbf{k g} / \mathbf{m}^{2}\right) \\
\text { Média; mediana }(D P)\end{array}$ \\
\hline Argentina & $58,2(9,57)$ & 21,$9 ; 21,7(3,35)$ \\
\hline Brasil & $63,7(12,68)^{a}$ & 22,$5 ; 21,9(3,37)$ \\
\hline$E^{\prime * *}$ & $59,5(9,90)$ & 22,$0 ; 21,5(3,29)$ \\
\hline França & $58,2(7,02)$ & 21,$0 ; 20,7(2,24)^{b}$ \\
\hline
\end{tabular}

*Das 1.126 mulheres da amostra, nove não responderam à variável peso atual e/ou altura. ${ }^{* \star} E U A=$ Estados Unidos da América. $\mathrm{a}=$ significativamente maior do que a Argentina $(p<0,001)$, França $(p<0,001)$ e EUA $(p<0,001)$; b = significativamente menor do que a Argentina $(p<0,05)$, Brasil $(p<0,001)$ e EUA $(p<0,05)$.

As brasileiras apresentaram maior média de peso corporal, e as francesas apresentaram menor média de IMC. Desconsiderando o desvio padrão, a média de IMC variou de 21,0 a $22,5 \mathrm{~kg} / \mathrm{m}^{2}$, valores classificados pela WHO (2010) como "eutrofia".

Analisou-se, posteriormente, a classificação do estado nutricional das universitárias (Tabela 11), bem como a presença de associação do estado nutricional com o país e com a principal razão para se exercitar (Quadro 16).

Tabela 11. Distribuição das universitárias $(n=1117)^{*}$ dos quatro países quanto ao estado nutricional.

\begin{tabular}{lcc|cc|cc|cc}
\hline \multirow{2}{*}{ Estado nutricional } & \multicolumn{2}{c|}{ Argentina } & \multicolumn{2}{c|}{ Brasil } & \multicolumn{2}{c|}{ EUA } & \multicolumn{2}{c}{ França } \\
\cline { 2 - 10 } & $\mathbf{N}$ & $\%$ & $\mathbf{N}$ & $\%$ & $\mathbf{N}$ & $\%$ & $\mathbf{N}$ & $\%$ \\
\hline Baixo peso & 26 & 10,3 & 37 & 10,3 & 22 & 9,4 & 32 & 11,8 \\
\hline Eutrofia & 197 & 78,2 & 248 & 69,3 & 180 & 76,6 & 224 & 82,3 \\
\hline Sobrepeso & 23 & 9,1 & 63 & 17,6 & 25 & 10,6 & 16 & 5,9 \\
\hline Obesidade grau I & 03 & 1,2 & 08 & 2,2 & 07 & 3,0 & - & - \\
\hline Obesidade grau II & 02 & 0,8 & 02 & 0,6 & - & - & - & - \\
\hline Obesidade grau III & 01 & 0,4 & - & - & 01 & 0,4 & - & - \\
\hline TOTAL & 252 & 100 & 358 & 100 & 235 & 100 & 272 & 100
\end{tabular}

*Das 1.126 mulheres da amostra, nove não responderam à variável peso atual e/ou altura. 
Quadro 16. Associações entre o estado nutricional e o país, e entre o estado nutricional e a principal razão para se exercitar.

\begin{tabular}{|c|c|}
\hline \multicolumn{2}{|c|}{ Associações com o estado nutricional: } \\
\hline PAíS $(0<0,001)$ : & RAZÃO $(0<0,05)$ : \\
\hline $\begin{array}{l}\text { V. Sobrepeso (residuo ajustado }=4,5 \text { ) } \\
\text { Eutrofia (residuo ajustado }=-3,6 \text { ) }\end{array}$ & $\begin{array}{l}\text {.1. Obesidade grau II (residuo ajustado }=2,9 \text { ) } \\
\text { Baixo peso (residuo ajustado }=-3,0 \text { ) }\end{array}$ \\
\hline $\begin{array}{l}\uparrow \text { Eutrofia (residuo ajustado }=2,8 \text { ) } \\
\downarrow \text { Sobrepeso (residuo ajustado }=-3,3 \text { ) }\end{array}$ & $\begin{array}{l}\uparrow \text { Baixo peso (residuo ajustado }=3,2 \text { ) } \\
\text { Eutrofia (residuo ajustado }=-2,1 \text { ) }\end{array}$ \\
\hline
\end{tabular}

$\uparrow:$ Resíduo ajustado $\geq 2$ (frequência maior do que esperada). $\downarrow$ Resíduo ajustado $\leq-2$ (frequência menor do que a esperada).

A associação com o estado nutricional ocorreu apenas para brasileiras e francesas $(p<0,001)$. No Brasil houve uma frequência menor mulheres eutróficas e maior com sobrepeso; enquanto na França foi observado o contrário.

O estado nutricional também foi associado à principal razão para se exercitar $(p<0,05)$ : para aquelas que se exercitam para "perder peso", a frequência de obesidade grau II foi maior do que o esperado e a de "baixo peso", menor; enquanto entre aquelas que nunca se exercitam, a frequência de "baixo peso" foi maior do que a esperada e a de "eutróficas" foi menor (Quadro 16).

A fim de complementar a interpretação da associação das referidas categorias de estado nutricional com a razão "perda de peso", especificamente, analisou-se também o estado nutricional das universitárias que responderam esta opção como principal razão para exercício (Tabela 12). 
Tabela 12. Estado nutricional das universitárias que responderam "perda de peso" como principal razão para exercício $(n=212)$, de acordo com o país.

\begin{tabular}{|c|c|c|c|c|c|c|}
\hline \multirow{2}{*}{ Estado nutricional } & \multirow{2}{*}{$\begin{array}{l}\text { Argentina } \\
\text { (N) }\end{array}$} & \multirow{2}{*}{$\begin{array}{l}\text { Brasil } \\
(\mathrm{N})\end{array}$} & \multirow{2}{*}{$\begin{array}{l}\text { EUA } \\
(\mathrm{N})\end{array}$} & \multirow{2}{*}{$\begin{array}{c}\text { França } \\
\text { (N) }\end{array}$} & \multicolumn{2}{|c|}{ TOTAL } \\
\hline & & & & & $\mathbf{N}$ & $\%$ \\
\hline Baixo peso & - & 05 & 02 & 03 & 10 & 4,72 \\
\hline Eutrofia & 40 & 32 & 47 & 50 & 169 & 79,72 \\
\hline Sobrepeso & 07 & 04 & 11 & 03 & 25 & 11,79 \\
\hline Obesidade grau I & 01 & 01 & 02 & - & 04 & 1,89 \\
\hline Obesidade grau II & 02 & 01 & - & - & 03 & 1,41 \\
\hline Obesidade grau III & - & - & 01 & - & 01 & 0,47 \\
\hline
\end{tabular}

${ }^{*}$ Relativo ao total de mulheres em cada país.

A "perda de peso" foi citada como principal razão para exercício por 18,8\% $(n=212)$ da amostra, todavia, apenas 3,77\% (n=08) destas 212 jovens apresentavam obesidade (graus I, II ou III) e 11,79\% ( $n=25)$ sobrepeso - na amostra, 151 mulheres (13,5\% do total de respostas) foram classificadas com sobrepeso ou obesidade, 849 eutróficas (76\%), 117 com baixo peso (10,5\%). Assim, das demais jovens que responderam "perda de peso" como principal razão para exercício, mais do que $80 \%$ era eutrófica ou apresentava baixo peso, ou seja, do ponto de vista de saúde, fazer exercício para "perder peso", não se justifica.

Realizou-se ainda uma ANACOR múltipla entre o país, o estado nutricional e a principal razão para se exercitar (Figura 9). 


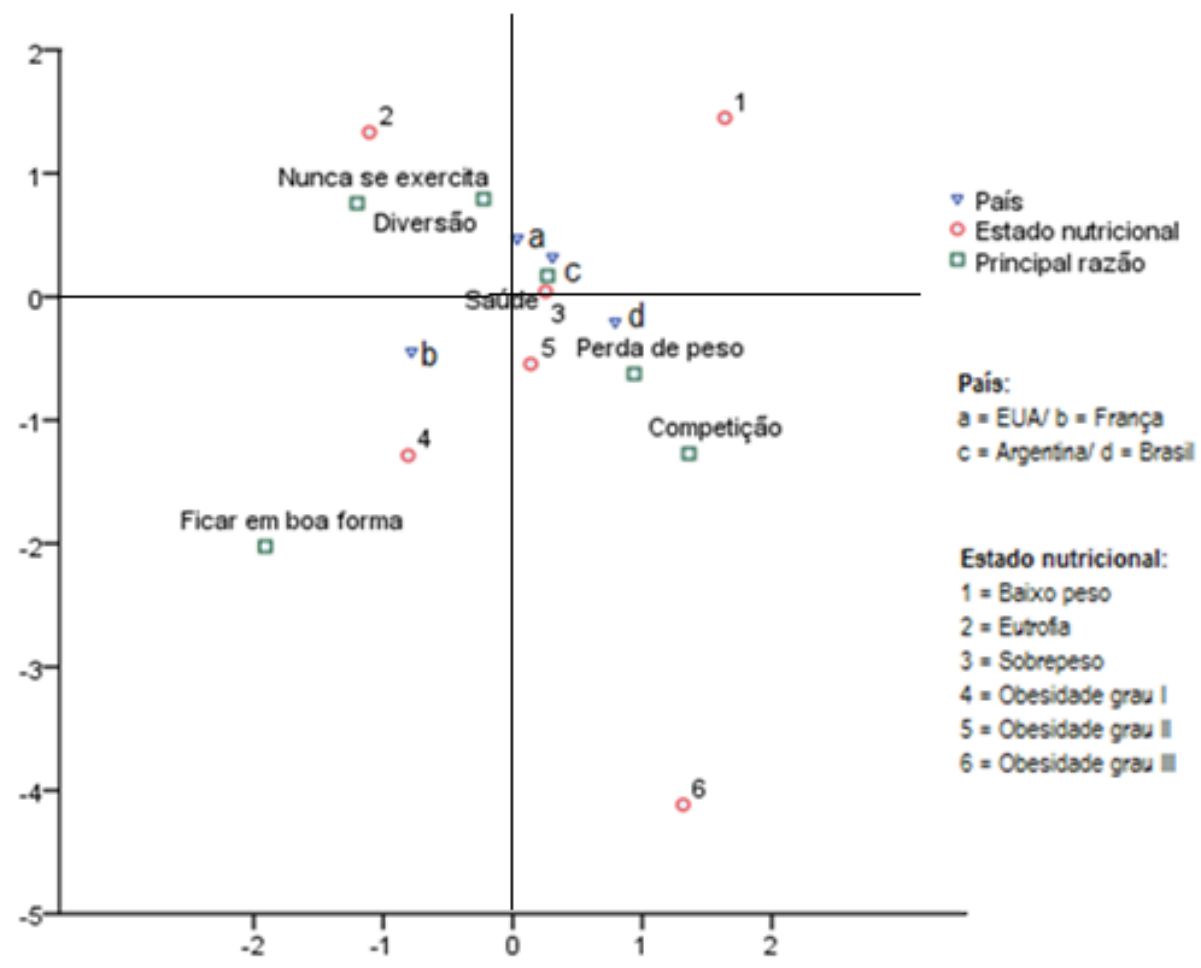

Figura 9. Análise de correspondência do estado nutricional, país e a principal razão para se exercitar entre as universitárias $(n=1.126)$.

São observados diferentes perfis de associação, um formado por mulheres eutróficas que se exercitam por "diversão" (ou que nunca se exercitam); um segundo composto por estadunidenses e argentinas, com sobrepeso ou obesidade grau II, que se exercitam por "saúde", e por último, um perfil de brasileiras que se exercitam principalmente pela "perda de peso".

A resposta para "preocupação com a rotina de exercício" (variável a qual $4,3 \%$ da amostra, $n=48$, respondeu "absolutamente verdadeiro"; maior nos EUA) foi analisada também com relação à principal razão para se exercitar (Quadro 17). 
Quadro 17. Efeito da principal razão para se exercitar, do país e da interação destas variáveis sobre a preocupação com a rotina de exercícios.

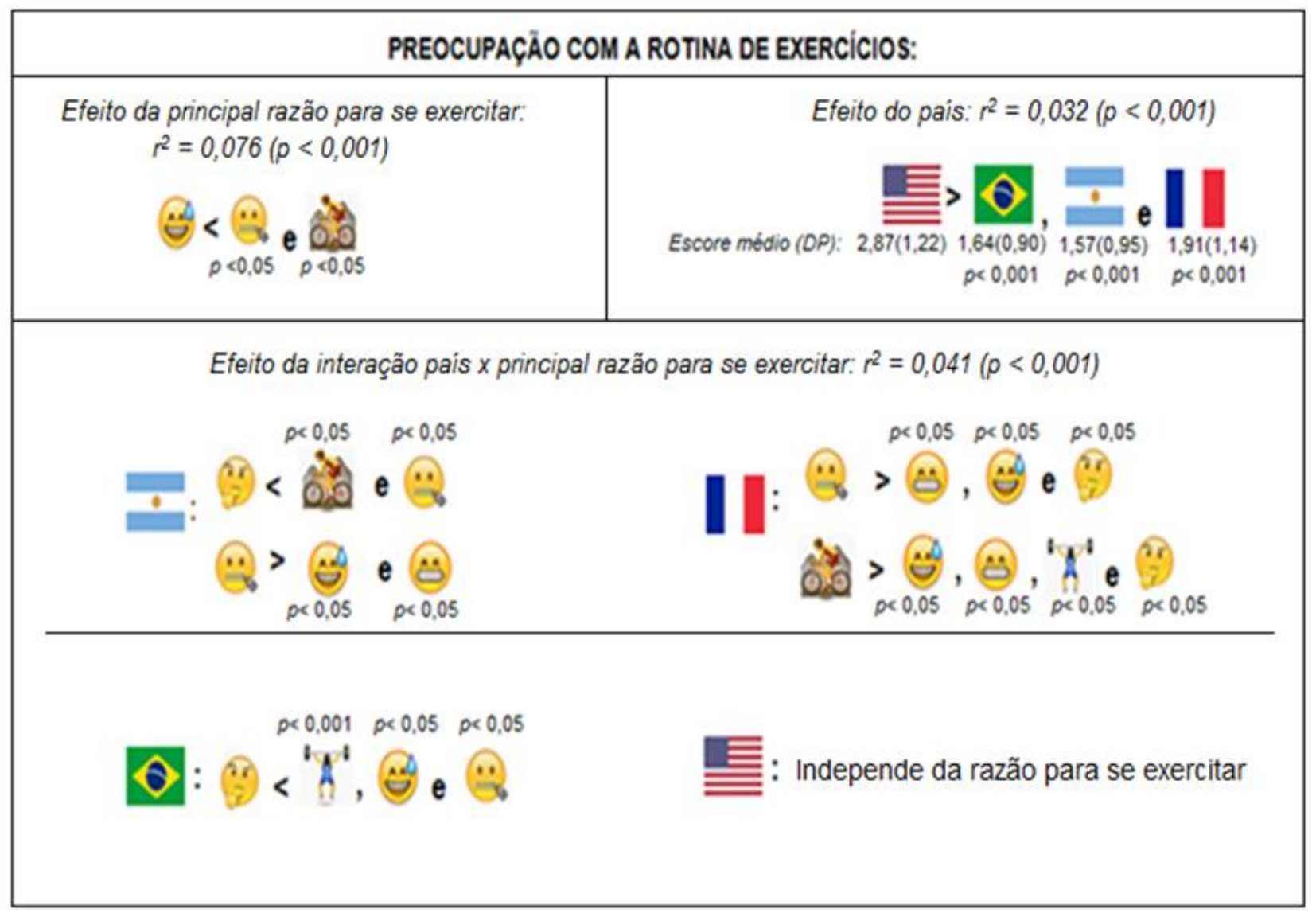

Legendas:

Principal razõo para se exercitar:

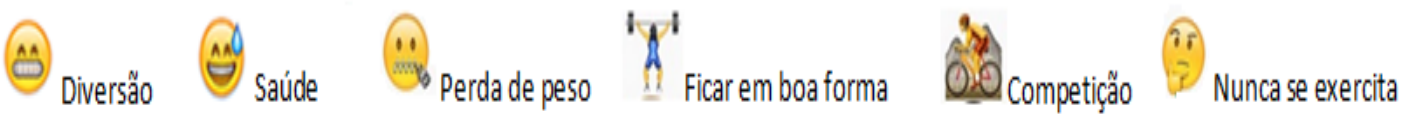

Observou-se efeito do país $\left(r^{2}=0,032\right)$, da razão para se exercitar $\left(r^{2}=0,076\right)$ e da interação destas variáveis $\left(r^{2}=0,041\right)$ sobre a preocupação com a rotina de exercícios - o maior efeito foi da razão para se exercitar. As estadunidenses apresentaram escore maior do que as demais, todavia, a preocupação das estadunidenses foi independente da razão para se exercitar. 
Para as argentinas, a preocupação com a rotina de exercícios daquelas que nunca se exercitam foi menor do que as que se exercitam por "competição" e por "perda de peso" - houve também maior preocupação para aquelas que responderam se exercitar para "perda de peso" do que para "diversão" e "saúde". Para as brasileiras, a preocupação com a rotina de exercícios daquelas que nunca se exercitam foi menor do que as que se exercitam para "ficar em boa forma", por "saúde" e para "perda de peso". Para as francesas, a preocupação das que se exercitam por "competição" foi maior do que por pelas demais razões (exceto para "perda de peso"); além disso, a preocupação para "perda de peso" foi maior do que por "diversão" e "saúde".

Analisou-se também a resposta para "culpa quando não se exercita" com relação à principal razão para se exercitar (Quadro 18$)-13,1 \%$ das mulheres ( $n=$ 148) responderam como "absolutamente verdadeiro" para esta variável.

Quadro 18. Efeito da principal razão para o exercício sobre a culpa por não se exercitar.

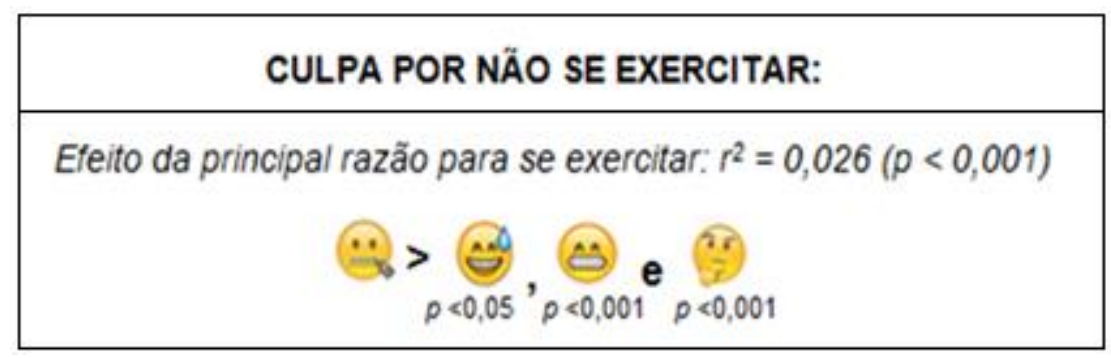

Legendas:

Principal razão para se exercitar:

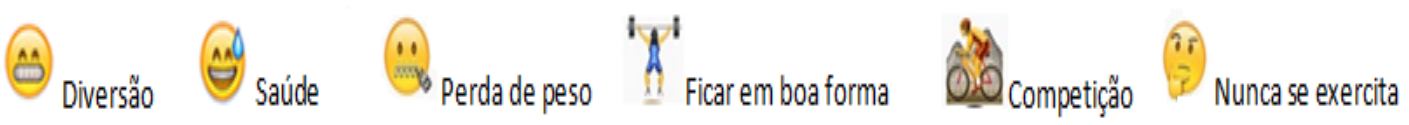

$r^{2}: 0,01=$ pequeno; $\geq 0,09=$ médio; $\geq 0,25=$ grande

A culpa por não se exercitar foi diferente apenas em função da principal razão para o exercício $\left(r^{2}=0,026\right)$ : maior para "perda de peso" do que por "saúde", "diversão" ou nunca se exercitar. Cabe ressaltar que 2,1\% $(n=24)$ das mulheres responderam simultaneamente "absolutamente verdadeiro" (ou seja, a atitude mais 
inadequada) para a preocupação excessiva com exercícios e culpa por não se exercitar. O estado nutricional destas jovens é apresentado na Tabela 13.

Tabela 13. Estado nutricional das universitárias que responderam "absolutamente verdadeiro" para preocupação e culpa relacionadas ao exercício.

\begin{tabular}{lcccccc}
\hline \multirow{2}{*}{ Estado nutricional } & \multicolumn{2}{c}{ Preocupação } & \multicolumn{2}{c}{ Culpa } & \multicolumn{2}{c}{ Preocupação e culpa } \\
\cline { 2 - 7 } & $\mathbf{N}$ & $\%$ & $\mathbf{N}$ & $\%$ & $\mathbf{N}$ & $\%$ \\
\hline Baixo peso & 09 & 18,8 & 14 & 9,5 & 05 & 20,8 \\
\hline Eutrofia & 31 & 64,6 & 108 & 72,9 & 14 & 58,4 \\
\hline Sobrepeso & 07 & 14,6 & 19 & 12,8 & 05 & 20,8 \\
\hline Obesidade grau I & 01 & 2,0 & 04 & 2,7 & - & - \\
\hline Obesidade grau II & - & - & 02 & 1,4 & - & - \\
\hline Obesidade grau III & - & - & 01 & 0,7 & - & - \\
\hline \multicolumn{1}{c}{ TOTAL } & 48 & 100 & 148 & 100 & 24 & 100
\end{tabular}

Observou-se que dentre as mulheres que responderam "absolutamente verdadeiro" para preocupação e culpa (ou ambas) relacionadas ao exercício, menos do que $5 \%$ apresenta obesidade, no máximo $21 \%$ tem sobrepeso, sendo a maioria eutrófica.

Por fim, na análise proposta a este "manuscrito", verificaram-se as respostas das universitárias sobre cirurgias plásticas. O Quadro 19 apresenta os efeitos do país, da razão para se exercitar e da interação destas varáveis sobre a possibilidade de aderir a uma cirurgia plástica. 
Quadro 19. Efeito do país, da principal razão para se exercitar e da interação destas variáveis sobre a possibilidade de realizar uma cirurgia plástica.

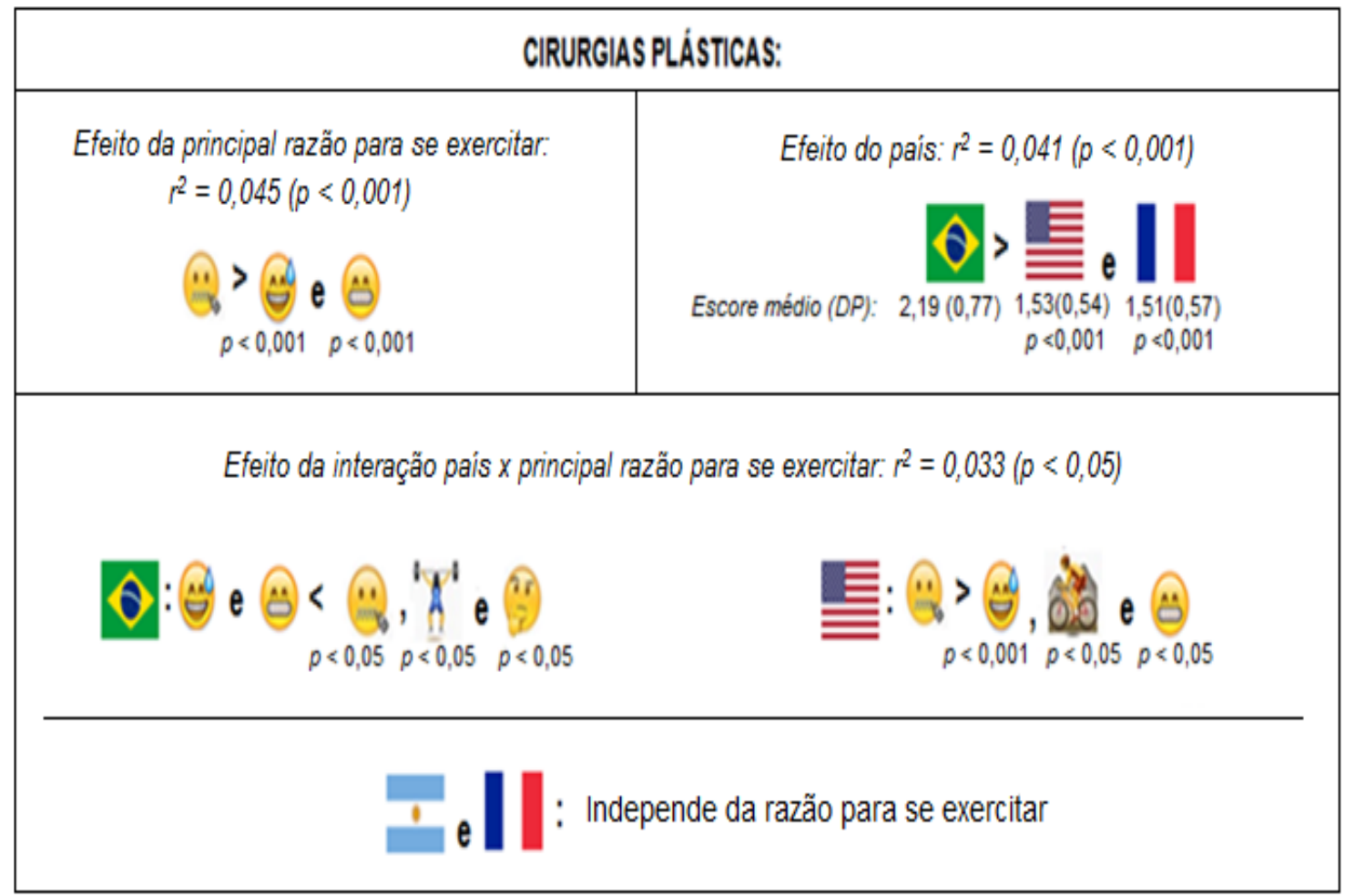

Legendas:

Principal razão para se exercitar:

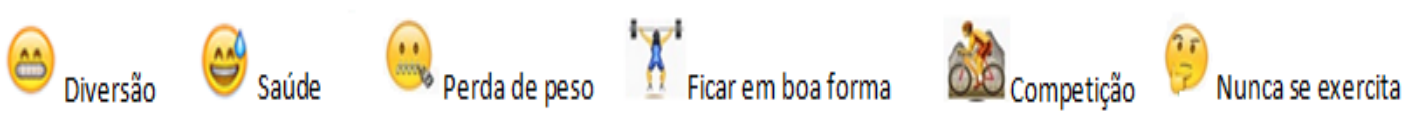
$r^{2}: 0,01=$ pequeno; $\geq 0,09=$ médio; $\geq 0,25=$ grande

O efeito da razão para exercício $\left(r^{2}=0,045\right)$ foi maior do que 0 do país $\left(r^{2}=\right.$ $0,041)$ e da interação $\left(r^{2}=0,033\right)$ : para as que se exercitam principalmente para "perder peso", a possibilidade de uma cirurgia plástica foi maior do que pelas razões "saúde" e "diversão".

No Brasil, a possibilidade de adesão às cirurgias plásticas foi maior do que nos EUA e França. Houve efeito da interação país e razão para exercício para o Brasil - cuja possibilidade de aderir às cirurgias foi menor para as mulheres que se exercitam por "saúde" ou "diversão" do que por "perda de peso", "ficar em boa forma" ou as que nunca se exercitam - e EUA, onde houve maior possibilidade quando os 
exercícios eram feitos para "perder peso" do que por "diversão", "saúde" ou "competição". Para as argentinas e francesas a possibilidade de realizar uma cirurgia plástica não foi diferente em função da razão para se exercitar.

Verificou-se que 26 universitárias (2,3\% do total) já fizeram alguma plástica estética. A Tabela 14 apresenta o estado nutricional destas mulheres.

Tabela 14. Estado nutricional das mulheres que já realizaram cirurgia plástica estética $(n=26)$, de acordo com o país.

\begin{tabular}{lcccc}
\hline Estado nutricional & $\begin{array}{c}\text { Argentina } \\
(\mathbf{N})\end{array}$ & $\begin{array}{c}\text { Brasil } \\
(\mathbf{N})\end{array}$ & $\begin{array}{c}\text { EUA } \\
\mathbf{( N )}\end{array}$ & $\begin{array}{c}\text { França } \\
(\mathbf{N})\end{array}$ \\
\hline Baixo peso & - & 01 & 02 & - \\
\hline Eutrofia & 05 & 09 & 02 & - \\
\hline Sobrepeso & - & 05 & 01 & - \\
\hline Obesidade grau I & - & - & - & - \\
\hline Obesidade grau II & - & - & - & - \\
\hline Obesidade grau II & - & - & - & - \\
\hline \multicolumn{1}{c}{ TOTAL } & 05 & 15 & $05^{*}$ & 0
\end{tabular}

Nota: Mais uma universitária estadunidense já realizou cirurgia plástica, entretanto, esta não respondeu à variável peso atual e/ou altura, portanto, neste país o total corresponde a seis mulheres.

Entre as mulheres que já realizaram alguma cirurgia plástica estética, a maior parte (aproximadamente 65\%) era eutrófica, 24\% tinham sobrepeso e nenhuma delas era obesa. Aparentemente, o maior número de cirurgias foi observado no Brasil, contudo, devido à baixa frequência de mulheres que já realizaram cirurgias em cada país, não houve diferença estatística entre eles.

Foi analisada também a frequência de universitárias que responderam que "nunca consideraria" realizar uma cirurgia plástica estética (Tabela 15). 
Tabela 15. Universitárias que nunca considerariam realizar uma cirurgia plástica estética $(n=442)$, segundo o país.

\begin{tabular}{lcc}
\hline \multicolumn{1}{c}{ País } & $\mathbf{N}$ & (\% das + no país) \\
\hline Argentina & 95 & 37,4 \\
\hline Brasil & 63 & 17,5 \\
\hline EUA & 141 & 59,2 \\
\hline França & 143 & 52,2 \\
\hline TOTAL & 442 &
\end{tabular}

Entre as brasileiras, a frequência de respostas "nunca consideraria" realizar uma cirurgia plástica foi menor do que nos demais países $(p<0,05)$ - as argentinas também apresentaram menor frequência do que as estadunidenses.

\subsubsection{Discussão}

Ser do sexo feminino explicou as diferenças entre as questões exploradas neste estudo, para uma série de variáveis. Mesmo assim, dentre as mulheres dos quatro países, questões diferentes emergiram.

No entendimento da relação das variáveis com o exercício, encontrar que a principal razão para fazê-lo foi "saúde" pode parecer bastante "adequado", mas a exploração dos resultados traz o questionamento sobre o que entra no conceito ou na resposta "saúde" das universitárias - em tempos nos quais a magreza se mistura com a "saúde", especialmente para as mulheres (COSTA e VENÂNCIO, 2004; SCHWARTZ e BROWNELL, 2004; ALVES e CARVALHO, 2010; LEITZKE et al., 2014; TEIXEIRA et al., 2015).

A resposta se exercitar para "perda de peso" foi apontada por menos de $20 \%$ da amostra (mais frequente entre as estadunidenses e menos entre as brasileiras), mas a análise da relação desta resposta com comportamentos disfuncionais voltados para controle/perda de peso mostrou que aquelas que apontam esta razão fazem mais restrições alimentares, se preocupam mais com a comida e como ela pode afetar a aparência, fazem mais dietas, se preocupam mais sobre ter excesso 
de peso, têm mais compulsões alimentares e vômitos intencionais, têm mais preocupação com a rotina de exercícios e mais culpa por não se exercitar.

Pode-se pensar que quem faz exercício porque quer perder peso faz qualquer coisa em busca deste objetivo (perder peso), como dieta, restrição, e até vomitar. Novamente não se pode falar em relações causais. Lembrando que quem faz exercício para "perder peso" é mais insatisfeito com sua IC (conforme apontado no manuscrito 1), e também tem mais comportamentos disfuncionais, como os aqui analisados. Como discutido no manuscrito 1, exercitar-se para "perder peso" não é uma "boa motivação", nem mesmo para quem tem excesso de peso.

Sabe-se que fazer dietas é muito comum, especialmente entre jovens. ALVARENGA et al. (2013) encontraram entre universitárias brasileiras ( $n=2.489$ ) que $40,7 \%$ faziam regime para emagrecer; $35,6 \%$ usavam dieta ou métodos compensatórios e 23,9\% pulavam refeições. Na avaliação de universitárias argentinas ( $n=83$ ), CRUZ et al. (2011) observaram que $24 \%$ delas faziam dietas. Entre franceses ( $n=3457,2.201$ mulheres), TAVOLACCI et al. (2015) verificaram que $26,3 \%$ já haviam feito dieta pelo menos uma vez e $25 \%$ tinham medo de perder o controle sobre a quantidade de comida ingerida. E em estudo com universitárias estadunidenses ( $n=560$ ), ACKARD et al. (2002) encontraram que a frequência de dietas foi positivamente associada à baixa autoestima, depressão, medo, insegurança e, inclusive, preocupação com a rotina de exercícios físicos.

Colocar-se em movimento obviamente implica em gasto calórico, que, condições metabólicas normais, e associado a um desequilíbrio na relação dietaexercício físico pode levar a uma perda do peso corporal, assim, pode-se dizer - de certa forma - que "a atividade física emagrece". O problema é agregar valores extrínsecos para promover um discurso ideológico no qual exercício tem como função "emagrecer" ou queimar calorias, no qual beleza é sinônimo de magreza e corpo "sarado" é sinônimo de saúde (ALVES e CARVALHO, 2010).

Para mulheres a prática de exercícios pode se tornar um comportamento de mudança corporal orientado à perda de peso; mas, quando a finalidade é puramente estética, a prática de exercícios pode trazer sentimentos de preocupação, culpa (ACKARD et al., 2002; TEIXEIRA et al., 2015; CARVALHO, 2016; HURST et al., 
2017) - e comportamentos disfuncionais, que podem até desencadear um transtorno alimentar (restrição, compulsão e purgação).

Assim, embora a razão "saúde" tenha sido a mais frequentemente mencionada nos quatro países como a principal para se exercitar, pode-se concluir que algumas atitudes inadequadas em relação à alimentação e ao corpo estavam presentes neste grupo de jovens, e associadas ao uso do exercício "para perder peso".

Avaliando um amostra probabilística de 2.380 universitários brasileiros com idade entre 18 e 35 anos, (51\% do sexo feminino), GUEDES et al. (2012b) encontraram que, para as mulheres, as principais razões para exercício eram controle de peso corporal e aparência física.

Tais achados corroboram o que foi discutido por ALVES e CARVALHO (2010) a respeito das armadilhas do discurso da atividade física e saúde: "deve-se fazer atividade física para se ter saúde". Quais os pressupostos que fundamentam e justificam o uso do verbo dever? Trata-se de uma mensagem que agrega imperativos morais, éticos e estéticos, uma motivação introjetada - definida como uma motivação externa, associada à expectativa de aprovação de si mesmo e dos outros, de evitar a ansiedade, e melhorar os aspectos relacionados ao ego e orgulho próprio (LEGNANI, 2009; VICENTE JR et al., 2015) - na qual o indivíduo internaliza ideias externas de "cuidados com saúde", a fim de evitar a culpa caso não o faça (ALVES e CARVALHO, 2010; HUST et al., 2015).

Segundo HUST et al. (2015) a motivação introjetada é mais prejudicial às mulheres, especialmente quando relacionada aos comportamentos de mudança corporal orientados à perda de peso, uma vez que as mulheres sofrem maior pressão, sentem mais culpa e vergonha de aspectos corporais do que os homens. A saúde passa, neste sentido, a ser um guarda-chuva simbólico no qual tudo cabe: ter saúde passa a ser igualmente cuidar da forma, do peso, da aparência, da dieta, da manutenção da beleza e da juventude (EDMONDS, 2007; FERREIRA, 2010).

Pode-se antever, a partir destes resultados, que explorar a motivação para a prática de atividades físicas é muito importante (TEIXEIRA et al., 2015), não apenas avaliar se a prática existe e com que frequência - foco de muitos trabalhos e 
intervenções. É preciso considerar que nem toda prática de atividade física é saudável (e nem inferir que uma pessoa preocupada com sua rotina de exercícios pode ser algo positivo) muito menos ser culpado por não se exercitar - "motivação" às vezes induzida por profissionais de saúde. Assim, os comportamentos associados, motivações e preocupações devem ser avaliados (ALVARENGA, 2008).

A análise do estado nutricional destas universitárias elucidou que atitudes disfuncionais relacionadas ao exercício são mais frequentes entre as eutróficas, como fazê-los principalmente para reduzir o peso corporal (maior frequência entre estadunidenses), bem como maior preocupação e culpa relacionada ao exercício.

A busca pela magreza e a preocupação com o aumento do peso corporal drive for thinness -, representam aspectos centrais da imagem corporal feminina, $e$ muitas vezes, independem do estado nutricional (McCREARY e SASSE, 2000; NUÑEZ, 2007; GONÇALVES, 2008; CARVALHO, 2016). Estar acima do peso tido como "ideal" parece ser uma preocupação considerável de mulheres de todas as faixas etárias (independente do peso atual), assim estas têm sido tomadas pela indústria enquanto um rico e crescente mercado. Cada vez mais produtos e discursos são criados para abarcar suas "necessidades" como consumir a academia, a dieta, o emagrecedor que seja considerado melhor, para o resultado em busca da "estética da magreza" (LEITZKE et al., 2014).

Com relação às cirurgias plásticas, encontrou-se também que a possibilidade de realizá-las foi maior para aquelas que responderam se exercitar para "perder peso".

O achado de mais respostas frequentes no Brasil do que nos EUA (e França) é parcialmente congruente com os últimos dados estatísticos mundiais do ISAPS (2017), pois os EUA são os campeões mundiais em número de cirurgias plásticas e o Brasil é o segundo lugar. Em relação às estadunidenses, este estudo encontrou que a frequência de jovens que nunca considerariam realizar uma cirurgia plástica foi maior do que a das brasileiras e argentinas, resposta surpreendente, uma vez que diverge bastante da posição de liderança mundial dos EUA quanto às cirurgias plásticas. 
Os dados do ISAPS (2017) mostraram também que o número de procedimentos realizados por mulheres em 2015 foi de 18.561 .509 (cerca de 8,1 milhões de cirurgias plásticas e 10,4 milhões de procedimentos estéticos), o que corresponde a $85,6 \%$ do total. Curiosamente, segundo o ISAPS (2017), o procedimento mais realizado entre as mulheres é o aumento de mamas (silicone) que não tem relação com perder peso -, mas o segundo é a lipoaspiração seguida de blefaroplastia, abdominoplastia e rinoplastia.

A imagem da mulher se justapõe à de beleza. Cultivar a beleza, a boa forma e a "saúde" apontam para uma ideologia que se impõe como um verdadeiro estilo de "bem-estar" (NOVAES, 2006; CUCH, 2013), numa tríade da perfeição física: beleza, saúde e juventude (GOELLNER, 2003; NOVAES, 2010). O que encarcera a mulher ao mito do embelezamento não é o fato de ela desejar cuidar de si e da sua aparência, mas, sim, as representações que este mito cria, de forma que ela se sinta invisível ou incorreta se não atingir os padrões estipulados (GOELLNER, 2003). Neste contexto de maior cobrança às mulheres quanto ao atendimento dos inatingíveis padrões de beleza, os estudos sobre imagem corporal, transtornos alimentares, comportamentos alimentares inadequados, cirurgias plásticas estéticas são predominantemente desenvolvidos com amostra feminina (NUÑES, 2007; ALVARENGA et al., 2010a; CAMPANA et al., 2012; COELHO et al., 2015; KONG e HARRIS, 2015; SWAMI et al., 2015; ASHIKALI et al., 2016).

Mas, no cenário atual, no qual comer se tornou o palco de uma luta moral e estética (MENNUCCl et al., 2015), os comportamentos compensatórios - dietas, restrições alimentares, exercícios físicos excessivos, vômitos intencionais - com objetivo de evitar ganho de peso após a ingestão de alimentos deixam de ser práticas restritas ao contexto dos transtornos alimentares e atingem também a população não clínica (WARDLE et al., 2004; LePAGE et al., 2008).

Os resultados apresentados neste manuscrito evidenciam que, para estas universitárias, a prática de dietas, vômitos intencionais e culpa por não se exercitar independem do país. Para as demais variáveis analisadas, destacam-se efeitos dos países: as argentinas tiveram maior escore para restrições alimentares; as brasileiras apresentaram maior peso corporal, maior preocupação com excesso de 
peso e mais chances de realizar uma cirurgia plástica; as estadunidenses foram as mais preocupadas com a rotina de exercícios; por último, as francesas, apresentaram menor IMC, maior preocupação com a comida e como ela afeta a aparência (mais preocupadas do que as estadunidenses e argentinas, mas não diferiram das brasileiras) e maior escore para compulsões alimentares. Por este panorama, não é possível falar em comportamentos mais ou menos disfuncionais, eles foram frequentes nos quatro países, de maneiras diferentes.

De qualquer forma, o fato de haver mais restrições entre as argentinas remete a uma realidade descrita de preocupação com comida e aparência corporal, num país onde os ideais de beleza e magreza têm demasiada influência na economia, e no qual há elevada frequência de transtornos alimentares (MEEHAN e KATZMAN, 2001; PELLICER, 2011). Já o dado sobre as francesas e as brasileiras apresentarem maiores escores na questão "Eu estou preocupado sobre o que eu como e de que modo isto afeta a minha aparência" pode ter significados diferentes entre os países, uma vez que, tradicionalmente, os franceses dedicam mais tempo e atenção às refeições (ROZIN et al., 2003; ROZIN et al., 2011) e, pelos achados deste estudo, a preocupação das brasileiras quanto à comida parece estar mais relacionada às possíveis "consequências" sobre as formas corporais. Quanto às compulsões alimentares entre as francesas, o dado é divergente do que a literatura descreve a respeito representação das refeições neste país - comer é um momento de comunhão, de prazer (GOLDENBERG, 2011), - não se pode descartar, no entanto, a possibilidade de um viés de interpretação da questão.

Observando também um dos perfis de associação obtidos na ANACOR (Figura 9) é interessante pensar que as eutróficas se exercitam mais por "diversão" - mulheres com excesso de peso não poderiam ter esta opção como sua principal razão para se exercitar?

Já para as brasileiras o resultado de maior peso corporal pode parecer justificativa para "maior preocupação com excesso de peso", e o resultado da ANACOR de se exercitar principalmente pela "perda de peso". No entanto, não se pode considerar preocupação com excesso de peso seja exatamente algo positivo, mesmo para aqueles com excesso! Ter maior preocupação/insatisfação, seja com 
a IC (conforme discutido no manuscrito 1) ou com peso, não levam exatamente a comportamentos mais saudáveis. Pelo contrário, neste estudo esta razão para se exercitar se associou a comportamentos disfuncionais.

Pode-se concluir que a razão para se exercitar está relacionada com a preocupação e culpa com atividade física e atitudes alimentares inadequadas (além da consideração de fazer cirurgia plástica) para mulheres universitárias destes quatro países.

\subsection{RESULTADOS PARA O MANUSCRITO 3}

Pergunta de partida: "De que maneira se dá a relação entre a razão para se exercitar e o estado nutricional, preocupação com a rotina de exercício, com a comida e com a aparência entre universitários do sexo masculino de quatro países?"

Os universitários do sexo masculino $(n=569)$ representavam $33,6 \%$ da amostra do estudo. Entre eles, os argentinos apresentaram média de idade superior aos demais, que não diferiram entre si.

Foi observada associação entre o país e a principal razão para exercício ( $p$ $<0,001)$. A análise da principal razão para se exercitar, entre os homens argentinos, brasileiros, estadunidenses e franceses apontou semelhanças e diferenças (Quadro 20). 
Quadro 20. Hierarquia da principal razão para se exercitar, segundo o país.

\begin{tabular}{|c|c|c|c|c|}
\hline $\begin{array}{l}\text { Principal razäo para } \\
\text { se exercitar }\end{array}$ & ARGENTINA & BRASIL & EUA & FRANÇA \\
\hline $1^{8}$ & $\begin{array}{l}\text { Residuo ajustado: } 2,6 \\
(52,0 \%)\end{array}$ & $\begin{array}{r}\hat{\theta}(29,1 \%) \\
\text { Residuo ajustado: }-2,4\end{array}$ & $\begin{array}{r}\text { Residuo sjustado: } 3,7 \\
(48,8 \%)\end{array}$ & Residuo sjustado: 4,1 \\
\hline $2^{9}$ & (c) $(28,0 \%)$ & Residuo sjustado: 4,0 & $\begin{array}{c}\text { Residuo ajustado: }-3,5 \\
(14,7 \%)\end{array}$ & $\begin{array}{l}\text { Residuo sjustado: }-2,4 \\
(27,5 \%)\end{array}$ \\
\hline $3^{8}$ & $\therefore(8,0 \%)$ & (A) $(24,2 \%)$ & 'A' & 'A' \\
\hline $4^{8}$ & $(8,0 \%)$ & Residuo ajustado: 2,5 & (3) $(8,5 \%)$ & Residuo sjustado: 3,5 \\
\hline $5^{\mathrm{a}}$ & 20.0 $(2,0 \%)$ & . $_{6}(6,3 \%)$ & की & $(3 \%)$ \\
\hline $6^{\theta}$ & Residuo ajustado: $-3,0$ & Residuo ajustado: $-2,8$ & . $_{6}(7,0 \%)$ & Residuo ajustado: $-2,7$ \\
\hline
\end{tabular}

Legendas:

Principal razão para se exercitar:

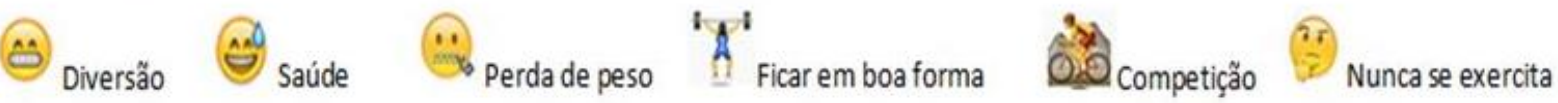

: Resíduo ajustado $\leq-2$ (frequência menor do que a esperada). Ґ: Residuo ajustado $\geq 2$ (frequência maior do que a esperada).

Mais universitários responderam "saúde" na Argentina e EUA, do que Brasil e França. Também na Argentina a frequência de respostas "ficar em boa forma" foi menor que no Brasil; e a resposta "diversão" foi maior na França e menor nos EUA.

Assim como para as mulheres, a "saúde" foi a razão mais citada pelos argentinos, brasileiros e estadunidenses como a principal razão para exercício, enquanto para os franceses, a principal foi a "diversão" ("saúde" foi a segunda). A razão "ficar em boa forma" foi a segunda mais frequente entre os brasileiros, a terceira entre franceses e estadunidenses, e a última entre os argentinos. A "competição" foi mais citada pelos franceses do que pelos demais. 
A análise das 11 opções de respostas quanto ao "principal tipo de exercício", apontou que a soma dos três mais frequentes representam mais do que $60 \%$ das repostas em cada país; e houve diferença entre os países $(p<0,001)$ - Quadro 21.

Quadro 21. Frequências dos três principais tipos de exercícios de acordo com o país.

\begin{tabular}{|c|c|c|c|c|}
\hline $\begin{array}{l}\text { Principais } \\
\text { exercicios }\end{array}$ & ARGENTINA & BRASIL & EUA & FRANÇA \\
\hline $1^{8}$ & $\dot{\gamma}_{(18 \%)} \mathrm{e} \boldsymbol{X}_{(18 \%)}$ & $\hat{\boldsymbol{X}}_{\text {Residuo ajustado: }}(23,8 \%)$ & $\int_{(29,5 \%)}$ & Residuo ajustado: 4,9 \\
\hline $2^{\mathrm{a}}$ & ${ }_{\text {Residuo ajustado: } 3,4}$ & Residuo ajustado: $7,0_{(21,5 \%)}$ & $\overbrace{(20,9 \%)}$ & $\mathscr{\gamma}_{(16,2 \%)}$ \\
\hline $3^{a}$ & $\underset{\text { Residuo ajustado: } 2,9}{\approx} \underbrace{}_{(14 \%)}$ & Residuo ajustodo: $-2,0_{(14,8 \%)}$ & $\dot{\boldsymbol{\lambda}}_{(15,5 \%)}$ & $\dot{\hat{\lambda}}_{(13,8 \%)}$ \\
\hline
\end{tabular}

Legendas:

Principal forma de exercicio:

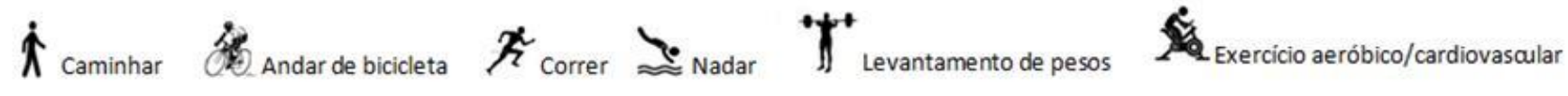

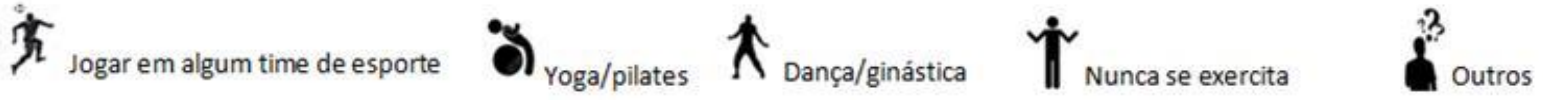
: Residuo ajustado $\leq-2$ (frequência menor do que a esperada). I: Residuo ajustado $\geq 2$ (frequência maior do que a esperada).

A caminhada foi uma modalidade comum aos quatro países, com maior destaque no Brasil. Entre os argentinos, brasileiros e franceses, a mais frequente foi caminhar ou jogar em algum time de esporte; enquanto nos EUA, a primeira mais frequente foi levantamento de pesos.

A principal razão para se exercitar foi analisada com relação à principal forma de exercício. Houve associação entre eles para os brasileiros $(p<0,001)$, estadunidenses $(p<0,001)$ e franceses $(p<0,001)$, mas não para os argentinos $(p>0,05)$ - Quadro 22. 
Quadro 22. Associações entre a principal forma de exercício e a principal razão para se exercitar entre os universitários do Brasil, EUA e França.

\begin{tabular}{|c|c|c|}
\hline$\theta$ & 竦 & \\
\hline 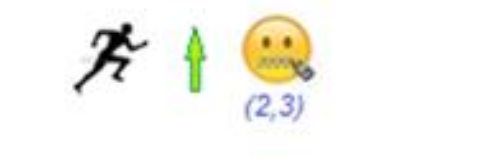 & $\not 2 \Delta \Theta(3,0)$ & 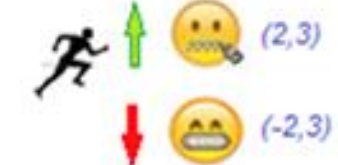 \\
\hline 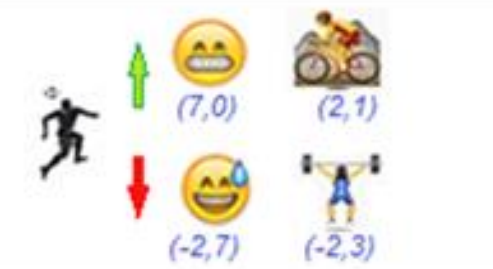 & 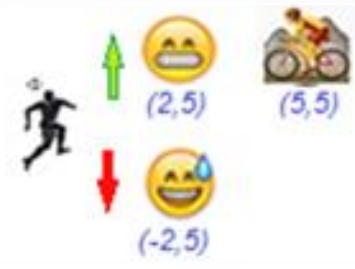 & Iิ कें \\
\hline$\approx A \Leftrightarrow(2,9)$ & $\underset{0}{\approx} \hat{f} \ddot{\theta}_{(2,6)}$ & 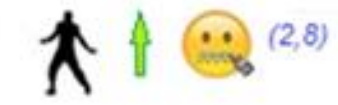 \\
\hline 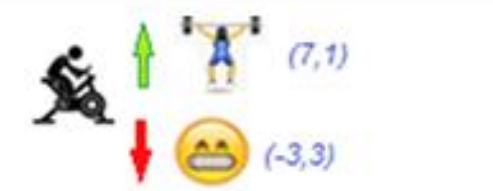 & •f' ${ }^{\prime} \underbrace{A}_{(6,3)}$ & •ft ${ }^{\prime} A^{\prime}(6,1)$ \\
\hline 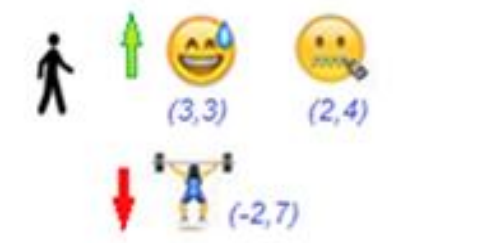 & & \\
\hline 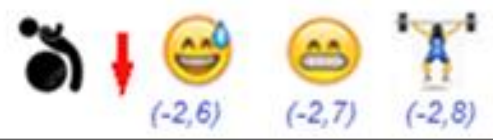 & & \\
\hline
\end{tabular}




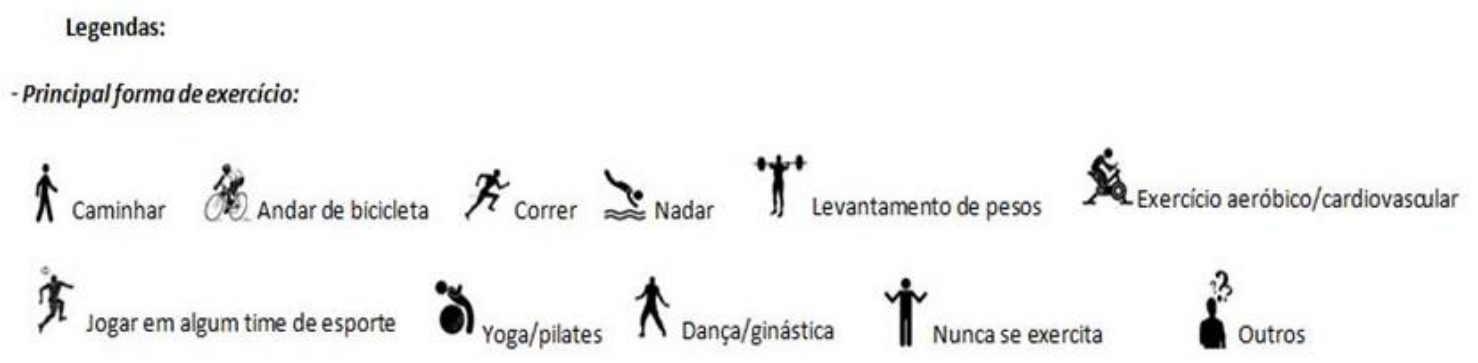

-Principal razão para se exercitar:

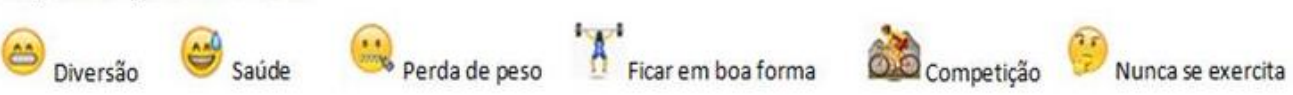

Os residuos ajustados $\leq-2$ ou $\geq 2$ são indicados entre parênteses:

$\downarrow$ : Residuo ajustado $\leq-2$ (frequência menor do que a esperada). ॠ: Resíduo ajustado $\geq 2$ (frequência maior do que a esperada).

Excluindo-se aqueles que nunca se exercitam, notam-se algumas associações apenas para os brasileiros:

- maior número de homens que usam principalmente os aparelhos de exercício aeróbico/cardiovascular para "ficar em boa forma";

- número menor de homens que fazem yoga/pilates por "saúde", "diversão" ou "ficar em boa forma".

Além disso, para os brasileiros e estadunidenses, jogar em algum time de esporte foi associado a "diversão" e "competição"; enquanto na França apenas à "competição". Entre os brasileiros e os franceses, a corrida foi associada a "perder peso", já para os estadunidenses à "saúde".

O principal tipo de exercício foi analisado também com relação à preocupação com a rotina de exercícios (Quadro 23). 
Quadro 23. Efeito da principal forma de exercício e da interação desta variável com o país sobre a preocupação com a rotina de exercícios.

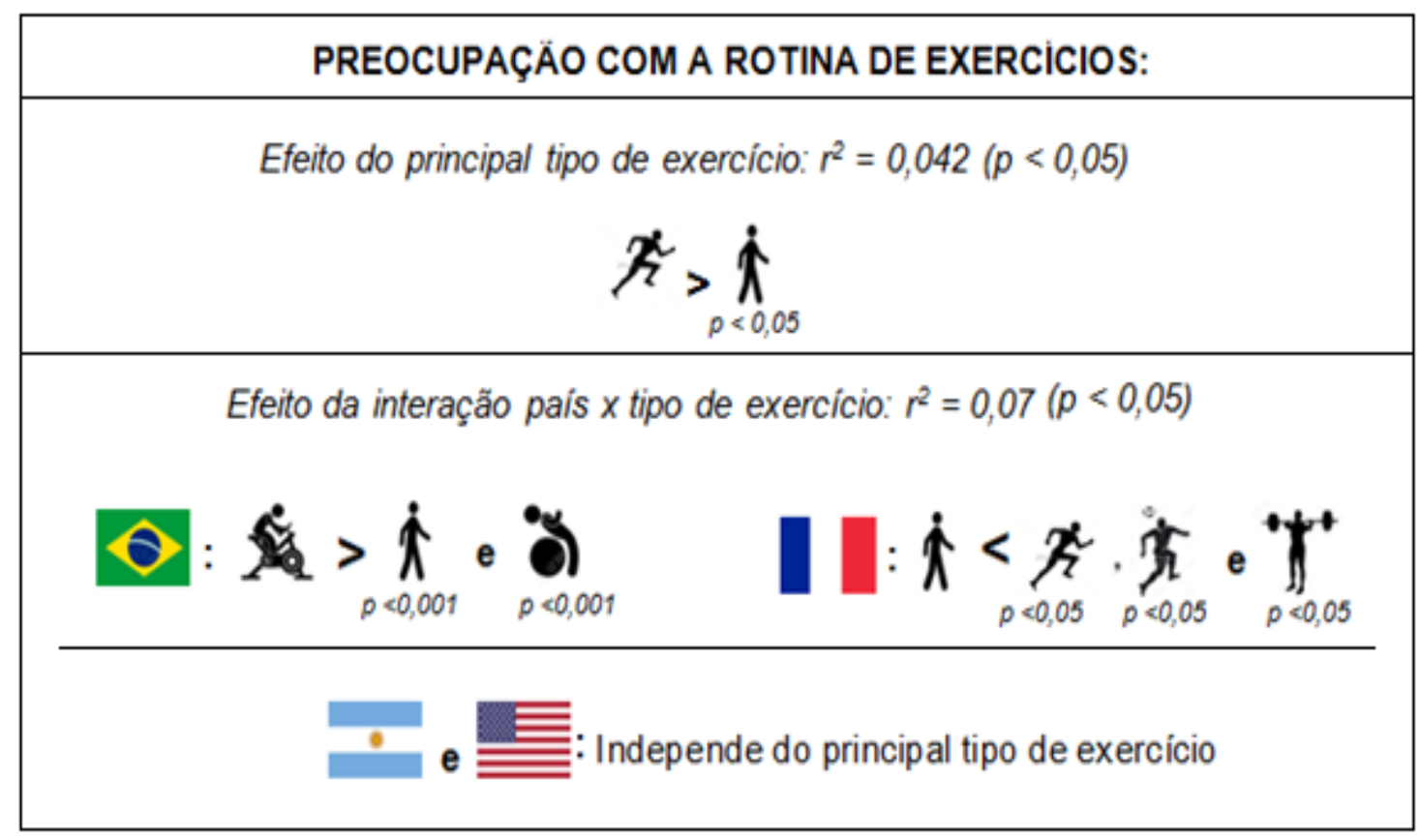

Legendas:

Principal forma de exercício:

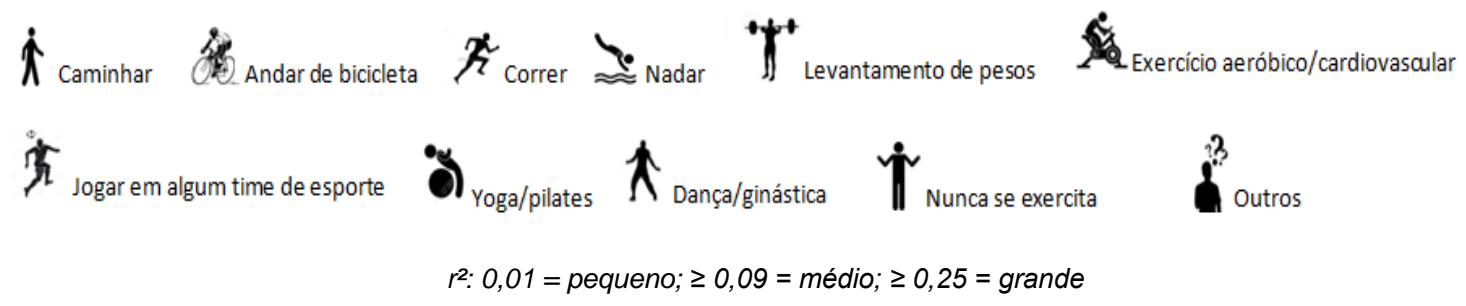

Observou-se que a preocupação com a rotina de se exercitar (variável cuja resposta "absolutamente verdadeiro" correspondeu a $4,7 \%, n=27$, e a resposta "muito verdadeiro" a 10,4\%, n= 59 da amostra geral de homens) foi diferente em função da principal forma de exercício $\left(r^{2}=0,042\right)$ e da interação desta variável com o país $\left(r^{2}=0,07\right)$ - maior efeito -, mas não apenas do país separadamente.

Para os brasileiros adeptos principalmente aos aparelhos aeróbicos, a preocupação com a rotina de exercícios foi maior do que a preocupação referida por aqueles adeptos à caminhada e yoga/ pilates. Entre os franceses, a preocupação referida pelos adeptos à caminhada foi menor do que a dos adeptos à corrida, jogar em time de esporte e ao levantamento de pesos. Entre os argentinos 
e estadunidenses, a preocupação com a rotina de exercícios foi independente da principal forma de exercício.

A preocupação com a com a rotina de exercícios foi analisada também com relação à principal razão para se exercitar (Quadro 24).

Quadro 24. Efeito da principal razão para se exercitar sobre a preocupação com a rotina de exercícios.

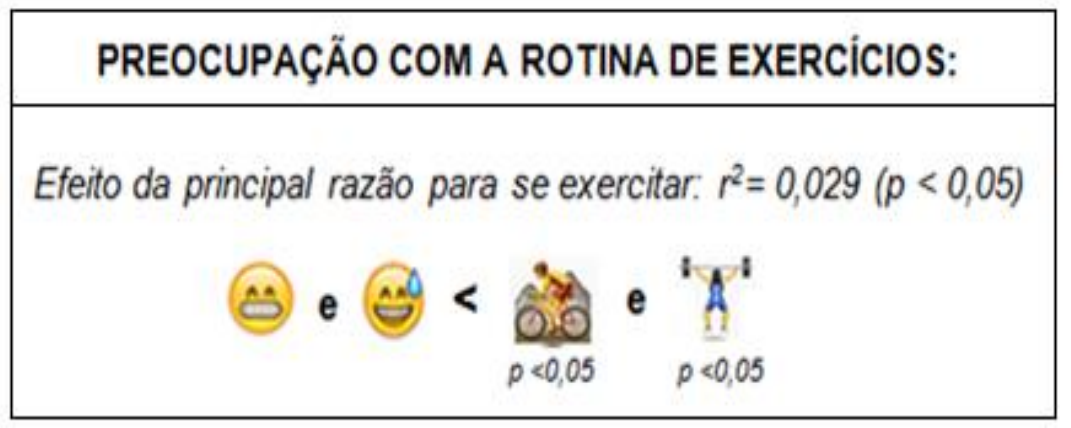

Legendas:

Principal raz̃oo para se exercitar:

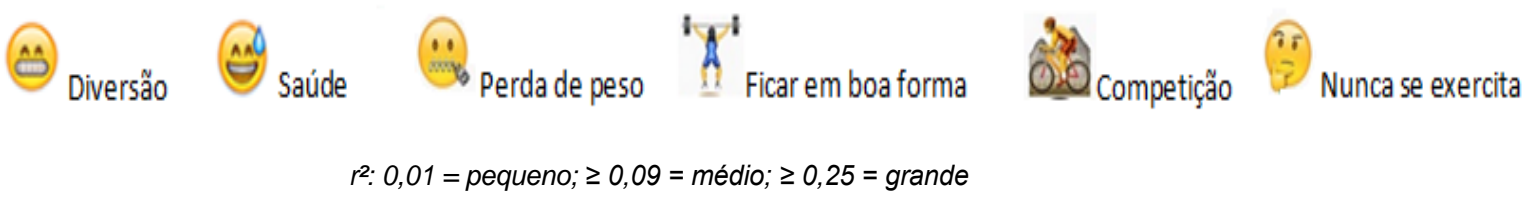

Nos quatro países, quem respondeu se exercitar principalmente por "diversão" ou por "saúde", referiu menor preocupação com a rotina de exercícios do que aqueles que o faziam principalmente por "competição" ou para "ficar em boa forma". Não houve efeito do isolado do país e tampouco em sua interação com a razão para se exercitar.

Analisou-se a razão para se exercitar com relação à preocupação sobre o que se come e como isto afeta a aparência. Houve efeito da razão $\left(r^{2}=0,032\right)$, do país $\left(r^{2}=0,034\right)$ e efeito ainda maior para a interação destas variáveis $\left(r^{2}=0,051\right)-$ Quadro 25. 
Quadro 25. Efeito do país, da principal razão para se exercitar e da interação destas variáveis sobre a preocupação com a comida e aparência.

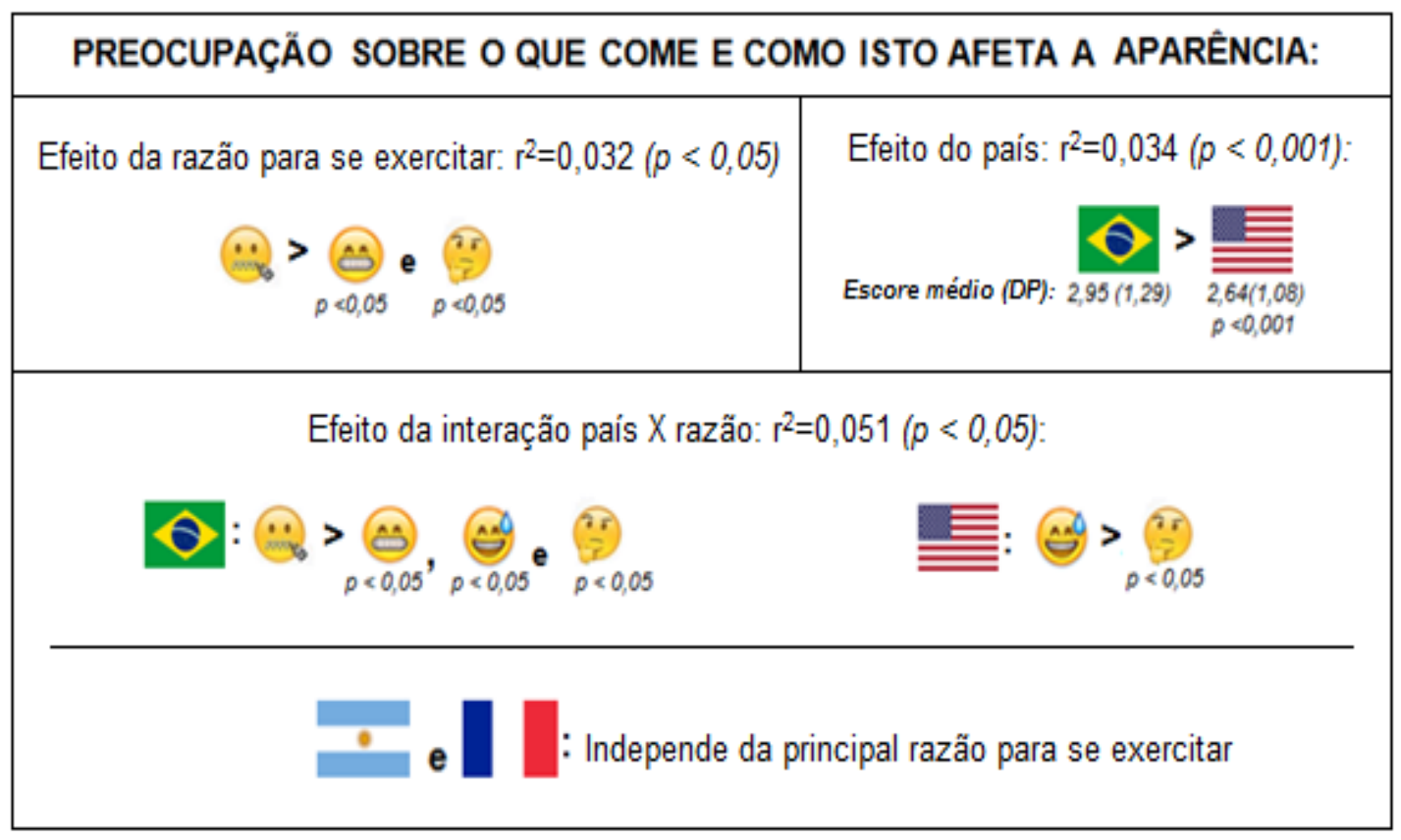

Legendas:

Principal raz̃õo para se exercitar:

(A) Diversão $\quad \hat{\theta}$ Saú
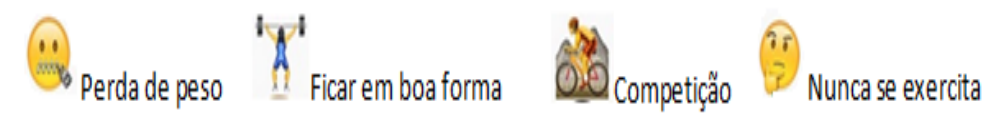

$r^{2}: 0,01$ = pequeno; $\geq 0,09=$ médio; $\geq 0,25=$ grande

Quanto ao efeito do país, os brasileiros referiram maior preocupação com a comida e seus efeitos sobre a aparência do que os estadunidenses, sendo a preocupação daqueles que fazem exercícios para a "perda de peso" maior do que a de quem faz por "saúde", por "diversão" - e de quem nunca se exercita. Para os estadunidenses, a única diferença foi maior preocupação para os que se exercitam por "saúde" em relação aos que nunca se exercitam. Para os argentinos e franceses, a preocupação com a comida e a aparência não foi diferente em função da principal razão para exercício. 
Buscando explorar este resultado, a média de IMC dos universitários dos quatro países bem como a classificação do estado nutricional são apresentados nas Tabelas 16 e 17, respectivamente.

Tabela 16. Peso corporal atual e IMC dos universitários argentinos, brasileiros, estadunidenses e franceses.

\begin{tabular}{lcc}
\hline \multicolumn{1}{c}{ País } & $\begin{array}{c}\text { Peso atual }(\mathbf{k g}) \\
\text { Média }(D P)\end{array}$ & $\begin{array}{c}\text { IMC }\left(\mathbf{k g} / \mathbf{m}^{\mathbf{2}}\right) \\
\text { Média; mediana }(D P)\end{array}$ \\
\hline Argentina & $77,2(12,35)$ & 24,$5 ; 24,2(3,24)^{\mathrm{a}}$ \\
\hline Brasil & $64,7(13,41)^{\mathrm{b}}$ & 22,$3 ; 21,3(3,48)$ \\
\hline EUA $^{*}$ & $73,9(10,32)$ & 23,$2 ; 23,0(2,74)^{\mathrm{c}}$ \\
\hline França & $72,2(8,75)^{\mathrm{d}}$ & 22,$4 ; 22,2(2,28)$ \\
\hline
\end{tabular}

${ }^{\star} \mathrm{EUA}=$ Estados Unidos da América.

$a=$ significativamente maior do que o Brasil $(p<0,001)$ e França $(p<0,001)$; b significativamente menor do que a Argentina ( $p<0,001)$, França $(p<0,001)$ e EUA $(p<0,001)$; $c=$ significativamente maior do que o Brasil $(p<0,05)$; $d=$ significativamente menor do que a Argentina $(p<0,05)$.

Os brasileiros apresentaram a menor média de peso corporal. A média de IMC dos homens dos quatro países variou entre 22,3 e $24,5 \mathrm{~kg} / \mathrm{m}^{2}$, valores que, desconsiderando-se o desvio padrão, são caracterizados pela OMS como "eutrofia" (WHO, 2010) - os argentinos apresentaram média de IMC maior do que os brasileiros e franceses. A classificação do estado nutricional dos universitários é apresentada na Tabela 17. 
Tabela 17. Distribuição dos universitários $(n=567)^{\star}$ dos quatro países quanto ao estado nutricional.

\begin{tabular}{|c|c|c|c|c|c|c|c|c|c|c|}
\hline \multirow{2}{*}{ Estado nutricional } & \multicolumn{2}{|c|}{ Argentina } & \multicolumn{2}{|c|}{ Brasil } & \multicolumn{2}{|c|}{ EUA } & \multicolumn{2}{|c|}{ França } & \multicolumn{2}{|c|}{ Total } \\
\hline & $\mathbf{N}$ & $\%$ & $\mathbf{N}$ & $\%$ & $\mathbf{N}$ & $\%$ & $\mathbf{N}$ & $\%$ & $\mathbf{N}$ & $\%$ \\
\hline Baixo peso & - & - & 20 & 9,0 & 04 & 3,1 & 03 & 1,8 & 27 & 4,8 \\
\hline Eutrofia & 33 & 66,0 & 157 & 70,7 & 92 & 71,9 & 145 & 86,8 & 427 & 75,3 \\
\hline Sobrepeso & 14 & 28,0 & 37 & 16,7 & 30 & 23,4 & 18 & 10,8 & 99 & 17,5 \\
\hline Obesidade grau I & 03 & 6,0 & 08 & 3,6 & 02 & 1,6 & 01 & 0,6 & 14 & 2,5 \\
\hline Obesidade grau II & - & - & - & - & - & - & - & - & - & - \\
\hline Obesidade grau III & - & - & - & - & - & - & - & - & - & - \\
\hline TOTAL & 50 & 100 & 222 & 100 & 128 & 100 & 167 & 100 & 567 & 100 \\
\hline
\end{tabular}

A eutrofia foi o estado nutricional de $75,3 \%(n=427)$ dos homens desta amostra, enquanto 4,8\% ( $n=27)$ tinham baixo peso, 17,4\% $(n=99)$ tinham sobrepeso e $2,5 \%$ obesidade grau I ( $n=14)$ - nenhum dos homens foi classificado em obesidade grau II ou III. Quanto às frequências de jovens com excesso de peso (sobrepeso ou obesidade), especificamente em cada país, foram 34\% na Argentina, $20,3 \%$ no Brasil, $25 \%$ nos EUA e $11,4 \%$ na França. Nos quatro países, houve associações com 0 estado nutricional $(p<0,001)$ e as diferenças entre valores esperados e observados são apresentadas no Quadro 26.

Quadro 26. Associações que ocorreram entre os países e o estado nutricional.

\begin{tabular}{|c|c|}
\hline 0 & 『s sobrepeso $(2,1)$ \\
\hline 6 & $\begin{array}{l}\text { Daixo peso }(3,8) \\
\text { eutrofia }(-2,0)\end{array}$ \\
\hline 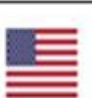 & 『s sobrepeso $(2,0)$ \\
\hline & $\begin{array}{l}\text { \eutrofia }(4,1) \\
\text { baixo peso }(-2,1) \text {; } \mid \text { sobrepeso }(-2,7)\end{array}$ \\
\hline
\end{tabular}

Os residuos ajustados $\leq-2$ ou $\geq 2$ são indicados entre parênteses:

: Residuo ajustado $\leq-2$ (frequência menor do que a esperada). ¿.: Residuo ajustado $\geq 2$ (frequência maior do que a esperada). 
A frequência de homens com baixo peso foi maior no Brasil e menor, na França; já a frequência daqueles com sobrepeso foi maior na Argentina e EUA, e menor na França. A eutrofia foi mais frequente entre os franceses, e menor do que a esperada entre os brasileiros.

Verificou-se que $10,2 \%(n=58)$ da amostra geral de homens responderam "absolutamente verdadeiro" para a preocupação sobre o que se come e como isto afeta a aparência, sendo a maior parte deles do Brasil $(n=34)$, seguido pela França $(n=10)$ e EUA $(n=09)$. Considerando-se os homens que responderam a opção "muito verdadeiro" (ou seja, a segunda pior opção) têm-se mais 18,3\% ( $n=104)$, ou seja, para $28,5 \%(n=162)$ da amostra geral de homens a preocupação com a comida e a aparência é "muito" ou "absolutamente" verdadeira - destes, 104 homens, 37,5\% ( $n=39)$ também respondeu "muita" ou "absolutamente" verdadeira para a preocupação com a rotina de exercícios. O estado nutricional destes homens é apresentado na Tabela 18.

Tabela 18. Estado nutricional dos homens que responderam a opção "muito verdadeira" ou "absolutamente verdadeira" para a preocupação com a rotina de exercício, sobre a comida e a aparência, e ambas as preocupações.

\begin{tabular}{lcccccc}
\hline Estado nutricional & $\begin{array}{c}\text { Preocupação } \\
\text { sobre o que se } \\
\text { come e como isto } \\
\text { afeta a aparência* }\end{array}$ & $\begin{array}{c}\text { Preocupação com } \\
\text { a rotina de } \\
\text { exercícios }\end{array}$ & \multicolumn{2}{c}{$\begin{array}{c}\text { Ambas as } \\
\text { preocupações* }\end{array}$} \\
\hline Baixo peso & $\mathbf{N}$ & $\%$ & $\mathbf{N}$ & $\%$ & $\mathbf{N}$ & $\%$ \\
\hline Eutrofia & 04 & 2,5 & 02 & 2,3 & 01 & 2,6 \\
\hline Sobrepeso & 125 & 77,2 & 65 & 75,6 & 28 & 71,8 \\
\hline Obesidade grau I & 29 & 17,9 & 18 & 20,9 & 09 & 23,0 \\
\hline Obesidade grau II & - & 2,5 & 01 & 1,2 & 01 & 2,6 \\
\hline Obesidade grau III & - & - & - & - & - & - \\
\hline \multicolumn{1}{c}{ TOTAL } & 162 & 100 & 86 & 100 & 39 & 100 \\
*Considerando-se apenas as respostas “muito verdadeiro" e "absolutamente verdadeiro".
\end{tabular}


Entre os homens mais preocupados com os exercícios e com a comida e aparência (separada ou simultaneamente), mais de $70 \%$ eram eutróficos e aproximadamente $25 \%$ tinham sobrepeso ou obesidade - frequências semelhantes às verificadas para a amostra total de homens (Tabela 17).

Analisou-se o efeito da principal razão para se exercitar e do país sobre o IMC e foram verificados efeitos das variáveis isoladamente e em interação (Quadro 27).

Quadro 27. Efeitos do país, da principal razão para se exercitar e da interação destas variáveis sobre o Índice de Massa Corporal.

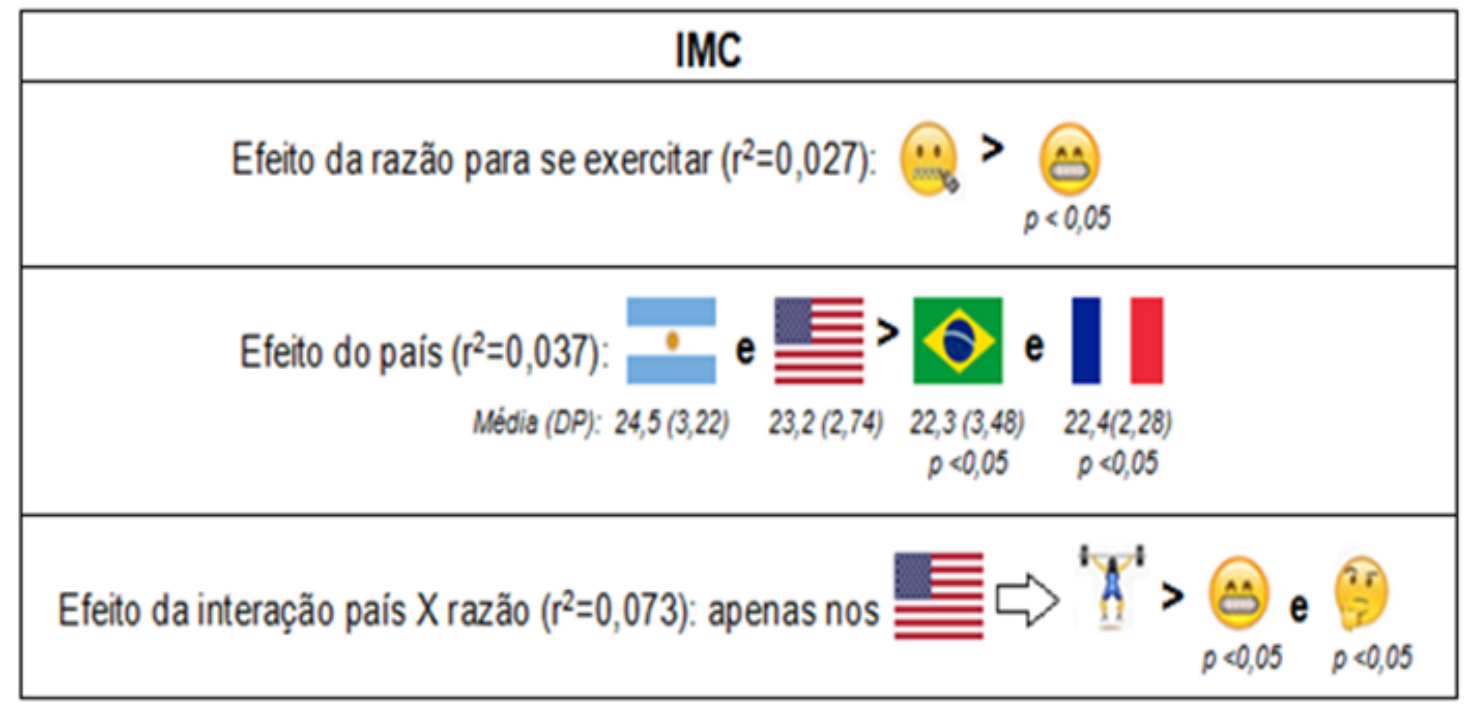

Legendas:

Principal razão para se exercitar:

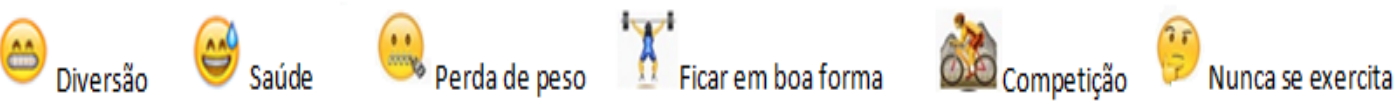

$r^{2}: 0,01=$ pequeno $; \geq 0,09=$ médio $; \geq 0,25=$ grande

A média de IMC dos homens que se exercitam principalmente para "perda de peso" foi maior do que a daqueles que o fazem por "diversão" $\left(r^{2}=0,027\right)$. Além disso, houve efeito do país $\left(r^{2}=0,037\right)$ : os argentinos e estadunidenses apresentaram maiores médias de IMC do que brasileiros e franceses. $O$ efeito da interação da razão para se exercitar com o país foi ainda maior do que o efeito das 
variáveis isoladamente $\left(r^{2}=0,073\right)$, entretanto, esta interação ocorreu apenas para os estadunidenses.

Ao se analisar razão para exercício e a classificação do estado nutricional (e não o IMC), houve associação apenas entre os estadunidenses $(p<0,05)$ - Quadro 28. Verificaram-se frequências maiores do que as esperadas de universitários com obesidade grau I que se exercitam principalmente por "competição", daqueles com sobrepeso que praticam exercícios para a "perda de peso" ou "ficar em forma", e dos universitários com baixo peso que nunca se exercitam.

Quadro 28. Associação entre a principal razão para se exercitar e o estado nutricional, entre os universitários estadunidenses.
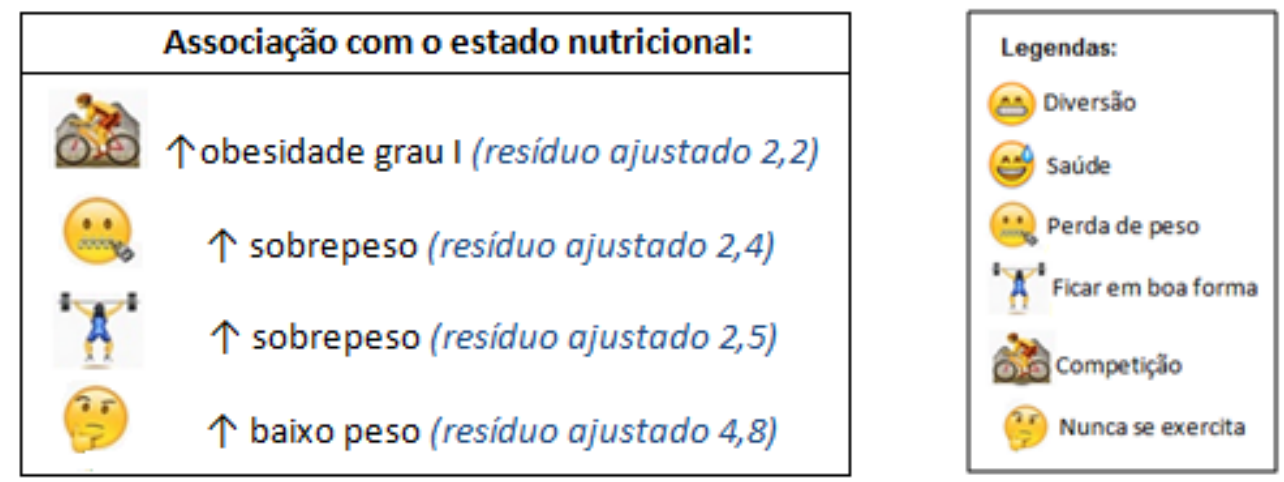

$\uparrow:$ Resíduo ajustado $\geq 2$ (frequência maior do que esperada).

A fim de verificar se o IMC influenciou a preocupação com a rotina de exercícios e a preocupação com a comida e eventuais efeitos na aparência, esta variável foi incluída como covariável nas análises, que não se alteraram, ou seja, os efeitos descritos (Quadros 23 a 25) não ocorrem devido ao IMC.

\subsubsection{Discussão}

Este manuscrito destacou os resultados para homens dos quatro países. A principal resposta de razão para se exercitar, de forma geral, foi "saúde", mas com diferenças entre eles, que foram atribuídas ao país de origem, marcando diferenças culturais. 
Na comparação com a literatura, GUEDES et al. (2012b) avaliaram amostra probabilística de 2380 universitários brasileiros com idade entre 18 e 35 anos, (49\% do sexo masculino) e encontraram que para estes, as principais razões para a prática de atividade física eram relacionadas à condição física e à competição mas, no presente estudo, os brasileiros responderam "saúde", "ficar em boa forma" e "diversão" como principais razões para exercício. Com uma amostra menor de brasileiros ( $n=63 ; 54 \%$ do sexo masculino), LEGNANI et al. (2011) encontraram que dentre os homens, hierarquicamente, as principais razões foram lazer e bem estar, prevenção de doenças, condição física e controle do stress.

Em estudo com estadunidenses ( $n=2199 ; 49 \%$ do sexo masculino), EGLI et al. (2011) observaram que a prática de exercícios entre os homens era motivada principalmente por fatores intrínsecos (saúde e diversão/bem estar) além de força e resistência. Semelhantemente, os estadunidenses do presente estudo responderam "saúde", "diversão" e "ficar em boa forma". KILPATRICK et al. (2005) também avaliaram universitários estadunidenses ( $n=233 ; 43 \%$ do sexo masculino) e verificaram que a competição, o reconhecimento social e a condição física eram motivações mais importantes à prática de exercícios físicos - enquanto neste estudo, a "competição" foi a quinta principal razão, com frequência inferior a 8,0\%. Não foram localizados estudos que avaliaram, especificamente, as razões ou motivações para fazer exercícios entre universitários argentinos e franceses.

A literatura evidencia que a prática de exercícios físicos entre os homens tem objetivo relacionado às questões da aparência física - assim como as mulheres mas também à superação de desafios (SANTOS E SALLES, 2009; BRUNET e SABISTON, 2011; EGLI et al., 2011; PAULINE, 2013). No universo aqui observado, a "saúde", a "diversão" e o desejo de "ficar em boa forma" foram razões mais frequentemente mencionadas e, de certa forma, se relacionam aos principais exercícios praticados - caminhada, levantamento de pesos e jogos em times de esportes. Entretanto, no contexto atual da supervalorização da aparência corporal, a beleza é vinculada à saúde, e este vínculo fica bem explícito no uso do termo "sarado", um adjetivo que deriva do verbo "sarar", ou seja, "recobrar a saúde", mas que foi ressignificado para "corpo modelado" ou "corpo musculoso" (SANTOS e 
SALLES, 2009). Assim, da mesma maneira que discutido para as mulheres, a resposta saúde pode estar enviesada para outros significados.

Para discutir os achados é interessante pensar no "ambiente" para a prática de atividade física nos quatro países. Dentre estes, um que se tornou "o local" foram as academias de ginástica e de musculação, que, de acordo com SABINO (2007), surgem como "usinas de produção em forma, fabricando corpos para serem consumidos pela lógica do mercado". SANTOS e SALLES (2009) ressaltam também o fato de as academias de ginástica e musculação serem locais de socialização. As práticas corporais neste ambiente estão em constante processo de "esportivização", valendo-se de elementos como dedicação de tempo, sacrifícios autoimpostos, o medo de falhar ou de estar abaixo do rendimento "ideal" e ainda, a vigilância do corpo: pelas balanças, adipômetros, fitas métricas e espelhos (HANSEN e VAZ, 2004).

Os EUA são líderes mundiais em número de academias e em faturamento anual, em segundo lugar está o Brasil- com o terceiro maior faturamento anual do mundo - seguido pela Argentina (em número de academias), que apresenta o quinto maior faturamento do mundo (Quadro 29).

Quadro 29. Número de academias, faturamento anual e posição no ranking das academias da Argentina, Brasil, França e EUA no ano de 2016.

\begin{tabular}{|c|c|c|c|}
\hline País & $\begin{array}{c}\text { Academias } \\
\text { (n) }\end{array}$ & $\begin{array}{l}\text { Posição no } \\
\text { ranking }\end{array}$ & $\begin{array}{c}\text { Faturamento } \\
\text { anual (\$) }\end{array}$ \\
\hline Argentina & 7.900 & $3^{\circ}$ lugar mundial & 1.200 .000 .000 \\
\hline Brasil & 31.809 & $2^{\circ}$ lugar mundial & 2.442 .149 .000 \\
\hline EUA & 36.180 & $1^{\circ}$ lugar mundial & 25.800 .000 .000 \\
\hline França & 3.800 & 50 lugar na Europa & 2.654 .000 .000 \\
\hline
\end{tabular}

Fonte: International Health, Racquet \& Sportsclub Association (IHRSA), 2016.

A França tem posição bastante diversa, com pouco mais do que $10 \%$ do número de academias dos EUA (IHRSA, 2016), o que se reflete nos achados deste estudo: as três principais formas de exercícios entre franceses incluem aqueles 
praticados fora do ambiente das academias (jogos em time de esportes, corrida e caminhada). A elevada frequência de franceses que preferem estas modalidades pode também, de certa forma, contribuir com o fato de a França ter apresentado a maior frequência de jovens que responderam "competição" como principal razão para exercício, considerando-se o sentido desta em exercícios em equipe. Dados do Institut Régional de Développement du Sport (IRDS), na França, apontam que em 2015, entre os homens com idade acima de 15 anos, as modalidades mais frequentes foram caminhada, andar de bicicleta e natação, enquanto a musculação ficou em $9^{a}$ posição. Estes dados sobre academias se comunicam com o observado no presente estudo, pois as modalidades de levantamento de pesos e aparelhos de exercício aeróbico - que ocupam posição de destaque nos EUA, Brasil e Argentina - são frequentes em academias.

Deve-se considerar ainda, que algumas práticas ou modalidades esportivas podem ser supervalorizadas em virtude dos significados a elas atribuídos. Neste estudo, por exemplo, têm-se a associação entre jogar em algum time de esporte e frequência maior para se exercitar por "competição" (exceto na Argentina). A prática de disputas e competições pode ser considerada uma característica bastante generalizada do ethos masculino, em diversas culturas (MALYSSE, 2007; SABINO, 2007; GASTALDO e BRAGA, 2011).

As opções de resposta para a questão "principal razão para se exercitar" estavam dadas neste estudo (respostas fechadas), portanto, não se podem descartar possíveis vieses na resposta. Talvez uma exploração qualitativa traria razões e motivações subjacentes. De qualquer forma, no contexto do entendimento e visão atuais da prática de exercícios, mesmo aquelas com um maior dispêndio energético podem ser praticadas por questões de "saúde".

Dentre as alternativas de exercícios, a corrida vem se tornando cada vez mais popular, e isso se deve a fatores, como não serem necessárias habilidades muito específicas (comparada a outras modalidades), por contemplar a possibilidade de evolução de metas (tempo, distância), é uma modalidade acessível e de baixo custo. Praticantes de corrida podem começar a buscar esta prática por motivos como: melhoria do condicionamento e desempenho físico, perda de peso, 
saúde, bem-estar, diversão ou até mesmo fatores sociais (TRUCCOLO et al., 2008; GRATÃO e ROCHA, 2016). Interessante notar que, neste estudo, a prática de corrida foi associada a fazer exercícios por "saúde" para os estadunidenses (os quais apontaram a corrida como principal exercício com maior frequência do que nos demais países), e por "perda de peso" para os brasileiros e franceses.

Com relação ao estado nutricional, a associação com a principal razão para se exercitar ocorreu apenas entre os estadunidenses (país no qual $23,4 \%$ dos homens tinham sobrepeso e $1,6 \%$ era obeso). Diferentemente, do que foi encontrado por GUEDES et al. (2012a), em estudo com amostra probabilística de universitários brasileiros ( $n=2380 ; 49 \%$ do sexo masculino), no qual em ambos os sexos a importância dada às razões associadas ao controle de peso e aparência física na prática de exercícios aumentaram direta e proporcionalmente com o IMC: para os universitários com sobrepeso e obesidade, a prática de exercício físico ocorria em razão de fatores relacionados à prevenção de doenças, à reabilitação de saúde, controle de peso corporal - universitários eutróficos por sua vez, apresentaram como razões mais frequentes a diversão, controle do stress e afiliação. Cabe ressaltar que na amostra de GUEDES et al. (2012a), a frequência de homens com sobrepeso era de $21,2 \%$ e de obesos era de $5,5 \%$.

As questões relacionadas ao corpo e à imagem corporal na literatura são majoritariamente avaliadas e discutidas no âmbito do sexo e gênero feminino. Embora crescente, o destaque é menor para o sexo masculino. Existem diferenças quanto às preocupações com as formas corporais nos dois sexos, de maneira geral, mulheres procuram atingir um modelo de corpo magro, adotando comportamentos dirigidos para o emagrecimento - drive for thinness - enquanto homens procuram um corpo com maior massa muscular, dirigindo sua atenção para a muscularidade - drive for muscularity (DAKANALIS et al. 2015; CARVALHO, 2016). Atualmente, existem instrumentos específicos para avaliar este construto em homens, como a Muscle Appearance Satisfaction Scale - MASS (MAYVILLE et al., 2002), a Male Body Dissatisfaction Scale - MBDS (CARVALHO et al., 2013a), a Drive for Muscularity Scale, a Swansea Muscularity Attitudes Questionnaire e Masculine Body Ideal Distress Scale (CAMPANA et al., 2013). 
Nas sociedades ocidentais, o atual padrão de beleza para os homens preconiza o corpo mesomórfico, que consiste em um físico forte, retangular, de musculatura razoavelmente desenvolvida e bem delineada (BÖHME, 2000; DAKANALIS et al. 2015; STRATTON et al., 2015). Este corpo é comumente associado a atributos como força, saúde, atratividade, poder, sucesso pessoal, social e sexual (DAKANALIS et al. 2015; STRATTON et al., 2015; EDWARDS et al.,2016).

Este estudo não explorou a muscularidade diretamente, nem por perguntas, tampouco por escala de satisfação; pode-se conjecturar se a resposta "ficar em boa forma", traz de alguma forma este sentido - e no Brasil houve a maior frequência desta resposta (segunda principal razão).

As razões que eventualmente podem estar associadas à prática de exercício físico são diversas, fatores como sexo e idade se destacam; contudo, os atributos sociais e ambientais e o contexto cultural em que se está inserido, também devem ser considerados (BRUNET e SABISTON, 2011; GUEDES et al., 2012b). Segundo SALLIS e OWEN (apud LEGNANI, 2009), os determinantes mais fortemente associados à atividade física são variáveis psicológicas e comportamentais em reposta aos determinantes do ambiente social e físico, assim, enquanto em geral, para as mulheres os determinantes são relacionados ao controle do peso corporal, e para os homens, à aparência e à superação de desafios/competição (SANTOS E SALLES, 2009; BRUNET e SABISTON, 2011; EGLI et al., 2011; PAULINE, 2013; HURST et al., 2017).

No campo comportamental, o compromisso com prática de exercícios tem sido avaliado no âmbito da autodeterminação dos indivíduos, que engloba a motivação intrínseca - relacionada ao prazer e à satisfação do próprio envolvimento com a prática sem receber recompensas externas - e a motivação extrínseca, caracterizada por sua estreita identificação com reconhecimento social, premiações e recompensas (LEGNANI, 2009; BRUNET e SABISTON, 2011; EGLI et al., 2011; LEGNANI et al.,2011; HURST et al., 2017). O presente estudo questionou a "razão" para se exercitar - que está de alguma forma relacionada à "motivação" - mas o 
tipo de motivação não foi avaliada, o que poderia trazer respostas interessantes, mas apenas possível numa exploração qualitativa.

A amostra aqui avaliada foi composta exclusivamente por universitários, assim, é importante contextualizar a prática de exercícios no contexto universitário. Esta prática teve suas origens em escolas públicas inglesas no século XIX, a fim de "disciplinar o tempo livre" dos jovens das classes dominantes. Em 1923, o francês Jean Petit organizou a primeira edição dos Campeonatos Mundiais Universitários, em Paris; posteriormente, em 1949, a International University Sports Federation (FISU) foi oficialmente fundada. Os quatro países avaliados neste estudo fazem parte da FISU: Federación del Deporte Universitario Argentino (FeDUA), Confederação Brasileira do Desporto Universitário (CBDU), United States International University Sports Federation (USIUSF) e Fédération Française du Sport Universitaire (FFSU) - (BARBOSA, 2014; FISU, 2017).

Os esportes são parte importante especialmente na cultura estadunidense, cujo incentivo à prática tem início na fase escolar e permanece durante a universidade. Criada em 1910, na gestão do presidente Theodore Roosevelt, a National Collegiate Athletic Association (NCAA) é responsável pela organização dos esportes universitários nos EUA (SANDERSON e SIEGFRIED, 2015; NCAA, 2017). Destaca-se também a relevância do esporte universitário como meio de ingresso permanência na instituição, uma vez que um bom desempenho esportivo pode garantir ao estudante bolsas de estudos integrais ou parciais - dependendo da divisão/grupo ao qual a universidade pertence (MEDIC et al., 2007; NCAA, 2017).

Já para os brasileiros, o futebol é uma modalidade esportiva de grande destaque desde a infância (principalmente entre o público masculino), e pode assim ser entendido como um elemento da identidade nacional brasileira. Há que se ressaltar uma rivalidade histórica entre o futebol brasileiro e o argentino, na qual as disputas futebolísticas têm significado simbólico, contribuem para a "honra", imagem e soberania deste no continente sul-americano (BITENCOURT, 2009; CARVALHO, 2012). Para MARQUES et al. (2007) o esporte seria um fenômeno sócio-cultural, que engloba diversas práticas humanas manifestadas através da 
atividade corporal e transmite valores de acordo com o sentido dado à prática, ou seja, as razões e objetivos da atividade.

$\mathrm{Na}$ atualidade, não apenas o esporte, mas as práticas corporais como um todo vêm sendo padronizadas e difundidas como corretas e estabelecidas como mais adequadas ao bom desenvolvimento do corpo e à manutenção da saúde. $O$ corpo, portanto, passa a ser objeto de novas regras, novas técnicas, cálculo exato dos espaços e dos tempos, em outras palavras, um novo universo de performances surge. O exercício físico, assim, transforma-se em uma atividade precisamente codificada cujos movimentos se apresentam em detalhes e os resultados se calculam (SOARES, 2005).

Os resultados encontrados neste manuscrito apontaram que a preocupação com a rotina de exercícios foi maior entre os que se exercitam por "competição" e "ficar em boa forma", enquanto a preocupação com a comida e seus efeitos sobre a aparência foi maior entre os que responderam "perda de peso" como principal razão para exercício. Quanto aos efeitos do país sobre preocupação com a comida e a aparência, os brasileiros apresentaram maiores escores do que os estadunidenses - embora os EUA tenham sido o país com maior de frequência de homens com sobrepeso.

Quando comparados os efeitos da razão para se exercitar, do país e da interação destas (sobre as variáveis que avaliaram preocupação com exercícios e com a comida e aparência), o efeito da interação foi sempre maior. Estes resultados evidenciam a importância de que, além dos aspectos quantitativos (como tempo e frequência da atividade física), os aspectos qualitativos e comportamentais sejam considerados pelos profissionais de saúde quando das recomendações relacionadas à prática de exercícios físicos. 


\section{DISCUSSÃO GERAL DO ESTUDO}

Este estudo contemplou grande quantidade de variáveis, desta forma, os resultados foram apresentados inicialmente de forma geral, - destacando-se as diferenças encontradas em relação ao sexo, ao país e interação destas variáveis bem como quanto aos efeitos e poder destes construtos sobre cada parâmetro avaliado. Posteriormente, os resultados foram descritos de forma mais específica, abrangendo três temáticas: insatisfação corporal (manuscrito 1); relação entre razão para exercício com o contexto alimentar e corporal, entre as mulheres (manuscrito 2); e estas variáveis entre os homens (manuscrito 3).

Dentre os resultados gerais, destaca-se 0 fato de as mulheres terem apresentado atitudes alimentares mais disfuncionais (maior escore para dietas, restrição alimentar, preocupação com excesso de peso, vômitos, compulsão alimentar, preocupação com comida e seus efeitos sobre a aparência), maior insatisfação corporal e maior propensão à realização de cirurgia plástica estética do que os homens.

Tal achado é compatível com a literatura, que destaca maior insatisfação sempre entre a mulheres (RODIN et al., 1985; ALVARENGA et al., 2010b; TANTLEFF-DUNN et al., 2011), e maior presença de comportamento de risco para transtornos alimentares (dieta, restrição, compensação, purgação) também entre elas (ACKARD et al., 2002; NOVAES, 2006; ALVARENGA et al., 2013; LEITZKE et al., 2014; TAVOLACCI et al., 2015).

O estado nutricional das mulheres foi associado com o país apenas no Brasil e França: comparado aos outros três países, o Brasil apresentou a menor frequência de eutróficas e a maior frequência de jovens com sobrepeso, enquanto na França ocorreu o oposto (foi o país com maior a frequência de eutróficas e a menor de sobrepeso).

Ainda dentre os resultados gerais, destaca-se que os homens relataram

maior média de dias de atividade física na semana, maior preocupação com exercícios e desejavam uma figura de imagem corporal maior que a atual. Quanto ao estado nutricional, a frequência de homens com baixo peso foi maior no Brasil e 
menor na França; já a frequência daqueles com sobrepeso foi maior na Argentina e EUA, e menor na França. A eutrofia foi mais frequente entre os franceses, e menor do que a esperada entre os brasileiros.

Quanto à insatisfação corporal, observou-se que o efeito do estado nutricional foi maior do que o efeito do sexo, que por sua vez, foi maior do que o efeito país; contudo, o efeito da principal razão para exercício foi o maior dos efeitos. Em ambos os sexos, houve maior insatisfação entre aqueles que responderam se exercitar principalmente para "perder peso", mesmo quando o estado nutricional foi de "baixo peso" ou "eutrofia".

Classicamente, pessoas com maior peso corporal são mais insatisfeitas com sua IC, isto foi encontrado em estudos realizados com mulheres (ALMEIDA et al., 2002; ALVARENGA et al., 2010b; COSTA et al., 2010b; HERNÁNDEZ et al., 2012; SILVA et al., 2012b) e em ambos os sexos (HAUSENBLAS e FALLON, 2002; RECH et al., 2010; FERRARI et al., 2012; MARTINS et al., 2012), entretanto, não se pode assumir que o estado nutricional de excesso de peso seja uma "boa razão" para justificar a insatisfação corporal. Observa-se neste estudo (principalmente entre as mulheres), grande parte das pessoas que fazem exercícios para "perder peso" não têm uma necessidade real, do ponto de vista de saúde, para fazê-lo, mas este "objetivo" é incentivado por ideais nos quais a aparência física é o mais importante, preconizando-se a magreza, muscularidade, baixos percentuais de gordura - drive

for thinness, drive for muscularity, drive for leanness (SCHWARTZ e BROWNELL, 2004; MALYSSE, 2007; CARVALHO, 2016).

A insatisfação com a IC não foi relacionada à frequência semanal e a preocupação excessiva com a rotina de exercícios, tampouco à culpa por não se exercitar. Os construtos mais relacionados à insatisfação foram sexo (maior entre as mulheres), estado nutricional e, principalmente, exercitar-se para "perder peso".

\section{Resultados entre as mulheres}

Entre as mulheres, destacam-se algumas particularidades de acordo com o país, como o maior escore de restrições alimentares entre as argentinas, maior preocupação com exercícios físicos entre as estadunidenses, maior escore de 
compulsões alimentares entre as francesas, e por último, maior preocupação com excesso de peso e mais chances de realizar uma cirurgia plástica entre as brasileiras.

Existem fatores que podem apoiar a compreensão destes achados. As restrições alimentares entre as argentinas são parte de uma tentativa de controle do corpo e aparência, num país onde os ideais de beleza e magreza têm fortíssima influência na economia, inclusive em momentos históricos de crise (MEEHAN e KATZMAN, 2001), além do elevado número de indivíduos que sofrem de transtornos alimentares no país (PELLICER, 2011). No contexto acadêmico dos EUA, um bom desempenho esportivo é também um meio de ingresso e permanência na universidade (contemplação com bolsas de estudo), assim, a preocupação com a rotina de exercícios pode também ser parte deste universo (MEDIC et al., 2007; NCAA, 2017). Quanto às brasileiras serem mais propensas a realizar uma cirurgia plástica, corrobora a posição do Brasil como vice-campeão mundial em número de cirurgias plásticas (ISAPS, 2017). Além disso, como destacado por EDMONDS (2007), GOLDENBERG e RAMOS (2007) e por CARVALHO et al. (2017), no Brasil, o corpo é um forte símbolo que consagra e torna visível as diferenças entre os grupos sociais, um corpo que, pela exposição constante devido ao clima tropical, requer constante "melhora".

O maior escore de compulsões alimentares entre as francesas chama a atenção, por estas terem apresentado a menor média de IMC, e principalmente, devido à relação que, culturalmente, os franceses têm com a comida, incluindo elementos como dedicar mais tempo e atenção ao preparo e consumo das refeições, e valorizar o prazer envolvido nestes momentos (GOLDENBERG, 2011). Convém ressaltar um possível viés de interpretação no conceito de compulsão alimentar, uma vez que havia uma explicação sucinta deste conceito no questionário ["Com que frequência você teve compulsão (comeu muito mais do que desejava comer no curso de 2 horas)"], neste caso, há que se considerar que entendimento do "comer mais do que desejava" pode estar relacionado à maior atenção voltada ao momento da refeição. 
Contudo, para a maior parte das variáveis, entre as mulheres, o efeito da razão para exercício foi maior do que o efeito do país - piores atitudes alimentares, maior culpa por não se exercitar e mais chances de cirurgias plásticas quando a razão foi "perda de peso". Este achado novamente reforça a importância de se investigar e discutir as razões/motivações para a prática de atividade física, e a exploração de comportamentos associados.

\section{Resultados entre os homens}

Quanto aos homens, o efeito das interações do país com a razão para exercício e com o tipo de exercício foram maiores do que os efeitos isolados destes construtos. A preocupação com a rotina de exercício foi maior entre os jovens adeptos às corridas do que às caminhadas, não houve efeito do país isoladamente - mas houve efeito na interação do país com o tipo de exercício entre os brasileiros (maior preocupação para os adeptos aos aparelhos de exercícios aeróbicos do que à caminhada e yoga/pilates) e franceses (os praticantes de caminhada eram menos preocupados do que os adeptos à corrida, jogos em times de esportes e levantamento de pesos). Quanto à razão para se exercitar, independente do país, os homens que praticavam AF por "competição" ou para "ficar em boa forma" também eram mais preocupados com a rotina de exercícios.

A excessiva preocupação com os exercícios físicos, numa cultura ocidental de extrema valorização da aparência corporal, pode representar um fator de risco para a dependência ao exercício físico - padrão de exercício adaptativo e desajustado, caracterizado por tolerância, abstinência, exagero, perda do controle, elevado dispêndio de tempo, conflitos, continuidade mesmo em meio a prejuízos físicos, sociais e psicológicos (DeCOVERLEY VEALE, 1987; HAUSENBLAS e DOWNS, 2002; TAVARES, 2015) - todavia, a classificação da prática de exercícios como uma dependência, implicaria uma avaliação mais específica, distanciando-se do foco deste estudo.

Colocados os principais resultados deste estudo em relação às mulheres e aos homens, convém salientar que no instrumento aqui utilizado, os universitários 
responderam à variável "sexo" - termo que designa a caracterização genética, anatômica e fisiológica dos seres humanos, sendo, portanto, uma variável qualitativa categórica binária, com duas categorias mutuamente excludentes: sexo feminino ou masculino (OLINTO, 1998) - e não ao "gênero", conceito estudado pela filósofa feminista Judith Butler desde os anos 1990, o qual a autora elucida ser um fenômeno inconstante e contextual, que não denotaria um ser substantivo, "mas um ponto relativo de convergência entre conjuntos específicos de relações, cultural e historicamente convergentes" (BUTLER, 2003; CARVALHO et al., 2016). Acreditase que seria interessante explorar questões de gênero, sexualidade e polivalência sexual, principalmente pelo fato de a amostra ser universitária - no entanto, tal tema é bastante amplo e complexo e foge aos objetivos da presente pesquisa.

Nos dias atuais, os valores e os saberes que disciplinam os cuidados com a saúde são influenciados por parâmetros cada vez mais efêmeros e imprecisos, trata-se de cuidados atravessados por sentidos e discursos que incorporam preocupações estéticas, com a beleza, a imagem e a forma física, e se encontram aparentemente muito distantes das principais discussões da Saúde Pública (FERREIRA, 2010). Neste "discurso da saúde", é a aparência do corpo que dita, geralmente, o caminho em busca de poder e o sucesso nas relações sociais (COSTA e VENÂNCIO, 2004).

Cuidar do próprio corpo e da saúde passa pela construção de uma réplica perfeitamente sincronizada de si mesmo, como uma segunda pele imperceptível recobrindo a primeira, entretanto, algumas práticas apenas reforçam nas pessoas uma versão de determinados estilos de vida, que na verdade não Ihes pertencem. Enquanto a forma física é alçada a novo objeto de adoração da sociedade de consumo, o corpo - enquanto conteúdo - torna-se um mero objeto, prisioneiro de uma aparência programada e descartável (COSTA e VENÂNCIO, 2004; MALYSSE, 2007; SABINO, 2007).

Neste sentido, comparar as questões que envolvem os "cuidados" com o corpo e a alimentação em população de características relativamente semelhantes (universitários), mas ao tempo em diferentes culturas robustece a coexistência da diversidade no que é "universal". Por exemplo, a ideologia contemporânea de que 
as mulheres devem ser magras e belas, acaba sendo universal (pelo menos em países ocidentais), porém, em cada cultura, cada elemento pode ter uma representação diversa, seja maior preocupação em seguir a rotina de exercícios (como as estadunidenses deste estudo), ou uma maior propensão às cirurgias plásticas (como as brasileiras), ou, ainda, abrindo mão de determinados alimentos em prol da "boa forma" (restrições alimentares entre as argentinas). Contudo, no contexto moderno das Ciências da Saúde - muitas vezes, pautadas pela objetividade, mensurabilidade, racionalidade de evidências, quantificação e funcionamento adequado de órgãos -, aspectos mais subjetivos como desejo, afetos, percepções, memórias e histórias de vida, relações familiares, dimensões culturais ocupam posições de menor importância (NOVAES, 2006; KRAEMER et al., 2014), não contemplando, portanto, a multidimensionalidade e complexidade do ser humano (GOLDENBERG e RAMOS, 2007).

No âmbito da alimentação, uma visão puramente fisiológica pode reduzi-la a um ideal único que independe do conjunto de representações, conhecimentos e práticas aprendidas e compartilhadas pelos indivíduos de um grupo social. Um ideal que praticamente ignora o sujeito, seu desejo, sua história de vida, seus prazeres cotidianos, afetos, reduzindo-o a um ser que ingere calorias e nutrientes (KRAEMER et al., 2014). Assim, na prática nutricional e de saúde como um todo, é fundamental refletir que a comida é carregada de subjetividade e conceitos de identidade, comer é muito mais do que ingerir alimentos, pois a comida é um símbolo de pertencimento familiar, cultural, social e existencial, portanto, envolve também saúde, prazer, questões emoções, econômicas, científicas (KRAEMER et al., 2014; ALVARENGA e KORITAR, 2015)

Em se tratando do corpo e imagem corporal, é importante que os profissionais de saúde atentem-se ao questionamento dos padrões de beleza e sua disseminação na mídia e redes sociais, para então estimular o senso crítico em relação à alimentação, exercícios físicos e pressão sociocultural pela magreza/muscularidade (SATO, 2011; DUNKER et al., 2015). Além disso, reflexões em torno das atitudes em relação à atividade física são imprescindíveis, antes de aderir ingênua ou cegamente à imposição do "mexa-se", "movimente-se", pautados 
pelo cronômetro, pela busca de uma performance para correr mais, fazer mais abdominais, diminuir o peso corporal, mesmo quando a pessoa se sente muito bem e apenas está fora dos padrões de beleza ocidentais (SOARES, 2005).

No que diz respeito às limitações deste estudo, cabe mencionar o uso de instrumento não validado, cujas opções de respostas eram predefinidas (questionário fechado) - uma exploração qualitativa, provavelmente, traria respostas subjacentes. Em geral, os estudos que avaliam a motivação para exercício utilizam o Exercise Motivations Inventory (EMI-2), um instrumento cujos itens são agrupados em 10 fatores: diversão/bem-estar, controle de estresse, reconhecimento social, afiliação, competição, reabilitação de saúde, prevenção de doenças, controle de peso corporal, aparência física e condição física (GUEDES et al., 2012a), entretanto, no presente estudo, foi investigada a razão para exercício (conceitualmente diferente de motivação) bem como outros temas relacionados, por meio de questões de múltipla escolha. Além disso, até onde se conhece, a literatura ainda não apresenta instrumento/questionário validado com foco multidisciplinar abrangendo simultaneamente os principais construtos aqui avaliados (atitudes alimentares, imagem corporal e atividade física).

Quanto ao modo de aplicação do questionário (online), convêm salientar a maior possibilidade de vieses como recusa e desistência do preenchimento, reconhecimento do convite de participação (e-mail) como spam, distração durante o preenchimento. Ademais, considerando-se as temáticas aqui investigadas, a abstenção de pessoas cuja relação com o corpo, com a atividade física e/ou as atitudes alimentares sejam comprometidas pode ser maior.

Ainda em relação ao instrumento, a Escala de Stunkard para avaliação da imagem corporal apresenta alguns problemas metodológicos, como o número de silhuetas, detalhes da face que influenciam na escolha da silhueta como um todo, intervalo de variação entre as silhuetas (SCAGLIUSI et al., 2006; CAMPANA et al., 2009), além disso, as silhuetas aumentam em peso e não em muscularidade, aspecto que na atualidade é muito relevante, principalmente entre os homens. Entretanto, este é um método válido para mulheres e homens (SCAGLIUSI et al., 2006; CONTI et al., 2013), tem boa confiabilidade e, a Escala de Silhuetas 
Brasileiras (KAKESHITA, 2008), que possivelmente seria mais apropriada para a avaliação da imagem corporal, não é validada para os outros países além do Brasil.

Especificamente quanto à amostra, o número de universitários foi diferente entre países (maior no Brasil) e sexos (66,4\% de mulheres), sendo que o número de universitários do sexo masculino na Argentina foi pequeno $(n=52)$. Outro aspecto importante, principalmente no que diz respeito à imagem corporal, são as diferenças étnicas entre os universitários de cada país (para os argentinos, brasileiros e estadunidenses, a maior parte da amostra era branca, mas o número de jovens de outras etnias foi diferente) - a variável etnia não foi questionada entre os franceses, devido ao fato de o país ter uma lei que proíbe tal questionamento (FRANÇA, 1978). Além disso, a amostra de universitários de cada país foi proveniente de uma única universidade, assim, os resultados encontrados podem não incluir toda a variabilidade cultural presente em diferentes regiões destes países.

Por fim, a diversidade de cursos aos quais os alunos eram matriculados em cada país pode ter influenciado nas concepções de corpo "ideal", uma vez que a literatura mostra que universitários envolvidos em cursos na área da saúde podem sofrer maiores cobranças para que sejam exemplos de "saúde perfeita" (incluindo questões corporais e alimentares) - como Nutrição e Educação Física. Estes estudantes podem apresentar maior risco para desenvolvimento e manutenção de transtornos de imagem corporal e/ou alimentares; e também, alguns indivíduos predispostos a estes transtornos podem optar por carreiras na área da saúde, atraídos por conteúdos como alimentação, prática de atividade física, bioquímica, metabolismo.

Investigações futuras poderão contemplar a avaliação conjunta dos construtos aqui discutidos, com outras amostras (incluindo regiões diversas dos países) e outros instrumentos de avaliação.

De qualquer forma, este estudo tem uma série de pontos fortes, dentre eles a abordagem conjunta de imagem corporal, relação com o corpo, atividade física, cirurgias plásticas e atitudes alimentares em população universitária - temas que a literatura nacional e a internacional abordam de forma mais isolada; assim, até onde se sabe este é o primeiro estudo a avaliar todos estes construtos conjuntamente, 
inclusive no que diz respeito aos aspectos mais qualitativos do exercício (principal razão, tipo de exercício, preocupação e culpa relacionada a não fazer exercício). Outro ponto é a amostra numerosa e de diferentes países - para a validade externa deste estudo, ou seja, a capacidade da amostra de detectar uma diferença que se espera existir na população (poder observado), verificaram-se valores superiores a $80 \%$ para a maior parte das variáveis, em consonância com o proposto por COHEN (1988): a probabilidade esperada de falha em detectar um efeito verdadeiro deve ser estimada em 0,2, assim, o nível de poder recomendado é de 0,8 ou $80 \%(1,0$ $0,2)$.

Além disso, destaca-se o mérito de uma discussão mais profunda a respeito de aspectos que comumente fazem parte das recomendações de um "estilo de vida saudável", mas que podem ser nocivas, por exemplo, praticar exercícios visando perder peso ou compensar "excessos alimentares", atribuir demasiada importância ao peso corporal como indicador de saúde e felicidade, eixo puramente estético nos cuidados com o corpo.

A relação das pessoas com alimentação, imagem corporal, atividade física e o corpo é multidimensional e integrada, portanto, estudá-los conjuntamente pode elucidar importantes questões pertinentes à promoção de uma melhor qualidade de vida, aceitação corporal, valorização pessoal, bem estar, autoconhecimento, além da prevenção e tratamento de agravos à saúde mental. Ademais, o estudo destes construtos conjuntamente é oportuno a fim de incentivar a reflexão de nutricionistas, educadores físicos, psicólogos, médicos e profissionais de saúde como um todo acerca de quais tipos de comportamentos e atitudes são realmente saudáveis e benéficos às pessoas. 


\section{CONCLUSÃO}

As hipóteses deste estudo (apresentadas no item 1.6 - Introdução) foram, em sua maioria, confirmadas, pois (1) independente do país, as mulheres apresentaram maior insatisfação corporal, faziam mais dietas e restrições alimentares; (2) exercitar-se especificamente para "perder peso" teve relação com atitudes disfuncionais para com o corpo e com a atividade física, porém houve pouca diferença entre os países e os sexos; e (3) universitários brasileiros apresentaram maior propensão às cirurgias plásticas do que os estadunidenses.

Quanto às semelhanças e diferenças dos construtos avaliados:

-Atitudes alimentares: As atitudes alimentares, em geral, foram mais disfuncionais entre as mulheres (independente do país), ou seja, o determinante foi ser mulher. Contudo, as argentinas foram as mais adeptas às restrições alimentares, as francesas e brasileiras as mais preocupadas com a comida e seus efeitos sobre a aparência, e as francesas, as que tiveram maior escore de "compulsões" alimentares;

-Atividade física: Entre as mulheres, exercitar-se com o objetivo de "perder peso" foi relacionado a atitudes alimentares disfuncionais e culpa por não se exercitar. Em ambos os sexos, os estadunidenses foram os que mais valorizam a rotina de exercícios (possivelmente devido ao papel do desempenho esportivo no ingresso e permanência na universidade);

-Cirurgias plásticas: A correlação entre cirurgias plásticas e insatisfação corporal foi positiva e fraca. O Brasil foi o país no qual houve maior propensão a realizar tais procedimentos;

-Imagem corporal: Os brasileiros, independente do sexo, abririam mão de

mais anos de vida para ter e manter o corpo ideal pelos próximos 20 anos. Independente do país, as mulheres apresentaram mais insatisfação corporal do que os homens. Em ambos os sexos, jovens com sobrepeso e obesidade eram mais insatisfeitos do que os eutróficos. Contudo, o maior determinante de insatisfação corporal foi exercitar-se principalmente para perder peso. 
Acentua-se assim a relevância de um cuidado em saúde que vá além perspectiva biológica mensurável, mas que considere a subjetividade, os valores culturais e as diferenças entre homens e mulheres, uma vez que pode haver diferentes formas de manifestação de fenômenos considerados "universais", e, dependendo do aspecto avaliado (alimentação, atividade física, imagem corporal), estes fatores têm influências diversas. 


\subsection{CONSIDERAÇÕES FINAIS: A CONSTRUÇÃO DE SABERES POR} MEIO DE VIVÊNCIAS ESPECIALMENTE SINGULARES

A construção de uma dissertação de mestrado é também um processo de formação de pesquisadores, por isto, dedico esta seção do trabalho ao compartilhamento de algumas vivências no decorrer desta importante etapa em minha história.

Durante os anos graduação em Nutrição na FSP/USP tive a oportunidade de fazer quatro anos de iniciação científica, sendo três deles mais voltados às políticas públicas de alimentação (alimentação escolar, especificamente) e um ano com foco em transtornos alimentares, que acredito ter sido meu maior incentivo a prosseguir na área acadêmica. Depois disso, pude ampliar conhecimentos ao cursar um aprimoramento em transtornos alimentares no HC-FMUSP, no qual desenvolvi um trabalho de conclusão de curso com a temática central de imagem corporal, a partir de então, o mestrado foi "inevitável", tive a conviç̧ão de que realmente queria prosseguir como pesquisadora, nesta área.

Conversei com a prof ${ }^{-}$Marle e ela me apresentou a possibilidade de um projeto que explorava não só o que já tinha grande interesse em pesquisar, mas também a atividade física. Fantástico! Fiquei ainda mais animada com a ideia, afinal, a atividade física é construto que ocupa um lugar importante em minha vida pessoal.

Considerando os obstáculos que a área acadêmica encontra em relação ao financiamento público, chegamos ao consenso de que eu poderia continuar em meu emprego na área regulatória de alimentos. Era janeiro de 2015, e eu tinha que apresentar o plano de estudos, incluindo as disciplinas que pretendia cursar durante o mestrado, neste momento percebi as primeiras dificuldades em estudar temáticas tão interdisciplinares, pois as disciplinas mais "óbvias" na Nutrição, na Educação Física e Psicologia pareciam não contemplar tudo aquilo que precisava explorar.

Entendi. O caminho era seguir "por mares nunca navegados" em minha trajetória acadêmica. Comecei a buscar também referências com uma visão de corpo e alimentação no âmbito das Ciências Sociais e Antropologia, foi quando li obras de autoras como Joana de Vilhena Novaes e Mirian Goldenberg, despertando novos horizontes e interesses em meu processo de formação. 
No segundo semestre do mestrado, matriculei-me numa disciplina oferecida na Escola de Artes, Ciências e Humanidades da Universidade de São Paulo (EACH/USP), cujo nome era "Estudos Interdisciplinares em Sociologia do Esporte e do Lazer". Fui muito bem recebida pelo professor (Marco Antonio Bettine de Almeida), que em tom de brincadeira também questionou "o que uma nutricionista espera de uma disciplina cujo nome começa com Sociologia?". Brincadeiras à parte, esta disciplina me proporcionou excelentes reflexões, troca de saberes (meus colegas de classe eram historiadores, jornalistas, filósofos e, os que mais se aproximavam de minha formação, eram os bacharéis em Esporte), a chance de participar de um capítulo de e-book (com a autoria do capítulo "Imagem corporal no contexto fitness das academias: corpos ou vitrines?"), além disso, autores como Pierre Bourdieu, Marcel Mauss, Norbert Elias passaram a fazer parte de minha "bagagem" acadêmica.

No início de 2016, participei de um curso de verão ("Corpo, arte e clínica") ministrado pela professora Yara M. Carvalho na FSP/USP - quando pude conhecer novos olhares sobre o corpo, seus limites e possibilidades; e também um pouco da obra do filósofo espanhol Baruch de Spinoza. Foi incrível!

Além do âmbito acadêmico propriamente dito, o período o mestrado foi também de grande crescimento pessoal, de intensas transformações, de autoconhecimento, de vivenciar situações enxergando por novos prismas. Foi necessário um novo olhar sobre mim, sobre meu corpo, cognições, pensamentos e atitudes. Houve risos, lágrimas, orações, insights, gargalhadas, desespero, ansiedade, descobertas (muitas!), sessões de terapia, saída do emprego, contratempos de saúde e um inexplicável turbilhão de emoções.

Particularmente sobre o corpo e a atividade física, pude refletir sobre como me apropriei destes elementos de formas muito diferentes ao longo da vida: o corpo disciplinado dos anos de ballet e jazz na infância/adolescência, o corpo que experimentou emoções diversas no time de handebol da FSP/USP nos três primeiros anos da graduação, o corpo cujos limites foram (e são) superados em sessões de musculação e em corridas, o corpo que encontra nas aulas de zumba 
uma forma mais livre e engraçada de se movimentar, e mais recentemente, o corpo que se conectou mais com minhas subjetividades, nas aulas de yoga e de pilates.

Ao fim desta jornada, sinto que amadureci como pesquisadora e como pessoa. $O$ mestrado me proporcionou experiências especialmente singulares, a Aline de hoje, certamente, está diferente da Aline do início de 2015.

E que venha o doutorado! 


\section{REFERÊNCIAS BIBLIOGRÁFICAS}

Ackard DM, Croll JK, Kearney-Cooke A. Dieting frequency among college females: association with disordered eating, body image, and related psychological problems. J Psychosom Res. 2002; 52(3):129-36.

Almeida GAN, Loureiro SR, Santos JE. A Imagem corporal de mulheres morbidamente obesas avaliada através do Desenho da Figura Humana. Psicol. Reflex. Crit. 2002; 15(2): 283-92.

Almeida MAB, Gutierrez G. Estado, Mercado e Cultura: a produção cultural no tempo livre. Licere (Online). 2010; 13:1-29.

Almeida MAB, Xavier EM, Santos RF. O Nacional Desenvolvimentismo e as Políticas Públicas de Exercícios Físicos, Esporte e Lazer. RG\&PP. 2013; 3:72-91.

Alvarenga $\mathrm{M}$, Koritar P. Atitude e comportamento alimentar - determinantes de escolhas e consumo. In: Alvarenga M, Figueiredo M, Timerman F, Antonaccio C. Nutrição Comportamental. Barueri: Manole; 2015. 23-50.

Alvarenga M, Philippi ST. Estrutura, padrão, consumo e atitude alimentar: conceitos e aplicações nos transtornos alimentares. In: Alvarenga M, Scagliusi FB, Philippi ST. Nutrição e transtornos alimentares - Avaliação e tratamento. Barueri: Manole; 2011. 17-36.

Alvarenga M, Polacow V, Scagliusi F. Dieta e seus efeitos no comportamento alimentar. In: Alvarenga M, Figueiredo M, Timerman F, Antonaccio C. Nutrição Comportamental. Barueri: Manole; 2015. 69-100. 
Alvarenga MS, Dunker KLL, Philippi ST, Scagliusi FB. Influência da mídia em universitárias brasileiras de diferentes regiões. J Bras Psiquiatr. 2010a; 59(2):11118.

Alvarenga MS, Lourenço BH, Philippi ST, Scagliusi FB. Disordered eating among Brazilian female college students. Cad. Saúde Pública. 2013; 29(5):879-88.

Alvarenga MS, Philippi ST, Lourenço BH, Sato PM, Scagliusi FB. Insatisfação com a imagem corporal em universitárias brasileiras. J Bras Psiquiatr. 2010b;59(1):4451.

Alvarenga MS. Transtornos alimentares. In: Hirschbruch MD, Carvalho JR (Org.). Nutrição esportiva: uma visão prática. $2^{2}$ ed. São Paulo: Manole; 2008.

Alves FS, Carvalho Y. Práticas corporais e grande saúde: um encontro possível. Movimento. 2010;16(4):229-44.

Amaral ACS. Adaptação transcultural do sociocultural Attitudes Towards Appearance Questionnaire - 3 (SATAQ - 3) para a população brasileira. [Dissertação de Mestrado]. Juiz de Fora: Universidade Federal de Juiz de Fora (UFJF) em parceria com a Universidade Federal de Viçosa (UFV); 2011.

Andrade SS. Saúde e beleza do corpo feminino - algumas representações no Brasil do Século XX. Movimento. 2003; 9(1):119-43.

Andrew R, Tiggemann M, Clark L. The protective role of body appreciation against media-induced body dissatisfaction. Body Image. 2015;15:98-104.

Anzai K. O corpo enquanto objeto de consumo. Rev. Bras. Ciênc. Esporte. 2000; 21:71-5. 
[APA] American Psychiatric Association. Diagnostic and Statistical Manual of Mental Disorders (DSM-V.). 5.ed. Arlington: APPI, 2013.

[ASAPS] American Society for Aesthetic Plastic Surgery. Annual Cosmetic Surgery National Data Bank Statistics. Disponível em: http://www.surgery.org/sites/default/files/2014-Stats.pdf. Acesso em 11/01/2016, às $11 \mathrm{~h}: 20 \mathrm{~min}$.

Ashikali EM, Dittmar H, Ayers S. Adolescent girls' views on cosmetic surgery: A focus group study. J Health Psychol. 2016; 21(1):112-21.

As-Sa'edi E, Sheerah S, Al-Ayoubi R, Al-Jehani A, Tajaddin W, Habeeb H. Body image dissatisfaction: Prevalence and relation to body mass index among female medical students in Taibah University, 2011. J Taibah Univ Med Sci. 2013; 8(2): 12633.

Audencia Nantes School of Management. International Student Guide. Disponível em:

http://www.audencia.com/fileadmin/documents/audenciaA_propos/International/ International-student_guide.pdf. Acesso em 26/04/2017, às 19h:40min.

Avalos L, Tylka TL, Wood-Barcalow N. The Body Appreciation Scale: development and psychometric evaluation. Body Image. 2005; 2(3):285-97.

Barbosa CG. Liderança na gestão do esporte universitário: proposta da criação de uma rede de dados. [Dissertação de Mestrado]. Rio Claro: Universidade Estadual Paulista; 2014.

Barbosa MR, Matos PM, Costa ME. Um olhar sobre o corpo: o corpo ontem e hoje. Psicol. soc. (Impr.). 2011; 23(1): 24-34. 
Batista A, Neves CM, Filgueiras JF, Ferreira MEC. Dimensão atitudinal da imagem corporal e comportamento alimentar em graduandos de educação física, nutrição e estética da cidade de Juiz De Fora - MG. Rev. Educ. Fís/UEM. 2015; 26(1): 69-77.

Bitencourt FG. Esboço sobre algumas implicações do futebol e da copa do mundo para o Brasil: identidade e ritos de autoridade. Rev. Bras. Cienc. Esporte. 2009; 30(3): 173-89.

Bize R, Johnson JA, Plotnikoff RC. Review Physical activity level and health-related quality of life in the general adult population: A systematic review. Prev Med. 2007:45:401-15.

Böhme MTS. Cineantropometria - componentes da constituição corporal. Rev. bras. cineantropom. desempenho hum. 2000; 2(1):72-9.

Bosi MLM, Luis RR, Morgado CMC, Costa MLS, Carvalho RJ. Autopercepção da imagem corporal entre estudantes de nutrição: um estudo no município do Rio de Janeiro. J Bras Psiquiatr 2006; 55(2):108-13.

Bosi MLM, Uchimura KY, Luiz RR. Eating behavior and body image among psychology students. J Bras Psiquiatr. 2009;58(3):150-55.

Brasil. Ministério da Saúde. Conselho Nacional de Saúde. Resolução n 196/96. Diretrizes e norma regulamentadoras de pesquisa envolvendo seres humanos. Brasília: Diário Oficial da União. 16 out 1996.

Brunet J, Sabiston CM. Exploring motivation for physical activity across the adult lifespan. Psychol Sport Exerc. 2011;12:99-105.

Buenos Aires. Decreto oㅡ 172 de 27 de marzo de 2012. Reglamentación de la Ley no 3.330. Boletín Oficial de la Ciudad de Buenos Aires, 12 de abril de 2012. 
Buenos Aires. Ley o 12665 de 4 de mayo de 2005. Marcación de la indumentaria de la mujer adolescente. Boletín Oficial de la Ciudad de Buenos Aires, 23 de junio de 2005.

Buenos Aires. Ley № 3.330 de 03 de diciembre de 2009. Garantia a los habitantes de la Ciudad de Buenos Aires la existencia de un mínimo de ocho (8) talles correspondientes a las medidas corporales normalizadas en las Normas IRAM de la serie 75300 y sus actualizaciones, en los establecimientos comerciales cuya actividad principal, accesoria u ocasional sea la venta, fabricación o provisión de indumentaria. Boletín Oficial de la Ciudad de Buenos Aires, 27 de enero de 2010.

Butler J. Problemas de gênero: feminismo e subversão da identidade. Renato Aguiar, tradutor. Rio de Janeiro: Civilização Brasileira, 2003.

Campana ANNB, Campana MB, Tavares MCGCF. Escalas para avaliação da imagem corporal nos transtornos alimentares no Brasil. Aval. psicol. 2009; 8(3):43746.

Campana ANNB, Ferreira L, Tavares MCGCF. Associações e diferenças entre homens e mulheres na aceitação de cirurgia plástica estética no Brasil. Rev Bras Cir Plást. 2012;27(1):108-14.

Campana ANNB, Tavares MCGCF, Swami V, Silva D. An examination of the psychometric properties of Brazilian Portuguese translations of the Drive for Muscularity Scale, the Swansea Muscularity Attitudes Questionnaire, and the Masculine Body Ideal Distress Scale. Psychol Men Masc.2013;14(4):376-88.

Campana ANNB, Tavares MCGCF. Imagem corporal: conceito e evolução das pesquisas. In: Tavares MCGCF, Campana ANNB. Avaliação da imagem corporal: instrumentos e diretrizes para a pesquisa. São Paulo: Phorte; 2009. 21-48. 
Carvalho APGB, Sordi BA, Silva DSN, Pinheiro IS, Silva LFM, Valente MBB. Patologizando o abjeto: a transexualidade como categoria diagnóstica. Hum@nae. 2016;10(2).

Carvalho BT. Futebol, identidade e as relações Brasil-Argentina: a luta simbólica pela hegemonia na América do Sul. Rev. Neiba, Cad. Argent.-Bras. 2012; 1:26-37.

Carvalho PHB, Alvarenga MS, Ferreira MEC. An etiological model of disordered eating behaviors among Brazilian women. Appetite. 2017;116:164-72.

Carvalho PHB, Ferreira MEC, Kotait M, Teixeira PC, Hearst N, Cordás TA, Conti MA. Equivalências conceitual, semântica e instrumental: análises preliminares da versão em português (Brasil) da Male Body Dissatisfaction Scale (MBDS). Cad. Saúde Pública. 2013a;29(2): 403-9.

Carvalho PHB, Filgueiras JF; Neves MC; Coelho FD; Ferreira MEC. Checagem corporal, atitude alimentar inadequada e insatisfação com a imagem corporal de jovens universitários. J Bras Psiquiatr. 2013b; 62(2):108-14.

Carvalho PHB. Adaptação e avaliação do modelo teórico de influência dos três fatores de imagem corporal para jovens brasileiros. [Tese de Doutorado]. Juiz de Fora: Universidade Federal de Juiz de Fora; 2016.

Cash TF, Henry PE. Women's body images: the results of a national survey in the USA. Sex Roles. 1995;33:19-28.

Cash TF, Pruzinsky T (orgs). Body Image: a handbook of theory, research, and clinical practive. New York: Guilford Press; 2002. 
Cash TF. Body-image attitudes among obese enrollees in a commercial weight-loss program. Percept Mot Skills. 1993;77(3 Pt 2):1099-103.

Cassimiro ES, Galdino FFS, Sá GM. As concepções de corpo construídas ao longo da história ocidental: da Grécia Antiga à contemporaneidade. Revista Metavoia UFSJ. 2012; 14:61-79.

Claumann GS, Pereira EF, Inácio S, Santos MC, Martins AC, Pelegrini A. Satisfação com a imagem corporal em acadêmicos ingressantes em cursos de educação física. Rev. Educ. Fís/UEM. 2014; 25 (4):575-83.

Coelho FD, Carvalho PHB, Fortes LS, Paes ST, Ferreira MEC. Insatisfação corporal e influência da mídia em mulheres submetidas à cirurgia plástica. Rev. Bras. Cir. Plást. 2015;30(4):567-73.

Coelho FD, Carvalho PHB, Paes ST, Ferreira MEC. Cirurgia plástica estética e (in) satisfação corporal: uma visão atual. Rev. Bras. Cir. Plást. 2017;32(1):135-40.

Cohen J. Statistical Power Analysis for the Behavioral Sciences (second ed.). New York: Lawrence Erlbaum Associates, 1988.

Cohen R, Blaszczynski A. Comparative effects of Facebook and conventional media on body image dissatisfaction. J Eat Disorder. 2015; 23(3): 1-11.

Conti MA, Cordás TA, Latorre MRDO. A study of the validity and reliability of the Brazilian version of the Body Shape Questionnaire (BSQ) among adolescents. Rev. Bras. Saúde Mater Infant. 2009; 9(3):331-8.

Conti MA, Ferreira ME, Carvalho PH, Kotait MS, Paulino ES, Costa LS et al. Stunkard Figure Rating Scale for Brazilian men. Eat Weight Disord. 2013;18(3):31722. 
Cordás TA, Castilho S. Imagem corporal nos transtornos alimentares - instrumentos de avaliação: Body Shape Questionnaire. Psiquiatr. Biol. 1994; 2(1):17-21.

Costa EMB, Venâncio S. Atividade física e saúde: discursos que controlam o corpo. Pensar prát. 2004; 7(1):59-74.

Costa KCBC, Santos NO, Modesto SF, Benute GRG, Lobo RCMM, DeLucia MCS. Insatisfação corporal em estudantes universitários da área de saúde nos Estados de Alagoas e Sergipe. Mudanças - Psicologia da Saúde. 2010a; 18 (1).

Costa LC, Vasconcelos FA, Peres KG. Influence of biological, social and psychological factors on abnormal eating attitudes among female university students in Brazil. J Health Popul Nutr. 2010b; 28(2):173-81.

Costa R. Políticas da vida e pedagogia do corpo. In: Carvalho YM, Fraga AB, Gomes IM (orgs.). As práticas corporais no campo da saúde. São Paulo: Hucitec; 2016. 3 vol. 23-41.

Cruz GS, Murawski BM, Rutsztein G. Conductas y actitudes alimentarias, imagen corporal y perfeccionismo en estudiantes universitarias mujeres. Anu. investig. 2011;18:25-34.

Cuch RC. A mulher d'Elle: o ideal de beleza contemporâneo estampado na capa da revista. Leitura Flutuante. 2013; 5 (2):57-81.

Dakanalis A, Timko A, Madeddu F, Volpato C, Clerici M, Riva G et al. Are the Male Body Dissatisfaction and Drive for Muscularity Scales reliable and valid instruments? J Health Psychol. 2015 ;20(1):48-59. 
Damasceno ML, Schubert A, Oliveira AP, Sonoo CN, Vieira JLL, Vieira LF. Associação entre comportamento alimentar, imagem corporal e esquemas de gênero do auto-conceito de universitárias praticantes de atividades físicas. Rev. bras. ativ. fís. saúde. 2011; 16(2):138-43.

Dantas JB. Um ensaio sobre o culto ao corpo na contemporaneidade. Estud. pesqui. psicol. (Impr.). 2011;11(3): 898-912.

DeCoverley Veale DM. Exercise dependence. Br J Addict. 1987;82(7):735-40.

DiPietro M, Silveira DX. Validade interna, dimensionalidade e desempenho da escala Body Shape Questionnaire em uma população de estudantes universitários brasileiros. Rev Bras Psiquiatr. 2009;31(1):21-4.

Dunker K, Alvarenga M, Romano E, Timerman F. Nutrição comportamental na prevenção conjunta de obesidade e comer transtornado. In: Alvarenga $M$, Figueiredo M, Timerman F, Antonaccio C. Nutrição Comportamental. Barueri: Manole; 2015. 445-64.

Dutra JL. "Onde você comprou esta roupa tem para homem?": A construção de masculinidades nos mercados alternativos de moda. In: Nu \& Vestido: Dez antropólogos revelam a cultura do corpo carioca. Rio de Janeiro: Record; 2007.359409.

Eagly $\mathrm{AH}$, Chaiken S. The psychology of attitudes. Orlando: Harcourt Brace Jovanovich College Publishers; 1993.

Edmonds A. No universo da beleza: notas de campo sobre cirurgia plástica no Rio de Janeiro. In: Nu \& Vestido: Dez antropólogos revelam a cultura do corpo carioca. Rio de Janeiro: Record;2007.189-261. 
Egli T, Bland HW, Melton BF, Czech DR. Influence of age, sex, and race on college students' exercise motivation of physical activity. J Am Coll Health. 2011;59(5):399406.

Ericksen WL, Billick SB. Psychiatric Issues in Cosmetic Plastic Surgery. Psychiatr Q. 2012;83:343-52.

Fardouly J, Vartanian LR. Negative comparisons about one's appearance mediate the relationship between Facebook usage and body image concerns. Body Image. 2015; $12: 82-8$.

Fermino RC, Pezzini MR, Reis RS. Motivos para prática de atividade física e imagem corporal em frequentadores de academia. Rev Bras Med Esporte. 2010;16(1):18-23.

Ferrari EP, Gordia AP, Martins CR, Silva DA, Quadros TM, Petroski EL. Insatisfação com a imagem corporal e relação com o nível de atividade física e estado nutricional em universitários. Motri. 2012;8(3):52-8.

Ferrari EP. Percepção da imagem corporal e fatores associados em universitários do curso de Educação Física. [Dissertação de Mestrado]. Santa Catarina: Universidade Federal de Santa Catarina; 2012.

Ferreira FR. Algumas considerações acerca da medicina estética. Ciênc. saúde coletiva. 2010; 15(1):67-76.

Ferreira FR. Os sentidos do corpo: cirurgias estéticas, discurso médico e Saúde Pública. [Tese de Doutorado]. Rio de Janeiro: Escola Nacional de Saúde Pública Sérgio Arouca - ENSP; 2006. 
Ferreira MEC, Amaral ACS, Fortes LS, Conti MA, Carvalho PHB, Miranda VPN. Imagem corporal: contexto histórico e atual. In: Ferreira MEC, Castro MR, Morgado FFR (orgs). Imagem corporal: reflexões, diretrizes e práticas de pesquisa. Juiz de Fora: Editora UFJF; 2014.15-29.

Ferriani MGC, Dias TS, Silva KZ, Martins CS. Auto-imagem corporal de adolescentes atendidos em um programa multidisciplinar de assistência ao adolescente obeso. Rev Bras Saúde Matern Infant. 2005; 5:27-33.

Field A. Descobrindo a estatística usando o SPSS. Porto Alegre: Artmed, 2009.

Fishbein M, Ajzen I. Belief, attitude, intention and behavior: an introduction to theory and research. Massachusetts: Addison-Wesley; 1975.

[FISU] International University Sports Federation. FISU History. Disponível em: http://www.fisu.net/fisu/history. Acesso em 08/02/2017, às 20h45min.

Florindo AA, Brownson RC, Mielke GI, Gomes GA, Parra DC, Siqueira FV et al. Association of knowledge, preventive counseling and personal health behaviors on physical activity and consumption of fruits or vegetables in community health workers. BMC Public Health. 2015;15(1).

Florindo AA, Latorre MRDO, Tanaka T, Jaime PC, Zerbini CAF. Fatores associados à prática de exercícios físicos em homens adultos e idosos voluntários residentes na grande São Paulo. Rev. bras. epidemiol. 2001; 4(2):105-13.

Fontes ACD, Vianna RPT. Prevalência e fatores associados ao baixo nível de atividade física entre estudantes universitários de uma universidade pública da região Nordeste - Brasil. Rev. bras. epidemiol. 2009; 12(1): 20-9 
Forbes GB, Jung J, Vaamonde JD, Omar A, Paris L, Formiga NS. Body Dissatisfaction and Disordered Eating in Three Cultures: Argentina, Brazil, and the U.S. Sex Roles. 2012; 66(9): 677-94.

Fortes LS, Almeida SS, Ferreira MEC. Imagem corporal e transtornos alimentares em atletas adolescentes: uma revisão. Psicol. estud. 2013; 18(4):667-77.

Fortes LS, Kakeshita IS, Filgueiras JF, Pasian SR, Almeida SS, Ferreira MEC. Imagem corporal e infância. In: Ferreira MEC, Castro MR, Morgado FFR (orgs). Imagem corporal: reflexões, diretrizes e práticas de pesquisa. Juiz de Fora: Editora UFJF, 2014; 49-62.

Fortes LS, Meireles JFF, Neves CL, Almeida SS, Ferreira MEC. Disordered eating, body dissatisfaction, perfectionism, and mood state in female adolescents. Rev. Nutr. 2015; 28(4):371-83.

Fortes LS, Miranda VPN, Carvalho PHB, Ferreira MEC. Influências do nível de atividade física e do estado nutricional na insatisfação corporal de universitários de Educação Física. HU rev. 2011; 37(2): 175-80.

França. Loi n 78-17 du 6 janvier 1978 relative à l'informatique, aux fichiers et aux libertes. Journal Officiel du 7 janvier 1978.

Galak E. A educação física busca o aperfeiçoamento da raça: políticas públicas, saúde, eugenia e educação dos corpos. In: Gomes IM, Fraga AB, Carvalho YM (orgs.). Práticas corporais no campo da saúde: uma política em formação. Porto Alegre: Rede Unida; 2015. 47-74.

Garcia S, Lustosa PRB, Barros NR. Aplicabilidade do método de simulação de Monte Carlo na previsão dos custos de produção de companhias industriais: o caso da companhia Vale do Rio Doce. RCO-FEA-RP/USP. 2010; 4(10):152-73. 
Gastaldo EL, Braga AA. Corporeidade, esporte e identidade masculina. Rev. Estud. Fem. 2011; 19(3): 875-93.

Gillen MM. Associations between positive body image and indicators of men's and women's mental and physical health. Body Image. 2015;13:67-74.

Gioria YM, Mesa M, Escudero D. Ley de Talles en el Contexto de los Trastornos Alimentarios. Diaeta. 2014; 32(148):24-30.

Goellner SV. Bela, maternal e feminina: imagens da mulher na Revista Educação Physica. ljui, RS: Unijuí, 2003.

Goldenberg M, Ramos MS. A civilização das formas: o corpo como valor. In: Nu \& Vestido: Dez antropólogos revelam a cultura do corpo carioca. Rio de Janeiro: Record;2007.19-40.

Goldenberg M. A comida como objeto de pesquisa: entrevista com Claude Fischler. Psicol. clin. 2011;23(1):223-42.

Gomes MS. Tortura no Brasil: o legado sombrio da ditadura militar. Rev. Fac. Direito São Bernardo do Campo. 2014;20.

Gomes RM. A política da vida e a saúde. In: Fraga AB, Carvalho YM, Gomes IM (orgs.). As práticas corporais no campo da saúde. São Paulo: Hucitec; 2013.52-82.

Gonçalves CO, Campana ANNB, Tavares MCGCF. Influência da atividade física na imagem corporal: Uma revisão bibliográfica. 2012a; 8(2):70-82.

Gonçalves MC, Turelli FC, Vaz AF. Corpos, dores, subjetivações: notas de pesquisa no esporte, na luta, no balé. Movimento. 2012b;18(3):141-58. 
Gonçalves TD, Barbosa MP, Rosa LCL, Rodrigues AM. Comportamento anoréxico e percepção corporal em universitários. J Bras Psiquiatr. 2008; 57(3):166-70.

Gratão AO, Rocha CM. Dimensões da motivação para correr e para participar de eventos de corrida. R. bras. Ci. e Mov. 2016; 24(3):90-102.

Gualano B, Tinucci T. Sedentarismo, exercício físico e doenças crônicas. Rev. Bras. Educ. Fís. Esporte. 2011; 25(37):37-43.

Guedes DP, Legnani RFS, Legnani E. Motivos para a prática de exercício físico em universitários de acordo com o índice de massa corporal. Rev Bras Ativ Fis e Saúde. 2012a;17(4):270-74.

Guedes DP, Legnani RFS, Legnani E. Motivos para a prática de exercício físico em universitários e fatores associados. Rev. bras. Educ. Fís. Esporte. 2012b; 26(4):67989.

Guerra PH, Mielke GI, Garcia LMT. Comportamento sedentário. Rev. Corpoconsciência. 2014; 18(1):23-36.

Hair JF, Anderson RE, Tatham RL, Black WC. Análise multivariada de dados. $5^{\circ} \mathrm{ed}$. Porto Alegre: Bookman, 2005.

Hansen R, Vaz AF. Treino, culto e embelezamento do corpo: um estudo em academias de ginástica e musculação. Rev. Bras. Cienc. Esporte. 2004; 26 (1): 13552.

Hausenblas HA, Downs DS. Exercise dependence: a systematic review. Psychol Sport Exerc. 2002; 3: 89-123. 
Hausenblas HA, Fallon EA. Relationship among body image, exercise behavior, and exercise dependence symptoms. Int J Eat Disord. 2002;32(2):179-85.

Henderson-Kin D, Brooks KD. Materialism, Sociocultural Appearance Messages, and Paternal Attitudes Predict College Women's Attitudes About Cosmetic Surgery. Psychol Women Q. 2009; 33:133-42.

Hernández N, Alves D, Arroyo M, Basabe N. Del miedo a la obesidad a la obsesión por la delgadez; actitudes y dieta. Nutr Hosp. 2012; 27(4):1148-55.

Hurst M, Dittmar H, Banerjee R, Bond R. "I just feel so guilty": The role of introjected regulation in linking appearance goals for exercise with women's body image. Body Image. 2017;20:120-29.

[IHRSA] International Health, Racquet \& Sportsclub Association. The IHRSA Global Report 2016.

[IRDS] Institut Régional de Développement du Sport. Les chiffres clés du sport en Île-de-France 2015. Disponível em: http://www.sports.gouv.fr/lMG/pdf/chiffrescles_du_sport_2015.pdf. Acesso em 09/02/2017, às 11h10min.

Irwin JD. Prevalence of university students' sufficient physical activity: a systematic review. Percept Motor Skills. 2004;98:927-43.

[ISAPS] International Society of Aesthetic Plastic Surgery. Global Statistics on Cosmetic Surgery 2014. Disponível em: http://www.isaps.org/news/isaps-globalstatistics. Acesso em 03/01/2016, às 13h:50min.

[ISAPS] International Society of Aesthetic Plastic Surgery. Global Statistics on Cosmetic Surgery 2015. Disponível em: https://www.isaps.org/Media/ Default/global-statistics. Acesso em 09/03/2017, às 12h:36min. 
Jain P, Tiwari GK. Positive Body Image and General Health: A Mixed Methods Study. Int. j. Indian psychol. 2016; 4(76):33-51.

Jordan SW, Corcoran J. Considerations in Breast Augmentation in the Adolescent Patient. Semin Plast Surg. 2013; 27(1): 67-71.

Jung F, Spahlholz J, Hilbert A, Riedel-Heller SG, Luck-Sikorski C. Impact of WeightRelated Discrimination, Body Dissatisfaction and Self-Stigma on the Desire to Weigh Less. Obes Facts. 2017;10(2):139-151.

Kakeshita IS. Adaptação e validação de escalas de silhuetas para crianças e adultos brasileiros. [Tese de Doutorado]. Ribeirão Preto: Faculdade de Filosofia, Ciências e Letras de Ribeirão Preto da Universidade de São Paulo; 2008.

Kilpatrick M, Hebert E, Bartholomew J. College students' motivation for physical activity: differentiating men's and women's motives for sport participation and exercise. J Am Coll Health. 2005;54(2):87-94.

Kong $\mathrm{P}$, Harris LM. The sporting body: body image and eating disorder symptomatology among female athletes from leanness focused and nonleanness focused sports. J Psychol. 2015; 149(1-2):141-60.

Kraemer FB, Prado SD, Ferreira FR, Carvalho MCVS. O discurso sobre a alimentação saudável como estratégia de biopoder. Physis. 2014; 24(4):1337-59.

Laus MF. Influência do padrão de beleza veiculado pela mídia na satisfação corporal e escolha alimentar de adultos. [Tese de Doutorado]. Ribeirão Preto: Faculdade de Filosofia, Ciências e Letras de Ribeirão Preto da Universidade de São Paulo; 2012. 
Legnani RFS, Guedes DP, Legnani E, Barbosa Filho VC, Campos W. Fatores motivacionais associados à prática de exercício físico em estudantes universitários. Rev. Bras. Ciênc. Esporte. 2011; 33(3):761-72.

Legnani RFS, Legnani E, Pereira EF, Gasparotto GS, Vieira LF, Campos W. Transtornos alimentares e imagem corporal em acadêmicos de Educação Física. Motriz rev. educ. fís. 2012; 18(1): 84-91.

Legnani RFS. Fatores motivacionais associados à prática do exercício físico em universitários. [Dissertação de Mestrado]. Londrina, Universidade Estadual de Londrina; 2009.

Leitzke ATS, Baptista TJR, Silva AM. Relações entre beleza e saúde feminina: um olhar a partir da perspectiva de professoras de educação física. Motrivivência. 2014; 26(43):183-97.

Lemma A. Copies without originals: the psychodynamics of cosmetic surgery. Psychoanal Quart. 2010; 79(1):129-57.

Lepage ML, Crowther JH, Harrington EF, Engler P. Psychological correlates of fasting and vigorous exercise as compensatory strategies in undergraduate women. Eat Behav. 2008;9(4):423-9.

Littleton H. Body Image Dissatisfaction: Normative Discontent? Sex Roles. 2008; 59: 292-93.

Mahmud N, Crittenden N. A comparative study of body image of Australian and Pakistani young females. Br J Psychol. 2007; 98:187-97.

Malagoli LS. Corpos em movimento: conceitos e perspectivas na virada do século XXI. [Dissertação de Mestrado]. São Paulo: Universidade de São Paulo; 2006. 
Malysse S. Em busca do $(\mathrm{H})$ alteres ego: Olhares franceses nos bastidores da corpolatria carioca. In: Nu \& Vestido: Dez antropólogos revelam a cultura do corpo carioca. Rio de Janeiro: Record;2007.79-139.

Martins CR, Gordia AP, Silva DAS, Quadros TMB, Ferrari EP, Teixeira DM, et al.. Insatisfação com a imagem corporal e fatores associados em universitários. Estud. psicol. 2012; 17(2): 241-46.

Mayo C, George V. Eating Disorder Risk and Body Dissatisfaction Based on Muscularity and Body Fat in Male University Students. J Am Coll Health. 2014; 62(6): 407-15.

Mayville SB, Williamson DA, White MA, Netemeyer RG, Drab DL. Development of the Muscle Appearance Satisfaction Scale: a self-report measure for the assessment of muscle dysmorphia symptoms. Assessment. 2002;9(4):351-60.

McCreary DR, Sasse DK. An exploration of the drive for muscularity in adolescent boys and girls. J Am Coll Health. 2000; 8(6):297-304.

Medic N, Mack DE, Wilson PM, Starkes JL. The Effects of Athletic Scholarships on Motivation in Sport. J Sport Behav. 2007;30(3):292-306.

Meehan OL, Katzman MA. Argentina: The social body at risk. In: Nasser M, Katzman MA, Gordon RA. Eating Disorders and Cultures in Transition. New York:BrunnerRoutledge; 2001.148-170.

Meireles JFF, Neves CM, Fortes LS, Ferreira MEC. Insatisfação corporal e comportamento alimentar: comparações em razão dos estágios maturacionais de meninos adolescentes. Coleç. Pesqui. Educ. Fís. 2015; 14(4): 87-94. 
Meneguci J, Santos DAT, Silva RB, Santos RG, Sasaki JE, Tribess $S$ et al. Comportamento sedentário: conceito, implicações fisiológicas e os procedimentos de avaliação. Motricidade. 2015; 11(1):160-74.

Mennucci L, Timerman F, Alvarenga M. Como a subjetividade influencia o comportamento alimentar? In: Alvarenga M, Figueiredo M, Timerman F, Antonaccio C. Nutrição Comportamental. Barueri: Manole; 2015. 51-67.

Miranda VPN, Neves CM, Filgueiras JF, Carvalho PHB, Ferreira MEC. Nível de atividade física e satisfação corporal em estudantes de Educação Física. R. bras. Ci. e Mov. 2013; 21(2): 98-105.

Miranda VPN, Filgueiras JF, Neves CM, Teixeira PC, Ferreira MEC. Insatisfação corporal em universitários de diferentes áreas de conhecimento. J Bras Psiquiatr. 2012;61(1):25-32.

Morton KL, Atkin AJ, Corder K, Suhrcke M, van Sluijs EMF. The school environment and adolescent physical activity and sedentary behavior: a mixed-studies systematic review. Obes Rev. 2016;17(2):142-58.

[NCAA] National Collegiate Athletic Association. What is the NCAA? Disponivel em: http://www.ncaa.org/about/resources/media-center/ncaa-101/what-ncaa. Acesso em 09/02/2017, às 9h15min.

Nahas MV. Atividade física, saúde e qualidade de vida: conceitos e sugestões para um estilo de vida ativo. Londrina: Midiograf, 2010.

Nichols SD, Dookeran SS, Ragbir KK, Dalrymple N. Body image perception and the risk of unhealthy behaviours among university students. West Indian Med J. 2009; 58(5):465-71. 
Novaes JV. O intolerável peso da feiura: sobre mulheres e seus corpos. Rio de Janeiro: Editora PUC-Rio, 2006.

Nunes RT, Lopes ECD, Damasceno VO, Miranda R, Bara Filho MG. Dependência do Exercício Físico e Insatisfação com a Imagem Corporal. HU ver. 2007; 33(4): 113-118.

Nuñez PRM. Exercício físico na imagem corporal: o jogo entre o imaginário e o real. [Dissertação de Mestrado]. Campo Grande: Universidade Católica Dom Bosco; 2007.

Ogden J, Veale D, Summers Z. The development and validation of the Exercise Dependence Questionnaire. Addic Res. 1997;5:343-56.

Olinto MTA. Reflexões sobre o uso do conceito de gênero e/ou sexo na epidemiologia: um exemplo nos modelos hierarquizados de análise. Rev. Bras. Epidemiol. 1998; 1(2):161-9.

Oliveira CS, Gordia AP, Quadros TMB, Campos W. Atividade física de universitários brasileiros: uma revisão da literatura. RAS. 2014;12(42):71-7.

Oliveira FP, Bosi MLM, Vigário PS, Vieira RS. Comportamento alimentar e imagem corporal em atletas. Rev Bras Med Esporte. 2003; 9(6):348-56.

Paula Al. Percepção de dimensões corporais de adolescentes do sexo feminino. Aspectos psicofísicos e comportamentais [Tese de Doutorado]. São Paulo: Universidade Estadual Paulista; 2010.

Pauline J. Physical Activity Behaviors, Motivation, and Self-Efficacy Among College Students. Coll Stud J. 2013; 47(1):64-74. 
Pellicer E. Moda, cuerpo y trastornos alimenticios en la Argentina moderna [Undergraduate Honors Theses]. 2011. Disponível em: http://scholar.colorado.edu/cgi/viewcontent.cgi?article=1773\&context=honr_theses. Acesso em 21/04/2017, às 15h20min.

Pereira VA. Corpo ideal, peso normal: transformações na subjetividade feminina. Curitiba: Juruá Editora, 2010.

Plotnikoff RC, Costigan SA, Williams RL, Hutchesson MJ, Kennedy SG, Robards SL et al. Effectiveness of interventions targeting physical activity, nutrition and healthy weight for university and college students: a systematic review and meta-analysis. Int J Behav Nutr Phys Act. 2015;12(45).

Pompili M, Girardi P, Innamorati M, Tatarelli G, Ruberto A, Ferrari V. Body Uneasiness and Suicide Risk in a Non-Clinical Sample of University Students. Arch Suicide Res. 2007; 11(2): 193-202.

Prado MCL. Associação entre transtornos alimentares, fatores orexígenos, anorexígenos, perinatais e neonatais em universitários. [Tese de Doutorado]. Pernambuco: Universidade Federal de Pernambuco; 2012.

Quadros TMB, Gordia AP, Martins CR, Silva DAS, Ferrari EP, Petroski EL. Imagem corporal em universitários: associação com estado nutricional e sexo. Motriz Rev Educ Fís. 2010;16(1):78-85.

Rech CR, Araújo EDS, Vanat JR. Autopercepção da imagem corporal em estudantes do curso de educação física. Rev. bras. educ. fís. esporte. 2010; 24 (2):285-92 . 
Reel JJ, Petrie TA, SooHoo S, Anderson CM. Weight pressures in sport: examining the factor structure and incremental validity of the weight pressures in sport females. Eat Behav. 2013; 14(2):137-44.

Robinson K, Ferraro FR. The relationship between types of female athletic participation and female body type. J Psychol. 2004; 138(2):115-28.

Rodin J, Silberstein L, Striegel-Moore R. Women and weight: a normative discontent. In: Sonderegger, TB., ed. Nebr Symp Motiv. Psychology and gender. Lincoln, NE: University of Nebraska Press; 1985:245-307.

Rodrigues AA, Caniato AMP. "Corpo-mercadoria", sob controle e punição: Prenúncios de uma subjetividade aniquilada? Rev. Mal-Estar Subj. (Impr.). 2009; 9(2):647-87.

Rodríguez-Cano T, Beato-Fernández L, Llario AB. Body dissatisfaction as a predictor of self-reported suicide attempts in adolescents: a Spanish community prospective study. J Adolesc Health. 2006;38 (6):684-8.

Roiz DS. O corpo no Ocidente Medieval. Rev. Estud. Fem. 2010; 18(2):611-14.

Rozin P, Bauer R, Catanese D. Food and life, pleasure and worry, among American college students: gender differences and regional similarities. J Pers Soc Psychol. 2003;85(1):132-41.

Rozin P, Fischler C, Imada S, Sarubin A, Wrzesniewski A. Attitudes to food and the role of food in life in the U.S.A., Japan, Flemish Belgium and France: possible implications for the diet-health debate. Appetite. 1999;33(2):163-80. 
Rozin P, Fischler C, Shields C, Masson E. Attitudes towards large numbers of choices in the food domain: a cross-cultural study of five countries in Europe and the USA. Appetite. 2006;46(3):304-8.

Rozin P, Kabnick K, Pete E, Fischler C, Shields C. The ecology of eating: smaller portion sizes in France Than in the United States help explain the French paradox. Psychol Sci. 2003;14(5):450-4.

Rozin P, Remick AK, Fischler C. Broad Themes of Difference between French and Americans in Attitudes to Food and Other Life Domains: Personal Versus Communal Values, Quantity Versus Quality, and Comforts Versus Joys. Front Psychol. 2011; 2(177):1-9.

Runfola CD, Thornton LM, Pisetsky EM, Bulik CM, Birgegård A. Self-image and suicide in a Swedish national eating disorders clinical register. Compr Psychiatry. 2014; 55: 439-49.

Ruby MB, Alvarenga MS, Rozin P, Kirby TA, Richer E, Rutsztein G. Attitudes toward beef and vegetarians in Argentina, Brazil, France, and the USA. Appetite. 2016;96:546-54.

Saikali CJ, Soubhia CS, Scalfaro BM, Cordás TA. Imagem corporal nos transtornos alimentares. Rev. psiquiatr. clín. 2004; 31(4):164-6.

Salerno M, Rombaldi AJ, Reichert FF, Silva MC. Conhecimento sobre atividade física e saúde dos profissionais de academias de Pelotas, RS, BR. Rev Bras Med Esporte. 2015;21(5):345-49.

Sampaio RPA, Ferreira RF. Beleza, identidade e mercado. Psicol. rev. 2009; 15(1):120-40. 
Sanderson AR, Siegfried JJ. The Case for Paying College Athletes. J. Econ. Perspect. 2015; 29(1): 115-38.

Sant'Anna DB. As infinitas descobertas do corpo. Cad. Pagu. 2000; 14:235-49.

Santos JCNS. Relação entre composição corporal, imagem corporal, atividade física e inteligência emocional em alunos universitários: estudo numa população portuguesa. [Tese de Doutorado]. Huelva: Universidad de Huelva; 2012.

Santos SF, Salles AD. Antropologia de uma academia de musculação: um olhar sobre o corpo e um espaço de representação social. Rev. bras. Educ. Fís. Esporte. 2009; 23(2): 87-102.

Sarwer DB, Cash TF, Magee L, Williams EF, Thompson JK, Roehrig M et al. Female college students and cosmetic surgery: an investigation of experiences, attitudes, and body image. Plast Reconstr Surg. 2005;115(3):931-8.

Sarwer DB, Thompson JK, Cash TF. Body image and obesity in adulthood. Psychiatr Clin North Am. 2005;28(1):69-87.

Sato PM, Timerman F, Fabbri AD, Scagliusi FB, Kotait MS. A imagem corporal nos transtornos alimentares: como o terapeuta nutricional pode contribuir para 0 tratamento. In: Alvarenga M, Scagliusi FB, Philippi ST. Nutrição e transtornos alimentares - Avaliação e tratamento. Barueri: Manole; 2011. 477-482.

[SBCP] Sociedade Brasileira de Cirurgia Plástica. Câmara dos deputados aprova cirurgia plástica reparadora no SUS para mulheres vítimas de violência. Disponível em: http://www2.cirurgiaplastica.org.br/camara-dos-deputados-aprova-cirurgiaplastica-reparadora-no-sus-para-mulheres-vitimas-de-violencia/. Acesso em 10/04/2017, às $18 \mathrm{~h} 40 \mathrm{~min}$. 
[SBCP] Sociedade Brasileira de Cirurgia Plástica. Número de cirurgias plásticas entre adolescentes aumenta $141 \%$ em 4 anos. Disponível em: http://www2.cirurgiaplastica.org.br/numero-de-cirurgias-plasticas-entreadolescentes-aumenta-141-em-4-anos/. Acesso em 11/01/2016, às 10h:45min.

Scagliusi FB, Alvarenga M, Polacow VO, Cordás TA, Oliveira GKQ, Coelho D et al. Concurrent and discriminant validity of the Stunkard's figure rating scale adapted into Portuguese. Appetite. 2006;47(1):77-82.

Scagliusi FB, Cordás TA, Polacow VO, Coelho D, Alvarenga M, Philippi ST, Lancha Jr AH. Tradução da escala de desejo de aceitação social de Marlowe \& Crowne para a língua portuguesa. Rev. Psiq. Clín. 2004;31(6):272-8.

Schaumberg K, Anderson D. Dietary restraint and weight loss as risk factors for eating pathology. Eat Behav. 2016;23:97-103.

Schieber K, Kollei I, Zwaan M, Martin A. Classification of body dysmorphic disorder - What is the advantage of the new DSM-5 criteria? J Psychosom Res. 2015; 78: 223-27.

Schtscherbyna A, Soares EA, Oliveira FP, Ribeiro BG. Female athlete triad in elite swimmers of the city of Rio de Janeiro, Brazil. Nutrition. 2009; 25(6):634-9.

Schwartz MB, Brownell KD. Obesity and body image. Body Image. 2004;1(1):43-56.

Scrinis G. Nutritionism. The Science and Politics of Dietary Advice. New York: Allen \& Unwin; 2013.

Sides-Moore L, Tochkov K. The thinner the better? Competitiveness, depression and body image among college student women. J Coll Stud. 2011:449-46. 
Silva DAS, Nunes HEG. Imagem corporal e estágios de mudança de comportamento para atividade física em universitários. Rev Bras Ativ Fis e Saúde. 2014; 19(5): 597-8.

Silva DAS, Pereira IMM, Oliveira ACC. Impacto da escolaridade materna e paterna na percepção da imagem corporal em acadêmicos de Educação Física. Motri. 2012a; 8(2):22-31.

Silva RF, Venditti Júnior R, Miller J. Imagem corporal na perspectiva de Paul Schilder: contribuições para trabalhos corporais nas áreas de educação física, dança e pedagogia. Mal-estar na Cultura/ UFRGS. 2012b. Disponível em: http://www.ufrgs.br/difusaocultural/adminmalestar/documentos/arquivo/01\%20silva \%20miller\%20imagem\%20corporal.pdf. Acesso em 06/12/2015, às 12h05min.

Silva YV. Análise de correspondência: uma abordagem geométrica. [Dissertação de Mestrado]. Minas Gerais: Universidade Federal de Viçosa; 2012.

Simões AC, Conceição PFM, Nery MAC. Mulher, esporte, sexo e hipocrisia. In: Simões AC, Knijnik JD. O Mundo psicossocial da mulher no esporte: comportamento, gênero e desempenho. São Paulo: Aleph; 2004. 61-86.

Slade PD. What is body image? Behav Res Ther. 1994; 32(5):497-502.

Soares CL. A arte de "aperfeiçoar a espécie humana": do exercício que corrige ao exercício que educa. In: Carvalho YM, Fraga AB, Gomes IM (orgs.). As práticas corporais no campo da saúde. São Paulo: Hucitec; 2016. 3 vol.42-75.

Soares CL. Práticas corporais: invenção de pedagogias? In: Silva AM, Damiani IR. Práticas corporais: gênese de um movimento investigativo em Educação Física. Florianópolis: Nauemblu Ciência \& Arte; 2005. 43-65. 
Sousa TF, Barbosa AR, Santos SFS, Alvarenga AM, Fonseca AS, Nahas MV. Associação entre a participação na Educação Física escolar e a prática de esportes coletivos durante a universidade. Rev Bras Cineantropom Desempenho Hum. 2016,18(2):222-32.

Souza AC, Alvarenga MS. Insatisfação com a imagem corporal em estudantes universitários - Uma revisão integrativa. J. bras. psiquiatr. 2016; 65(3): 286-99.

Souza MCDFP, Souza LV, Barroso SM, Comin FS. Padrões alimentares e imagem corporal em mulheres frequentadoras de academia de atividade física. Psico-USF. 2013; 18(3): 445-54.

Stice E, Shaw HE. Role of body dissatisfaction in the onset and maintenance of eating pathology: a synthesis of research findings. J Psychosom Res. 2002;53(5):985-93.

Stratton R, Donovan C, Bramwell S, Loxton NJ. Don't stop till you get enough: Factors driving men towards muscularity. Body Image. 2015;15:72-80.

Stunkard A, Sorensen T, Schlusinger F. Use of Danish adoption register for the study of obesity and thinness. In: Kety S, Rowland LP, Sidman RL, Matthysse SW, editors. The genetics of neurological and psychiatric disorders. New York: Raven; 1983:11520.

Swami V, Airs N, Chouhan B, Leon MAP, Towellb T. Are There Ethnic Differences in Positive Body Image Among Female British Undergraduates? Eur Psychol. 2009a; 14(4):288-96.

Swami V, Arteche A, Chamorro-Premuzic T, Furnham A, Stieger S, Haubner T. Looking good: factors affecting the likelihood of having cosmetic surgery. Eur J Plast Surg. 2008; 30:211-18. 
Swami V, Campana ANNB, Ferreira L, Barrett S, Harris AS, Tavares MCGCF. The Acceptance of Cosmetic Surgery Scale: Initial examination of its factor structure and correlates among Brazilian adults. Body Image. 2011; 8:179-85.

Swami V, Chamorro-Premuzic T, Bridges S, Furnham A. Acceptance of cosmetic surgery: Personality and individual difference predictors. Body Image. 2009; 6:7-13.

Swami V, Frederick DA, Aavik T, Alcalay L, Allik J, Anderson D et al. The Attractive Female Body Weight and Female Body Dissatisfaction in 26 Countries Across 10 World Regions: Results of the International Body Project I. Pers Soc Psychol Bull. 2015; 36(3):309-325.

Swami V, Mammadova A. Associations Between Consideration of Cosmetic Surgery, Perfectionism Dimensions, Appearance Schemas, Relationship Satisfaction, Excessive Reassurance-Seeking, and Love Styles. Individ Differ Res. 2012;10(2):81-94 .

Tantleff-Dunn S, Barnes RD, Larose JG. It's not just a "woman thing:" The current state of normative discontent. Eat Disord. 2011; 19(5):392-402.

Tavares CP. Aspectos psicofísicos da imagem corporal e a sua relação com a dismorfia muscular e a dependência de exercício. [Tese de Doutorado]. Rio Claro: Universidade Estadual Paulista; 2015.

Tavares MCGCF. Imagem corporal: Conceito e desenvolvimento. Barueri: Manole; 2003.

Tavolacci MP, Grigioni S, Richard L, Meyrignac G, Déchelotte P, Ladner J. Eating Disorders and Associated Health Risks Among University Students. J Nutr Educ Behav. 2015; 47(5):412-20. 
Teixeira PC, Polacow VO, Queiros GKO, Alvarenga M. Relação entre exercício físico e transtornos alimentares. In: Alvarenga M, Scagliusi FB, Philippi ST. Nutrição e transtornos alimentares - Avaliação e tratamento. Barueri: Manole; 2011. 133144.

Teixeira PC, Polacow VO, Timerman F, Fontana M, Alvarenga M. Nutrição Comportamental e atividade física. In: Alvarenga M, Figueiredo M, Timerman F, Antonaccio C. Nutrição Comportamental. Barueri: Manole; 2015. 465-84.

Thompson JK, Altabe M. Psychometric qualities of the figure rating scale. Int J Eat Disord. 1991;10(5):615-9.

Thompson JK, Coovert MD, Stormer SM. Body image, social comparison, and eating disturbance: a covariance structure modeling investigation. Int $\mathrm{J}$ Eat Disord. 1999;26(1):43-51.

Timerman F, Alvarenga M, Fabbri A, Costa ACC, Pisciolaro F, Medeiros I et al. Nutrição Comportamental no tratamento dos transtornos alimentares. In: Alvarenga M, Figueiredo M, Timerman F, Antonaccio C. Nutrição Comportamental. Barueri: Manole; 2015. 381-412.

Timerman F, Scagliusi FB, Cordás TA. Acompanhamento da evolução dos distúrbios de imagem corporal em pacientes com bulimia nervosa, ao longo do tratamento multiprofissional. Rev Psiq Clín. 2010;37(3):113-7.

Trinca TP. O corpo-imagem na "cultura do consumo": uma análise histórico-social sobre a supremacia da aparência no capitalismo avançado. [Dissertação de Mestrado]. São Paulo: Universidade Estadual Paulista; 2008.

Truccolo AB, Maduro PA, Feijó EA. Fatores motivacionais de adesão a grupos de corrida. Motriz. 2008; 14(2):108-14. 
Tylka TL, Wood-Barcalow NL. What is and what is not positive body image? Conceptual foundations and construct definition. Body Image. 2015;14:118-29.

[UBA] Universidade de Buenos Aires. Senso de Estudiantes 2011. Disponível em: http://www.uba.ar/institucional/censos/Estudiantes2011.pdf. Acesso em26/04/2017, às $18 \mathrm{~h}: 50 \mathrm{~min}$.

Université de Nantes. Faculties, Departments, Institutes. Disponível em: http://www.univ-nantes.fr/65558674/1/fichepagelibre/\&RH=1297355335492\&R. Acesso em26/04/2017, às 19h:00.

[UPENN] University of Pennsylvania. The University of Pennsylvania by the numbers. Disponível em: http://www.upenn.edu/about/facts. Acesso em 26/04/2017, às 19h:50min.

[USP] Universidade de São Paulo. Anuário Estatístico. Disponível em: https://uspdigital.usp.br/anuario/AnuarioControle\#. Acesso em 26/04/2017, às 18h:26min.

Uusitalo AL. Overtraining: making a difficult diagnosis and implementing targeted treatment. Phys Sportsmed. 2001;29(5):35-50.

Vaz AF. Corpo, política, modernidade. Práticas corporais no campo da saúde: uma política em formação. In: Gomes IM, Fraga AB, Carvalho YM (orgs.). Práticas corporais no campo da saúde: uma política em formação. Porto Alegre: Rede Unida; 2015.75-92.

Vicente Jr C, Dunker K, Teixeira P, Timerman F, Alvarenga M. Entrevista motivacional. In: Alvarenga M, Figueiredo M, Timerman F, Antonaccio C. Nutrição Comportamental. Barueri: Manole; 2015. 215-36. 
Vilhena J, Medeiros S, Novaes JV. A violência da imagem: estética, feminino e contemporaneidade. Rev. Mal-Estar Subj. (Impr.). 2005; 1:109-44.

von Soest T,Kvalem IL, Roald HE, Skolleborg KC. The effects of cosmetic surgery on body image, self-esteem, and psychological problems. J Plast Reconstr Aesthet Surg. 2009; 62:1238-44.

Wardle J, Haase AM, Steptoe A, Nillapun M, Jonwutiwes K, Bellisle F. Gender differences in food choice: the contribution of health beliefs and dieting. Ann Behav Med. 2004;27(2):107-16.

Webb JB, Wood-Barcalow NL, Tylka TL. Assessing positive body image: Contemporary approaches and future directions. Body Image. 2015;14:130-45.

Weinberg C, Cordás TA. Do altar as passarelas - da anorexia santa à anorexia nervosa. São Paulo: Annablume; 2006.

[WHO] World Health Organization. Global database on Body Mass Index. Geneva; 2006. Disponível em: http://apps.who.int/bmi/index.jsp. Acesso em 10/01/2016, às 18h:40min.

[WHO] World Health Organization. Global recommendations on physical activity for health. Switzerland, 2010.

Wolf N. O mito da beleza. Rio de Janeiro: Rocco, 1992.

Zaccagni L, Masotti S, Donati R, Mazzoni G, Gualdi-Russo E. Body image and weight perceptions in relation to actual measurements by means of a new index and level of physical activity in Italian university students. J Transl Med. 2014;11(12). 
Zuckerman D, Abraham A. Teenagers and Cosmetic Surgery: Focus on Breast Augmentation and Liposuction. J Adolesc Health. 2008; 43(4):318-24. 


\section{ANEXOS}

\section{ANEXO 1. Artigo publicado no Jornal Brasileiro de Psiquiatria - Souza AC, Alvarenga MS. In satisfação com a imagem corporal em estudantes universitários - Uma revisão integrativa. J. bras. psiquiatr. 2016; 65(3): 286-99.}

\section{REVISÁo de LTTRRATURA Insatisfação com a imagem corporal em estudantes universitários - Uma revisão integrativa}

Body dissatisfaction among university students - An integrative review

Aline Cavalcante de Souza', Marle dos Santos Alvarenga?.,

\section{RESUMO}

Objetivo: Caracterizar a insatisfaçăo corporal entre estudantes universitúrios. Métodos: Revisão integrativa da literatura nas bases de dados PubMed, Lilacs, Bireme, portal SciElO e banco de teses com descritores indexados com os critérios de inclusăo: população exclusivamente universitária, apresentaçào de dados referentes à frequência/prevalência da insatisfaçăo corporal e/ou a caracterizaçăo de fatores relacionados. Resultados: Foram selecionados 76 estudos (40 nacionais e 36 internacionais). A amplitude de insatisfaçăo de imagem corporal em ambos os sexos foi de $8,3 \%$ a $87 \%$ nos estudos nacionals, e de $5,2 \%$ a $85,5 \%$ nos internacionais, avaliados, principalmente, por meio de escalas de silhuetas e/ou questionarios (como o Body Shape Questiannaire, o Eating Disorder Inventory, e o Body-Self Relations Question. naire Appearance Scales). Os fatores como exposiçào a midia e redes sociais, o periodo menstrual e a baíxa autoestima foram relacionados à insatisfaçào corporal. Conclusáo: A insatis-

Palavras-chave Imagem corporal estudantes, adulto, revisão. fação corporal é um fenômeno comum entre os universitários, mas apresentando grande amplitude dependendo do sexo, instrumento, método e objetivo do estudo. Padronização na avaliaçăo do construto é necessária para melhor compressăo e discussăo do problema.

\section{Keywords}

Body image, student, adult, review.

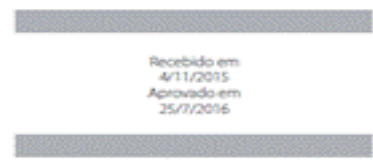

Dot no:1590006: 2065000000134

\section{ABSTRACT}

Objective: To characterize body dissatisfaction among university students. Methods: integrative literature's review on databases PubMed, Lilacs, Bireme, portal ScIELO and thesis data using indexed keywords with inclusion criteria: exclusively college students population, featuring directly data about frequency/prevalence of body dissatisfaction and/or characterization of related factors. Results: Seventy-six studies were selected (40 national and 36 international). The body dissatisfaction wide range in both sexes was from 8.39 to $87 \%$ in national studies, and from $5.2 \%$ to $85.5 \%$ in international; evaluated, primarily, by silhouettes scale and/or questionnaires (as the Body Shape Questionnaire, Eating Disorder Inventory and Body-Self Relations Questionnaire Appearance Scales). Factors like media and social networking service exposition, menstrual period, and low self esteem were related to body dissatisfaction. Concluslon: Body dissatisfaction is a common phenomena among college students, but featuring wide range depending on sex, instrument, method and study's objective. Construct evaluation's standardization is necessary in order to better comprehend and discuss the problem.

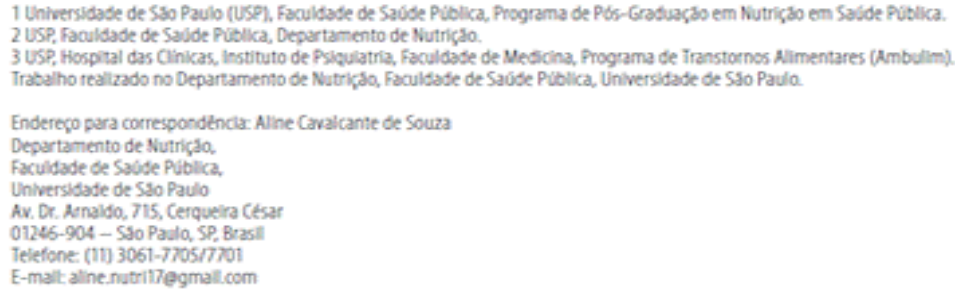




\title{
ANEXO 2. Documento emitido pelo Institutional Review Board, nos Estados Unidos da América: Isenção da necessidade de aprovação pelo Comitê de Ética e Pesquisa.
}

\author{
Whiverigy of Pernylumia

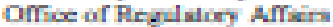

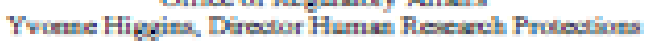

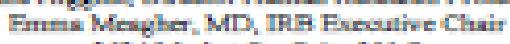

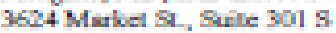

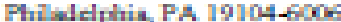 \\ PH: 215-573.25uy Fax 215.573-9498 \\ INSTITLTIONAL REYIEW BOARD

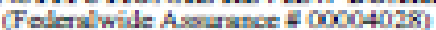

Puil Fouin

Protholuen

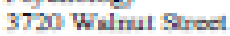

621닌

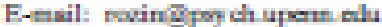

PETHETPA. INYTSTIABTOF

Paul Forin

TITI.F

SPLMADarax Aafmey

PFoTILC.

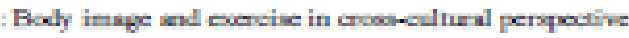

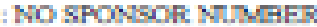

FFYTFW FMART

- 800577

EFi

Dher Th Furin

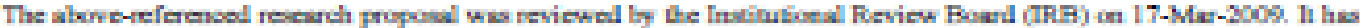

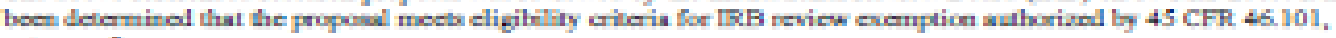
calcery 2

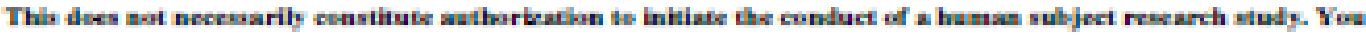

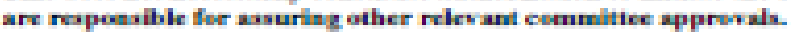

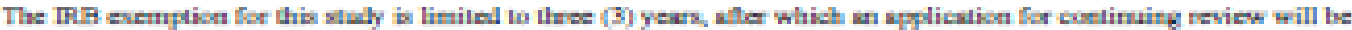

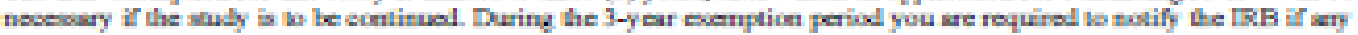

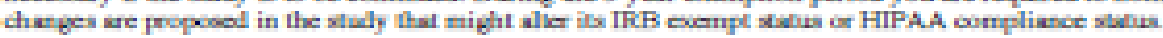

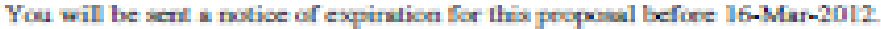

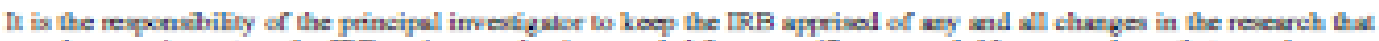

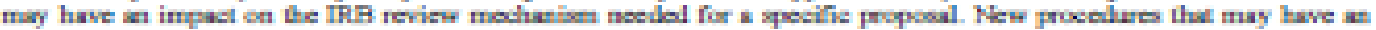

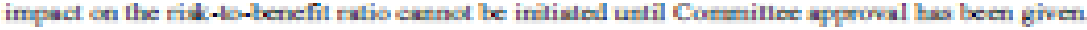

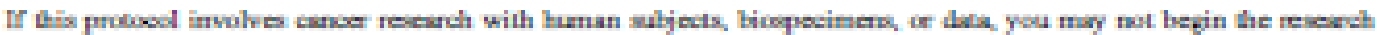

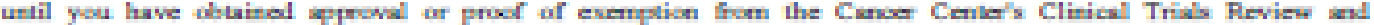
Mosiuritg Comminse

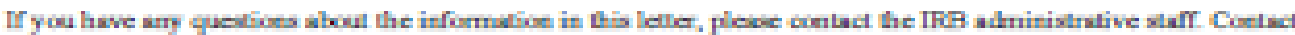

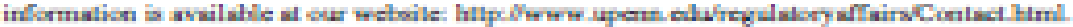

Thatk yeu for yeur experalin.

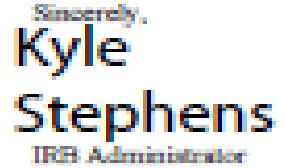

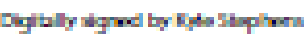

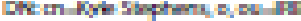

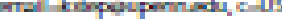
7raglatid themen

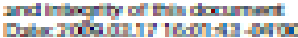


ANEXO 3. Ofício de aprovação do projeto de pesquisa principal ("Atitudes para com o exercício, dieta e imagem corporal em quatro diferentes países") pelo do Comitê de Ética e Pesquisa da Faculdade de Saúde Pública da Universidade de São Paulo.

\section{COMITÊ DE ÉTICA EM PESQUISA - COEP/FSP}

Uniwersidode de Sta Paulo

Faculdade de Savide Fúbich

MCOEPY $17 \pm 1$ of

Frotogoho

Proleda din Pusquiss

Pesquisedaria:
1807

ATITUDES PMAA GOM O ExERCION, DETA E MAGEM COFPOFAL EM

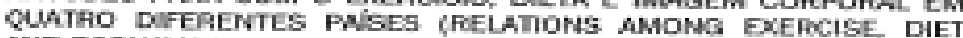
AND BOOH IMASE IFN FOUN DITFEFENT OOUNTRES

Marle dos Bantos Alvaratua

11 de JuLO da $200 \mathrm{E}$

Frezadoino or burtudarial.

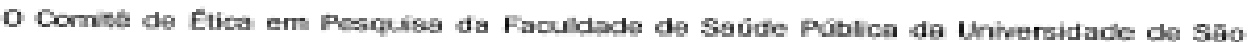

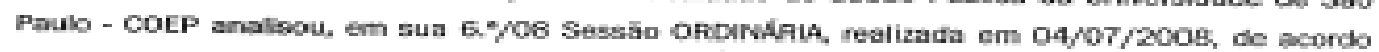

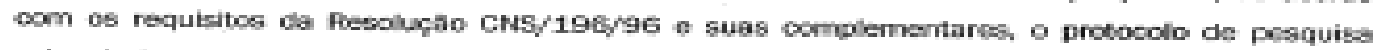

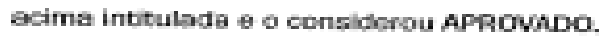

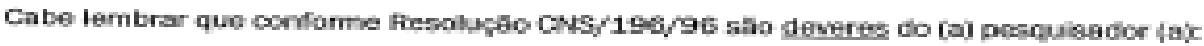

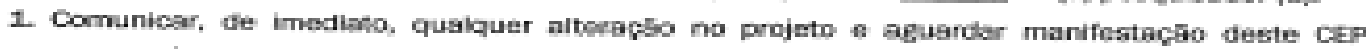

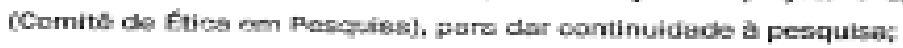

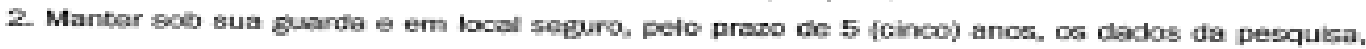

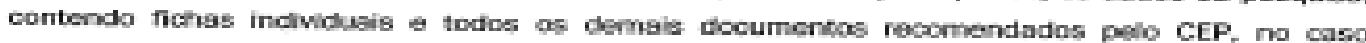
getentual sutibuta:

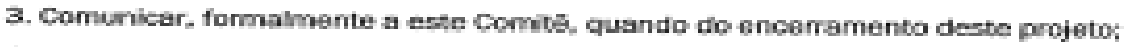

4. Flaborar e apmagntar rebtorbo parciais e finsis:

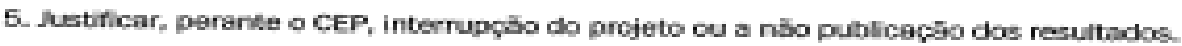

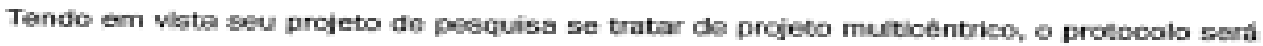

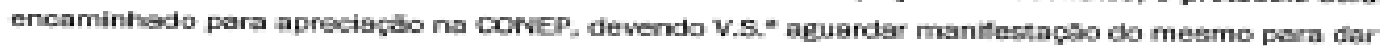
inloio a pesquises

Annekasements.

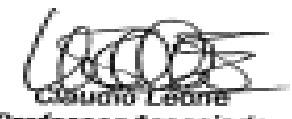

Protasaor Assochodo

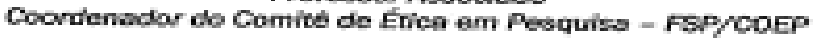

$11 \mathrm{~m}=5 r^{\prime}=$

Frof.- Dr." SOMLA TUCUNDUMA PHILIPPI

DEPARTMMENTO DE MUTRYGAO

Av. Dr. Armaklo, 715 - Asscsoria Acadomin - GEP: 01246-901 - S30 Pauk - SF

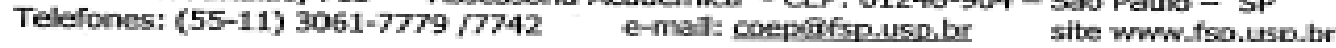


ANEXO 4. Aprovação do presente estudo pelo Comitê de Ética e Pesquisa da Faculdade de Saúde Pública da Universidade de São Paulo (parecer 1.553.827).

\section{FACULDADE DE SAÚDE PÚBLICA DA UNIVERSIDADE DE SÃO PAULO}

\section{PARECER CONSUBSTANCIADO DO CEP}

\section{DADOS DO PROJETO DE PESQUISA}

Título da Pesquisa: Atitudes em relação à atividade física de universitários de quatro países: relações com o corpo e imagem corporal

Pesquisador: Aline Cavalcante de Souza

Área Temática:

Versão: 1

CAAE: 53326316.0 .0000 .5421

Instituição Proponente: Faculdade de Saúde Pública USP/SP

Patrocinador Principal: Financiamento Próprio

DADOS DO PARECER

Número do Parecer: 1.553 .827

\section{Apresentação do Projeto:}

Trata-se de projeto de pesquisa de mestrado no Programa de Pós-graduação Nutrição em Saúde Pública. Serão utilizados dados secundários, coletados nos anos 2010 e 2012, de pesquisa submetida à apreciação do Comitê de Ética e Pesquisa da Faculdade de Saúde Pública da Universidade de São Paulo em 2009, e foi aprovada (CONEP FSP-USP 171/08).

Objetivo da Pesquisa:

Avaliar a prática de atividade física, relação com corpo, imagem corporal entre universitários, e verificar como estes construtos se relacionam e se diferenciam entre quatro países em ambos os sexos.

\section{Avaliação dos Riscos e Benefícios:}

Há riscos mínimos que são reconhecidos pelos proponentes.

\section{Comentários e Considerações sobre a Pesquisa:}

Pesquisa relevante que trará informações científicas importantes para o campo da promoção da saúde e atenção nutricional.

Considerações sobre os Termos de apresentação obrigatória:

Serão utilizados dados secundários de pesquisa que assegurou os direitos à confidencialidade,

Endereço: Av. Doutor Arnaldo, 715

Bairro: Cerqueira Cesar

CEP: $01.246-904$

UF: SP Município: SAO PAULO

Telefone: (11)3061-7779 Fax: (11)3061-7779 $\quad$ E-mail: coep@fsp.usp.br 


\section{FACULDADE DE SAÚDE PÚBLICA DA UNIVERSIDADE DE SÃO PAULO}

Continuação do Parecer: 1.553.827

livre escolha para se retirar a qualquer momento do estudo e foram fornecidos os contatos dos pesquisadores e do Comitê de Ética.

\section{Recomendaçōes:}

Nada a acrescentar.

Conclusões ou Pendências e Lista de Inadequaçóes:

Não há pendências.

Consideraçōes Finais a critério do CEP:

Este parecer foi elaborado baseado nos documentos abaixo relacionados:

\begin{tabular}{|c|c|c|c|c|}
\hline Tipo Documento & Arquivo & Postagem & Autor & Situação \\
\hline $\begin{array}{l}\text { Informações Básicas } \\
\text { do Projeto }\end{array}$ & $\begin{array}{l}\text { PB_INFORMAÇŐES_BÁSICAS_DO_P } \\
\text { ROJETO 602573.pdf }\end{array}$ & $\begin{array}{l}17 / 02 / 2016 \\
20: 31: 15\end{array}$ & & Aceito \\
\hline Folha de Rosto & Folha_de_rosto.PDF & $\begin{array}{c}17 / 02 / 2016 \\
20: 29: 34\end{array}$ & $\begin{array}{l}\text { Aline Cavalcante de } \\
\text { Souza }\end{array}$ & Aceito \\
\hline $\begin{array}{l}\text { Projeto Detalhado / } \\
\text { Brochura } \\
\text { Investigador }\end{array}$ & $\begin{array}{l}\text { Projeto_Qualificacao_Plataforma_Brasil. } \\
\text { pdf }\end{array}$ & $\begin{array}{l}14 / 02 / 2016 \\
11: 40: 14\end{array}$ & $\begin{array}{l}\text { Aline Cavalcante de } \\
\text { Souza }\end{array}$ & Aceito \\
\hline Outros & Instrumento_questionario_online.pdf & $\begin{array}{l}14 / 02 / 2016 \\
10: 42: 56\end{array}$ & $\begin{array}{l}\text { Aline Cavalcante de } \\
\text { Souza }\end{array}$ & Aceito \\
\hline $\begin{array}{l}\text { TCLE / Termos de } \\
\text { Assentimento / } \\
\text { Justificativa de } \\
\text { Ausência }\end{array}$ & Consentimento_em_participar.pdf & $\begin{array}{c}14 / 02 / 2016 \\
10: 38: 06\end{array}$ & $\begin{array}{l}\text { Aline Cavalcante de } \\
\text { Souza }\end{array}$ & Aceito \\
\hline Outros & $\begin{array}{l}\text { Institutional_Review_Board_EUA_Isenc } \\
\text { ao_necessidade_aprovacao_COËP.pdf }\end{array}$ & $\begin{array}{l}09 / 02 / 2016 \\
23: 34: 02\end{array}$ & $\begin{array}{l}\text { Aline Cavalcante de } \\
\text { Souza }\end{array}$ & Aceito \\
\hline Outros & $\begin{array}{l}\text { Oficio171_2008_Projeto_aprovado_COE } \\
\text { P FSP.pdf }\end{array}$ & $\begin{array}{l}09 / 02 / 2016 \\
23: 31: 56\end{array}$ & $\begin{array}{l}\text { Aline Cavalcante de } \\
\text { Souza }\end{array}$ & Aceito \\
\hline
\end{tabular}

Situação do Parecer:

Aprovado

Necessita Apreciação da CONEP:

Não 
ANEXO 5. Página inicial de consentimento em participar da pesquisa

\section{CrossCultBodyImage PORTUGUESE_2010}

\section{Introdução e consentimento}

Bem vindo e obrigado por sua participaçäo neste projeto de pesquisa!

Esta é uma pesquisa sobre atitudes em relaça ao alimento, corpo e a atividade física.

Sua participaçāo é absolutamente anỏnima (năo será pedidó nenhum tipo de informaçăo de identificaçăo, como seu nome) e voluntária. Você pode desistir de participar a qualquer momento.

Se você tiver qualquer pergunta, sinta-se a vontade para contatar o investigador responsável no Brasil, Professora Marle Alvarenga (marlealveusp.br) pós doutoranda na Faculdade de Saúde Pública da Universidade de Säo Paulo.

Obrigada novamente por participar!

(para iniciar a pesquisa, click no botäo abaixo e ao terminar click no botāo "done") 
ANEXO 6. Questionário da pesquisa

\section{1) Exercício}

${ }^{*}$ Qual você acha que é o seu peso ideal? (kg)

*Quanto você pesa? (kg)

${ }^{*} Q u a l$ é a sua altura? $(\mathrm{m})$

*Quantos dias na semana você faz atividade física?

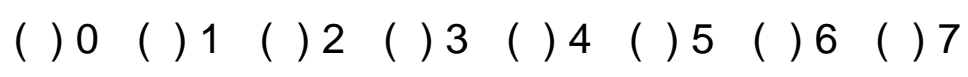

*Por favor, indique também a atividade que você considera que é sua principal forma de exercício.
( ) Caminhar
( ) Dança/Ginástica
( ) Andar de bicicleta
( ) Yoga/Pilates
( ) Correr
( ) Nunca se exercita
( ) Nadar
( ) Levantamento de pesos
( ) Jogar em algum time de esporte
( ) Máquinas de exercício aeróbico/ cardiovascular

Outro, por favor, especifique:

*Por favor, indique também qual você considera que é sua principal razão para se exercitar.
( ) Diversão
( ) Competição
( ) Saúde
( ) Perda de peso
( ) Ficar em boa forma
( ) Nunca se exercita
( ) Outro, por favor, especifique:

*Você faria exercícios por diversão mesmo que você não tivesse nenhum dos outros benefícios acima?
( ) Sim
( ) Não 


\section{II) Peso e alimentacão}

*Por favor, responda as seguintes questões numa escala de 1 a 5 (1- nunca 2raramente 3- às vezes 4- frequentemente 5 - quase sempre)

1

2

3

4

5

Eu faço dieta.

Eu conscientemente tento comer menos nas refeições,

para não ganhar peso.

Eu estou preocupado sobre ter excesso de peso.

*Para as seguintes marque verdadeiro ou falso

\begin{tabular}{|l|l|l|l|l|l|}
\hline & $\begin{array}{c}\text { Nem um } \\
\text { pouco } \\
\text { verdadeiro }\end{array}$ & $\begin{array}{c}\text { Pouco } \\
\text { verdadeiro }\end{array}$ & $\begin{array}{c}\text { De certa } \\
\text { forma } \\
\text { verdadeiro }\end{array}$ & $\begin{array}{c}\text { Muito } \\
\text { verdadeiro }\end{array}$ & $\begin{array}{c}\text { Absolutamente } \\
\text { verdadeiro }\end{array}$ \\
\hline $\begin{array}{l}\text { Se eu me sinto culpado sobre o } \\
\text { que comi eu vou fazer exercícios } \\
\text { físicos para queimar as calorias. }\end{array}$ & $\begin{array}{l}\text { Eu sou obsessivamente } \\
\text { preocupado com minha rotina de } \\
\text { exercícios. }\end{array}$ & & & & \\
\hline $\begin{array}{l}\text { Eu estou preocupado sobre o que } \\
\text { eu como e de que modo } \\
\text { isto afeta a minha aparência. }\end{array}$ & & & & & \\
\hline $\begin{array}{l}\text { Eu me sinto culpado se não me } \\
\text { exercito }\end{array}$ & & & & & \\
\hline
\end{tabular}



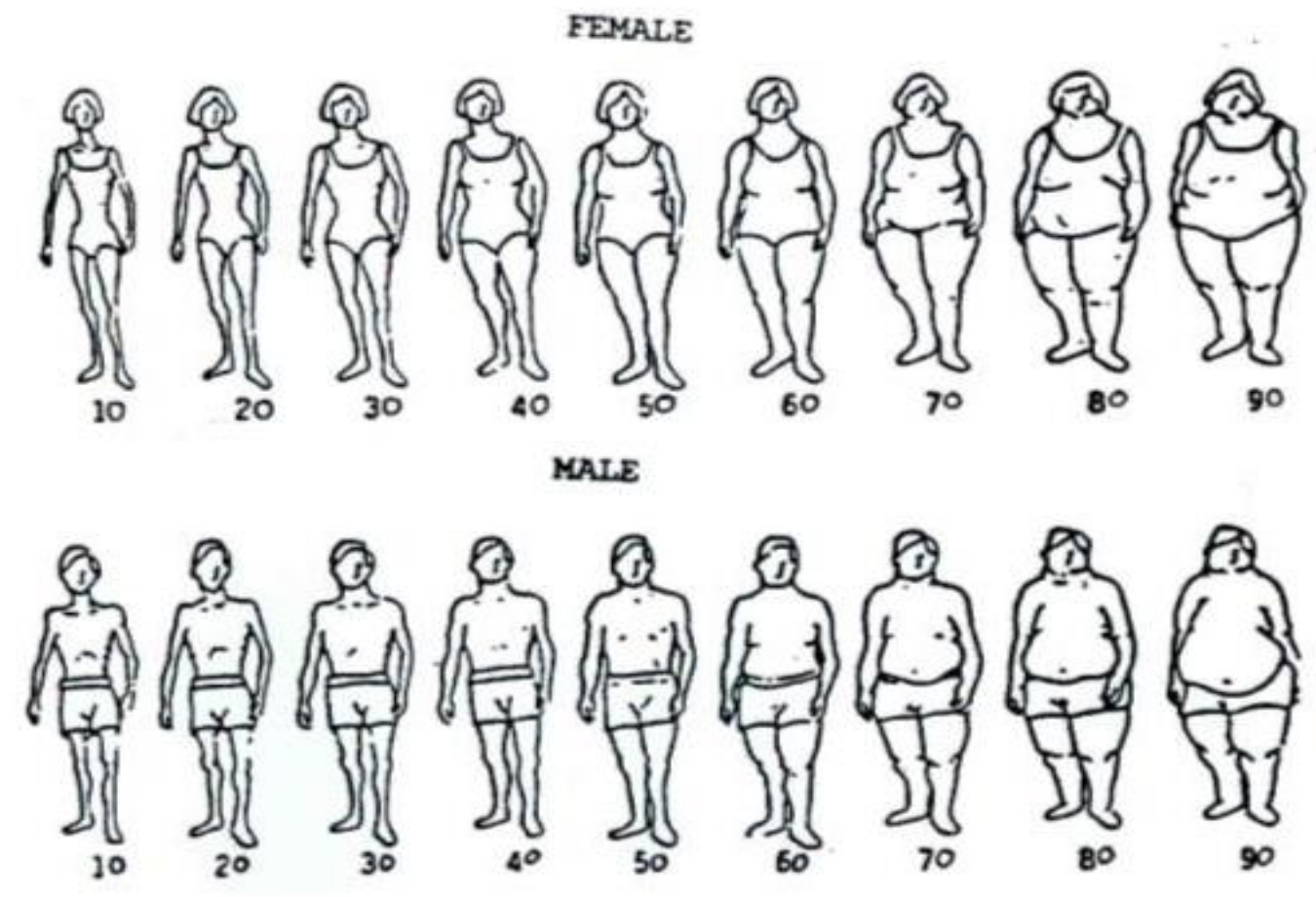

*Para as questões a seguir se refira as figuras acima. Observe que a figura mais magra é a 10 e a mais gorda é a 90. NA RESPOSTA VOCÊ PODE ESCOLHER VALORES ENTRE 10 E 90 E TAMBÉM INTERMEDIÁRIOS. Assim, 23 seria uma forma $1 / 3$ do caminho entre a figura 20 e a figura 30 . As próximas perguntas se referem às figuras do seu sexo (gênero).

Escolha a figura que melhor representa sua aparência atual:

Escolha a figura que você gostaria de ser: 
*Com que frequência você vomitou intencionalmente depois de comer com o propósito de perder peso?
( ) Nunca
( ) Uma ou duas vezes
( ) Ocasionalmente
( ) Frequentemente
( ) Quase diariamente

*Com que frequência você teve compulsão (comeu muito mais do que desejava comer no curso de 2 horas)?
( ) Nunca
( ) Uma ou duas vezes
( ) Ocasionalmente
( ) Frequentemente
( ) Quase diariamente

*De quantos anos (do total de sua vida) você abriria mão para ter e manter seu corpo ideal pelos próximos 20 anos? (sinta-se livre para usar decimais).

*Em que extensão você consideraria fazer uma cirurgia plástica cosmética? (lipoaspiração, prótese de mamas, reconstrução facial, etc)
( ) Nunca consideraria
( ) Talvez consideraria
( ) Seriamente consideraria
( ) Eu já fiz uma cirurgia plástica 


\section{IV) Dados sociodemográficos}

*Sua idade (em anos):

*Sexo:
( ) Masculino
( ) Feminino

*Sua raça/ etnia:

$\begin{array}{lll}\text { ( ) Indígena ( ) Asiático } & \text { ( ) Negro } & \text { ( ) Mulato } \\ \text { ( ) Hispânico ou da América latina (excluindo Brasil) } & \text { ( ) Branco/ caucasiano }\end{array}$

Outro, por favor, especifique:

*Universidade ou Faculdade:

${ }^{\star}$ Eu estou no meu ano da faculdade.

( ) Primeiro

( ) Segundo

( ) Terceiro

( ) Quarto

( ) Quinto

( ) Sexto ou mais

*Curso de graduação:

*Seu país de nascimento:

*Em que país você viveu a maior parte do tempo dos 10 anos até entrar na faculdade?

Em que estado ou região deste país? (se aplicável)

${ }^{\star}$ Que classe socioeconômica melhor descreve você?
( ) Baixa
( ) Média baixa
( ) Média
( ) Média alta
( ) Alta 
ANEXO 7. Escala de Silhuetas de Stunkard
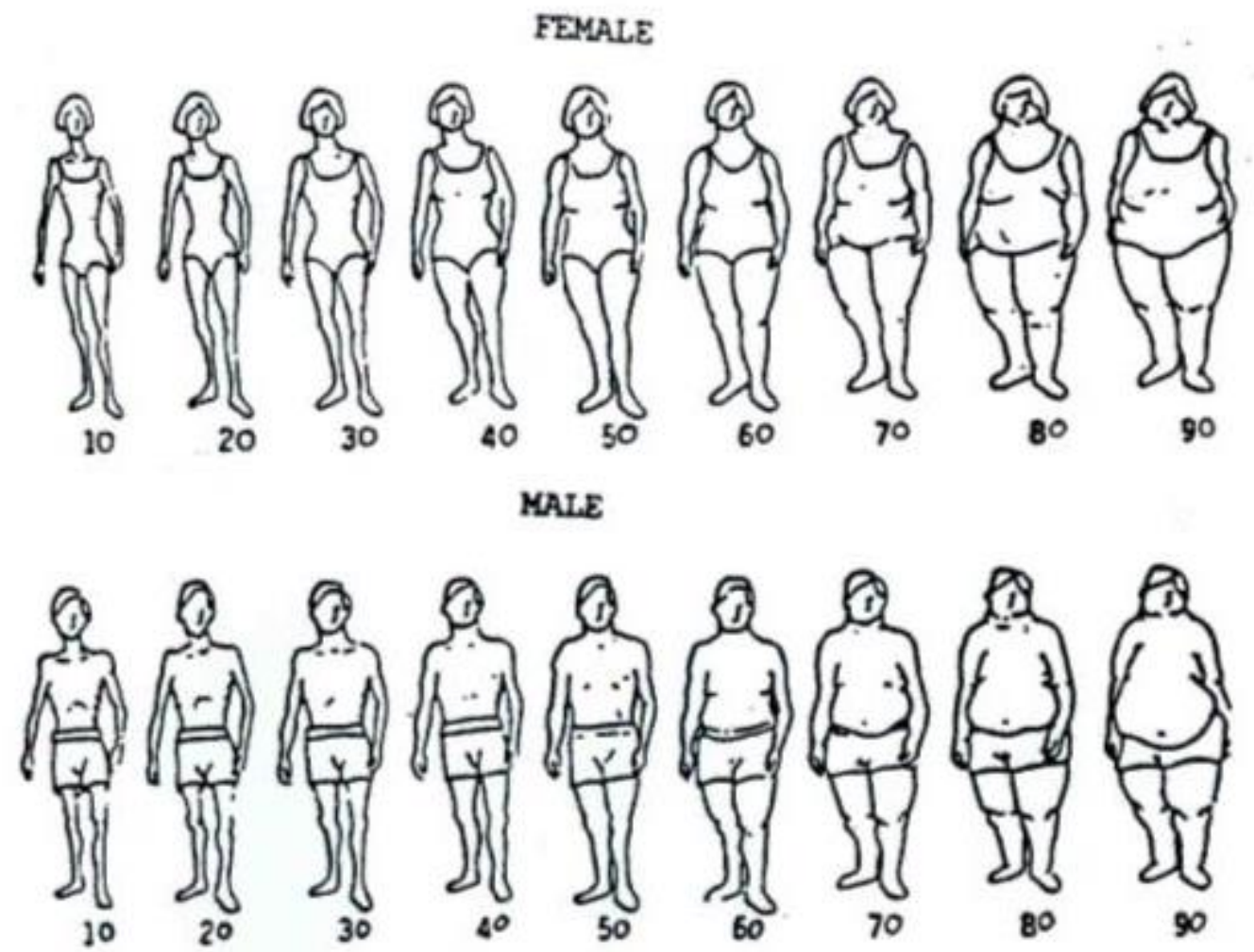
ANEXO 8. Atestado de participação no curso de verão "Corpo, arte e clínica", oferecido pela Faculdade de Saúde Pública da Universidade de São Paulo.

10/02/2016 https://uspdigital.usp.br/apolo/alunoRelFicha?print=s\&

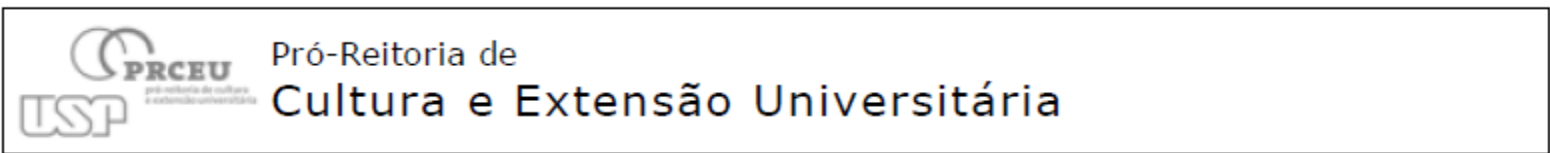

Ficha do Aluno

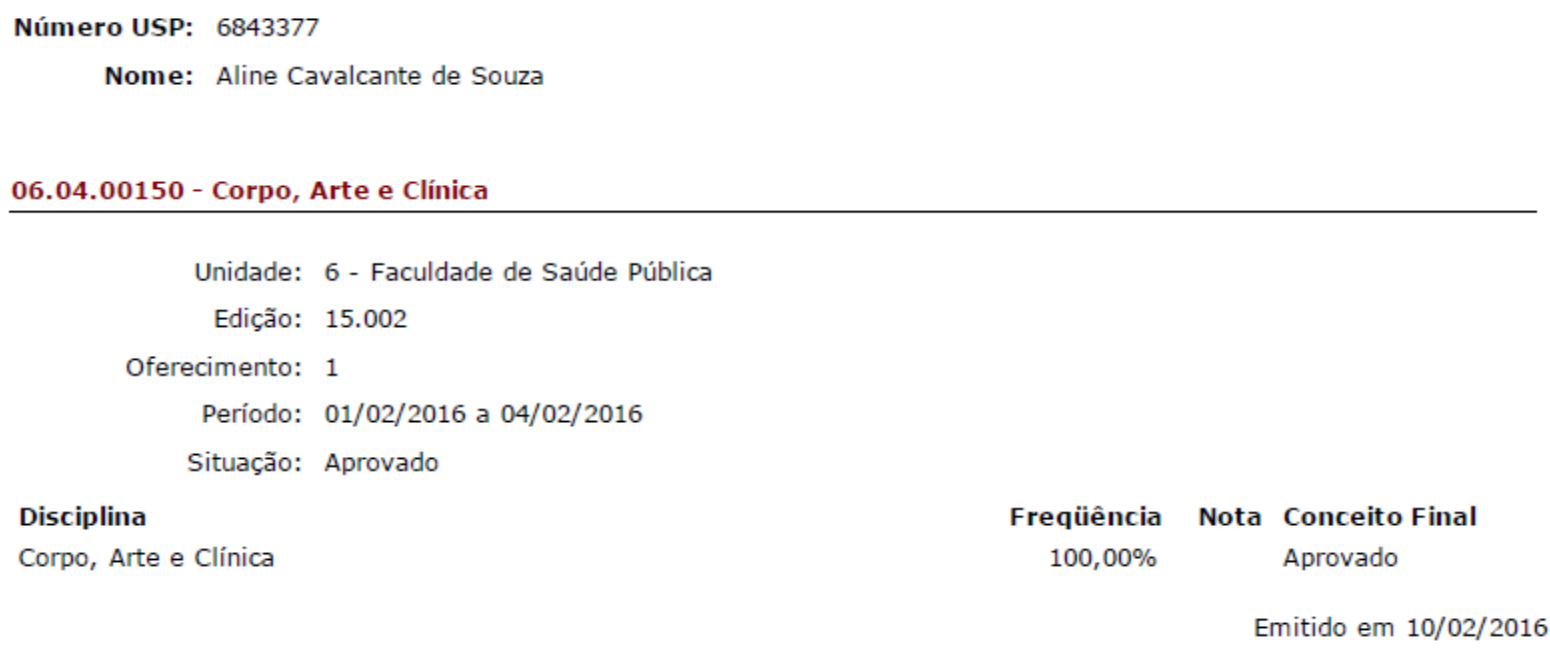


ANEXO 9. Capítulo de e-book desenvolvido durante a disciplina "Estudos Interdisciplinares em Sociologia do Esporte e do Lazer".

CAVALCANTE, AS. Imagem corporal no contexto fitness das academias: corpos ou vitrines? In: Marco Bettine. (Org.). Estudos Interdisciplinares do Esporte: Aspectos Filosóficos, Sociais, Políticos e Econômicos. São Paulo: Ludens; 2016. v. 3, p. 110-139.

\section{Sumário}

PREFÁCIO

PARTE 1 O CAMPO ESPORTIVO

Capitulo 1. Possiveis Categorias Sociológicas Para Análise Do Campo Esportivo.

Bärbara Schausteck de Almeida (UFPR); Leila Salvini (UFPR); Taiza Daniela Seron Kiouranis

(UFPR): Wanderley Marchi Jünior (UFPR)-

Capitulo 2. O Tempo e o Desempenho na Atividade Física - Um Olhar 30

Cronobiológico.

Luiz Merna-Barreto (USP).

Capitulo 3. A Espetacular Experiència dos Jogos da Vida

Luiz Gonzaga Godoi Trigo (USP): Edmur Antonio Stopoa (USP).

Capitulo 4. Jogo - Sobre Aproximações e Encontros

Ana Cristina Zimmermann (USP); Soraia Chung Saura (USP).

Capitulo 5. Um olhar para as transformações culturais e sociais por meio do 75 Esporte.

Marco Bettine (USP).

PARTE 2. CORPO, IMAGEM E DEFICIËNCIA: O ESPORTE COMO EXPRESSĀO SOCLAL

Capitulo 6. Imagem Corporal no Contexto Fitness das Academias: Corpos ou 110 Vitrines?

Aline Cavalcante de Souza (USP) 


\section{ANEXO 10. Currículo Lattes: Aline Cavalcante de Souza}

\section{Link: http://lattes.cnpq.br/4651627748573199}

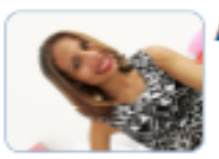

Aline Cavalcante de Souza

Endereso para acesar ete CV: http://lattescnpq-br/4651627/495/3199

útima atualiasabo do curriculo en 20/04/2017

Nutricionista graduada na Universidade de São Paulo - USP (2013). Mestranda em Nutrição e Saúde Pública na Universidade de São Paulo. Aprimorada em Transtornos Alimentares pelo Instituto de Psiquiatria do Hospital das Clínicas da Faculdade de Medicina da Universidade de São Paulo (2014). Possui formação como Técnica em Nutrição pela ETEC Carlos de Campos (2007). Possui experiência na área regulatória de alimentos. (Texto informado pelo autor)

Identificação

\begin{tabular}{ll}
\hline $\begin{array}{l}\text { Nome } \\
\text { Nome em citaçöes bibliográficas }\end{array}$ & $\begin{array}{l}\text { Aline Cavalcante de Souza } \\
\text { CAVALCANTE, A. S.rSOUZA, ALINE CAVALCANTE DE }\end{array}$ \\
Endereço & \\
\hline
\end{tabular}

Formação acadêmica/titulação

\begin{tabular}{|c|c|}
\hline 2015 & $\begin{array}{l}\text { Mestrado em andamento em Nutriç̧o e Saúde Pública. } \\
\text { Universidade de Săo Paulo, USP, Brasil. } \\
\text { Titulo: Atitudes em relaçăo à atividade fisica de universitários de quatro países: relaçöes }\end{array}$ \\
\hline $2009-2013$ & $\begin{array}{l}\text { com o corpo e imagem corporal,Orientador: (6) Marle dos Santos Alvarenga. } \\
\text { Graduaçăo em Nutriç̆o. } \\
\text { Universidade de Săo Paulo, USP, Brasil. }\end{array}$ \\
\hline $2006-2007$ & $\begin{array}{l}\text { Curso téenico/profissionalizante. } \\
\text { ETE Carlos de Campos, ETE, Brasil. }\end{array}$ \\
\hline
\end{tabular}

Formação Complementar

\begin{tabular}{ll}
\hline 2013 - 2014 & Aprimoramento em Transtornos Alimentares. (Carga horária: 224h). \\
& Instituto de Psiquiatria do HC-FMUSP, IPQ-HC-FMuSP, Brasil.
\end{tabular}

Atuação Profissional

\footnotetext{
Meta Regulatória, META REgULATÓRIA, Brasil.

Vínculo institucional

2013 - $2016 \quad$ Vínculo: Nutricionista, Enquadramento Funcional: Nutricionista - Assistente Regulatório,

Outras informaçöes $\quad$ Atuaçăo na área regulatória de alimentos.

Universidade de São Paulo, USP, Brasil.

Vínculo institucional

2009 - $2013 \quad$ Vínculo: Estudante, Enquadramento Funcional: Bolsista de Iniciaçŏo Científica, Carga

Outras informaçöes $\quad$ Atuaçăo em Projeto de Iniciaçăo Científica no Departamento de Nutriçăo FSP/USP.

Centro de Referência para Prevenção e Controle de Doenças Associadas à Nutr, CRNUTRI, Brasil.

Vínculo institucional

2013 - 2013

Vínculo: Estagiária, Enquadramento Funcional: Estagiária cumicular, Carga horária: 25

Outras informaçöes Estagiária curricular na área de Nutriçăo para Grupos Populacionais/Saúde Pública.
} 


\title{
ANEXO 11. Currículo Lattes: Marle dos Santos Alvarenga
}

Link: http://lattes.cnpq.br/5371598102267709

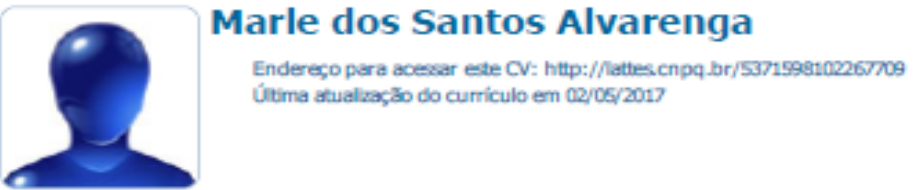

Possui graduação em Nutrição pela Universidade de São Paulo (1993), mestrado em Nutrição Humana Aplicada pela Universidade de São Paulo (1997) e doutorado em Nutrição Humana Aplicada pela Universidade de São Paulo (2001). Concluiu seu pós doutorado no Departamento de Nutrição da Faculdade de Saúde Pública da USP, com bolsa FAPESP - e short term scholar na Pennsylvania University (2010). Tem formação em Intuitive Eating pelo INTUITIVE EATING PRO Skills Training Teleseminar e Mindfulness Based Eating Training - MBEAT. Atualmente é professor contratado do Departamento de Nutrição da Faculdade de Saúde Pública da Universidade de São Paulo e é credenciada como orientadora no programa de pós graduação em Nutrição em Saúde Pública. Professor da Especialização e Mestrado Profissional do Centro Universitário São Camila. É supervisora do grupo de Nutrição do Programa de Transtornos Alimentares - Ambulim (IpQ-HC-FMUSP), coordenadora do Grupo Especializado em Nutrição, Transtornos Alimentares e Obesidade - GENTA; e idealizadora da Nutrição Comportamental. Tem experiência em consultório, atuando principalmente com transtornos alimentares, obesidade e comportamento alimentar. Sua área de pesquisa inclui os transtornos alimentares, a insatisfação corporal, a influência da mídia, o comportamento alimentar, os determinantes de consumo e as atitudes alimentares de diferentes populações clínicas e não clínicas. Envolve também a adaptação transcultural de instrumentos de pesquisa e a avaliação do estigma com relação à obesidade. (Texto informado pelo autor)

Identificação

Nome Marle dos Santos Alvarenga

Nome em citaçöes bibliográficas $\quad$ Alvarenga, M. S.;Alvarenga MS;Alvarenga M;Alvarenga MDS;Alvarenga Marle;ALVARENGA, MARLES.

Endereço

Endereço Profissional Consultório Particular.

Rua Cotoveb 303 sala 127

Perdizes

05021000 - Săo Paulo, SP - Brasil

Telefone: (11) 36723869

URL da Homepage: http://www.genta.com.br

Formação acadêmica/titulação

1997 - 2001

Doutorado em Nutriçăo Humana Aplicada.

Universidade de Säo Paulo, USP, Brasil.

Título: Bulimia nervosa: avaliaç̆o do padrăo e comportamențo alimentares, Ano de obtenģo: 2001.

Orientador: (4) Sonia Tucunduva Philippi.

Palavras-chave: Bulimila Nervosa; Comportamento alimentar; Transtornos alimentares; Padrdo alimentar.

Grande área: Ciências da Saúde

1994 - 1997

Setores de atividade: Nutriç̆̆o e Alimentaç̆o.

Mestrado em Nutriç̆o Humana Aplicada.

Universidade de Săo Paulo, USP, Brasil.

Título: Anorexia nervosa e bulimia nervosa: aspectos nutricionais,Ano de Obtenç̆o: 1997.

Orientador: (4) Sonia Tucunduva Philippi.

Bolsista do(a): Coordenaçäo de Aperfeigoamento de Pessoal de Nivel Superior, CAPES,

Brasil.

Palavras-chave: Bulimia Nervosa; Anorexia Nervosa; Transtornos alimentares; Aspectos

nutricionais.

Grande área: Clências da Saúde

$2003-2005$

Setores de atividade: Nutriçăo e Alimentaçă

Especializaç̆o em Especializaç̋o em Nutriç̆o Clínica.

Conselho Federal de Nutricionistas, CFN, Brasil. 